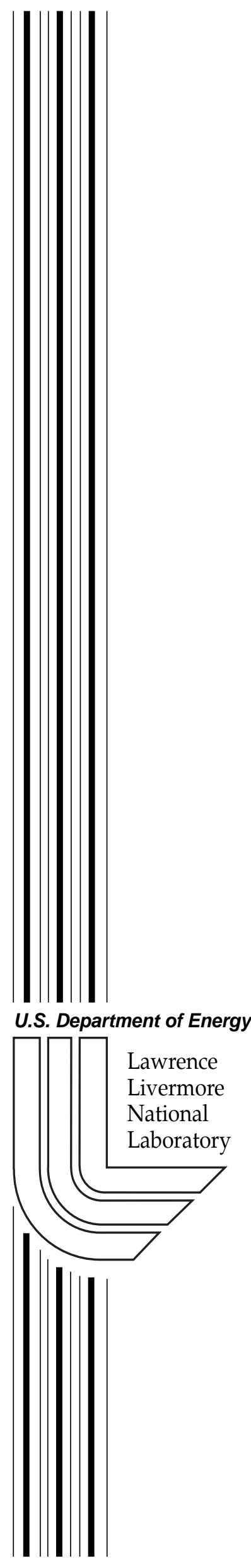

Preprint

UCRL-ID-145413

Mechanical Engineering Safety Note Analysis and Control of Hazards Associated with NIF Capacitor Module Events

S. Brereton

\title{
August 1, 2001
}




\section{Mechanical Engineering Safety Note}

\section{Analysis and Control of Hazards Associated with NIF Capacitor Module Events}

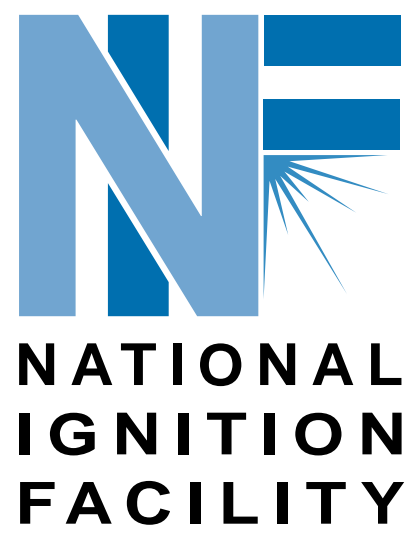

August, 2001 
This document was prepared as an account of work sponsored by an agency of the United States Government. Neither the United States Government nor the University of California nor any of their employees, makes any warranty, express or implied, or assumes any legal liability or responsibility for the accuracy, completeness, or usefulness of any information, apparatus, product, or process disclosed, or represents that its use would not infringe privately owned rights. Reference herein to any specific commercial product, process, or service by trade name, trademark, manufacturer, or otherwise, does not necessarily constitute or imply its endorsement, recommendation, or favoring by the United States Government or the University of California. The views and opinions of authors expressed herein do not necessarily state or reflect those of the United States Government or the University of California, and shall not be used for advertising or product endorsement purposes.

This work was performed under the auspices of the U.S. Department of Energy by University of California Lawrence Livermore National Laboratory under contract No. W-7405-Eng-48. 
Prepared by:

Sandra Brereton and the

NIF Capacitor Working Group

Reviewed by:

Mark Newton, Lead Engineer

Power Conditioning System

Reviewed by:

Steve Sutton, Mechanical Engineer

Laser Science Engineering Division

Reviewed by:

Dave Coats, Division Leader

Design and Construction Division

Plant Engineering

Approved by:

Bob Murray, Associate Division Leader

Laser Science Engineering Division 


\section{Distribution}

UCRL-ID-145413

Laser Science Engineering Division Office

Engineering Records Center

Sandra Brereton

Doug Larson

Chin Ma

Mark Newton

John Pastrnak

David Price

Dave Prokosch 


\section{Table of Contents}

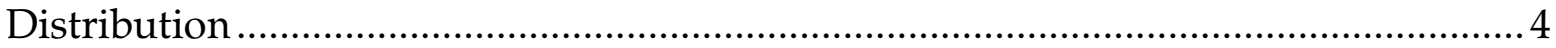

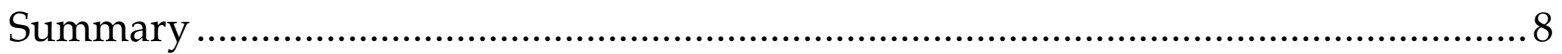

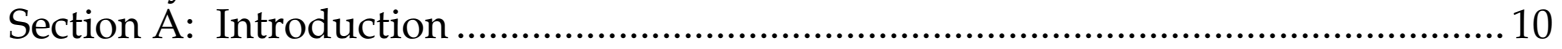

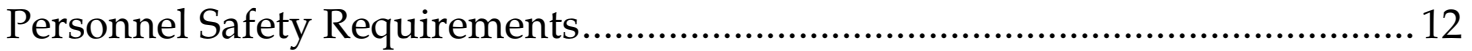

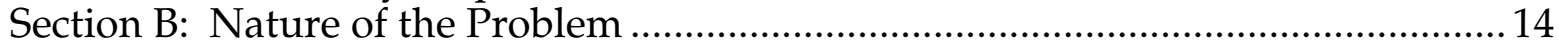

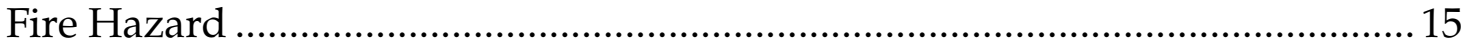

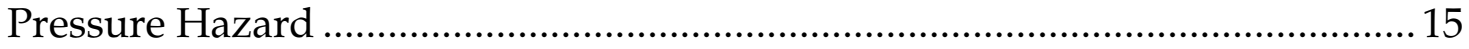

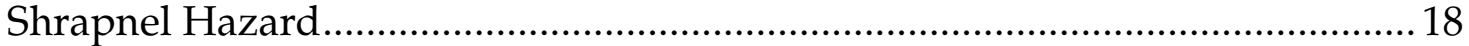

Summary of Explosive Events at FANTM and at LLNL ............................... 22

Section C: Design Solutions, Administrative Controls, and Post-Event Procedures

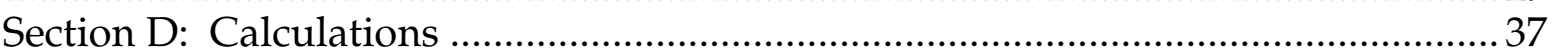

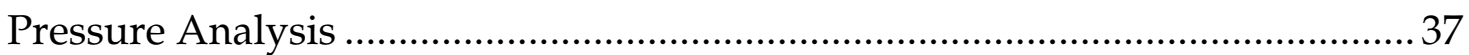

Analysis of Module Integrity During Explosive Events ............................... 51

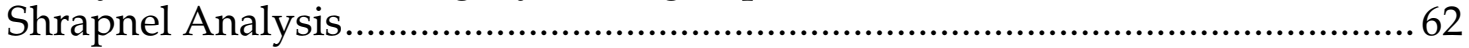

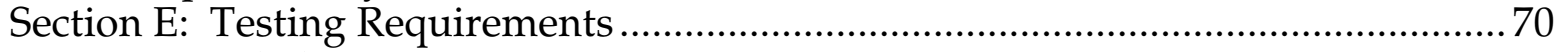

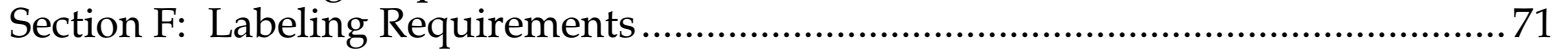

Section G: Associated Procedures ................................................................. 71

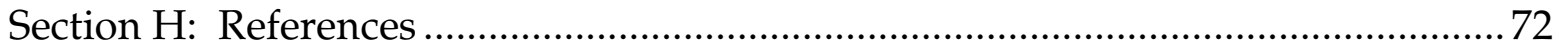

List of Contributors ................................................................................ 74

Appendix A: Pressure Calculations .......................................................... 75

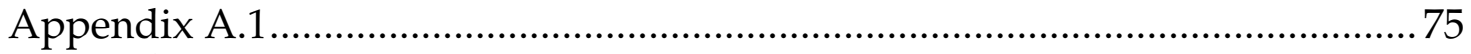

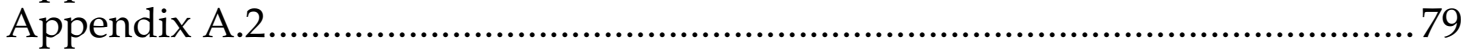

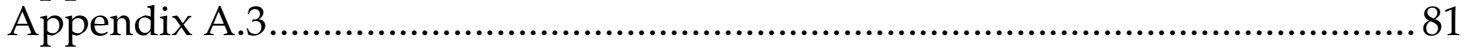

Appendix A.4

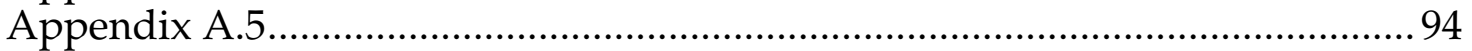

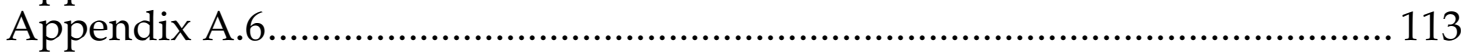

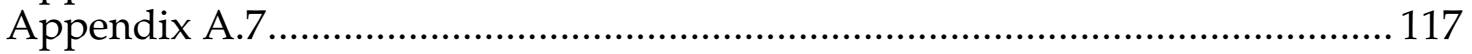

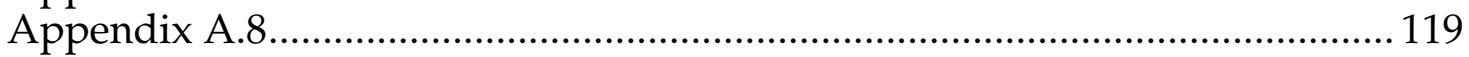

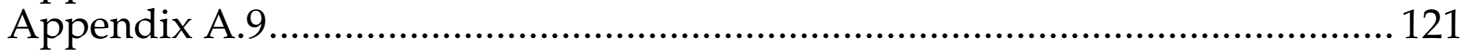

Appendix B: Fragment Calculations ............................................................ 136

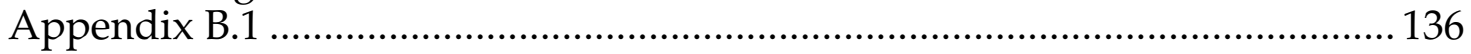

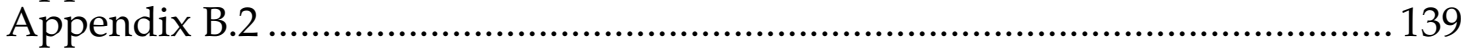

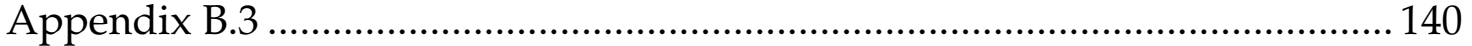

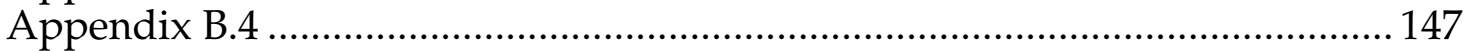

Appendix B.5 ................................................................................. 148

Appendix C: Calculation of Required Thickness of Energy Absorbing Material.. 152 Appendix D: Calculation of Maximum Credible Number of Simultaneous Events

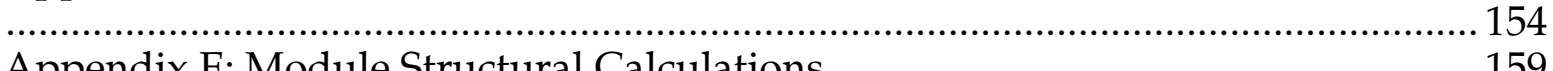

Appendix E: Module Structural Calculations ................................................ 159

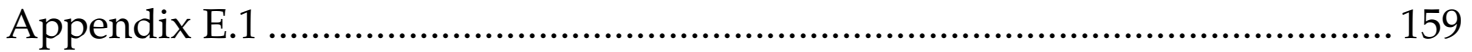

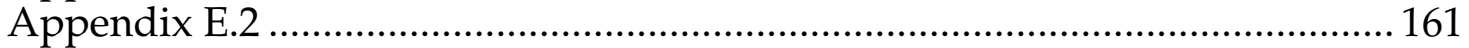

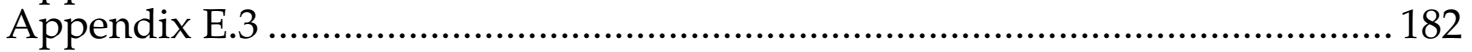




\section{List of Tables}

Table 1: Characteristics of Fragments Used in Analysis ........................................ 20

Table 2: Estimated Penetration Depths (inches) of Direct hits of Fragments into Facility Materials 21

Table 3: Estimated Thickness of Fragment Shielding Materials Required to Just Stop Fragments (inches, no safety factor included) ....................................... 21

Table 4: Summary of FANTM Occurences …………………………………....... 28

Table 5: Venting Time for Quasi-Static Pressure to reduce to Ambient Pressure 36

Table 6: Summary of Pressure Estimate Calculations ............................................... 43

Table 7: Estimated Pressures on Module Panels .........................................................53

Table 8: Beam Material Maximum Stresses During Overpressure Events.............57

Table 9: Maximum Membrane, Shear \& Von Mises Stresses for Plate-Shell Materials (psi) 58

Table 10: Bolting Schedule and Factor of Safety for Bolted Side Panels.................60

Table 11: Stresses and Factors of Safety for Front and Rear Doors..........................61 


\section{List of Figures}

Figure 1: Location of Capacitor Bays within NIF ........................................... 10

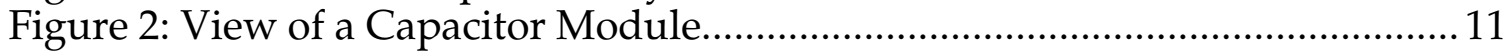

Figure 3: Layout of the FANTM Facility ......................................................... 22

Figure 4: Conditions After FANTM Event \#3-The figure shows that the main $4^{\prime} \times 8^{\prime}$ central door was broken during the event. The door was found leaning against the module. The figure also shows the flapper door that was found lying on the floor.

Figure 5: Conditions After FANTM Event \#3 -The figure shows the puncture of the roll-up door by the ejected flapper door. ............................................... 25

Figure 6: Conditions After FANTM Event \#4 -The figure shows the blackened oil draining out of the module from the failed capacitor case......................26

Figure 7: Modified Capacitor Module ................................................................. 29

Figure 8: Modified Capacitor Module, Slide view (note the side panels are not

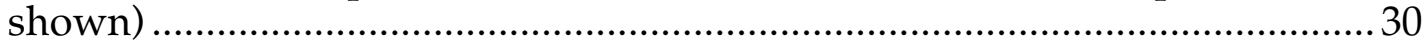

Figure 9: Pressure venting comparison (Pqs = 11 psig, FANTM Event \#5) .........32 Figure 10: Venting area comparison (Pqs = 11 psig, FANTM Event \#5) ............... 33 Figure 11: Venting area comparison $(\mathrm{Pqs}=40$ psig, bounding peak pressure estimate

Figure 12: Venting area comparison $(\mathrm{Pqs}=40$ psig, bounding peak pressure

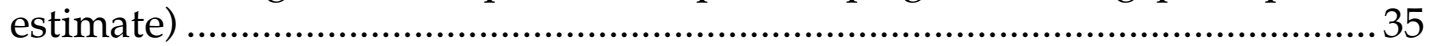

Figure 13: Comparison between theoretical calculations (at $\mathrm{P}_{\mathrm{qs}}=11 \mathrm{psig}$ ) and video data for the swinging doors (video data are taken from (Smith, 1999))

41

Solid curve represents calculated results for the bottom door.......................... 41

Dotted curve represents calculated results for the top door. ................................ 41

Figure 14: Comparison between Theoretical calculations (at $\mathrm{P}=10$ psig) and Video Data for the doors (video data are taken from Smith (1999)) ...............42 42

Solid curve represents calculated results for the bottom door............................. 42

Dotted curve represents calculated results for the top door. .............................42

Figure 15: NIF Capacitor Module (cabinet) under Overpressure Stresses induced from a Capacitor Failure Event ............................................................... 59

Figure 16: Rendering of the Capacitor Bay used in the Ray Tracking Analysis (mezzanine not shown)

Figure 17: Rendering (top view) of the Capacitor Bay used in the Ray Tracing Analysis (mezzanine not shown)

Figure 18: View of some fragment paths to the Capacitor Bay walls from Open Module

Figure 19: Side View Rendering of Modified Module design; (note: side plates are removed)

Figure 20: Rendering of Modified Module design; (note: side plates are removed) 


\section{Summary}

The NIF capacitor module was reviewed with respect to pressure venting and shrapnel containment during failures. A modified module concept was proposed that would adequately vent the pressure, yet be effective at containing shrapnel. Two large vents are provided on each side of the module. These have fixed vent areas, and are immediately accessible for pressure venting at the beginning of a pressure transient. A shrapnel shield is located on the outside of each vent opening forming a chute. The chute contains a collimator. This increases the number of bounces that shrapnel must take on the way out, and directs the shrapnel to the trap beneath. The trap contains a depth of clear pine, sufficient to completely absorb the energy of even the most energetic fragment considered.

Based on a review of the evidence from past capacitor failures at the FANTM facility at Sandia National Laboratory, Albuquerque, and additional theoretical estimates, the peak pressure generated in the module during explosive events was estimated to be less than 40 psig. This internal pressure in the FANTM module appears to be tolerable, as only minor damage to the module and to internal components was observed after events. The new module concept proposed here provides increased venting area, fully available at the initiation of an event. It is expected that even less damage would be observed if an event occurred in a module with this design. The module joints and connections were formally reviewed with respect to their tolerance to a brief internal pressure as high as 40 psig. With minor modifications that have been incorporated into the design, the module was shown to maintain its integrity during such events.

Some of the calculations performed estimated the quantity of dielectric oil that could be involved in a capacitor failure. It was determined that a very small amount of the available oil would contribute to the explosive event, on the order of $500 \mathrm{~g}$ or less. This is a small fraction of the total free oil available in a capacitor (approximately 10,900 g), on the order of $5 \%$ or less.

The estimates of module pressure were used to estimate the potential overpressure in the capacitor bays after an event. It was shown that the expected capacitor bay overpressure would be less than the structural tolerance of the walls. Thus, it does not appear necessary to provide any pressure relief for the capacitor bays.

The ray tracing analysis showed the new module concept to be $100 \%$ effective at containing fragments generated during the events. The analysis demonstrated that all fragments would impact an energy absorbing surface on the way out of the module. Thus, there is high confidence that energetic fragments will not escape the module. However, since the module was not tested, it was recommended that a form of secondary containment on the walls of the capacitor bays (e.g., 1.0 inch of fire-retardant plywood) be provided. Any doors to the exterior of the capacitor bays should be of equivalent thickness of steel or suitably armed with a thickness of plywood. 
Penetrations in the ceiling of the interior bays (leading to the mechanical equipment room) do not require additional protection to form a secondary barrier. The mezzanine and the air handling units (penetrations lead directly to the air handling units) provide a sufficient second layer of protection. 


\section{Section A: Introduction}

The NIF power conditioning system consists of a large collection of capacitors, inductors, and resistors, housed in modules with associated switches, controls, distribution system etc. The modules are located in four capacitor bays. The location of the four capacitor bays within the NIF is shown in Figure 1.

Capacitors and power conditioning systems of the type required for NIF have been observed to fail catastrophically during charging or while the capacitors are in a charged state. Several such catastrophic failures have occurred at the First Article NIF Test Module (FANTM) at Sandia National Laboratory in Albuquerque. Demonstration efforts with FANTM began in the fall of 1998, and continued through July of 1999. During that time, five catastrophic failures occurred. These events resulted in pressurization of the module, and generation of energetic shrapnel. In some cases, capacitor cases ruptured, spraying dielectric fluid into the module cavity. The oil mist has ignited, generating a dramatic fireball.

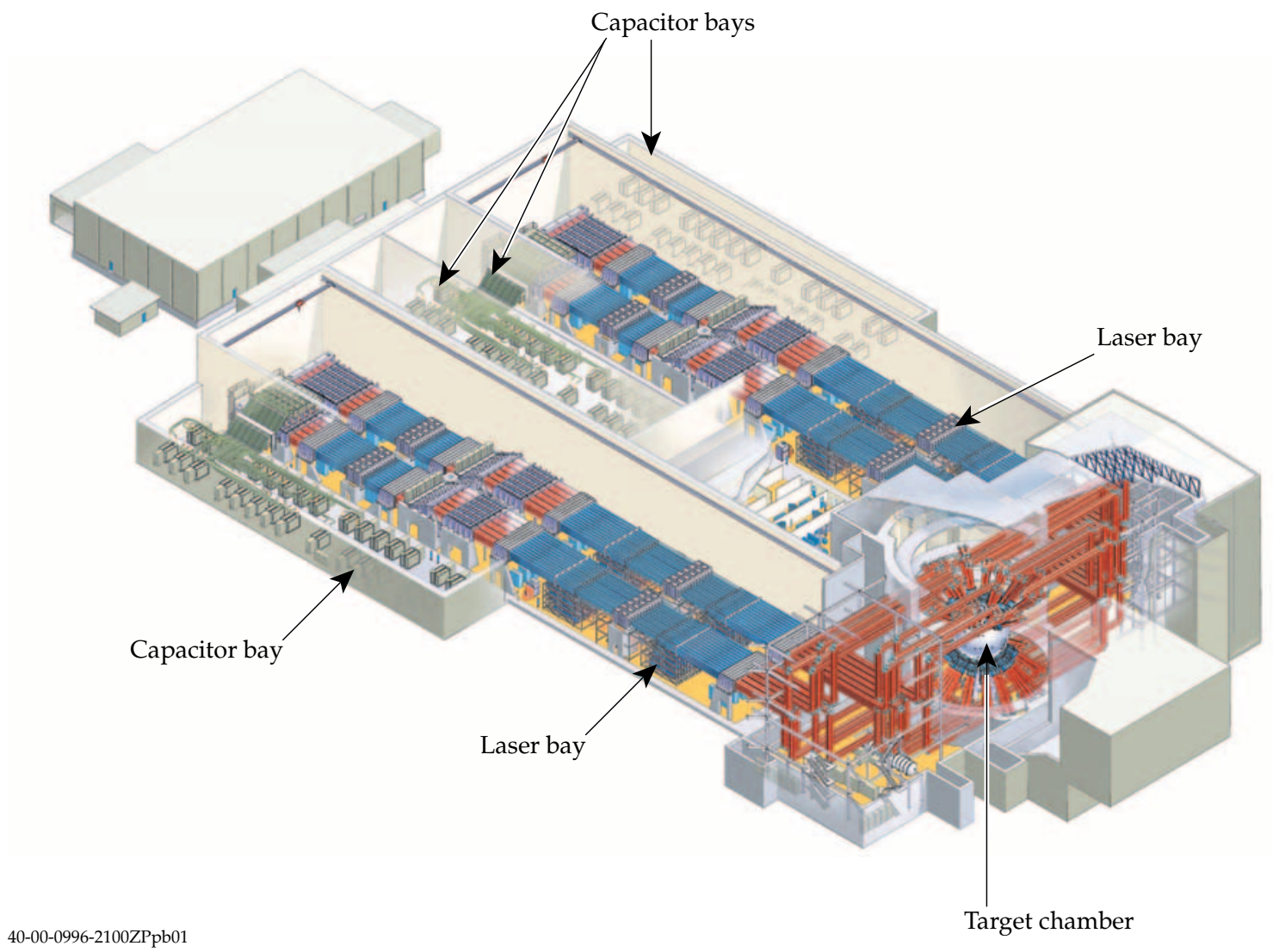

Figure 1: Location of Capacitor Bays within NIF 
The capacitor modules typically contain 20 capacitors (with a maximum of 24) connected in parallel to a common bus by fiberglass reinforced steel damping elements (see Figure 2). A failure in a capacitor can is thought to most likely be the result of pressure generated internally due to vaporization of the dielectric or thermal expansion resulting from electrical breakdown (either between plates or between plates and the grounded case) during capacitor charging and discharging. Capacitors used in NIF modules are self-healing for failure modes involving the internal windings. When minor discharge occurs between plates, the paths open and seal, and the capacitance of the unit decreases slightly.

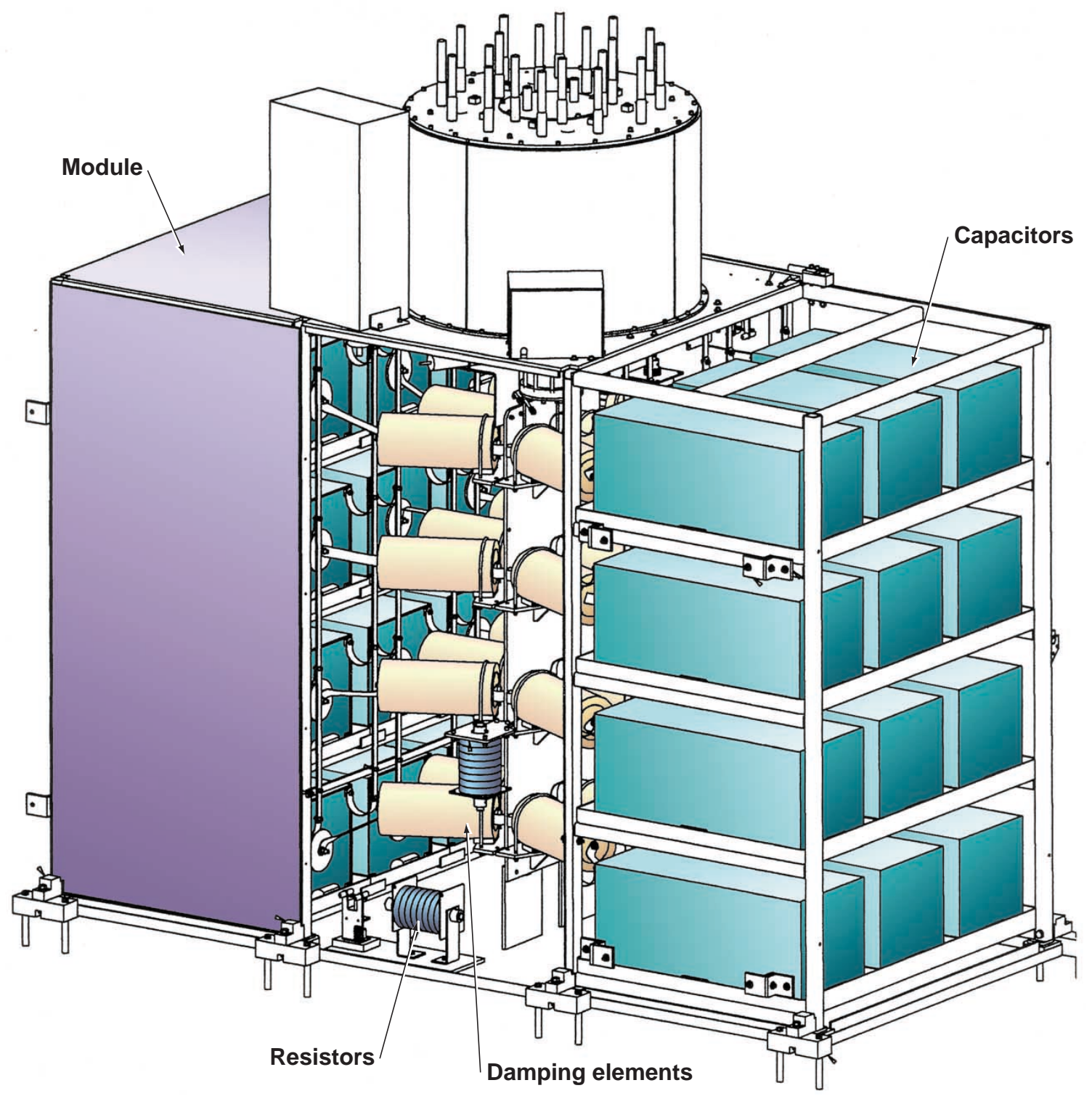

Figure 2: View of a Capacitor Module 
Other failure modes (e.g., involving connections exterior to the windings), however, can lead to explosive failures. Because the capacitors are connected in parallel, all capacitors will discharge through the fault with a maximum energy of $\sim 2 \mathrm{MJ}$ (corresponds to the maximum of 24 capacitors).

It is generally agreed that failures involving a fireball require the generation of dielectric as a fine mist or aerosol. If dielectric is produced outside the capacitor in vapor phase or as a fine aerosol, and if arcing is occurring simultaneously with the release of dielectric, the conditions for ignition exist. Note that the flammability characteristics of the candidate dielectric fluids (castor oil, rapeseed oil) have been studied in detail (Staggs et al., 1999). Sustaining a fire with these materials is extremely difficult. A transient ignition source such as a discharge arc could only produce a limited quantity of ignited fluid (Staggs et al., 1999). Thus, after an explosive event involving the ignition of a dielectric fluid, a sustained fire would not be expected. The fireballs that have been observed to date have been of short duration before self-extinguishing.

Other elements of the power conditioning unit (other than capacitors) have also been observed to explode. In particular, the resistors are vulnerable to this type of event. In this case, shorting occurs, dumping the electrical energy locally into the resistor. This occurs rapidly, resulting in heating and overpressurization, and stressing of the resistor to the point where it flies apart, becoming shrapnel. Damping elements have also failed in a similar way. Explosive failures of other module components (e.g., fiberglass tie rods, bus, etc.) have been studied and essentially eliminated (ACE, 1999). To date, explosions ${ }^{2}$ involving the dielectric oil (and a fireball) only occur when there is an internal failure of a capacitor.

\section{Personnel Safety Requirements}

DOE M 440.1-1, the DOE Explosives Safety Manual (DOE, 1996), provides the minimum design and personnel protection requirements for explosives facilities. Although no explosives are planned for use at the NIF, the impacts from power conditioning unit events are similar in nature to those resulting from explosives. Thus, the minimum personnel safety requirements from the DOE Explosives Safety Manual are considered applicable. These requirements are summarized below.

The DOE Explosives Safety Manual requires each bay or facility where explosives activities are performed to have levels of protection that are based on the hazard class (accident potential) determined for the activity. The levels of protection may be accomplished by equipment design, structural design, operation design, operation separation, or provision of operational shields.

\footnotetext{
${ }^{2}$ Staggs et al. (1999) refer to these events as deflagrations.
} 
NIF capacitor charging/discharging operations are limited to personnel protected (remote) activities that represent a moderate to high accident potential. Since it is anticipated that an occasional capacitor failure will occur, capacitor charging/discharging operations are considered similar to remote explosives machining or pressing operations and are defined as DOE Class I activities.

Bays and facilities for Class I activities are required to provide protection to prevent fatalities and serious injuries to all personnel, including personnel performing the activity, personnel in other occupied areas, and all transient personnel. This protection may be achieved by controlling blast and debris through suppression, containment, or establishment of an exclusion area with positive access control. The following hazards to personnel must be protected against:

- Overpressures greater than 5 psig ( $34 \mathrm{kPa}$ above atmospheric pressure) maximal effective overpressure or greater than 2.3 psig (16 $\mathrm{kPa}$ above atmospheric pressure) peak positive incident pressure.

- Structural collapse of the building from overpressure or debris impact. Structural collapse is the failure of a structural component as a direct result of the facility being subjected to various loadings (judged in accordance with the ability of the structure to remain intact so that explosion propagation and serious injury to personnel will not occur).

- Missiles (hazardous fragments). Hazardous fragments that can cause serious injuries are defined as those having greater than $11 \mathrm{ft}-\mathrm{lb}$ impact energy.

- Thermal fluxes greater than $0.3 \mathrm{cal} / \mathrm{cm}^{2} / \mathrm{sec}$.

As noted earlier, access to the capacitor bays will be controlled by the safety interlock system. Personnel will not be permitted in the area, including the adjacent laser bays, when the capacitors are being charged, or while they are charged. Since personnel will not be present in the capacitor bays while the capacitors are charged, exposure of personnel to overpressures and high thermal fluxes (items 1 and 4) during an event are not a concern. The structural integrity of the building and the generation of missiles, however, are a concern. To address building integrity issues (item 2), overpressures potentially generated in the capacitor bays have been assessed and compared to those pressures that would challenge the structural integrity of the bay walls. Debris generated from the events is small in size and should not be a structural threat to the walls (i.e., should not cause the walls to fall down). However, it may be capable of penetrating walls, and present a personnel hazard. To address the generation of hazardous fragments (item 3), ray tracing has been performed to understand the potential shrapnel pathways and to determine the effectiveness of the module at containing shrapnel. Recommendations related to the module design have been made, essentially eliminating the issue of hazardous fragments leaving the bay.

\footnotetext{
${ }^{3}$ Maximal effective pressure (peak positive normal reflected pressure) is defined as the total pressure that results instantaneously at the surface when a blast (shock) wave traveling in one medium strikes another medium. Blast overpressure (peak positive incident pressure) is defined as the pressure acting in the initial or incident blast (shock) wave from an explosion.
} 
This work has focused on mitigating the impacts of explosive events involving capacitor modules. This reduces the consequences of such events, and hence, the risk. The other contribution to the risk arises from the frequency of occurrence of the failures. An estimate of the frequency of occurrence of these types of events is provided in this report, based on the data from FANTM. Although not addressed in this report, the design team has actively explored ways of reducing the frequency of occurrence of these events (LLNL, 1999a). Together these activities have reduced the overall risk from capacitor module failures.

This engineering safety note focuses on personnel safety issues related to capacitor module failures. It follows the outline given in the Mechanical Engineering Design Safety Standards for Engineering Safety Notes (LLNL, 1995). An Engineering Safety Note is necessary in this case because the capacitor module is a piece of custom designed equipment, and it is the responsibility of LLNL to ensure safe design. This note reviews the overall design of the capacitor module, and assesses its adequacy with respect to controlling the pressure and shrapnel hazards. It reviews the capacity of the module to withstand the loads generated during the events, and ensures that the module structural integrity will be maintained. Section B of this note details the nature of the hazards. Section C identifies a concept that effectively addresses the hazards. It also summarizes associated administrative controls and procedures related to ensuring the safety of capacitor operations vis-as-vis the explosion hazard. Section $D$ describes in detail the set of calculations performed to support the claims of maximum module pressure, maximum capacitor bay pressure, and shrapnel paths. It shows how these modifications adequately control the hazards. Sections $\mathrm{E}$ and $\mathrm{F}$ identify testing and labeling requirements. Section $\mathrm{G}$ identifies associated procedures, and Section $\mathrm{H}$ provides the references. Details of the calculations supporting the pressure analysis are provided in Appendix A. Calculations and code output related to the shrapnel analyses are provided in Appendix B. Appendix $C$ provides calculations supporting the adequacy of the new concept with respect to energy absorption of shrapnel. Appendix D documents the probability analysis related to the number of simultaneous events that may occur. Appendix E provides supporting details related to the structural analysis of the module.

\section{Section B: Nature of the Problem}

As outlined in the previous section, there are three basic hazards associated with capacitor module events:

- Fire

- Overpressure

- Shrapnel. 


\section{Fire Hazard}

The fire hazard has already been studied in detail (Staggs et al., 1999), as discussed in the previous section. The burning characteristics of the dielectric fluid are fairly well understood. It is difficult to sustain a fire with the oil for any length of time. In addition, the NIF capacitor bays are fully sprinklered. These factors combine to reduce the fire hazard to very low levels. This safety note focuses on obtaining a better understanding of the overpressure and shrapnel hazards, and showing that the module design safely addresses these hazards. The overpessure and shrapnel hazards are discussed in more detail in this section.

\section{Pressure Hazard}

During explosive events, the rapid deposition of energy leads to localized heating and pressurization, over a very short time period. Usually, an initial shock wave is produced, over 10s to 100 s of microseconds. This is followed by a longer duration quasi-static pressure, which decays over time, and lasts $10 \mathrm{~s}$ of milliseconds. Materials generally respond less sensitively to the shock wave. The quasi-static pressure, however, persists for a long enough time that damage to materials and components might be expected.

In the case of the explosive capacitor module events, there exists two potential sources of overpressure. First, the rapid dumping of electrical energy into components, such as a resistor, can result in such effects. Second, if the dumping of electrical energy leads to failure of a capacitor can, then an oil mist can be created. An electrical arc can ignite the air-oil mixture, leading to a chemical deflagration. The rapid reaction, increase in temperature, and generation of reaction products results in overpressure.

Historically, for exploding systems, there has been a tendency to relate the total energy release to an equivalent amount of TNT (LLNL, 1995). While there have been some spectacular component failure events at FANTM (three involving capacitors and one involving a resistor), it is not entirely clear that there is a direct equivalency of an electrical discharge (and possible oil ignition) to that of a high explosive such as TNT. However, for the purpose of this document, an estimate of the stored maximum potential energies is provided below. 
The maximum stored electrical energy for the complete capacitor module consisting of 24 capacitors is 2MJ. The heat of detonation for TNT is (DOE, 1992)

or

$$
\Delta H_{D}=1.97 \times 10^{6} \frac{f t-l b f}{l b(T N T)}
$$

$$
\Delta H_{D}=2.67 \frac{M J}{l b(T N T)}
$$

Thus, for a $100 \%$ energy efficiency conversion, a $2 \mathrm{MJ}$ electrical discharge (by itself) would suggest an equivalent chemical explosive weight of

$$
W_{\text {spark(max) }}=\frac{2 M J}{2.67 \frac{M J}{l b(T N T)}}=0.75 l b(T N T)
$$

The maximum free oil in a single capacitor has been estimated at 3 gallons. For castor oil the heat of combustion is

$$
\Delta H_{C}=15,950 \frac{B T U}{l b}
$$

For a worst case $100 \%$ combustion of the oil, this gives a stored energy of

$$
E_{\text {oil (max) }}=(3 \text { gallons })(0.96)\left(\frac{62.4 l b}{f t^{3}}\right)\left(\frac{0.133 f t^{3}}{g a l}\right)\left(15950 \frac{B T U}{l b}\right)\left(\frac{1055.9 J}{B T U}\right)=402.5 M J
$$

On a $100 \%$ energy equivalency basis, this has a maximum equivalent weight of TNT of

$$
W_{\text {oil (max) }}=\frac{402.5 M J}{2.67 \frac{M J}{l b(T N T)}}=150 l b(T N T)
$$

The total TNT equivalency would be given by the total energy released

$$
\begin{gathered}
E_{\max }=E_{\text {spark }}+E_{\text {oil }} \\
W_{\text {eqiv.TNT }}=\alpha W_{\text {spark }}+\beta W_{\text {oil }}
\end{gathered}
$$

where $\alpha, \beta$ are the conversion efficiencies of the electrical discharge and the oil ignition. Table 4 (see later in this section) provides some information on failures that actually occurred at FANTM, including the amount of stored electrical energy at the time of failure. Section D, Methods \#6 to \#9, includes various bounding estimations of the quantity of dielectric oil that could be involved in a capacitor failure. It was determined that a very small amount of the available oil would contribute to the explosive event, on the order of $500 \mathrm{~g}$ or less. This is a 
small fraction (on the order of $5 \%$ or less) of the total oil available in a capacitor (approximately 10,900 g, see the above evaluation). For the following analysis it is usually considered that $\alpha=1$ and $\beta \approx 0$; or in other words, very little of the oil actually participates.

It should be noted that a TNT reaction occurs in microseconds, while oil burning is a much slower process. Thus, care must be taken when referring to TNT equivalent, which may generate the same peak pressure, but the shock wave phenomenon is very different.

A study of the burning characteristics of various dielectric fluids that might be used in NIF capacitors was undertaken (Staggs et al., 1999). This showed that it is very difficult to create a sustained burn with any of the materials, and that only a small amount of oil would likely be involved in any event. The experimental evidence supports the argument presented above.

The overpressure presents a threat to the individual capacitor module and to the capacitor bays. The survivability of the capacitor module and of the capacitor bay walls is the main issue explored here. Pressure estimates were derived from evidence of past events at FANTM, as well as from first principles. The evidence drawn upon and the theoretical approaches used are discussed in the next section.

The capacitor bays are basically of two types. The exterior bays (bays 1 and 4) are approximately $252 \mathrm{ft} \times 51 \mathrm{ft} \times 26 \mathrm{ft}$. The exterior walls are a steel-braced frame design, with the exterior closed by metal siding. The total thickness of steel in the exterior walls is approximately 0.1 inches. The exterior bays' roofs are insulated metal deck. The interior walls, shared with a laser bay, are equivalent to approximately 2 inches of gypsum board. The interior bays (bays 2 and 3) are slightly smaller than the exterior bays, $250 \mathrm{ft} \times 49 \mathrm{ft} \times 26 \mathrm{ft}$. Their common wall and the walls they share with the laser bays and support areas are equivalent to approximately 2 inches of gypsum board. The walls on the east end, which adjoin the Optics Assembly Building corridor, and the walls on the west end, which adjoin the LTAB operations area, are also constructed of approximately 2 inches of gypsum board. The mechanical equipment room is located above bays 2 and 3. The floor of the mechanical equipment room/ceiling of the interior bays is concrete (at least 4 inches) on metal deck. The walls and ceilings of the capacitor bays were not designed to withstand any significant pressure. The ultimate strength static pressure capacity of the NIF capacitor bay walls is about 30 psf (0.2 psi) (Parsons, 1996). 


\section{Shrapnel Hazard}

During the explosive events, components within the modules are stressed and fragmentation can occur. High velocity fragments can be generated. The primary concern associated with the high velocity fragments is their potential to escape the module, penetrate the capacitor bay walls and harm personnel outside.

The Mechanical Engineering Design Safety Standards (LLNL, 1995) indicates that fragment hazard evaluation should be done by postulating a reasonable fragment. Reasonable fragments for this analysis were determined from the evidence from past events at FANTM. A number of fragments were collected, including chunks of resistor and pieces of copper strapping. Characteristics of these pieces of shrapnel are summarized in Table 1, and discussed below.

\section{Fragment 1}

Fragment 1 is a piece of ceramic, hollow core dump resistor ${ }^{4}$. Fragments of this type were found outside the FANTM module. To estimate the velocity of the resistor fragment, the Gurney equation for right circular cylinders was used. The Gurney equation is normally used to estimate the velocities of bomb casing fragments that result from the detonation of explosives that are surrounded by a metallic casing. It is believed that velocities obtained in this manner are conservative since any electrical energy dissipated is dispersed throughout the ceramic case thickness as opposed to internal to the case per the Gurney methodology. The estimated velocity calculated for Fragment 1 was determined to be $943 \mathrm{ft} / \mathrm{s}$. Details of the calculation for estimating the velocity of Fragment 1 are provided in Appendix B.1.

\section{Fragment 2}

Fragment 2 is a long, slender copper fragment. Fragments of this type were also found outside the FANTM module. Because Fragment 2 is somewhat long and slender ("head-on" cross section of $0.0156 \mathrm{in}^{2}$ and length of 4 inches, compared to "broadside" cross section of $0.5 \mathrm{in}^{2}$ and length of $0.125 \mathrm{in}$ ), it could be viewed as a "long-rod penetrator". However, the observed fragments are actually bent and curled, more like a chunky fragment. These copper fragments are electromagnetically launched, and originate in curved sections of the copper strapping. Thus, there appears to be no mechanism to generate a straight fragment in the shape of a long-rod penetrator to begin with. As the fragment impacts surfaces, it would tend to deform more, becoming chunkier and even less like a long-rod penetrator. Fragment 2, acting truly as a long-rod penetrator, could have penetrated the capacitor module. However, there has been no evidence of piercing impacts, or any impacts that come close to penetrating the $3 / 8$ inch steel module casing. Given all of this, Fragment 2 as a long-rod penetrator was thought to be an inappropriate fragment for this situation. Thus,

\footnotetext{
${ }^{4}$ Fragments of similar size could also be created from a failure involving a damping element. However, the damping element material (epoxy) is less dense and the fragments would be lighter (failures that could generate metal shrapnel from an inductor have been eliminated). Further, not as much energy can be put into an inductor compared to a resistor. Consequently, damping element fragments should be less hazardous, and would be bounded by resistor fragments.
} 
the chunky version of Fragment 2, rather than the penetrator version, has been considered in this analysis.

The velocity of Fragment 2 was deduced from evidence within the module. The interior of the module was examined for damage that could have resulted from fragment impacts. The most severe pit identified was found to have a depth less than $1 / 8$ of an inch in aluminum. Conservatively, a depth of $1 / 8$ of a inch in steel was adopted as a penetration depth for Fragment $2^{5}$. The velocity the fragment would have been traveling to create this pit was then calculated from the penetration depth. This was found to be $1040 \mathrm{ft} / \mathrm{s}$. The supporting calculations for estimating Fragment 2 velocity are provided in Appendix B.2.

\section{Fragment 3}

Fragment 3 was a small copper fragment, found to have penetrated another capacitor in the module (one not directly involved in the event). The fragment did not penetrate into the depth of the can, but appeared to have come to a stop after penetrating the 0.07 inch thickness of the capacitor can. This information was used to estimate a velocity for Fragment 3 . The estimated velocity for Fragment 3 was $1248 \mathrm{ft} / \mathrm{s}$. The calculations for this estimate are provided in Appendix B.2.

Note that all of the fragments have energy greater than the $11 \mathrm{ft}-1 b_{\mathrm{f}}$ threshold and are considered hazardous.

${ }^{5}$ This is conservative by a factor of approximately 2 (see Appendix B.2). 
Table 1: Characteristics of Fragments Used in Analysis

\begin{tabular}{|c|c|c|c|}
\hline & Fragment 1 & Fragment 2 & Fragment 3 \\
\hline Material & $\begin{array}{l}\text { Resistor } \\
\text { (ceramic) }\end{array}$ & Copper & Copper \\
\hline Weight (oz) ${ }^{6}$ & 2 & 0.32 & 0.04 \\
\hline Cross Section $\left(\mathrm{in}^{2}\right)$ & 1.125 & $0.5^{7}$ & 0.0625 \\
\hline Volume (in $\left.{ }^{3}\right)$ & 1.125 & 0.0625 & 0.0078 \\
\hline Density $\left(\mathbf{l b} / \mathbf{f t}^{3}\right)$ & 140 & 555 & 555 \\
\hline Velocity $(\mathrm{ft} / \mathrm{s})^{8}$ & 943 & 1040 & 1248 \\
\hline $\begin{array}{l}\text { Energy }^{8} \\
\left(\mathrm{ft}-\mathrm{lb}_{\mathrm{f}}\right)\end{array}$ & 1726 & 336 & 60.5 \\
\hline $\begin{array}{l}\text { Vertical Momentum } \\
\left(\operatorname{lb}_{\mathrm{f}}-\mathrm{s}\right)^{8}\end{array}$ & 0.45 & 0.044 & 0.0055 \\
\hline
\end{tabular}

${ }^{6}$ The size distribution of collected resistor fragments is: $0.5,1,1,1,1.5,1.5,2,2.5,3,3 \mathrm{oz}$. They were all a similar chunky shape (almost a cube). The size distribution of copper fragments is not available.

7 "Broadside" cross section, compared to "head-on" cross section of $0.0156 \mathrm{in}^{2}$. See discussion in text arguing why a "long-rod penetrator" (i.e., fragment impacting head on) is overly conservative.

${ }^{8}$ Calculated values, see Appendices B.1, B.2, and B.4. 
Table 2: Estimated Penetration Depths (inches) of Direct hits of Fragments into Facility Materials

\begin{tabular}{|l|l|l|l|}
\hline Material & Fragment 1 & Fragment 2 & Fragment 3 \\
\hline $\begin{array}{l}\text { Steel: } \\
\text { Module 3/8” } \\
\text { Bay walls 0.1 “ }\end{array}$ & $\begin{array}{l}0.052-0.26 \\
\text { contained by } \\
\text { module; may } \\
\text { penetrate wall }\end{array}$ & $\begin{array}{l}0.123-0.16 \\
\begin{array}{l}\text { contained by } \\
\text { module; may } \\
\text { penetrate wall }\end{array}\end{array}$ & $\begin{array}{l}0.07-0.095 \\
\text { contained }\end{array}$ \\
\hline $\begin{array}{l}\text { Gypsum Board } \\
\left.\mathbf{( 2}^{\prime}\right)^{8}\end{array}$ & $1.8-4.5$ & $0.62-1.9$ & $0.67-2.4$ \\
\hline $\begin{array}{l}\text { Interior Roof (4" } \\
\text { concrete) }\end{array}$ & $\begin{array}{l}1.2 \\
\text { conetrates }\end{array}$ & $\begin{array}{l}\text { contained } \\
\text { may penetrate }\end{array}$ \\
\hline
\end{tabular}

${ }^{8}$ Estimated using either strawboard or fibreboard approximation, both of which are expected to be conservative (i.e., penetration depth is overestimated).

Table 3: Estimated Thickness of Fragment Shielding Materials Required to Just Stop Fragments (inches, no safety factor included)

\begin{tabular}{|l|l|l|l|}
\hline Material & Fragment 1 & Fragment 2 & Fragment 3 \\
\hline $\begin{array}{l}\text { Low grade } \\
\text { Plywood } \\
\text { (fire retardant) }\end{array}$ & $\begin{array}{l}1.3 \\
(1.4)^{9}\end{array}$ & $\begin{array}{l}1.5 \\
(1.6)^{9}\end{array}$ & $\begin{array}{l}0.86 \\
(0.90)^{9}\end{array}$ \\
\hline $\begin{array}{l}\text { High grade } \\
\text { Plywood (fire } \\
\text { retardant) }\end{array}$ & $\begin{array}{l}0.91 \\
(0.96)^{9}\end{array}$ & 1.0 & $(1.1)^{9}$ \\
\hline $\begin{array}{l}\text { Lumagard } \\
\text { Concrete }\end{array}$ & $7 / 32$ & $7 / 32$ & 0.58 \\
\hline
\end{tabular}

\footnotetext{
${ }^{9}$ Strength properties of fire-retardant plywood are decreased by about $10 \%$, resulting in a greater required shielding thickness (DOA, 1987).
} 
The impact of the fragments identified above, in terms of their penetration into each of the wall/roof/ceiling materials noted earlier, is summarized in Table 2. The formulations used to calculate these penetration depths, and justification of their applicability is provided in Appendix B.3. The exterior capacitor bay roofs were evaluated based on tolerance to vertical momentum, rather than a simple penetration depth calculation (formulation for penetration depth calculation was not available for this type of roof). The vertical momenta of the fragments are calculated as shown in Appendix B.4. At a fragment momentum of $0.451 \mathrm{lb}_{\mathrm{f}} \mathrm{s}$, for conventional built-up roofing without gravel, cracking has been observed; at a momentum of $0.991 \mathrm{lb}_{\mathrm{f}} \mathrm{s}$, no damage was observed for built-up roofing with a top layer of slag and gravel (similar to exterior bay roofs) (DOE, 1992). Thus, it would be expected that the exterior capacitor bay roofs (built-up roof with slag and gravel) would be able to contain the fragments (vertical momenta of all fragments is less than $0.454 \mathrm{lb}_{\mathrm{f}} \mathrm{s}$, see Appendix B.4). The interior bay ceilings (concrete) would also be adequate to contain the fragments (see Table 2). The fragments easily challenge the wall materials, as indicated in Table 2.

\section{Summary of Explosive Events at FANTM and at LLNL}

Below is a brief description of the five explosive events that occurred at the FANTM facility. This information is summarized in Table 4. Much of the postfailure evidence was used to back-calculate the conditions associated with these events. A layout of the FANTM facility is shown in Figure 3.

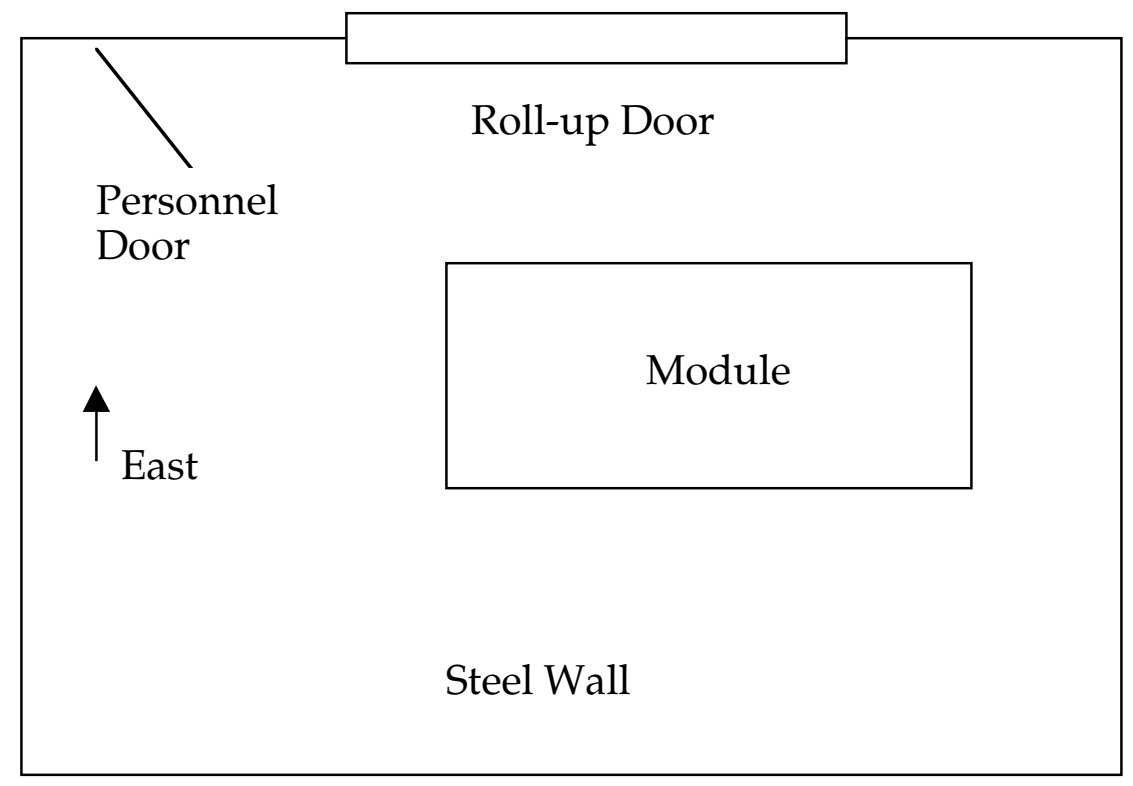

Figure 3: Layout of the FANTM Facility 
FANTM Explosive Failure \#1 (Wilson, 1998)

On September 11, 1998 (FANTM Shot \#114), one of the $300 \mathrm{mF}, 24 \mathrm{kV}$ capacitors exploded at a charge voltage of $16.5 \mathrm{kV}$. Film of the event showed a fireball, approximately $2-3 \mathrm{~m}$ in diameter, exiting the module from the edge of the large central door and immediately extinguishing. The $1^{\prime} \times 3^{\prime}$ flapper door fully opened, venting pressure as designed. No shrapnel or debris exited the module, and all containment doors remained in place.

Internal collateral damage was relatively minor: the failed capacitor, its associated damping element, a capacitor on the opposite side that was hit by shrapnel, and some buswork were replaced. Cleaning up the splattered and burned oil required a significant effort of more than one day.

The vendor identified the cause of the capacitor failure as an open circuit under the output terminal caused by poor or cold solder connections on the main output conductor.

\section{FANTM Explosive Failure \#2 (Wilson, 1998)}

On October 30, 1998 (FANTM Shot \#4415), one of the 300mF, 24kV capacitors exploded at a charge voltage of $11 \mathrm{kV}$. No film of the event was available. The $1^{\prime} \times 3^{\prime}$ flapper door fully opened, broke at its hinges, and was lying beside the module. The top mounting hooks on the two main $4^{\prime} \times 8^{\prime}$ central doors were broken and the doors were lying on the floor of the test cell. The roll-up door east of the facility was forced out of its tracks. There was significant smoke or haze within the cell after the event. A few of the bolts holding the secondary panels were snapped and the heads were found on the floor of the cell. No shrapnel or debris exited the module.

Internal collateral damage was greater than in the previous explosion, but still relatively minor: the failed capacitor, its associate damping element, the trigger fuse holder, several switch rods and the main switch insulator, and a larger amount of buswork were replaced. Cleaning up the splattered and burned oil required a significant effort of more than two days.

Just as before, the vendor identified the cause of the capacitor failure as an open circuit under the output terminal caused by poor or cold solder connections on the main output conductor. The larger event was likely due to more oil released, a more flammable or energetic oil, or both. At some point, the entire module (approximately $350 \mathrm{~kJ}$ stored) discharged either into this arc or some other arc generated during the failure.

FANTM Explosive Failure \#3 (Wilson, 1998)

On November 18, 1998 (after FANTM Shot \#5127), one of the main dump resistors exploded within the module during a routine dump test. Film of the event showed a flash within the module, red-hot particles within the module, but no fire. The 1' x 3' flapper doors fully opened, broke at their hinges, and were lying beside the module. The top mounting hooks on the two main $4^{\prime} \times 8^{\prime}$ central doors were broken and the doors were leaning against the module. 
The flapper door and four pieces of shrapnel hit the roll-up door east of the facility. There was significant smoke or haze within the cell after the event. A few more of the bolts holding the secondary panels were snapped and the heads were found on the floor of the cell. Dump resistor debris was found throughout the cell. Photos taken after this event are shown in Figures 4 and 5.

Internal collateral damage was significant: the dump resistor assembly, two capacitors that were penetrated by debris, gas lines and control wiring, the trigger blocking capacitor, and some buswork were replaced. Cleaning up the debris required a significant effort of more than a day.

\section{FANTM Explosive Failure \#4 (Moore, 1999)}

On December 11, 1998 (FANTM Shot \#6189) one of the capacitors exploded at a charge voltage of $6 \mathrm{kV}$. At the time of the event, the video recorders were operating, but there is no external action during the explosion. The capacitor split open on the side near the top of the case, blackened oil drained out of the capacitor case into the module drip pan. A small amount of castor oil was sprayed on the high voltage bus and dump resistor B. A photo taken after this event is shown in Figure 6.

Internal collateral damage was minor: a failed capacitor. There was no shrapnel. Cleaning up the splattered oil and replacing the capacitor required minimum effort of less than one half day.

Just as before, LLNL and the vendor identified the cause of the capacitor failure as an open circuit under the output terminal caused by poor or cold solder connections on the main output conductor.

\section{FANTM Explosive Failure \#5 (Moore, 1999)}

On January 28, 1999 (FANTM Shot \# Lamp 0485; Note: The FANTM shot numbers were reset to zero when the flashlamps were installed) an explosion occurred at a charge voltage of $23 \mathrm{kV}$.

The month prior to this failure the FANTM access doors had been extensively modified. This modification divided the west facing access door into two hinged doors. The bottom half of the access door is attached to a hinge bar that extended across the entire module and is held in place by four brackets. The brackets are welded to the module frame at the edges of the access door and the outside edges of the secondary panels. The top half of the door was held in place by hinge blocks that are bolted to the top of the module. Both doors are allowed to swing freely. The modification to east access door consisted of bolting one foot lengths of 3/8 inch steel chain to each corner of the door and the module frame. Film of the event showed a flash within the module, red-hot particles within the module, particles exiting the module and no fire. The west side $1^{\prime} \times 3^{\prime}$ flapper door opened, the hinged doors opened fully. 


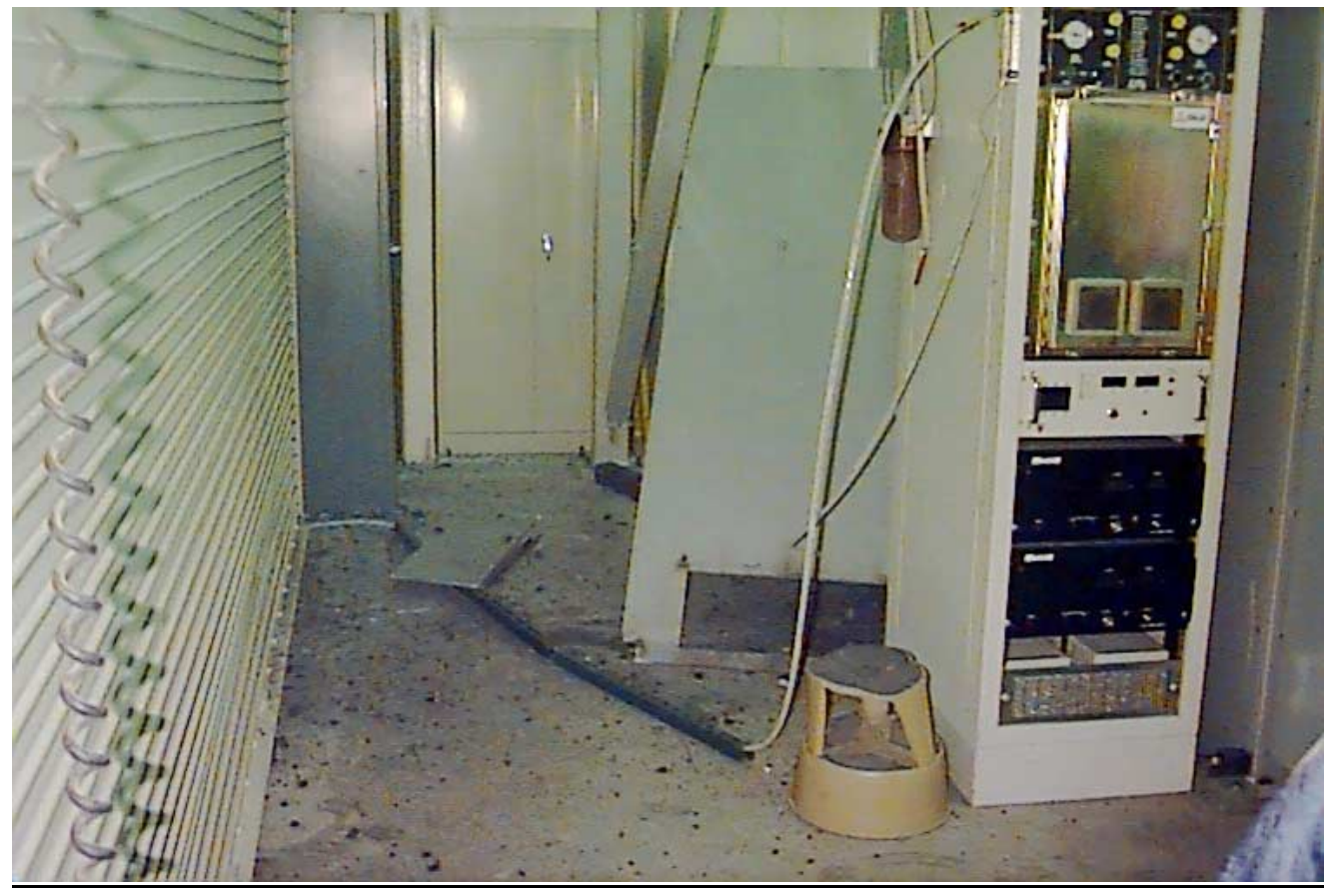

Figure 4: Conditions After FANTM Event \#3-The figure shows that the main 4'x8' central door was broken during the event. The door was found leaning against the module. The figure also shows the flapper door that was found lying on the floor.

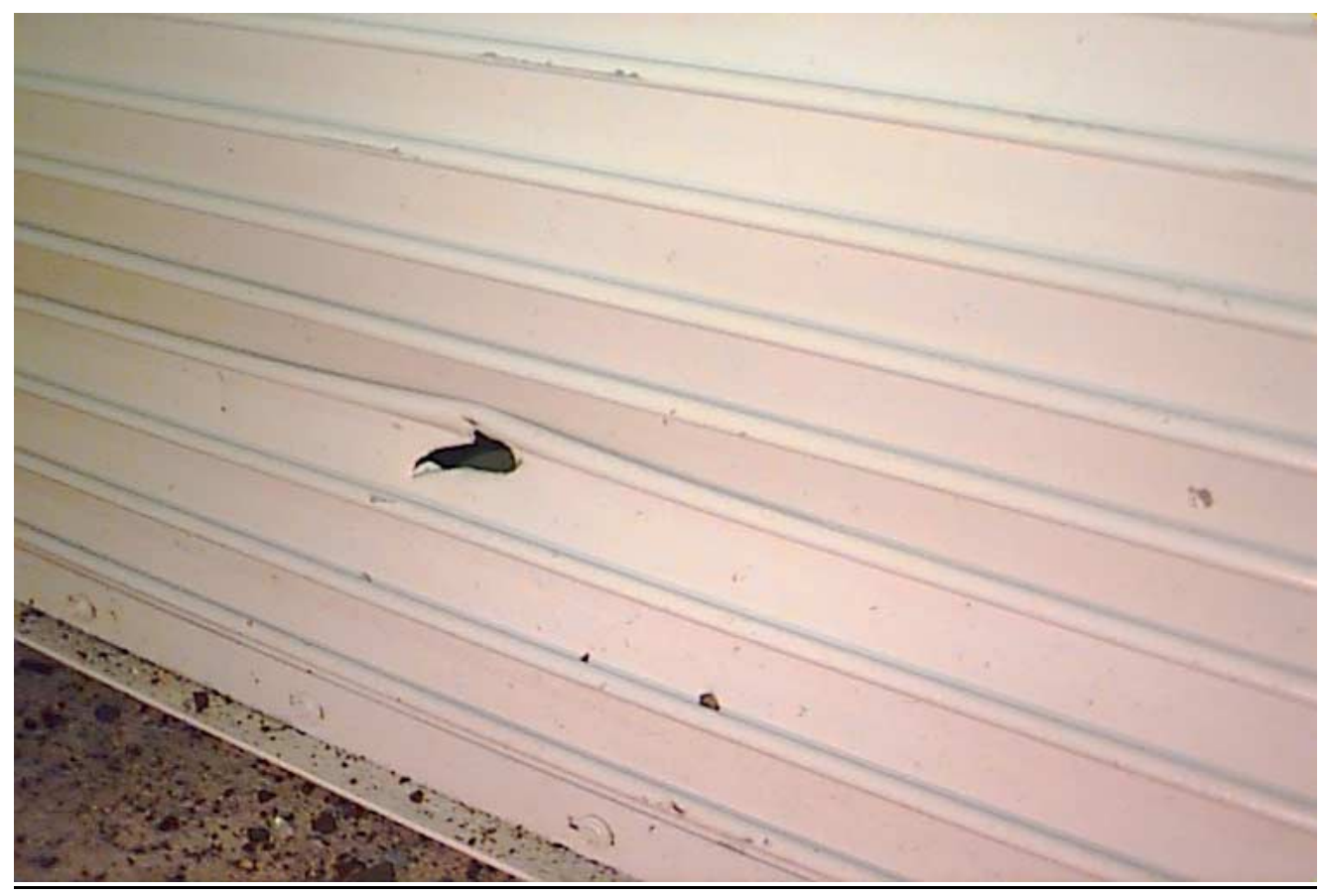

Figure 5: Conditions After FANTM Event \#3 -The figure shows the puncture of the roll-up door by the ejected flapper door. 

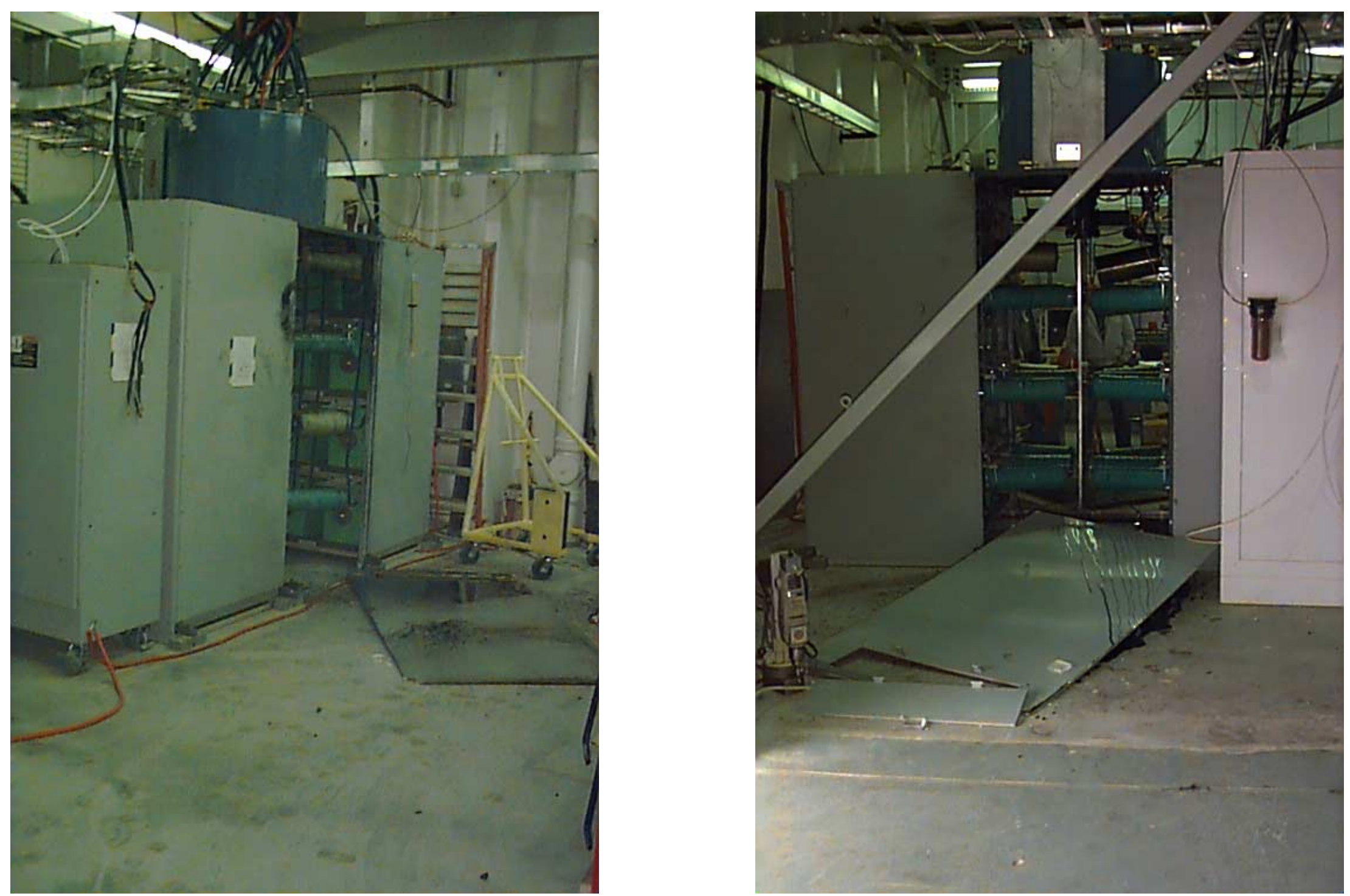

Figure 6: Conditions After FANTM Event \#4 -The figure shows the blackened oil draining out of the module from the failed capacitor case. 
All the bolts holding the secondary panel on the southwest side of the module were pulled out of the module. The southwest panel was held in position by the center hinge bar. The east door was moved off the module but was restrained by the chains.

Internal collateral damage was relatively minor: a failed capacitor and a damping element. Analysis of the failure revealed the cause to be external to the capacitor. It appears the connection to the damping element was too close to the capacitor case causing a breakdown between the capacitor case and the damping element. The breakdown caused the entire module (approximately $1.53 \mathrm{MJ}$ stored) to discharge through a single damping element into the fault. The discharge current caused the damping element to fail internally and explode.

Damping element debris was scattered throughout the cell. The capacitor header was broken and oil drained from the capacitor into the module; no blackened oil appeared in the module or the capacitor. The connecting strap between the capacitor was fused. Cleaning up the oil and debris required less than half a day.

\section{Events at LLNL}

LLNL has been testing individual candidate NIF capacitors for several years in the capacitor test facility in the basement of building 391. During that time, several catastrophic failures have been experienced in which the cases of capacitors ruptured. Unlike capacitor failures in a module where the total energy available can be as high as $2 \mathrm{MJ}$, there is less than $85 \mathrm{~kJ}$ involved in capacitor failures in the capacitor test facility. The impacts of these failures are dependent on the location of the failure within the capacitor.

Failures near the high voltage terminal of the capacitors often result in a mechanical failure of the insulator resulting in an explosive discharge of small quantities of the dielectric fluid. In some of the failures, the insulator broke into smaller pieces, which were propelled across the test facility. We have not observed any other source of shrapnel from a failure near the high voltage terminal. The header bolt is constrained by the lead it is attached to and the internal dielectric system in the capacitor consists of thin layers of metallized polypropylene, which is not conducive to the generation of shrapnel.

Failures that occurred in other areas of the capacitor did not generate any shrapnel. Oil was explosively discharged from capacitors but shrapnel discharged was nothing more than solid pieces of plastic insulating materials.

The first round of design qualification testing has been completed. Only capacitors that passed the extensive qualification testing are considered candidates for NIF. Three designs were qualified by life-testing $15-17$ capacitors for 25,000 shots or greater. During testing, no failures were experienced with any of the qualified designs. We have accumulated well over a million capacitor shots with no failures. Based on the results of this testing we expect to experience a much lower failure rate of capacitors than experienced on the FANTM facility in Albuquerque. 
Table 4: Summary of FANTM Occurences

\begin{tabular}{|c|c|c|c|c|c|c|c|c|}
\hline \multirow{2}{*}{$\begin{array}{l}\text { Event } \\
\text { No. }\end{array}$} & \multirow{2}{*}{$\begin{array}{l}\text { Sandia } \\
\text { FANTM } \\
\text { Shot \# }\end{array}$} & \multirow[t]{2}{*}{ Date } & \multirow[t]{2}{*}{ Fault } & \multirow{2}{*}{$\begin{array}{l}\text { Voltage } \\
(\mathrm{kV})\end{array}$} & \multirow{2}{*}{$\begin{array}{l}\text { Stored } \\
\text { Elec. } \\
\text { Energy }\end{array}$} & \multicolumn{2}{|c|}{ Module Configuration } & \multirow[t]{2}{*}{ Findings } \\
\hline & & & & & & Front panel & Rear panel & \\
\hline 1 & 114 & $9 / 11 / 98$ & Capacitor & 16.5 & $0.8 \mathrm{MJ}$ & $\begin{array}{l}\text { Large panel } \\
\text { w/small } \\
\text { flap(1'x3')@ top }\end{array}$ & $\begin{array}{l}\text { Large panel w/small } \\
\text { flap }\left(1 ' x 3^{\prime}\right) @ \text { bottom }\end{array}$ & $\begin{array}{l}1^{\text {st }} \text { capacitor explosion, bottom of module. All containment } \\
\text { doors remained in place. Partial basis for Pressure Calculation } \\
\text { Method \#6 (Fireball). }\end{array}$ \\
\hline 2 & 4415 & $10 / 30 / 98$ & Capacitor & 11 & $0.350 \mathrm{MJ}$ & $\begin{array}{l}\text { Large panel } \\
\text { w/small } \\
\text { flap(1'x3') @ top }\end{array}$ & $\begin{array}{l}\text { Large panel w/small } \\
\text { flap(1'x3') @ bottom }\end{array}$ & $\begin{array}{l}2^{\text {nd }} \text { capacitor explosion, center top north rack, blew off small } \\
\text { flapper doors, unfastened large front \& rear doors by failing } \\
\text { hooks, oil out to } 8 \text { ' from module. More explosion than shot } 114 \text {. } \\
\text { Basis for Pressure Calculation Method \#1 (Bowed Door), \#2 } \\
\text { (Failed Bolts) \#3 (Door hooks). }\end{array}$ \\
\hline 3 & \begin{tabular}{|c|} 
after Shot \\
5127
\end{tabular} & $11 / 18 / 98$ & Resistor & $\begin{array}{l}23.8 \\
(17 \mathrm{kV} \text { at } \\
\text { time of } \\
\text { failure })\end{array}$ & $\begin{array}{l}1.64 \mathrm{MJ} \\
(0.84 \mathrm{MJ} \\
\text { at time } \\
\text { of } \\
\text { failure) }\end{array}$ & $\begin{array}{l}\text { Large panel } \\
\text { w/small } \\
\text { flap(1'x3')@ top }\end{array}$ & $\begin{array}{l}\text { Large panel w/small } \\
\text { flap(1'x3') @ bottom }\end{array}$ & $\begin{array}{l}\text { Both small flapper doors failed at hinges; one penetrated the } \\
\text { roll-up door. Hooks holding large panel doors failed. Some } \\
\text { bolts failed. Large panels stayed in place; chunky pieces } \\
(\sim 30 \mathrm{~mm}) \text { cubes of ceramic resistor found across room. Basis for } \\
\text { Pressure Calculation Method \#2 (Failed Bolts), \#3 (Door } \\
\text { Hooks), \#4 (Trajectory of Small Flapper Door). }\end{array}$ \\
\hline 4 & 6189 & $12 / 11 / 98$ & Capacitor & 6 & $0.104 \mathrm{MJ}$ & $\begin{array}{l}\text { Large panel } \\
\text { w/small } \\
\text { flap(1'x3') @ top }\end{array}$ & $\begin{array}{l}\text { Large panel w/small } \\
\text { flap(1'x3') @ bottom }\end{array}$ & $\begin{array}{l}3^{\text {rd }} \text { capacitor explosion. Video of module showed no external } \\
\text { evidence of overpressure or fireball. All panels and bolts in } \\
\text { place. No shrapnel. Blackened oil contained within module. }\end{array}$ \\
\hline 5 & Lamp 0485 & $1 / 28 / 99$ & $\begin{array}{l}\text { Damping } \\
\text { element - } \\
\text { capacitor }\end{array}$ & 23 & $1.53 \mathrm{MJ}$ & $\begin{array}{l}2 \text { half height flap } \\
\text { doors w/ small } \\
\text { flap @ top }\end{array}$ & $\begin{array}{l}\text { Large panel w/small } \\
\text { flap(1'x3') @ bottom }\end{array}$ & $\begin{array}{l}\text { Not an internal capacitor fault - involved a failed connection to } \\
\text { damping element. Explosion. All bolts pulled out of panel } \\
\text { beside door. Damping element shorted to capacitor case. } \\
\text { Damping element failed internally. Damping element shrapnel. } \\
\text { Oil unblackened. Basis for Pressure Calculation Method \#5 } \\
\text { (Double Swinging Doors). }\end{array}$ \\
\hline
\end{tabular}




\section{Section C: Design Solutions, Administrative Controls, and Post-Event Procedures}

The module was re-examined to identify possible ways to adequately vent the module, and to provide better shrapnel containment. The modified concept is shown in Figures 7 and 8. Two large vents are provided on each side of the module. These have fixed vent areas, and do not require the swinging of a door before venting can begin (as did the final FANTM design). A shrapnel shield is located on the outside of each vent opening forming a chute. The chute contains a collimator. This increases the number of bounces shrapnel must take on the way out, degrading the shrapnel energy and directing it to the trap beneath. The trap contains 3.5 inches of clear pine (i.e., no knots), with the grain oriented vertically. This is sufficient to completely absorb the energy of even the most energetic fragment considered (see Appendix C). Some of the details of the design (lengths of shields, collimators, etc.) were determined based on the results of the ray tracing analysis (see next section).

Pressure venting following a capacitor module explosion is an important consideration in the design of the capacitor module. The basic requirement for venting is that adequate area be available, such that the overpressure can be vented in a short period of time (on the order of $10 \mathrm{msec}$ ).

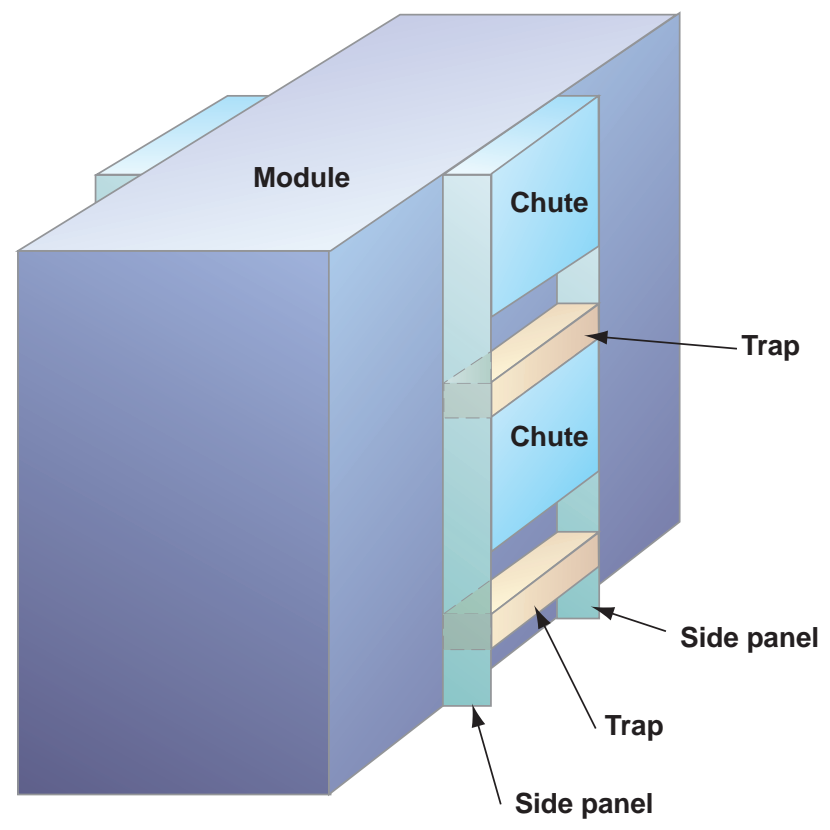

40-00-0799-1410pb01 13SJB/skl

Figure 7: Modified Capacitor Module 


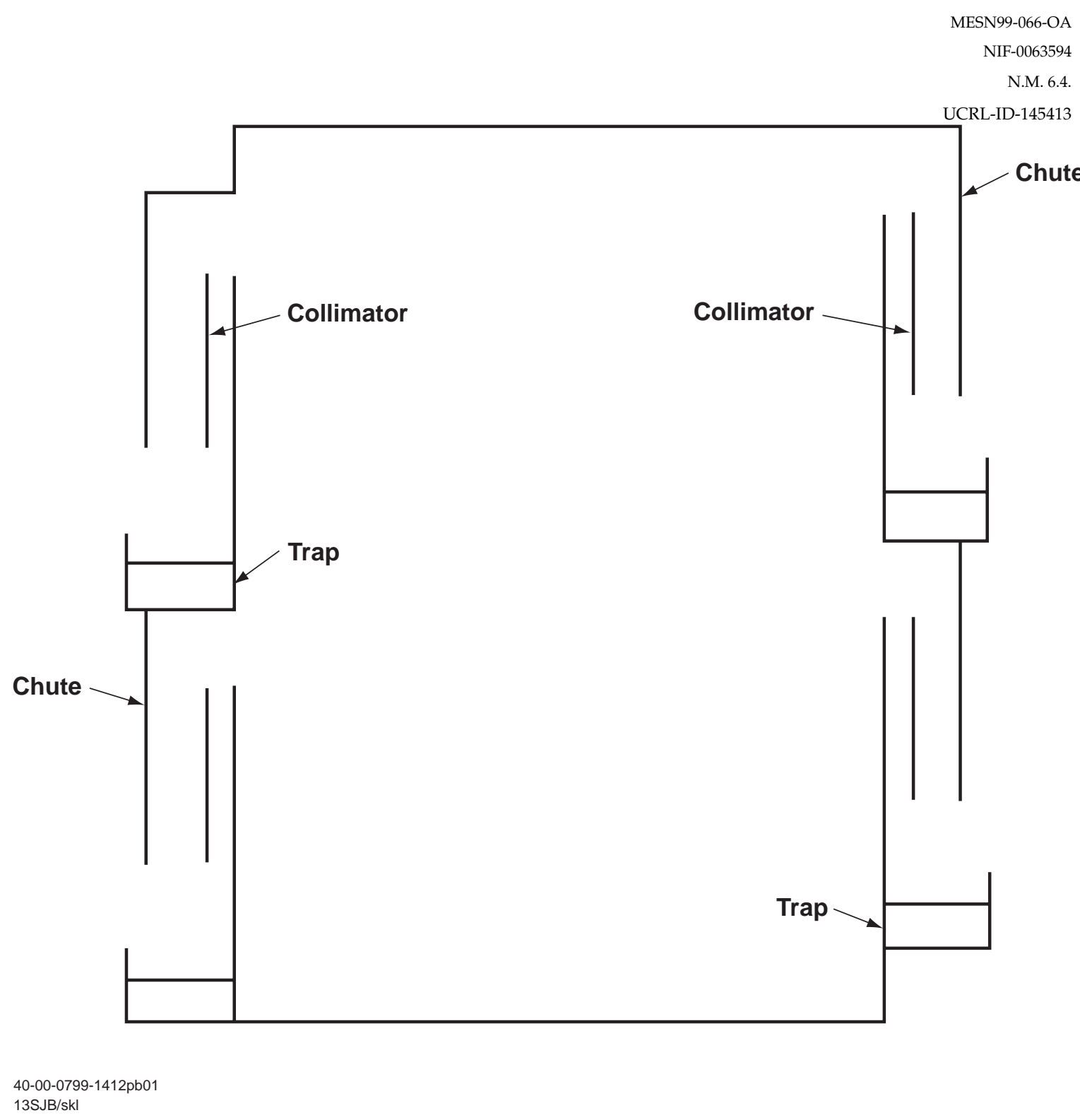

Figure 8: Modified Capacitor Module, Slide view (note the side panels are not shown)

During the course of this analysis, it was estimated that the module in FANTM Events \#3 and \#5 had vented completely within about $10 \mathrm{msec}$ (see Figures 9 and 10 , where this is determined from the analysis). 
The modified module has approximately $8.75 \mathrm{ft}^{2}$ of fixed venting area (approximately 15\% greater than the total venting area available from the doors swinging open in Event \#5, at the time when the overpressure has been reduced to zero ${ }^{10}$ ).

A comparison between the pressure venting of the module configuration during FANTM Event \#5 (double swinging doors) and that of a constant venting area of $8.75 \mathrm{ft}^{2}$ is depicted in Figure 9. Figure 9 shows that the pressure venting with $8.75 \mathrm{ft}^{2}$ of fixed vent area is much faster than that of the FANTM module with the double swinging doors. For a peak quasi-static pressure of 11 psig (see Calculations, next section, Method \#5, and equation (1) in Appendix A.5), the pressure drops to ambient pressure in $4.5 \mathrm{msec}$ in the former case, while it takes $9 \mathrm{msec}$ in the latter case. A comparison of the venting areas associated with the above two cases is given in Figure 10.

A similar comparison of pressure venting for a peak pressure of $40 \mathrm{psig}$ for the above two cases is depicted in Figure 11 (40 psig is the upper bound of all module pressure estimates, see Table 6 in Section D). Figure 11 shows that overall the constant venting with $8.75 \mathrm{ft}^{2}$ of area initially provides faster venting than the FANTM module with the double swinging doors (when it is more critical); although it takes $10.6 \mathrm{msec}$ for the pressure to drop to ambient pressure in the former case, while it takes $9 \mathrm{msec}$ in the latter case. A comparison of the venting areas associated with the above two cases for a peak quasi-static pressure of 40 psig is illustrated in Figure 12.

The venting times corresponding to various initial internal module quasi-static pressures when $8.75 \mathrm{ft}^{2}$ of vent area is provided are summarized in Table 5 . This shows that even if the module quasi-static pressure starts as high as $40 \mathrm{psig}$, it vents within approximately $10 \mathrm{~ms}$.

\footnotetext{
${ }^{10}$ Continued opening of the swinging doors occurs after the overpressure is reduced to zero, as a result of the door momentum.
} 


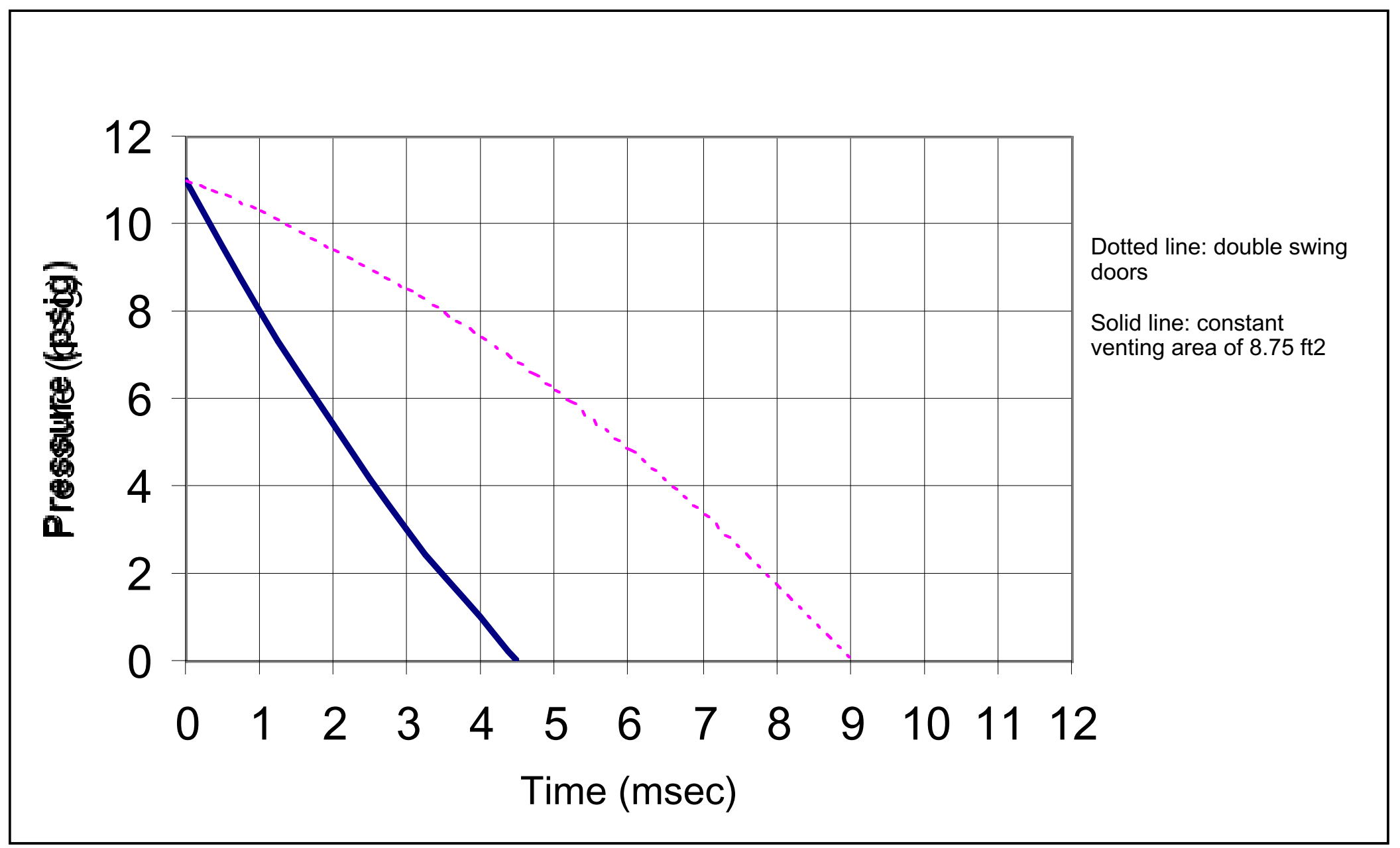

Figure 9: Pressure venting comparison (Pqs = 11 psig, FANTM Event \#5) 
Figure 10: Venting area comparison (Pqs = 11 psig, FANTM Event \#5)

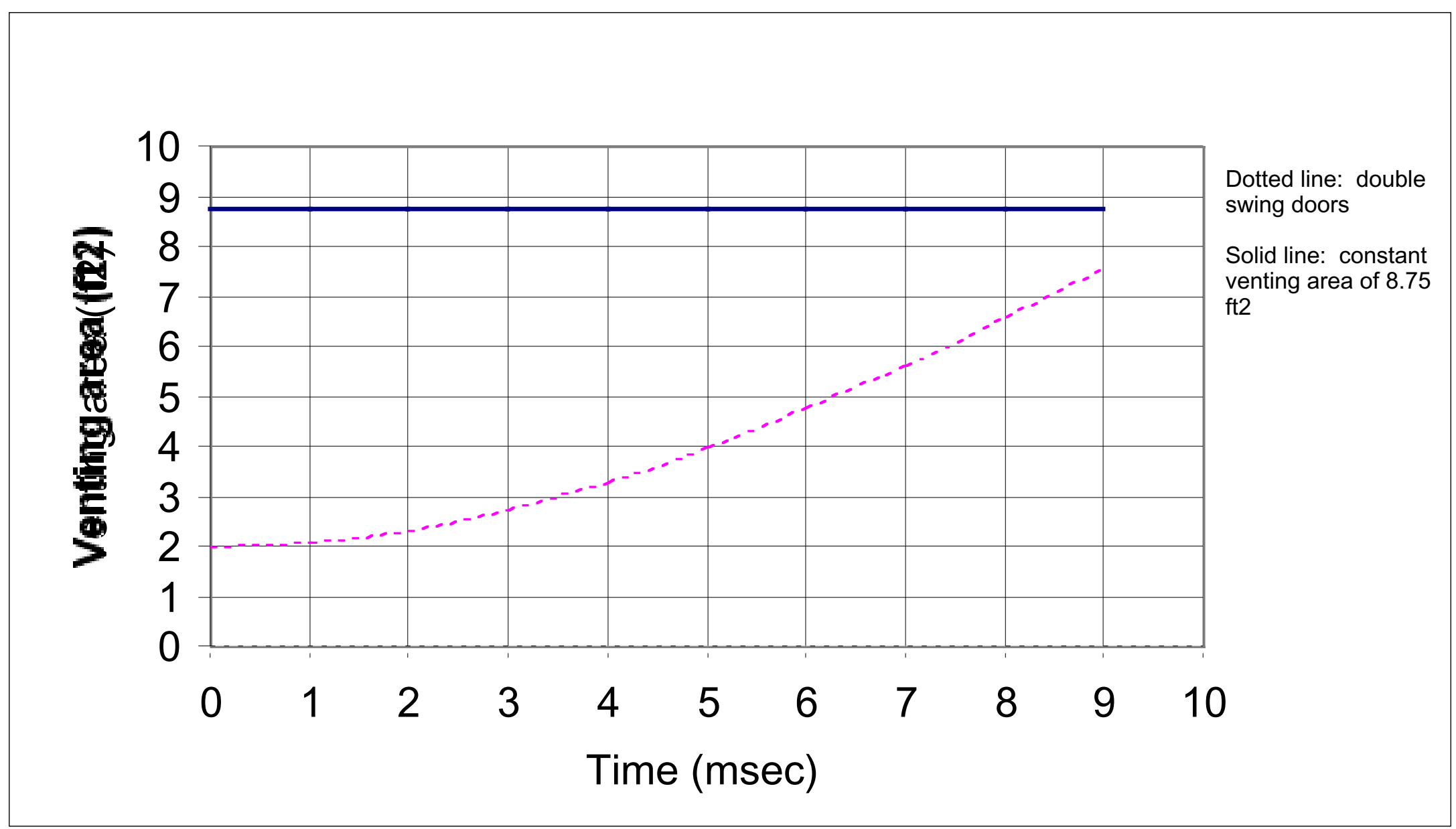




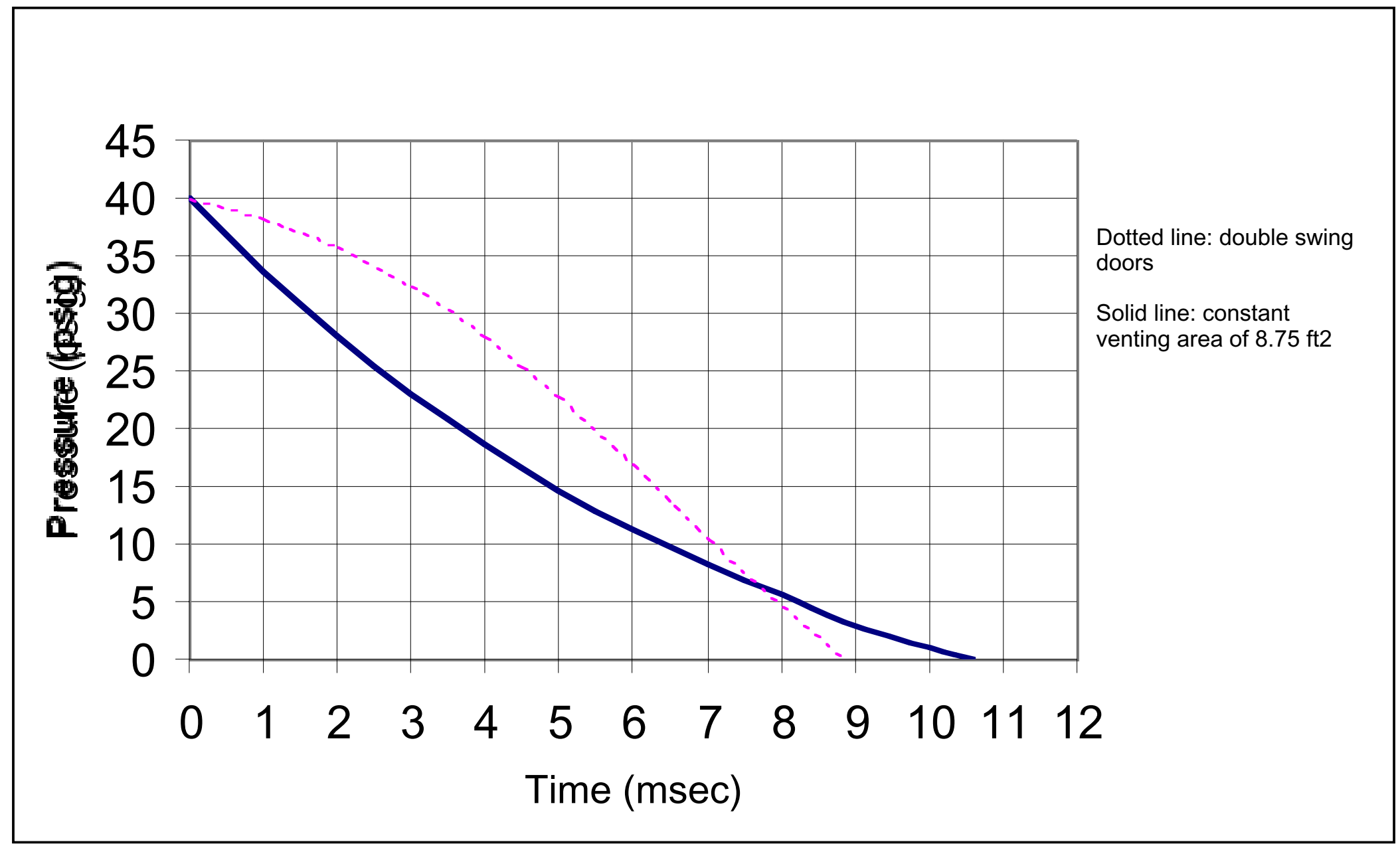

Figure 11: Venting area comparison ( $\mathrm{Pqs}=40 \mathrm{psig}$, bounding peak pressure estimate 


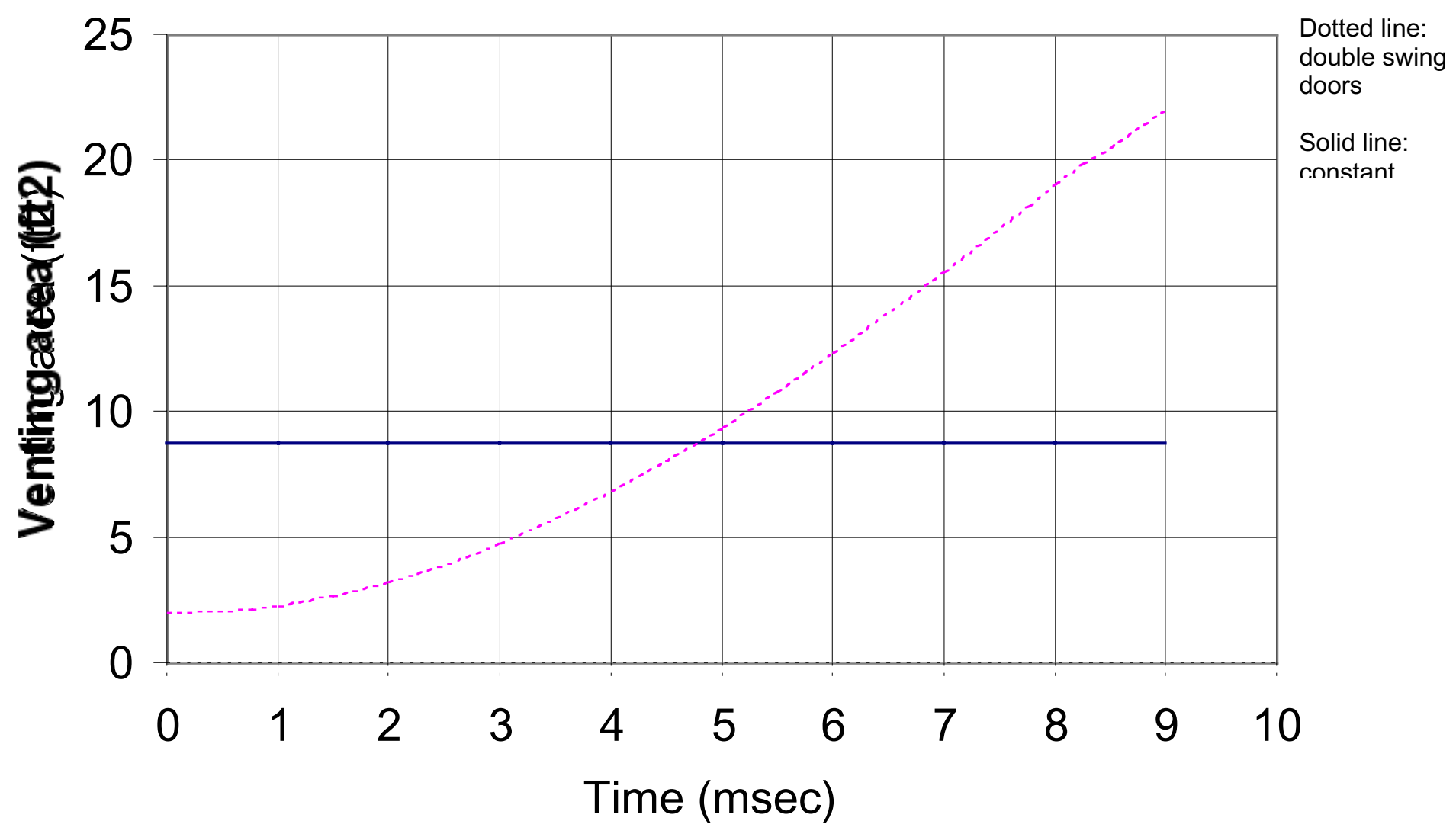

Figure 12: Venting area comparison (Pqs $=40$ psig, bounding peak pressure estimate) 
Table 5: Venting Time for Quasi-Static Pressure to reduce to Ambient Pressure

\begin{tabular}{|l|l|l|l|l|l|}
\hline \multicolumn{1}{|r|}{$\mathbf{P}_{\mathrm{qs}}(\mathrm{psig})$} & & $\mathbf{1 0}$ & $\mathbf{2 0}$ & $\mathbf{3 0}$ & $\mathbf{4 0}$ \\
\hline $\mathbf{\text { Time } ( \mathrm { ms } )}$ & $\mathbf{5}$ & $\left.\mathbf{1 0} \mathrm{ft}^{2}\right)$
\end{tabular}

This modified module was examined to assess its integrity (i.e., bolts and welds) under the anticipated pressure loads during an explosive event. Results of that analysis are provided in the next section.

This modified module was also examined in terms of shrapnel containment using ray tracing. Results of that analysis are also provided in the next section.

In addition to the physical aspects of the design, the safety of capacitor operations vis-as-vis the explosion hazard is controlled through administrative controls and post-event procedures. Access to the capacitor bays and neighboring laser bays will be controlled by physical interlocks on access doors and administrative procedures (LLNL, 1999). Personnel are not allowed in the capacitor bays while the capacitors are charging, or when they are charged.

After routine maintenance of capacitor modules, a procedure should require that all modules be checked, to ensure that all tools have been removed from the interior of the module, and any doors removed have been properly placed back onto the module.

Post-event procedures should be developed to address recovery from such occurrences. In addition to a clean-up process, the procedure should require that all module bolts and joints be inspected to ensure module integrity. The door vents, including the collimator and the shrapnel trap should also be inspected to ensure that they are in functional condition. 


\section{Section D: Calculations}

This section provides the basis for the calculations performed in support of estimating module and capacitor bay pressure. It provides the analysis supporting the claim that the module will remain intact during an explosive event. It also provides the ray tracing analysis, showing the adequacy of the module at containing shrapnel.

\section{Pressure Analysis}

Various methods were utilized to estimate the maximum quasi-static pressure that might be observed in a NIF capacitor module, and subsequently in a NIF capacitor bay. These included calculations based on observed evidence after events at FANTM, as well as theoretical calculations. Each approach is described briefly below. Details of the calculations are provided in Appendix A. A summary of the resulting module and bay pressure estimates are given in Table 6.

\section{Method \#1: Bowed Back Panel from FANTM Event \#2 (10/30/98)}

As a result of the $2^{\text {nd }}$ capacitor failure event (Event \#2, see Table 4, Summary of FANTM Events) both of the module's large doors were found to be permanently bowed out and deformed approximately 2 inches. From this deformation, an estimate of the total specific impulse that was applied to the doors can be made ( 37 psi-ms). Knowing the total specific impulse, one can estimate a fictitious equivalent amount of TNT, which if placed in the center of the module, would have produced this deformation ( $0.5 \mathrm{lb}$ TNT). Then, conservatively assuming that the fictitious average gas pressure in the module resulting from such a detonation ( $\sim 36$ psig) remained constant, expanding it out of the small module free volume into the capacitor bay volume gives a low maximum room overpressure of $\sim 3$ psf. This is well below the approximate wall structural limit of 30 psf. It is also conservative since the fictitious TNT gaseous byproducts are assumed to be at room temperature before venting from the module. Details of this calculation are provided in Appendix A.1.

Method \#2: Bolt Failure Calculation from FANTM Events \#2 and 3 (10/30 and $\underline{11 / 18 / 98)}$

As a result of events \#2 and \#3 (see Table 4, Summary of FANTM Events) some side panel bolts were found to have failed. Based on the size of the bolted-on panel and the static bolt strength properties, an upper bounding estimate of the largest average internal static pressure ( 28 psig) that could have been experienced by the FANTM module was made. Expanding this internal pressure out to the capacitor bay volume results in a low maximum room overpressure of $\sim 2.4$ psf, which is well below the wall structural limit of approximately $30 \mathrm{psf}$. Details of this calculation are provided in Appendix A.2. 
Method \#3: Door Hook Failure from FANTM Events \#2 and 3 (10/30 and 11/18/98)

As a result of events \#2 and \#3 (see Table 4, Summary of FANTM Events) door hooks that secured the large door panels were found to have failed. The location of the failure of each of the two hooks was at the minimum tensile area of each hook. Based on the size of the doors and the static hook strength properties, a lower or minimum bounding estimate of the largest average internal static pressure ( 14-20 psig) that could have been experienced by the door hook was made. During these two events it is not known when the hooks failed but since they all failed (on both doors of the module) the minimum internal pressure to cause this failure is assumed to be at least $14-20$ psig. The range of values is due to range of ultimate tensile strength for ASTM A36 bar stock (58-80 ksi). Expanding the 20 psig internal pressure out to the capacitor bay volume results in a bay overpressure of $\sim 1.7$ psf, which is well below the structural limit of approximately 30 psf. Details of this calculation are provided in Appendix A.3.

Method \#4: Trajectory of Small Flapper Door that Pierced the Roll up Door in FANTM Event \#3 (11/18/98)

The objective of this calculation was to estimate the peak quasi-static pressure inside the module, based on the location where the eastside 1' x 3' flapper door punctured the roll-up door during FANTM Event \#3 (see Figure 5). Measurements taken after the event determined that the puncture on the roll-up door was 11 inches above the ground. The calculation is described briefly in this section; the detailed derivation and equations are given in Appendix A.4.

After an explosion in an enclosed or partially vented containment, the pressure buildup will rapidly reach a peak quasi-static pressure, which will then decay exponentially as a function of time. The decay constant is linearly proportional to $\mathrm{A} / \mathrm{V}$, where $\mathrm{A}$ is the venting area of the containment and $\mathrm{V}$ is its volume. Therefore, for a given initial peak quasi-static pressure, the impulse due to the force acting on the flapper door can be evaluated as a function of time. The result can then be used to determine the velocity of the flapper door, which in turn, can be used to calculate the distance the flapper would travel as a function of time. Finally, the distance thus obtained can be used to determine the venting area and the associated pressure decay. The calculation can be carried out step by step using the finite difference method with a spread sheet.

The roll-up door is 8 feet away from the module and the bottom of the $1^{\prime} \times 3^{\prime}$ flapper door is 4 inches above the ground. As the flapper door travels horizontally towards the roll-up door, it will also drop in height due to gravity. There are many ways the flapper door could have traveled. For example, it could have rotated and translated at the same time, or it could have hit the ground and bounced before hitting the roll-up door. For the purpose of this calculation, elevation drops of the flapper door ranging from 3 in. to 5 in. are considered. The drop in elevation was used to estimate the time of flight. During this time period, the flapper door would have traveled 8 feet horizontally to hit the roll-up door. These results can be used to determine the peak quasistatic pressure that initially ejected the door. 
Several venting areas were considered in the calculation, including the venting due to the fly-away flapper door, the other small flapper door located on the other side of the module, and the two 4' $\times 8^{\prime}$ central doors, which were forced away from the module during the event. For elevation drops of 5 in., 4 in., and 3 in., the corresponding peak quasi-static pressures were determined to be 29 psig, 33 psig, and 38 psig, respectively. The peak quasi-static pressure is uncertain within a wide range, depending on the actual drop in elevation and path of travel. Since there is no video data to show the actual path of travel of the flapper door, FANTM Event \#3 is only used to provide some qualitative conjectures about the possible peak quasi-static pressure. In all three cases, the module pressure would reduce to ambient pressure in about $10 \mathrm{msec}$. Expanding the estimated module pressure to the bay volume, the resulting bay pressure is estimated to be less than 3 psf, well below the pressure tolerance of the bay walls.

\section{Method \#5: Double Swinging Doors in FANTM Event \#5 (1/28/99)}

The objective of this calculation was to estimate the peak quasi-static pressure inside the module by attempting to reproduce the positions of the swinging halfdoors as a function of time, as shown on the video taken during the event. The positions of the doors were recorded on video film taken during the explosion at 30 frames per second, i.e., $33.3 \mathrm{msec}$ between two consecutive frames. By looking at each of the frames, the swing angle of the bottom half- door, the top half-door, and the small flapper door could be roughly estimated.

These swing angles were used for comparison with theoretical calculations and conclusions on the peak quasi-static pressure were then drawn. The calculations are described briefly in this section; the detailed derivation and equations are given in Appendix A.5.

After an explosion in an enclosed or partially vented containment, the pressure buildup will rapidly reach a peak quasi-static gas pressure, which will then decay exponentially as a function of time. The decay constant is linearly proportional to $\mathrm{A} / \mathrm{V}$, where $\mathrm{A}$ is the venting area of the containment and $\mathrm{V}$ is its volume. Therefore, for a given initial peak quasi-static pressure, the impulse due to the torque acting on the door with respect to its hinge can be evaluated as a function of time by considering the gas pressure and the gravitational force. The result can then be used to determine the angular velocity of the swinging door, which in turn, can be used to calculate the swing angle. Finally, the swing angle thus obtained can be used to determine the venting area as a function of time and the associated pressure decay. This approach can be carried out step by step using the finite difference method with a spread sheet.

The angular displacement of the swinging doors depends on the peak quasistatic pressure, which is the only parameter in the calculation. The calculation considered several peak quasi-static pressures, such as 10,11, and 12 psig. The results indicate that the angular displacements of the bottom half-door, the top half-door, and the flapper door can be best overall reproduced by a peak quasistatic pressure of 11 psig. 
Several venting areas were considered in the calculation, including the swinging of the bottom half door, the top half door, the flapper door at the front, the flapper door at the back, and that provided due to the outward movement of the 4' $x 8^{\prime}$ east door (on the opposite side of the module to the swinging half doors). In addition, a fixed leakage area of $2 \mathrm{ft}^{2}$ around the bottom of the module was included (there is a one inch gap around the bottom of the module). The calculated results of the door position for a peak quasi-static pressure of 11 psig are depicted in Figure 13. Figure 13 also shows the swing angles of the bottom and top half-doors estimated from the video as a function of time (data are taken from Smith (1999)). Figure 13 indicates that the swing angles of the bottom and top half-doors shown on the video can be very well reproduced by a peak quasistatic pressure of 11 psig. It should be noted that the video data of the positions of the bottom and top half-doors within the first 0.1 second have large uncertainty (video was overexposed); therefore, the comparison within the first 0.1 second is less significant. The maximum swing angle calculated for the bottom half-door is $179^{\circ}$, which is within the range of the ultimate angle of $160^{\circ}$ to $180^{\circ}$, as determined by the video (see Smith (1999)). The calculation shows that the quasi-static pressure drops to ambient pressure in about $9 \mathrm{msec}$, the total impulse due to the quasi-static pressure over this $9 \mathrm{msec}$ period is 63 psi-ms. This is consistent with the findings given in Smith (1999), where by considering gravitational effects alone, they determined that the swing could have been caused by an initial impulse of 50 psi-ms.

For a peak quasi-static pressure of $11 \mathrm{psig}$, the calculation estimates that the small flapper door reaches $48^{\circ}$ at $33.3 \mathrm{msec}$ and $100^{\circ}$ at $66.6 \mathrm{msec}$. This is consistent with the video data for frames 1 and 2 . The calculated total venting area of the module increases from $2 \mathrm{ft}^{2}$ at 0 seconds (gap at bottom of module) to $7.4 \mathrm{ft}^{2}$ at $9 \mathrm{msec}$ (the increasing vent area is provided by the swinging doors and the movement of the back panel). At that point, the quasi-static pressure is reduced to ambient pressure.

A similar venting effect may be provided by a fixed venting area less than $7.4 \mathrm{ft}^{2}$. Expanding the 11 psig module pressure out into the bay volume would result in a bay pressure of less than 1 psf. This would not present a structural threat to the bay walls.

The calculated results for a peak quasi-static pressure of 10 psig are depicted in Figure 14. The results fit the video data better than those for an 11 psig peak quasi-static pressure for time less than 0.5 second. However, the maximum swing angle would only be $142^{\circ}$ in this case (and this does not match the video data well). Thus, the module pressure is better estimated to be 11 psig. 
Figure 13: Comparison between theoretical calculations (at $P_{q s}=11 \mathrm{psig}$ ) and video data for the swinging doors (video data are taken from (Smith, 1999))

Solid curve represents calculated results for the bottom door.

Dotted curve represents calculated results for the top door.

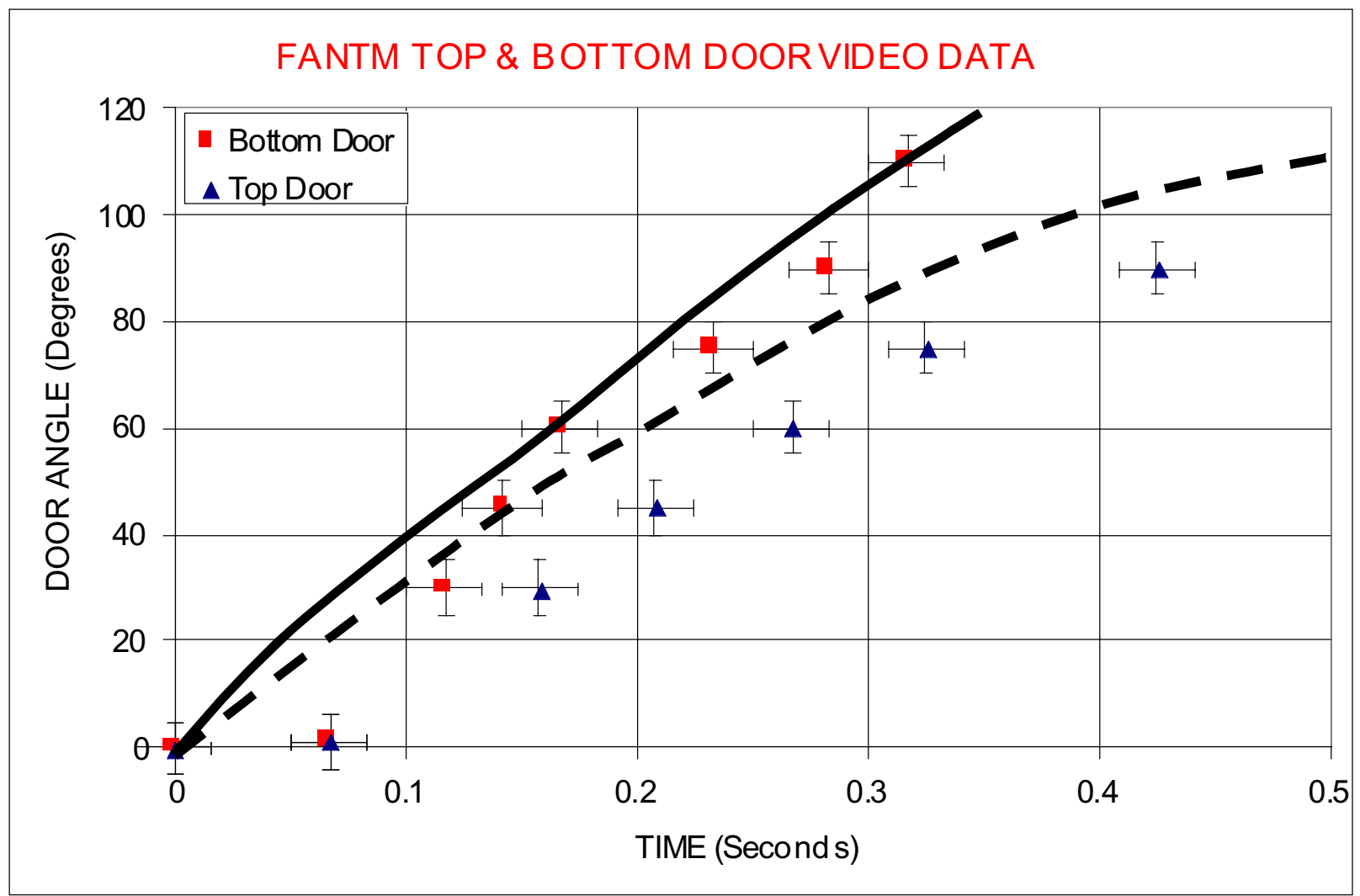


Figure 14: Comparison between Theoretical calculations (at $P=10 \mathrm{psig}$ ) and Video Data for the doors (video data are taken from Smith (1999))

Solid curve represents calculated results for the bottom door.

Dotted curve represents calculated results for the top door.

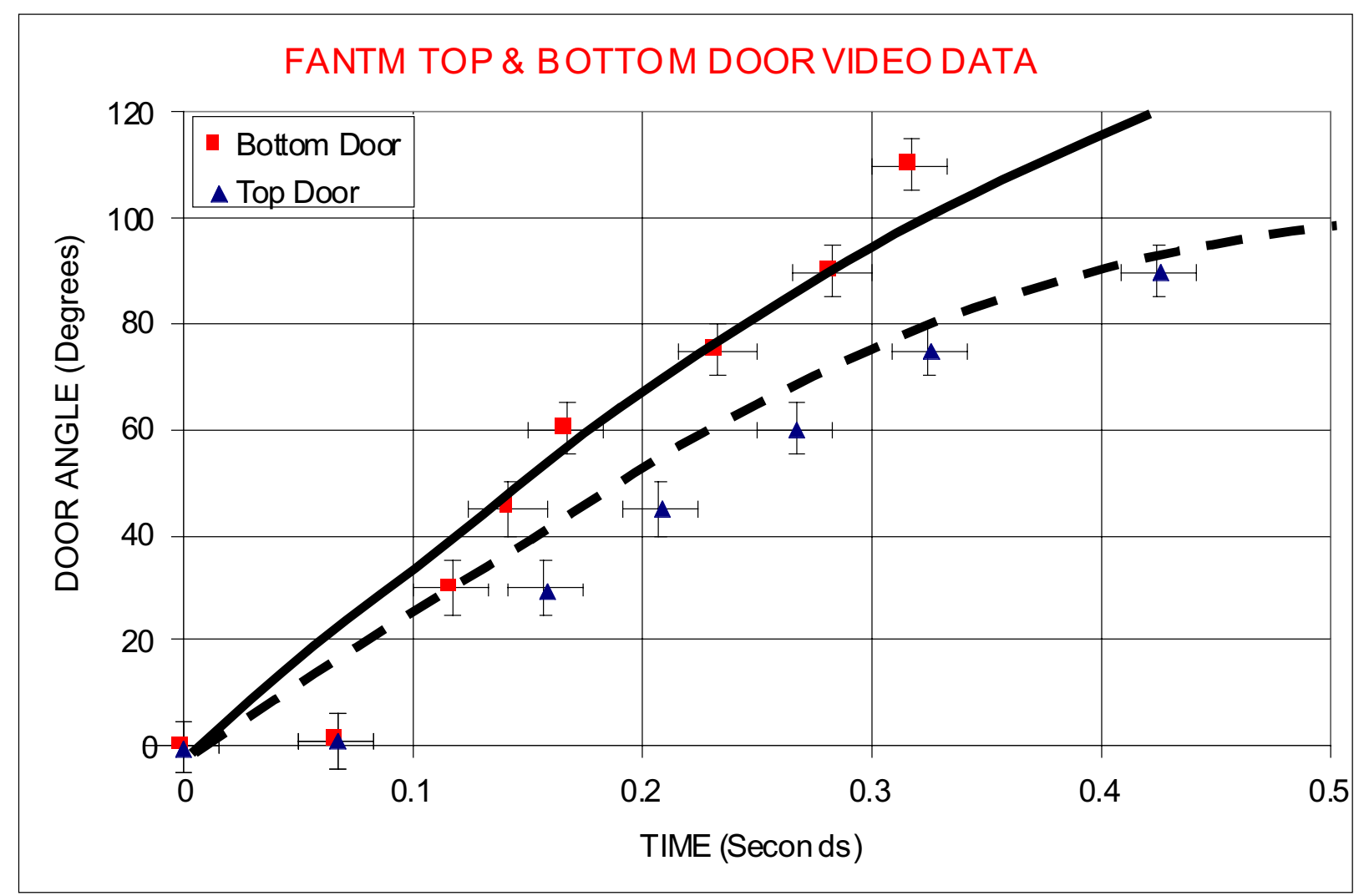


Table 6: Summary of Pressure Estimate Calculations

\begin{tabular}{|c|c|c|c|c|c|c|c|}
\hline Calculation & $\begin{array}{l}\text { Amount of Oil } \\
\text { Burned (g) }\end{array}$ & $\begin{array}{c}\text { Energy } \\
\text { Released or } \\
\text { Temperature } \\
\end{array}$ & $\begin{array}{c}\text { Module } \\
\text { Overpressure }\end{array}$ & $\begin{array}{c}\text { Bay } \\
\text { Overpressure }\end{array}$ & $\begin{array}{c}\text { Method to } \\
\text { Calculate Bay } \\
\text { Overpressure } \\
\end{array}$ & Conservatisms & Uncertainties \\
\hline $\begin{array}{l}1 . \quad \text { Panel } \\
\text { bowing } \\
\text { calculation, } \\
\text { FANTM \# } \\
\text { Event \#2 } \\
\text { (Appendix } \\
\text { A.1) }\end{array}$ & $19.4 \mathrm{~g}$ & $1.07 \mathrm{MJ}$ & $\begin{array}{l}\text { Impulse } 37.1 \\
\text { psi-ms } \\
\quad 36 \text { psig }\end{array}$ & 3 psf & $\mathrm{P} 1 \mathrm{~V} 1$ = P2V2 & $\begin{array}{l}\text { From impulse (assumed } \\
\text { to be entirely due to the } \\
\text { shock), estimate } \\
\text { equivalent TNT }(\sim 0.5 \mathrm{lb}) \\
\text { Heat capacity of } \\
\text { capacitor bay air } \\
\text { neglected }(\mathrm{T} 1=\mathrm{T} 2)\end{array}$ & $\begin{array}{l}\text { Actual permanent } \\
\text { deformation not known, } \\
\sim 2 \text { inches is best } \\
\text { recollection }\end{array}$ \\
\hline $\begin{array}{l}\text { 2. Bolt failure } \\
\text { calculation, } \\
\text { FANTM } \\
\text { Events \#2, } 3 \\
\text { (Appendix } \\
\text { A.2) }\end{array}$ & $\begin{array}{l}\text { Event \#2: } \\
\text { same as } \\
\text { above } \\
\text { Event \#3: } \\
\text { ND }^{11}\end{array}$ & $\begin{array}{l}\text { Event \#2: } \\
\text { same as } \\
\text { above } \\
\text { Event \#3: } \\
\text { ND }\end{array}$ & 28.7 psig $^{12}$ & $2.4 \mathrm{psf}$ & $\mathrm{P} 1 \mathrm{~V} 1=\mathrm{P} 2 \mathrm{~V} 2$ & 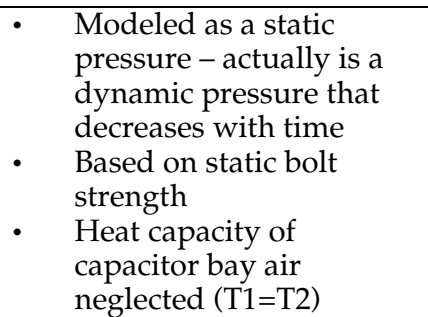 & $\begin{array}{ll}\text { - } & \text { Bolts may not be } \\
\text { uniformly loaded } \\
\text { - } \quad \text { Not clear if all bolts were } \\
\text { in place }\end{array}$ \\
\hline $\begin{array}{l}3 . \quad \text { Do or } \\
\text { hooks } \\
\text { calculation, } \\
\text { FANTM } \\
\text { Events \#2, } 3 \\
\text { (Appendix } \\
\text { A.3) }\end{array}$ & $\begin{array}{l}\text { Event \#2: } \\
\text { same as } \\
\text { above } \\
\text { Event \#3: } \\
\text { ND }\end{array}$ & $\begin{array}{l}\text { Event \#2: } \\
\text { same as } \\
\text { above } \\
\text { Event \#3: } \\
\text { ND }\end{array}$ & $\begin{array}{c}14-20 \text { psig } \\
\text { (minimum, } \\
\text { static) }\end{array}$ & $\begin{array}{l}1.2-1.7 \mathrm{psf} \\
\text { (minimum) }\end{array}$ & $\mathrm{P} 1 \mathrm{~V} 1$ = P2V2 & $\begin{array}{ll} & \text { Heat capacity of } \\
\text { capacitor bay air } \\
\text { neglected (T1=T2) } \\
\text { Weld strength based on } \\
\text { static properties }\end{array}$ & $\begin{array}{ll}\text { Bolts may not be } \\
\text { uniformly loaded }\end{array}$ \\
\hline $\begin{array}{l}\text { 4. Trajectory } \\
\text { of small } \\
\text { flapper } \\
\text { door/punc- } \\
\text { ture of roll- } \\
\text { up door, } \\
\text { FANTM }\end{array}$ & ND & ND & $29-38$ psig & $1.9-2.7 \mathrm{psf}$ & $\mathrm{P} 1 \mathrm{~V} 1$ = P2V2 & $\begin{array}{l}\text { Heat capacity of } \\
\text { capacitor bay air } \\
\text { neglected (T1=T2) }\end{array}$ & $\begin{array}{ll}\text { - } & \text { Door may have just } \\
\text { translated, or also } \\
\text { rotated } \\
\text { - } \quad \text { Door may have hit floor } \\
\text { Point in upswing where } \\
\text { hinge failed not known }\end{array}$ \\
\hline
\end{tabular}

\footnotetext{
${ }^{11}$ ND: Not Determined.

${ }^{12}$ Many fewer (maybe only 4) of the total compliment of bolts (22) may have been in place at the time of the event.
} 


\begin{tabular}{|c|c|c|c|c|c|c|c|}
\hline $\begin{array}{l}\text { Event \#3 } \\
\text { (Appendix } \\
\text { A.4) }\end{array}$ & & & & & & & \\
\hline $\begin{array}{l}5 . \quad \text { Door } \\
\text { pendulum } \\
\text { calculations (3 } \\
\text { doors), } \\
\text { FANTM Event } \\
\text { \#5 (Appendix } \\
\text { A.5) }\end{array}$ & ND & ND & 11 psig & 0.93 psig & $\mathrm{P} 1 \mathrm{~V} 1=\mathrm{P} 2 \mathrm{~V} 2$ & $\begin{array}{ll} & \text { Heat capacity of } \\
\text { capacitor bay air } \\
\text { neglected }(\mathrm{T} 1=\mathrm{T} 2)\end{array}$ & $\begin{array}{ll}\text { - } & \text { Limited resolution of } \\
\text { video due to frame } \\
\text { duration }(\sim 33 \mathrm{~ms}) \\
\text { - Visual estimate of door } \\
\text { angle } \\
\text { - } \begin{array}{l}\text { Did not include air drag } \\
\text { opposing swing }\end{array}\end{array}$ \\
\hline $\begin{array}{l}6 . \quad \text { Fireball } \\
\text { calculation, } \\
\text { FANTM Event } \\
\# 1 \text { (Appendix } \\
\text { A.6) }\end{array}$ & (1) $212 \mathrm{~g}$ & $\begin{array}{l}(1) \sim 9.8 \mathrm{MJ}^{13} \\
\text { air and oil } \\
\text { density } \\
\text { adjusted to } \\
2000 \mathrm{~K} \text {, flame } \\
\text { temperature }\end{array}$ & (1)ND & (1) 9.9 psf & $\begin{array}{l}\mathrm{C}_{\mathrm{v}} \Delta \mathrm{T}, \\
\frac{\mathrm{P} 1}{\mathrm{~T} 1}=\frac{\mathrm{P} 2}{\mathrm{~T} 2}\end{array}$ & $\begin{array}{l}\text { Complete burning of } \\
\text { cloud at stoichiometric } \\
\text { mixture }\end{array}$ & $\begin{array}{l}\text { Fireball size estimated } \\
\text { from video; temperature } \\
\text { not known }\end{array}$ \\
\hline & $\begin{array}{c}\text { (2) } 459-499 \mathrm{~g} \\
\mathrm{HE}\end{array}$ & (2) ND & (2) ND & (2) ND & & $\begin{array}{l}\text { - The equivalent quantity } \\
\text { of oil, in terms of } \\
\text { potential energy release } \\
\text { would be less than } \\
\text { indicated here }\end{array}$ & $\begin{array}{l}\text { Estimated duration of } \\
\text { approximately 0.2 s } \\
\text { (based on Rakaczky } \\
\text { (1975) appears to be } \\
\text { consistent, within a } \\
\text { factor of a few, with } \\
\text { observations on the } \\
\text { video }\end{array}$ \\
\hline $\begin{array}{l}\text { 7. Oxygen } \\
\text { limited } \\
\text { calculation } \\
\text { (Appendix } \\
\text { A.7) }\end{array}$ & $495 \mathrm{~g}$ & $20.4 \mathrm{MJ}^{1}$ & ND & 20.2 psf & $\begin{array}{l}\mathrm{C}_{\mathrm{v}} \Delta \mathrm{T}, \\
\frac{\mathrm{P} 1}{\mathrm{~T} 1}=\frac{\mathrm{P} 2}{\mathrm{~T} 2}\end{array}$ & $\begin{array}{l}\text { Oxygen overestimated } \\
\text { since pressure develops } \\
\text { in module (forcing air } \\
\text { out), and assumes } \\
\text { amount of oxygen at } \\
\text { ambient T and P } \\
\text { Oil is assumed to be in } \\
\text { optimum condition for } \\
\text { burn (drop size and } \\
\text { distribution, and } \\
\text { stoichiometry) }\end{array}$ & $\begin{array}{l}\text { Unclear if oxygen } \\
\text { limited }\end{array}$ \\
\hline
\end{tabular}

${ }^{13} 2 \mathrm{MJ}$ of electrical energy simply added in. 


\begin{tabular}{|c|c|c|c|c|c|c|c|}
\hline & & & & & & $\begin{array}{l}\text { - Assumes complete } \\
\text { combustion }\end{array}$ & \\
\hline $\begin{array}{l}8 . \\
\text { Vaporization } \\
\text { in capacitor } \\
\text { can (Appendix } \\
\text { A.8) }\end{array}$ & $316 \mathrm{~g}$ & $13.7 \mathrm{MJ}^{11}$ & ND & $13.8 \mathrm{psf}$ & $\begin{array}{l}\mathrm{C}_{\mathrm{v}} \Delta \mathrm{T}, \\
\frac{\mathrm{P} 1}{\mathrm{~T} 1}=\frac{\mathrm{P} 2}{\mathrm{~T} 2}\end{array}$ & $\begin{array}{l}\text { Thermal boundary layer } \\
\text { ignored (all energy } \\
\text { assumed to vaporize oil, } \\
\text { rather than to heat liquid } \\
\text { to temperature less than } \\
\text { the boiling point) }\end{array}$ & $\begin{array}{l}\text { Thickness of thermal } \\
\text { boundary layer not } \\
\text { known } \\
\text { Fraction of electrical } \\
\text { energy that does into } \\
\text { heating not certain }\end{array}$ \\
\hline $\begin{array}{l}\text { 9. Cheetah } \\
\text { calculation } \\
\text { (Appendix } \\
\text { A.9) }\end{array}$ & $500 \mathrm{~g}$ & $12.9 \mathrm{MJ}^{11}$ & ND & $13.1 \mathrm{psf}$ & $\begin{array}{l}\mathrm{C}_{\mathrm{v}} \Delta \mathrm{T}, \\
\frac{\mathrm{P} 1}{\mathrm{~T} 1}=\frac{\mathrm{P} 2}{\mathrm{~T} 2}\end{array}$ & & \\
\hline $\begin{array}{l}\text { 10. PV/T back } \\
\text { calculation }\end{array}$ & ND & $\begin{array}{l}2000 \mathrm{~K} \text { in } \\
\text { module, } \\
300 \mathrm{~K} \text { in bay }\end{array}$ & $<2359$ psi & 30 psf & $\begin{array}{l}\frac{\mathrm{P} 1 \mathrm{~V} 1}{\mathrm{~T} 1}= \\
\frac{\mathrm{P} 2 \mathrm{~V} 2}{\mathrm{~T} 2}\end{array}$ & $\begin{array}{l}\text { Bay wall limiting } \\
\text { calculation } \\
\text { Not based on any } \\
\text { physical evidence } \\
\text { Module would fly apart } \\
\text { at this extreme pressure, } \\
\text { so it could not have been } \\
\text { reached since module } \\
\text { integrity not } \\
\text { substantially } \\
\text { compromised }\end{array}$ & \\
\hline $\begin{array}{l}\text { 11. Fire Science } \\
\text { Analysis } \\
\text { (Staggs et al., } \\
\text { 1999) }\end{array}$ & $120 \mathrm{~g}$ & $2000 \mathrm{~K}$ & $\begin{array}{l}6.7 \text { atm (83.8 } \\
\text { psig) } \\
\text { completely } \\
\text { confined }\end{array}$ & $7.1 \mathrm{psf}$ & $\mathrm{P} 1 \mathrm{~V} 1=\mathrm{P} 2 \mathrm{~V} 2$ & $\begin{array}{ll}\text { - } & \text { Assumes module } \\
\text { unvented } \\
\text { No account for } \\
\text { temperature reduction } \\
\text { when expands into bay }\end{array}$ & $\begin{array}{l}\text { Actual peak temperature } \\
\text { not known for certain }\end{array}$ \\
\hline $\begin{array}{l}\text { 12. Parsons } \\
\text { electrical } \\
\text { energy dump } \\
\text { (Parsons, 1996) }\end{array}$ & ND & 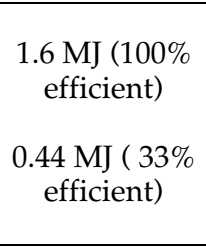 & ND & $\begin{array}{l}31.2 \mathrm{psf} \\
12.4 \mathrm{psf}\end{array}$ & Weibull & $\begin{array}{l}\text { Estimated quantity of } \\
\text { TNT from energy } \\
\text { Used Weibull equation } \\
\text { to calculate bay pressure, } \\
\text { and this is conservative } \\
\text { for a small equivalent } \\
\text { charge in a large volume }\end{array}$ & $\begin{array}{ll}\text { - Out of range for Weibull } \\
\text { equation }\end{array}$ \\
\hline
\end{tabular}


Method \#6: Fireball Calculation Based on FANTM Event \#1 (9/11/98)

This calculation utilizes evidence from the video of FANTM Event \#1, which occurred on $9 / 11 / 98$. On the video, there appears to be a large fireball created during the event. The size of the fireball is estimated to be no greater than $10 \mathrm{ft}$ in diameter. The analysis then assumes that a $10 \mathrm{ft}$ diameter spherical fireball containing oil and oxygen at the stoichiometric ratio burns to completion. The temperature of the fireball is assumed to be $2000 \mathrm{~K}$, the estimated flame temperature (Staggs et al., 1999). At $2000 \mathrm{~K}, 212 \mathrm{~g}$ of oil would burn, releasing $7.8 \mathrm{MJ}$ of energy. Adding the $2 \mathrm{MJ}$ of electrical energy results in $9.8 \mathrm{MJ}$ of energy being released. The resulting bay pressure is 9.9 psf. This is below the pressure tolerance of the bay walls. The module pressure was not estimated in this case. The supporting calculations for this approach are provided in Appendix A.6. Since the fireball is created as a result of burning oil, which is a relatively slow process, no shock wave is expected.

A second calculation related to the fireball was performed. Formulas relating the mass of a munition vs fireball diameter (Rakaczky, 1975) and mass of propellant vs fireball diameter (High, 1968) were used to estimate the approximate quantity of material involved. For a 2 meter fireball the munition estimate gives $0.31 \mathrm{lb}$, while the propellant estimate gives $0.283 \mathrm{lb}$. For a 3 meter fireball, the munition amount is $0.98 \mathrm{lb}$, while the propellant amount is $1.06 \mathrm{lb}$. Although the NIF capacitor modules will not contain munitions or propellants, empirical evidence from this single failure puts the range of equivalent explosive material in the 0.3 $1 \mathrm{lb}$ range, consistent with other estimates in this document. Note, however, that the burning of the oil actually occurs much more slowly (msecs) compared to explosive reactions ( $\mu$ secs). Thus, care must be taken when referring to a TNT equivalent, which may generate the same peak pressure, but the shock wave phenomenon is very different.

\section{Method \#7: Oxygen Limited Calculation}

This calculation assumes that there is a failure involving a capacitor, such that the free space in the module becomes saturated with oil mist. The oil and air are assumed to be at the stoichiometric ratio. An electrical arc is assumed to be present to ignite the mixture. Since the amount of oil sprayed into the module is not well known, this calculation assumes that the extent of the burn is limited by the amount of oxygen in the free space of the module. Because the chemical reaction results in an increase in pressure within the module, additional air will not be drawn in to replenish the oxygen supply. In fact, the increasing pressure and temperature during the burn would result in a decreased gas density in the burn mixture, reducing the oxygen available. Further, as the burning mixture expands, the pressure gradient continues to be against additional oxygen ingress. Thus, this should be a very conservative calculation. The mixture is assumed to maintain optimum conditions (both in terms of concentration ratio and size/ distribution of oil droplets) throughout the burn. Since the fireball is created as a result of burning oil, which is a relatively slow process, no shock wave is expected. 
The detailed calculations are provided in Appendix A.7. It was determined that $495 \mathrm{~g}$ of oil could burn. An energy release of $18.4 \mathrm{MJ}$ was estimated from the burning oil. The maximum of $2 \mathrm{MJ}$ of available electrical energy is probably consumed in creating the conditions of the oil mist (i.e., pressurizing the capacitor). However, this calculation adds that energy into the total release, giving 20.4 MJ. A module pressure is not calculated in this instance, but the resulting pressure in the capacitor bay is. The approach used is to redistribute the 20.4 MJ of energy released as internal energy of the air in the bay (using heat capacity of the air), and estimate a temperature rise. The pressure rise is determined from the temperature rise, using the ideal gas equation. The maximum overpressure in the bay is estimated to be $20.4 \mathrm{psf}$, which is below the 30 psf approximate pressure tolerance of the bay walls. This is thought to be conservative because it does not consider the thermal capacity of any of the equipment in the bay. The module pressure was not determined in this case.

\section{Method \#8: Vaporization in Capacitor Can}

This calculation assumes that there is a short in a capacitor can that results in localized heating and vaporization of some of the oil. The energy is utilized to vaporize a small sphere of oil. The vaporized oil is assumed to pressurize the can, resulting in failure. The vapor is then assumed to be available to burn in the explosive event. Details of this calculation are provided in Appendix A.8. It was determined that $316 \mathrm{~g}$ of oil could burn. This would result in a release of 11.7 MJ of chemical energy. Adding the $2 \mathrm{MJ}$ of electrical energy (note that this is probably all consumed in creating the explosive vapor, so this is double counting) gives a total potential energy release of $13.7 \mathrm{MJ}$. Using the same approach as described in Method \#7 for estimating the bay pressure, the estimated bay overpressure was determined to be 13.8 psf. This is below the pressure tolerance of the walls. The module pressure was not determined in this case. This is similar to a calculation performed for the capacitor bank in B141 (Takemori, 1989). Since the fireball is created as a result of burning oil, which is a relatively slow process, no shock wave is expected.

\section{Method \#9: Cheetah Calculations}

Cheetah is a thermochemical computer code that solves thermodynamic equations between product species to find chemical equilibria (Fried at al., 1997). Since the detonation point is a state in thermodynamic and chemical equilibrium, Cheetah can predict the properties of this state. Cheetah was used to predict the extent and energy release for burning oil released from a capacitor in an oxygen limiting condition. A similar quantity of oil was assumed to be involved as in Method \#7. However, Cheetah considers the thermodynamics of the system and determines what fraction of the initial fuel burns to completion, or to less oxidized states. Consequently, this is a more realistic calculation, and the energy release is less than would be for complete combustion in an oxygen limited state (Method \#7). Cheetah determined that 10.9 MJ of chemical energy would be released. Adding the $2 \mathrm{MJ}$ of electrical energy, a total of $12.9 \mathrm{MJ}$ of energy could be released from this event. 
Using the same approach as described in Method \#7 for estimating the bay pressure, the estimated bay overpressure is determined to be 13.1 psf. This is also below the pressure tolerance of the walls. A sample Cheetah output is given in Appendix A.9. Since the fireball is created as a result of burning oil, which is a relatively slow process, no shock wave is expected.

\section{Method \#10: PV/T Back-Calculation}

This approach starts with a limiting pressure on the capacitor bay walls (30 psf), at $300 \mathrm{~K}$, and estimates what the module pressure (if confined) would have had to have been to generate that pressure in the bay (assuming an internal module temperature of $2000 \mathrm{~K}$, the flame temperature). The estimated internal module pressure was found to be over 2300 psi. The evidence, including the condition of most of the internal components of the module (only minor damage was observed), suggests a much lower module pressure. Thus, it is very unlikely that a pressure equivalent to the failure threshold of the bay walls would result from any event.

\section{Method \#11: Fire Science Analysis}

A fire science study was undertaken to gain a better understanding of the burning characteristics of potential dielectric fluids (Staggs, 1999). As part of this study, an estimate of the amount of oil that might burn in an event and the module pressure were estimated. They estimated that $120 \mathrm{~g}$ of castor oil would burn. They also estimated a module pressure of $6.7 \mathrm{~atm}$. This is somewhat higher than the other estimates because it assumes an unvented module. From this information, an estimate of less than 10 psf on the capacitor bay walls was made (using PV ratio). This is below the pressure tolerance of the walls.

\section{Method \#12: Parsons Electrical Energy Dump}

Parsons, the AE firm for NIF, previously reviewed the impacts of explosive events (Parsons, 1996). At this time, it was not known that the capacitor oil could be involved. Parsons simply reviewed the potential impacts that could result from explosively dumping the electrical energy. They estimated a maximum pressure on the bay walls of less than 31.2 psf. They expected that the bay walls would survive such an explosive event. The Parsons calculations are conservative because:

- they aim the pressure wave directly at the walls,

- they use the Weibull equation, which is invalid for relatively small charges in a large volume.

Maximum Number of Simultaneous Capacitor Module Events

It was determined that the maximum credible number of simultaneous capacitor module events is two. The probability that two capacitor modules will explode and have their capacitor bay pressure pulses overlap is $2.0 \times 10^{-5}$. This is based on the data from FANTM, and an estimated overpressure duration in the capacitor bay of approximately 22 seconds. Details of the calculation are provided in Appendix D. 
The explosion rate estimated using FANTM data is expected to be high. In lifetime testing at LLNL, several designs were found to have no failures in 25,000 shots or more. Thus, NIF capacitor module failure rates are expected to be much lower than indicated above.

Since two events could occur within a window of time where their pressure pulses could overlap, the additive effects of the two events must be considered. For all estimates but Method \#7 and Method \#12, the maximum pressure of two pulses would still be less than the pressure tolerance of the bay walls (approximately $30 \mathrm{psf}$ ). Method \#10 assumes a bay pressure of $30 \mathrm{psf}$ and back calculates the module pressure. It is a fictitious calculation, and does not represent an estimate of the expected bay pressure. The peak capacitor bay overpressures estimated were 20.2 psf, based on the oxygen limited calculation (see Table 6, Method \#7), and 31.2 psf, based on the Weibull equation (see Table 6, Method \#12). The oxygen limited calculation is thought to be a very conservative and bounding pressure estimate because:

- The oil is assumed to be in the optimal condition (drop size, distribution, stoichiometry) for burn,

- The oil is assumed to burn to completion,

- The amount of oxygen assumed available in the calculation is based on ambient pressure and temperature (293 K, $1 \mathrm{~atm})$; as conditions evolve during the burn, both pressure and temperature will rise, reducing the cloud density and the availability of oxygen.

Thus, the expectation is that the bay pressure after an event will be much less than that estimated with the oxygen limited calculation. The calculation with Cheetah is a similar, but more sophisticated calculation compared to the oxygen limited calculation (see Table 6, Method \#9). The mix is assumed to be oxygen limited, but chemical thermodynamics and kinetics come into play, and a much less efficient burn is predicted. This calculation predicts a bay pressure rise of only 13.1 psf. All of the other pressure estimates are more consistent with this latter prediction (or less), than with the oxygen limited calculation.

In Method \#12, the bay overpressure was calculated using the Weibull equation. This is known to be invalid for large volumes containing small charges. It is further conservative because the heat capacity of the air is not taken into account. If the bay pressure is calculated using the heat capacity of the air, it is estimated to be 1.6 psf.

It is expected, then, that if two module events were to occur within a single charge period, the residual pressure from the first event, plus the additional pressure from the second event, would still be below the structural pressure threshold of the capacitor bay walls. 
Conclusions

Based on a review of the evidence from past capacitor failures at the FANTM facility at Sandia National Laboratory, Albuquerque, and additional theoretical estimates (see Table 6), the pressure generated during an explosive event in the module was estimated to be less than $40 \mathrm{psig}$. This internal pressure in the FANTM module appears to be tolerable, as only minor damage to the module and to internal components was observed after events. The new module concept proposed here provides increased venting area, fully available at the initiation of an event. The module joints and connections have been formally reviewed with respect to their tolerance to a brief internal pressure as high as 40 psig (see next section). With the implementation of some minor modifications, the module was shown to withstand the pressure and remain intact.

Some of the calculations performed estimated the quantity of dielectric oil that could be involved in a capacitor failure. It was determined that a very small amount of the available oil would contribute to the explosive event, on the order of $500 \mathrm{~g}$ or less. This is a small fraction of the total free oil available in a capacitor (approximately 10,900 g). Thus, the value of $\beta$, the conversion efficiency of the oil mentioned in Section B, is expected to be on the order of $5 \%$ or less. This is consistent with the findings of other studies related to the burning of oil in capacitor failures (Staggs, 1999).

Methods \#6 to \#9 evaluate the increase in pressure in the capacitor bay due to oil burning following a capacitor module failure. The oil burning is a much slower process than an explosion, thus the dynamic load on the bay wall is not addressed.

The estimates of module pressure were used to estimate the potential overpressure in the capacitor bays after an event. This was generally done in two ways:

- Expanding the estimated module overpressure into the bay volume $\left(\mathrm{P}_{1} \mathrm{~V}_{1}=\right.$ $\left.\mathrm{P}_{2} \mathrm{~V}_{2}\right)$

- Converting the energy release in the event to the internal energy of the capacitor bay air $\left(\mathrm{C}_{\mathrm{v}} \Delta \mathrm{T}\right)$, and estimating the increase in pressure from the estimated temperature rise of the gases $\left(\mathrm{P}_{1} / \mathrm{T}_{1}=\mathrm{P}_{2} / \mathrm{T}_{2}\right)$.

It was shown that the expected capacitor bay overpressure was less than the pressure tolerance of the walls. Thus, it does not appear necessary to provide any pressure relief for the capacitor bays. 


\section{Analysis of Module Integrity During Explosive Events}

The capacitor rack design was analyzed to assess the module structural integrity during possible pressure excursions due to capacitor explosions. The results of the analysis indicated that the stresses in structural materials would be within yield. The bolting of bolted panels was shown to be more than adequate for the pressures on those panels. Required weld sizes for welded panels to remain intact have also been determined. The module doors and their attachments were also assessed and found to adequately maintain their integrity.

\section{Effective Blast Pressure on Panels}

The FANTM prototype assembly experienced several capacitor explosions, as described elsewhere in this document, resulting in internal pressures. The calculated pressure value of 11-38 psi is sufficiently large that if uniformly applied to all panel internal surfaces, it should have caused failure of a number of those panels. These panels did not fail or show evidence of imminent failure after any of the FANTM events. Thus, actual pressures experienced by the module components must have been lower than this.

End Panels. During a capacitor failure, the calculated quasi-static pressures of $11-38$ psig are dynamic pressures. For a modified fixed venting area of $8.75 \mathrm{ft}^{2}$, the quasi-static pressures drop to the ambient pressure in a very short decay time ranging from approximately 4.5 - $10.3 \mathrm{msec}$ (see Table 5). A panel can generally withstand a much larger dynamic pressure than a static pressure depending on the natural period and other factors of the panel. Based on this, conservative calculations show that the front and rear panels can both withstand a dynamic pressure of 40 psig with a $10 \mathrm{msec}$ decay time, and the response is similar to a 12 psi static load (see Appendix E.1).

Pressures throughout the module will vary with location, depending on the distance from the pressure source. Maximum pressures would be expected in the center of the module, near the doors. Pressures elsewhere can be calculated as follows. Assuming that a pressure wave expands outwardly like a sound wave, the value of pressure at a point on a given surface should decrease in proportion to the square of the distance to that point from the origin of the pressure ("inverse square rule"), ignoring thermodynamic effects such as cooling and expansion (gas expansion would decrease pressure by the cube of distance). The distance would include the circuitous path from a hypothetical blast source to the point in question (meaning that the pressure wave would need to pass around rather than through capacitors and other objects). Starting with a pressure at the module doors, and applying this assumption, a mean pressure on the end panels of approximately 4 psi was calculated. 
The design pressure of 4 psi on the end panels is somewhat higher than what was apparently present during the FANTM events (yielding would have begun at about 2.7 psi, see Appendix E.3), and is consistent with the lack of observed damage to the end panels. In order to accommodate a design pressure of 4 psi, some modifications to the end panels were required, and are described later.

The flat-plate panels were hand-analyzed (with SuperCalc spreadsheets) using conventional plate-and-shell stress formulae (Young, 1989) and it was determined that several design modifications were required if panels were to remain elastic and panel fasteners remained intact (in some observed blasts, panels remained elastic but fasteners were known to have failed, meaning that the panels were not subject to full bending between supported edges). It was a criterion of the analysis that panel fasteners not fail, since loss of panel edge support could provide new shrapnel paths out of the module, thus creating hazards to personnel and to other equipment. A sample calculation (the original end panel design) is provided in Appendix E.3.

Other Panels. The mid-points of the side panels are only slightly farther away from a point of pressure source than are the mid-points of the doors. Therefore, the door pressure of 12 psi is applied to the side panels as well. It was assumed that a design pressure of 12 psi would also apply to the top panels and the top-hat switch assembly, due to their proximity to the doors and side panels. These pressures are summarized in Table 7.

Given the test unit original bolting pattern, a value of 12 psi on the side panels is above the pressure (6 psi) which ought to have caused some damage to side panel bolts, and some damage to bolts was observed. This value is therefore consistent with observations. In order to accommodate this design pressure, some modifications to the side panels and their bolting are described later.

No damage to the top panels was recorded in the FANTM events, therefore the design pressure of 12 psi for the top panels is probably greater than these panels would see for a door pressure of 12. To accommodate this design pressure, some modifications to the top panels are described later.

Front and Rear Doors. The front and rear door panels are removable panels not welded and bolted to the module, they can withstand a static pressure of 12 psig and remain elastic (see Appendix E.2). Based on this, conservative calculations show that the front and rear panels can both withstand a dynamic pressure of 40 psig with a $10 \mathrm{msec}$ decay time (see Appendix E.1).

Design Modifications for Overpressure

The hand calculations and subsequent computer finite element analysis indicated certain design changes would be necessary to prevent panel yielding, door yielding, and/or fastener failure. 
End Panels. The hand analysis (see Appendix E.3) indicated that the end panels required a stiffener on the panel bottom at mid-height, creating two subpanels and reducing the effective panel height by $50 \%$. The revised design provides for a bottom transverse stiffener (and angle bar), and a mid-height transverse stiffener $(2 \times 2 \times 3 / 16$ square tube). Both stiffeners are attached to the panel, and the bottom stiffener must be attached to the cabinet frame or nearby shelf structure. The mid-height stiffener does not need to be attached to the frame or shelf. Revised stresses are within yield for this panel.

Side Panels. The hand analysis indicated that the side panels needed to be attached to the three intermediate $2 \times 2 \times 3 / 6$ square tube shelf bars so as to subdivide the height of each panel into four sub-panels. This is accomplished by welding the panel to the three shelf bars on one side of the assembly, and bolting the panel to the three shelf bars on the other side.

Table 7: Estimated Pressures on Module Panels

\begin{tabular}{|l|l|}
\hline Panel & $\begin{array}{l}\text { Estimated Peak } \\
\text { Pressure (psi) }\end{array}$ \\
\hline End & 4.0 \\
\hline Side & 12.0 \\
\hline Top & 12.0 \\
\hline Top Hat & 12.0 \\
\hline
\end{tabular}

Top Panels. The hand analysis showed that the top panels require attachment to the transverse square tube (already present under the middle of each panel) so as to subdivide the top panel into two sub-panels. This is accomplished by welding.

Top Hat. The underside of the top hat is in close proximity to the source of a hypothetical blast, but the interior of the top hat is shielded from full pressure by switch parts. Due to the top hat configuration, no hand analysis was performed. The computer analysis indicated that top hat plate and shell stresses were less than yield without any design changes. This prediction of no damage agrees with observations during actual capacitor failures. 
Side Panel Fasteners. The hand analysis indicated that the proposed fasteners (3/8-16 cap screws threaded into tapped 3/16" tubing wall) were not sufficiently strong unless the number of fasteners was greatly increased. The design has been changed to use threaded inserts, blind-swaged into untapped holes (welded inserts are also acceptable, but would be difficult), thus developing the full strength of the cap screws. A few of the bolts are to be located on the shelf bars so as to subdivide the side panels as earlier described.

Framing Changes. In the finite element analysis, an overstress condition was found in the cabinet framing in the vicinity of the attachment of the top hat to the cabinet tops. Two possible mitigating changes were proposed, and the change that was selected by the design group was to provide corner braces at the upper corners on the open face of each cabinet (the face nearest the bust bar). Each brace is a mitered piece of $3 \times 2 \times 1 / 4^{\prime \prime}$ rectangular tubing, with its center line intersection 8 " inboard and $8^{\prime \prime}$ below the intersection of the centerlines of horizontal and vertical square tubes. The braces thus shorten the effective length of the top bar by $16^{\prime \prime}$, and the increased stiffness of this bar also reduces stresses in the top-panel center bars.

Doors. Analysis of the doors identified some areas of localized stress. These can be mitigated by providing reinforcements in these areas.

- On both the front and rear doors, the vent chute entrance openings are locations of major stress concentrations in the event of internal pressurization due to electrical faults. On both doors, each inlet is to be reinforced by doubler plates welded to the main plates. The horizontal doubler plates are to be $3^{\prime \prime}$ high and the full width of the inlet, and the vertical doubler plates are to be $3^{\prime \prime}$ wide by $5^{\prime \prime}$ high at each side of the inlet. The horizontal and vertical doublers form an inverted U (see Figure E.2-6, Appendix E.2). The doublers can be cut from material removed from the main plate vent chute openings, and may be perimeter fillet-welded to the door main plates.

- On both doors, the side plates (which form the chutes) are over-stressed at the vent chute inlet openings. These areas are to be reinforced by doubler plates welded to the side plates between the main plate and the baffle plate. These doubler plates are to have the same vertical length as the doublers on the door main plates (approximately $8^{\prime \prime}$ ), and except for the rear door lower vent, these doublers may be A36, perimeter fillet-welded to the vent chute side plates. The rear-door lower vent side plate doublers see higher stresses than the others and must be A529 (42 ksi yield) and need to be periodically plugwelded to the side plate as well as perimeter fillet-welded. 
- On each side of the waist of each door are small cutouts so that the door will clear the waist latch brackets when the door is being lowered into place. These cutouts are also locations of major stress concentrations in the event of internal pressurization. These cutouts need to be faired into the door with 45 degree transitions to avoid a sharp corner, and they also need to be reinforced by doubler plates welded to both main door plates, immediately under the latch bar (perimeter and plug-welded).

- On the front door only, waist cutout reinforcements are needed on the interior of the chute (as well as on the exterior under the latch). These areas are to be reinforced by 8 " high by 1 " wide doubler plates, perimeter-welded to the main door plate. These doublers do not occur on the rear door since the vent inlets appear at this location and doubler plates cannot be used.

- Several locations of over-stress were associated with the window: On both doors the window cover plate was over-stressed on the vertical edge of the cover away from the hinges. Also the window opening vertical edge under the window latch was over-stressed (in both cases due to the concentrated load of the window latch). On the front door, the main door plate horizontal edge above the window was over-stressed. On the rear door, the main door plate horizontal edge below the window was over-stressed. Reinforcing beam members (square tube and angle bar) have been selected to eliminate all of the over-stresses mentioned in this paragraph.

- On the rear door, the upper, right corner of the window is a site of stress concentration. This area is to be reinforced by a doubler plate welded to the main plate. The corresponding location on the front door is not a site of high stress due to the fact that near this point on the front door, the door main plate has a vent chute opening that reduces pressure load in this region.

- On both doors, the region of the bottom restraint was a place of stress concentration. On the front door, this area is to be reinforced by doubler plates welded to the main plates. On the rear door, at the corresponding location, a square tube beam member (added for reinforcing the window opening) will reinforce the main door plate restraint locations.

$\underline{\text { Results of Finite ElementAnalysis }}$

Finite element stress analysis of the modified cabinet was performed using the linear, elastic GEMINI program (LLNL, 1985), with the model developed using the SLIC modeling language (LLNL, 1991). Model generation was done both on a PC and a SUN Sparc. Finite element runs were done on a SGI using GEMINI release of September 1997 and June 2000. Graphics were produced on an SGI workstation by TAURUS version “6.16.98” (LLNL 1991a). 
Cabinet Analysis. The previously described pressures were applied as static loads on the cabinet components (panels top hat, fasteners, frame), and combined with gravity stresses to obtain total stress, by means of two purposewritten programs: comb-bms and comb-sh, running on an SGI. For certain nonsymmetric sections with high calculated stresses (materials 4 and 14, see Table 8), combined beam forces were resolved into beam stresses by a SuperCalc spreadsheet, which included the effect of the neutral axes offset by cabinet plating welded to cabinet frame square tube members.

The combined gravity+blast stresses are shown in the Table 8 for various beam element types in the structure. The blast stresses for plate and shell elements are shown in Table 9. 
Table 8: Beam Material Maximum Stresses During Overpressure Events

\begin{tabular}{|c|c|c|c|}
\hline Material Number & $\begin{array}{c}\text { Maximum (abs) } \\
\text { Stress (psi) }\end{array}$ & Yield Stress (psi) & Safety Factor \\
\hline 1 & 41,217 & $46,000$. & 1.12 \\
\hline 2 & 18,311 & $46,000$. & 2.51 \\
\hline 3 & 21,888 & $46,000$. & 1.10 \\
\hline 4 & 41,932 & $46,000$. & 1.13 \\
\hline 5 & 40,659 & $46,000$. & 2.13 \\
\hline 6 & 21,552 & $46,000$. & 1.21 \\
\hline 7 & 37,862 & $46,000$. & 2.45 \\
\hline 8 & 36,544 & $46,000$. & 6.00 \\
\hline 9 & 14,706 & $36,000$. & 7.74 \\
\hline 10 & 7,667 & $46,000$. & 1.16 \\
\hline 11 & 5,944 & $46,000$. & 23.26 \\
\hline 12 & 39,502 & $46,000$. & 1.02 \\
\hline 14 & 1,977 & $46,000$. & 1.36 \\
\hline 15 & 44,940 & $46,000$. & 2.26 \\
\hline 16 & 33,878 & $46,000$. & 1.28 \\
\hline
\end{tabular}

${ }^{14}$ Square and rectangular tube materials are cold-formed steel, ASTM A500, Grade B (46 ksi yield), angle-bar and flat-bar materials are hot-rolled, mild steel ASTM A36 (36 ksi yield). The extent of plating welded to the beam members is also shown.

\begin{tabular}{|c|c|c|}
\hline Material & Use & Section \\
\hline 1 & corner posts (bolted-open) & $2 \times 2 \times 3 / 16$ sq tube stl. w/ no plate \\
\hline 2 & corner posts (bolted-welded) & $2 \times 2 \times 3 / 16$ sq tube stl. w/ 12" plate \\
\hline 3 & corner posts (welded-welded) & $2 \times 2 \times 3 / 16$ sq tube stl. corner plate \\
\hline 4 & corner posts (welded-open) & $2 \times 2 \times 3 / 16$ sq tube stl. w/ 12" plate \\
\hline 5 & shelf (X) sq-tube levels 1-4 & $2 \times 2 \times 3 / 16$ sq tube stl. w/ no plate \\
\hline 6 & shelf (X) sq-tube level 1 & $2 \times 2 \times 3 / 16$ sq tube stl. w/ 12" plate \\
\hline 7 & shelf (X) sq-tube levels 2-4 & $2 \times 2 \times 3 / 16$ sq tube stl. w/ 24" plate \\
\hline 8 & shelf (Z) sq-tube levels 1-4 & $2 \times 2 \times 3 / 16$ sq tube stl. w/ no plate \\
\hline 9 & shelf (Z) L-bars levels 1-4 & $\begin{array}{l}\text { 5x3x1/4 angle, mild steel, no } \\
\text { plate }\end{array}$ \\
\hline 10 & Top sq-tube (X) bars & $2 \times 2 \times 3 / 16$ sq tube stl. w/ 12" plate \\
\hline 11 & Top sq-tube (X) bars & $2 \times 2 \times 3 / 16$ sq tube stl. corner plate \\
\hline 12 & Top-hat rect-tube (Z) bars & $\begin{array}{l}2 \times 2 \times 3 / 16 \text { sq tube w/ 14" pl \& flat } \\
\text { bar }\end{array}$ \\
\hline 13 & Top sq-tube (Z) bars & $2 \times 2 \times 3 / 16$ sq tube stl. corner plate \\
\hline 14 & Mid-top sq-tube (Z) bars & $2 \times 2 \times 3 / 16$ sq tube stl. w/ 24" plate \\
\hline 15 & sq tube (Z) end-pl stiffener & $2 \times 2 \times 3 / 16$ sq tube stl. w/ 24" plate \\
\hline 16 & bottom stiffener & $2.5 \times 2.5 \times 1 / 4$ angle-bar w/ 12" plate \\
\hline 17 & portal-frame brace sq tube & sq tube stl. w/ no plate \\
\hline
\end{tabular}


Table 9: Maximum Membrane, Shear \& Von Mises Stresses for Plate-Shell Materials (psi)

\begin{tabular}{|c|c|c|c|c|}
\hline \multirow[b]{2}{*}{$\begin{array}{l}\text { Material } \\
\text { Number }^{15}\end{array}$} & \multicolumn{3}{|c|}{ Maximum of Absolute Values of Stresses } & \multirow[b]{2}{*}{$\begin{array}{l}\text { Yield Stress } \\
\text { (psi) }\end{array}$} \\
\hline & $\begin{array}{l}\text { Maximum } \\
\text { Membrane }\end{array}$ & $\begin{array}{l}\text { Maximum } \\
\text { Shear }\end{array}$ & $\begin{array}{l}\text { Maximum } \\
\text { Von Mises }\end{array}$ & \\
\hline 1 & 12,260 & 3,567 & 10,850 & 36,000 \\
\hline 2 & 23,740 & 3,076 & 21,080 & 36,000 \\
\hline 3 & 12,310 & 4,587 & 11,610 & 36,000 \\
\hline 5 & 25,280 & 8,201 & 23,180 & 36,000 \\
\hline
\end{tabular}

A graphic of structural deformations due to blast is shown, Figure 15. Note that the blast deformations are exaggerated by a factor of 20 in this figure (TAURUS graphic), and shell element stress contours are superimposed over the shell element plates. Note that in the cabinet graphic, both doors are removed (they were modeled separately) and the view is from the front door side towards the rear door side.

Note that in Figure 15, TAURUS draws all beam members as a rectangular tube with dimensions based on the ratios of moment of inertia to section modulus. Note also that beam members and plating panels are drawn along centerlines and thus beams appear to penetrate the plating panels which actually cover the beam members. The highest-stressed members for blast loading are the beam members in the middle of top plates (beam material \#14) and the vertical posts on the far side (beam material \# 4).

The design currently uses Grade 8 cap screws for shipping, not blast reasons. This calculation uses the lower-strength Grade 2 cap screw to account for the possibility that the stronger bolts may be replaced with weaker bolts during the life of the machine. This conservative philosophy is consistent with the language of the MEDSS (LLNL, 1995a). Since a grade 2 cap screw provides a substantial factor of safety against bolt failure, one need not be concerned about replacing Grade 8 bolts with Grade 2 during future maintenance.

15

\begin{tabular}{|l|l|}
\hline Material 1 & side plates - mild steel, yield 36 ksi \\
\hline Material 2 & top plate - mild steel, yield 36 ksi \\
\hline Material 3 & end plates - mild steel, yield 36 ksi \\
\hline Material 4 & Not used \\
\hline Material 5 & top hat plate - mild steel, yield 36 ksi \\
\hline
\end{tabular}




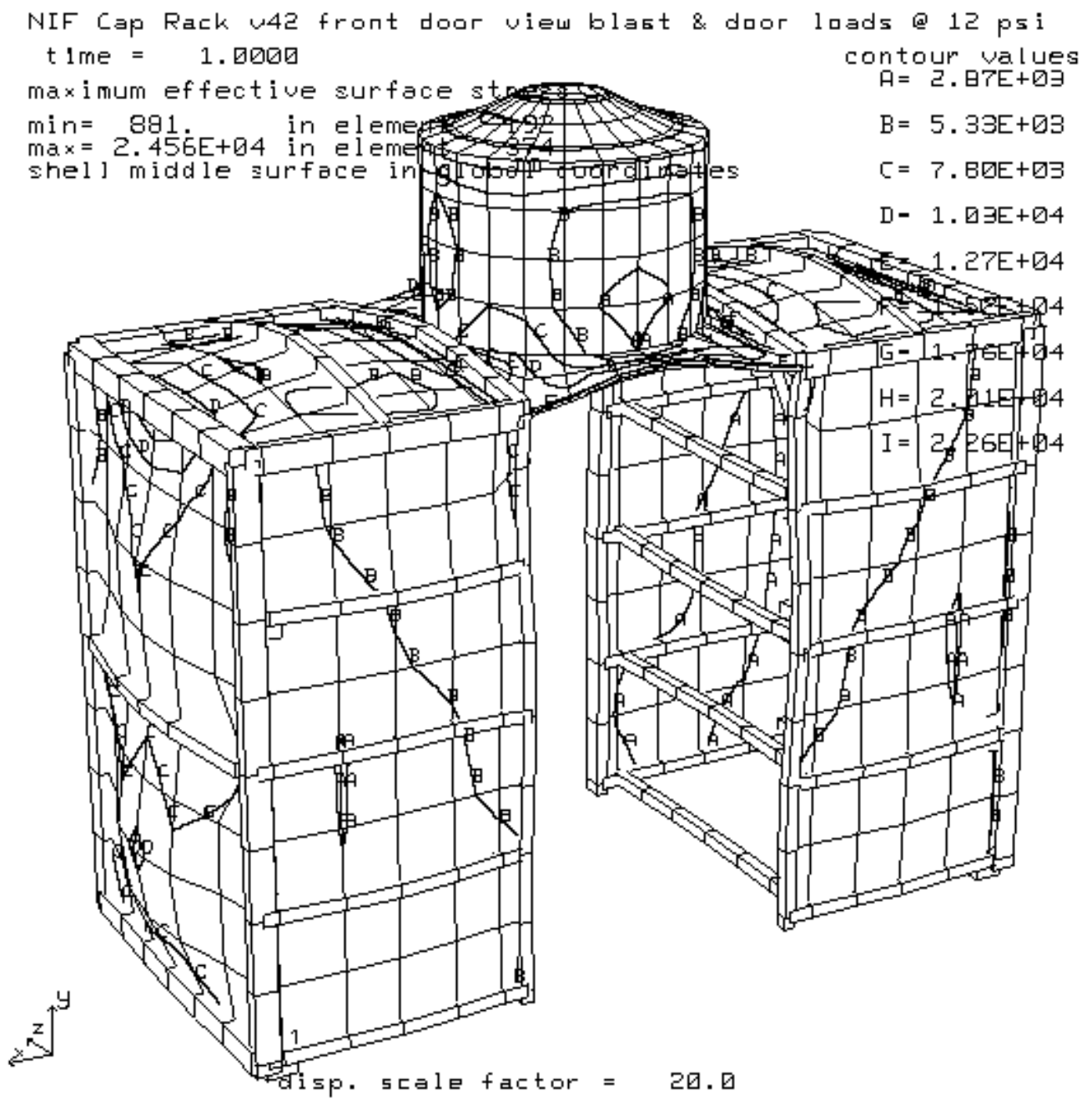

Figure 15: NIF Capacitor Module (cabinet) under Overpressure Stresses induced from a Capacitor Failure Event 
Table 10: Bolting Schedule and Factor of Safety for Bolted Side Panels

\begin{tabular}{|l|l|l|l|l|l|l|l|l|}
\hline $\begin{array}{l}\text { Panel } \\
\text { Name }\end{array}$ & $\begin{array}{l}\text { Length } \\
\text { (in) }\end{array}$ & $\begin{array}{l}\text { Width } \\
\text { (in) }\end{array}$ & $\begin{array}{l}\text { Pressure } \\
\text { (psi) }\end{array}$ & $\begin{array}{l}\text { Total } \\
\text { Load } \\
\text { (lbs) }\end{array}$ & $\begin{array}{l}\text { Number of } \\
\text { mid- } \\
\text { supports }\end{array}$ & $\begin{array}{l}\text { Total } \\
\text { Perimeter } \\
\text { (in) }\end{array}$ & $\begin{array}{l}\text { Total } \\
\text { Perimeter } \\
\text { (ft) }\end{array}$ & $\begin{array}{l}\text { Average } \\
\text { Edge } \\
\text { Load } \\
\text { (Ibs/ft) }\end{array}$ \\
\hline Side & 89 & 44 & 12 & 46,992 & 3 & 398 & 33.17 & $1,416.84$ \\
\hline End & 89 & 60 & 4 & 21,360 & 1 & 358 & 29.83 & 715.98 \\
\hline Top & 44 & 60 & 12 & 31,680 & 1 & 268 & 17.33 & $1,827.69$ \\
\hline
\end{tabular}

One 3/8-6 Grade 2 bolt yield strength: 4372 lbs (LLNL, 1995a)

Assume full strength when used with inserts: $4372 \mathrm{lb}$

\begin{tabular}{|l|l|l|l|l|l|l|l|}
\hline $\begin{array}{l}\text { Panel } \\
\text { Name }\end{array}$ & $\begin{array}{l}\text { Length } \\
\text { (in) }\end{array}$ & $\begin{array}{l}\text { Width } \\
\text { (in) }\end{array}$ & $\begin{array}{l}\text { Pressure } \\
\text { (psi) }\end{array}$ & $\begin{array}{l}\text { Minimum } \\
\text { Bolt } \\
\text { Spacing } \\
\text { (in) }\end{array}$ & $\begin{array}{l}\text { Minumum } \\
\text { Bolt } \\
\text { Count }\end{array}$ & $\begin{array}{l}\text { Proposed } \\
\text { Bolt Count }\end{array}$ & $\begin{array}{l}\text { Factor of } \\
\text { Safety }\end{array}$ \\
\hline Side & 89 & 44 & 398 & 37.00 & 11 & 21 & 1.91 \\
\hline
\end{tabular}

Welded Side Panels

Welding of the non-bolted panels to their supporting frame members must be consistent with the loading shown in Table 10. Conventional fillet welding has a nominal allowable strength of 600 pounds per lineal inch of weld per 1/16 inch of fillet size, including $50 \%$ margin of safety (AISC).

A panel welding schedule of approximately $1 / 8^{\prime \prime}$ fillet skipped at about $50 \%$ on length will have an allowable strength of about 7,200 pounds per lineal foot, and is adequate since the greatest load in Table 10 is 1,828 pounds per lineal foot. A fillet size larger than $3 / 16$ would not be justified since the framing square tube has a wall thickness of $3 / 16^{\prime \prime}$.

Door analyses. The two doors, being attached to the cabinet with simple connections, were analyzed separately from the cabinet frame and from each other. Door support reactions were extracted from the door analyses and added to the cabinet analysis as applied loads.

Maximum stresses and actual factors of safety for both doors (as modified) and all materials are shown in Table 11. The proposed design modifications mitigate high stresses at points of stress concentration previously evident and bring the design into conformance with the intent of the LLNL MEDSS factors of safety, as shown in Table 11. 
Table 11: Stresses and Factors of Safety for Front and Rear Doors

\begin{tabular}{|c|c|c|c|}
\hline Material Number ${ }^{16}$ & $\underset{(\text { ksi) }}{\text { Maximum Stress }}$ & Yield Stress (ksi) & Safety Factor \\
\hline \multicolumn{4}{|l|}{ Front Door Results } \\
\hline \multicolumn{4}{|l|}{ Beam Materials } \\
\hline 1 Door Top Reinforcement & 23.13 & 46.0 & 1.99 \\
\hline 2 Unused & - & 46.0 & - \\
\hline 3 Window cover hinges, latch & 19.87 & 46.0 & 2.31 \\
\hline 4 Window opening rein. & 10.60 & 46.0 & 4.34 \\
\hline 5 Window cover rein. beam & 23.96 & 46.0 & 1.92 \\
\hline \multicolumn{4}{|l|}{ Shell Materials } \\
\hline 1 Main door Plate A36 & 38.58 & 36.0 & 0.93 \\
\hline 2 Chute Cover Plates A36 & 20.09 & 36.0 & 1.79 \\
\hline 3 Chute Exit Lip Strips A 36 & 6.04 & 36.0 & 5.96 \\
\hline 4 Chute Bottom Plates A36 & 36.50 & 36.0 & 0.99 \\
\hline 5 Chute Bottom Plates A 36 & 24.96 & 36.0 & 1.44 \\
\hline 6 Chute Baffles A36 & 8.53 & 36.0 & 4.22 \\
\hline 7 Window Cover Plate A36 & 28.06 & 36.0 & 1.28 \\
\hline 8 Bottom and Side Doublers & 32.64 & 36.0 & 1.10 \\
\hline 9 Waist Latch Interior Dblrs & 25.67 & 36.0 & 1.40 \\
\hline 10 Vent Inlet Doublers A36 & 38.58 & 36.0 & 0.93 \\
\hline \multicolumn{4}{|l|}{ Rear Door Results } \\
\hline \multicolumn{4}{|l|}{ Beam Materials } \\
\hline 1 Door Bottom Reinforcement & 19.12 & 46.0 & 2.41 \\
\hline 2 Unused & - & 46.0 & - \\
\hline 3 Window cover hinges, latch & 20.86 & 46.0 & 2.21 \\
\hline 4 Window opening rein. & 15.30 & 46.0 & 3.01 \\
\hline 5 Window cover rein. beam & 24.69 & 46.0 & 1.86 \\
\hline \multicolumn{4}{|l|}{ Shell Materials } \\
\hline 1 Main door Plate A36 & 37.50 & 36.0 & 0.96 \\
\hline 2 Chute Cover Plates A36 & 14.99 & 36.0 & 2.40 \\
\hline 3 Chute Exit Lip Strips A 36 & 6.17 & 36.0 & 5.84 \\
\hline 4 Chute Side Plates A36 & 25.53 & 36.0 & 1.41 \\
\hline 5 Chute Bottom Plates A 36 & 25.35 & 36.0 & 1.42 \\
\hline 6 Chute Baffles A36 & 5.98 & 36.0 & 6.02 \\
\hline 7 Window Cover Plate A36 & 30.51 & 36.0 & 1.18 \\
\hline 8 Side Plate Doublers & 25.53 & 36.0 & 1.41 \\
\hline 9 Window Corner Doublers & 28.32 & 36.0 & 1.27 \\
\hline 10 Vent Inlet Doublers A36 & 37.50 & 36.0 & 0.96 \\
\hline 11 Side Plate DblrA529 & 41.36 & 42.0 & 1.02 \\
\hline
\end{tabular}

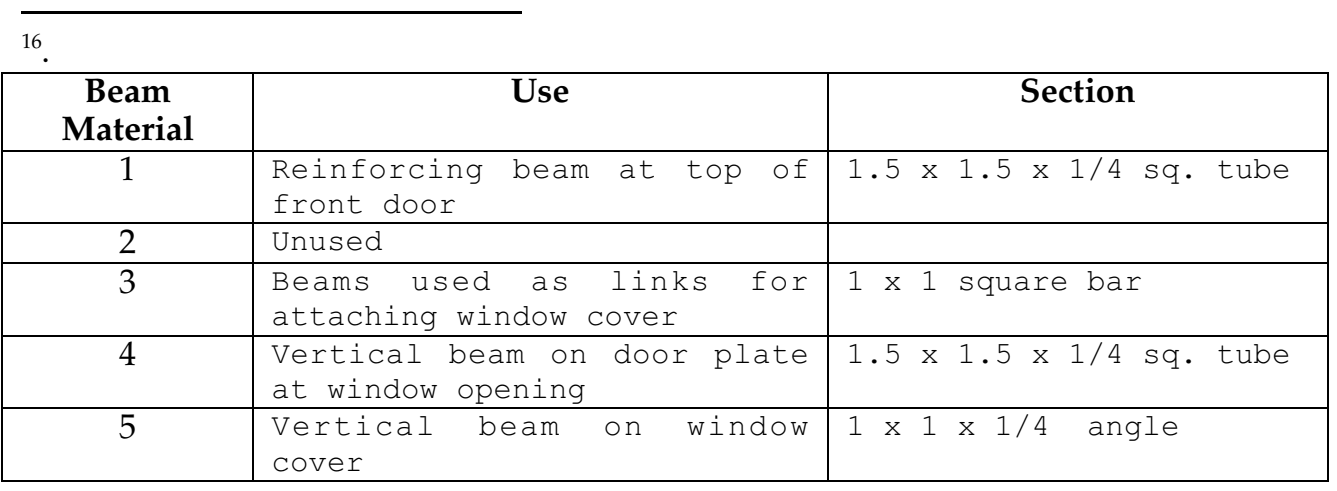


Notes:

1. This stress exceeds the allowable (yield) but occurs in only one element (extent less than 1 square inch) at each side of each vent inlet, in the main door plate (and doubler) and front door side plates.

The doubler plates in these regions were modeled as two plates of one thickness sharing the same plane, which understates both their stiffness and strength, and these stresses are therefore overstated.

Modeling the doubler plates as doubling the thickness of the main plate (instead of as a second plate of like thickness) would be less conservative and reduce the calculated stress by a factor of nearly two.

2. This stress is maximum in the doubler plate on the inside of the side plates at the lower vent inlet only, and requires A529 steel (42 yield) doubler plates -- with plug welding to make the plates act as one. The maximum stress in the side plate is less than 36 , allowing A36 to be used for the side plates (material \#4).

The upper vent inlet is lower stressed and can use A36 doubler plates without plug-welding (material \# 8).

\section{Shrapnel Analysis}

\section{Analysis Methodology}

To explore the pathways traveled by shrapnel, modified ray-tracing software was used. A customized version of the Persistence of Vision ${ }^{\mathrm{TM}}$ Ray-Tracer (POVRay $^{\mathrm{TM}}$ ) version 3.02 code for the Macintosh ${ }^{\mathrm{TM}}$ Operating System (MacOS ${ }^{\mathrm{TM}}$ ) was used. POV-Ray is a mature, open-source, third generation graphics code that creates three-dimensional, very high quality (photo-realistic) images with realistic reflections, shading, textures, perspective, and other effects using a rendering technique called ray-tracing. It reads a text file that describes the objects and lighting in a scene and generates an image of that scene from the viewpoint of a camera, also described in the text file.

The customized code (POV-Ray Ricochet Tracker, V3.02 - Custom Build 2) generates fragment trajectory paths at user designated angle intervals in three dimensions, tracks these trajectory paths through any complex three-dimensional space, and outputs detailed data for each ray as requested by the user. The available data output includes trajectory source location, initial direction of each trajectory, vector data for each surface/trajectory interaction, and any impacts with designated model target surfaces during any trajectory segment (direct path or reflected paths). This allows determination of the three-dimensional trajectory of each simulated fragment, as well as overall and individual fragment probabilities of impact with any designated target(s) in the three-dimensional model. 
It also allows identification of any areas of particular concern due to grouping (in discrete areas) of fragment paths that lead to hits on the target areas of concern.

The default code output includes data for specified fragment paths up through four reflections, with the number of target hits for each path segment listed. Output is grouped by target number, arbitrarily assigned in order as the target objects are declared in the input model text file. Hits on the targets are listed by path segments (e.g., direct path, one bounce, two bounces, etc.).

The code has the capability to output a separate data file containing full $x, y$, and $z$ directional data for each fragment path, to output just the data for a user specified number of reflections, or to output data for just the paths that lead to hits on the specified targets.

The code assumes that the shrapnel originates from a point source located at the defined camera position in the model. The shrapnel pieces are assumed to be ideal, spherical, point-sized objects. Travel paths are assumed to be short and at high speed, i.e., gravitational curvature of the shrapnel paths is ignored. Reflections are assumed to be ideal, i.e., the reflection angle is equal to the incident angle.

Both irregular fragment shapes and rotational momentum of the fragments would be expected to cause individual fragments to deviate from the ideal fragment paths. However, the aggregate real-world fragment paths would not be expected to significantly deviate from the ideal paths because of the averaging out of the deviations. Any collisions or other interactions between fragments are ignored.

The three-dimensional NIF Capacitor Bay model developed for this analysis included a $250 \mathrm{ft}$. x $50 \mathrm{ft}$. x $26 \mathrm{ft}$. room, containing 48 capacitor modules. Also included in the model were the capacitor bay mezzanine and cable ramps, stairs, and various doors (personnel doors and roll-up door). A rendering of the bay containing the modules is provided in Figures 16 and 17. Within the capacitor module, the capacitors, damping elements, and resistors were included. Initial runs were performed with an open module (as shown in Figure 18). Later runs were performed with modified module doors which provided venting, while restricting the shrapnel escape paths. The model of the modified module used in the analysis had no openings other than the shield door that protects the vent openings (see Figures 7 and 8). The one inch gap at the bottom of the FANTM module was eliminated in the model because the actual configuration has a drip pan and other components that shield the gap opening. A simplified module model was used in the interest of time.

The POV rendering of the modified module is shown in Figures 19 and 20. The side plates that cover the shield plates were removed in the rendering for visibility. 
Analysis code runs were performed on a $400 \mathrm{MHz}$ Macintosh G3 and on a 233 $\mathrm{MHz}$ iMac (G3) using MacOS 8.5.1. Run times varied from a few seconds to three hours and thirty minutes, depending on the output options selected. Sources of shrapnel were located at the most likely shrapnel locations: upper and lower resistor and copper strapping locations. 720 five foot by five foot target squares were overlaid on all the wall surfaces for modeling purposes.

Code runs were done for various locations of the module in the bay, so that all unique locations would be addressed. Locations included: a module in the corner of the room, a module in the center of a row adjacent to an end wall, and a module near the middle of the room, adjacent to a side wall. Code runs were also done on a single module inside a box to determine the total number of fragments that could be expected to escape from the module with the shielded door design developed by the analysis team.

Code runs were done at several angular resolutions to determine the optimum resolution to ensure that all significant fragment paths that could lead to hits on the walls or ceiling were identified. There were significant changes in hit probabilities between 0.5 and 0.3 degree spacing and no significant changes between 0.3 and 0.2 degrees. Therefore, it is judged that any resolution of 0.2 degrees or less is adequate for the NIF model to ensure that all significant fragment paths are identified. Final analysis runs for the selected shot placements were done at 0.2 degree spacing. This gave approximately $1,000,000$ fragments for analysis, with initial fragment paths distributed evenly around the source. One run for the isolated module was done at 0.1 degrees (which gave approximately 4,000,000 fragments) and additional runs with the fragment source at various locations within the module were done at 0.2 degrees. A sample section of output from the POV-Ray code is provided in Appendix B.5. 


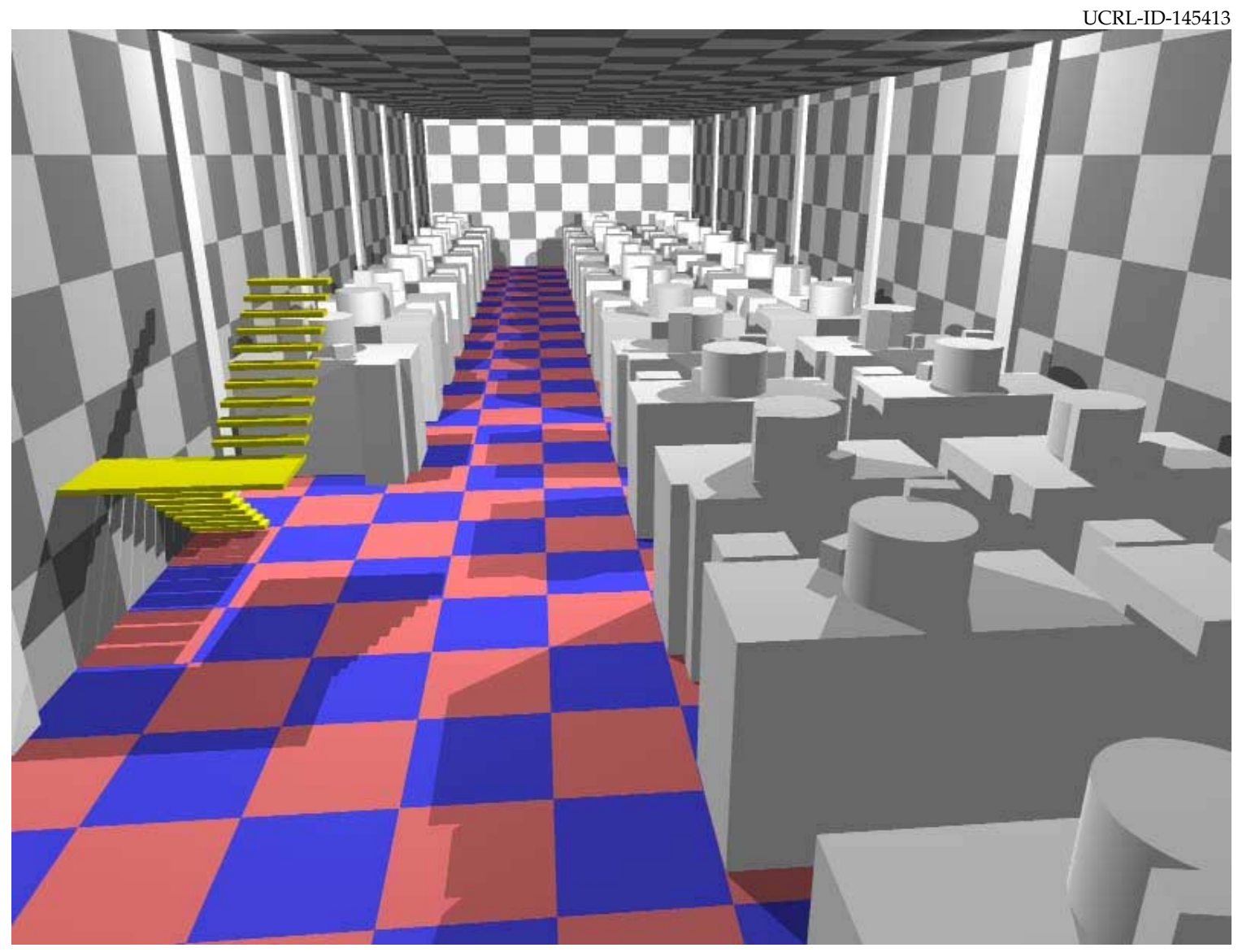

Figure 16: Rendering of the Capacitor Bay used in the Ray Tracking Analysis (mezzanine not shown)

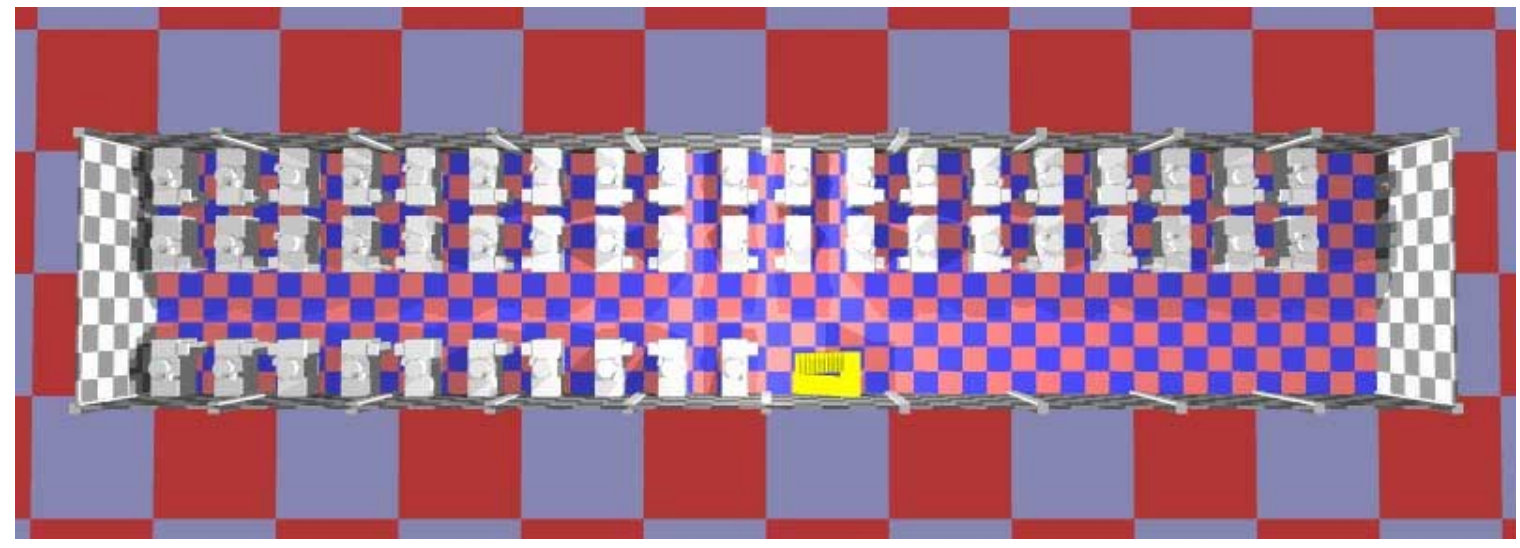

Figure 17: Rendering (top view) of the Capacitor Bay used in the Ray Tracing Analysis (mezzanine not shown) 


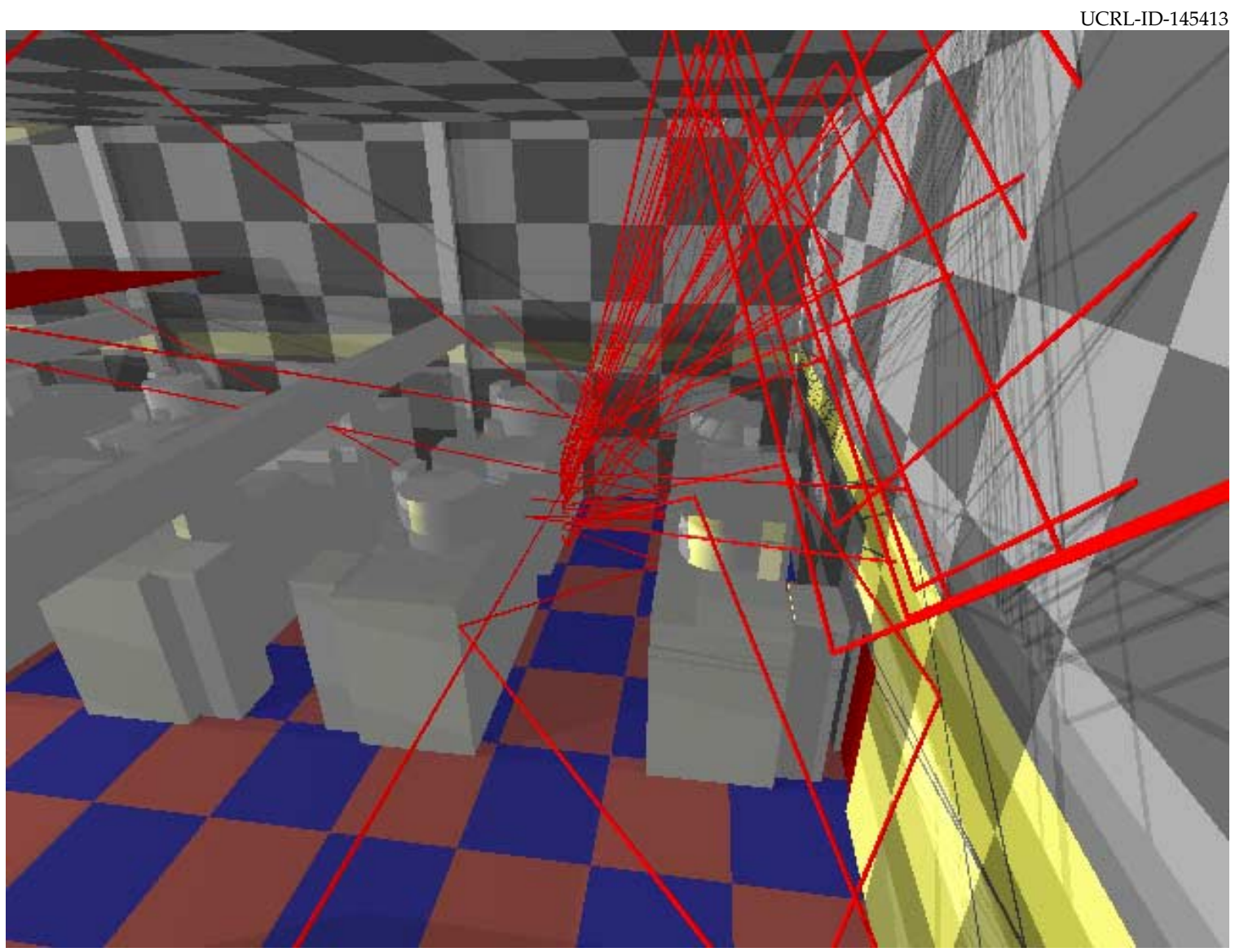

Figure 18: View of some fragment paths to the Capacitor Bay walls from Open Module 


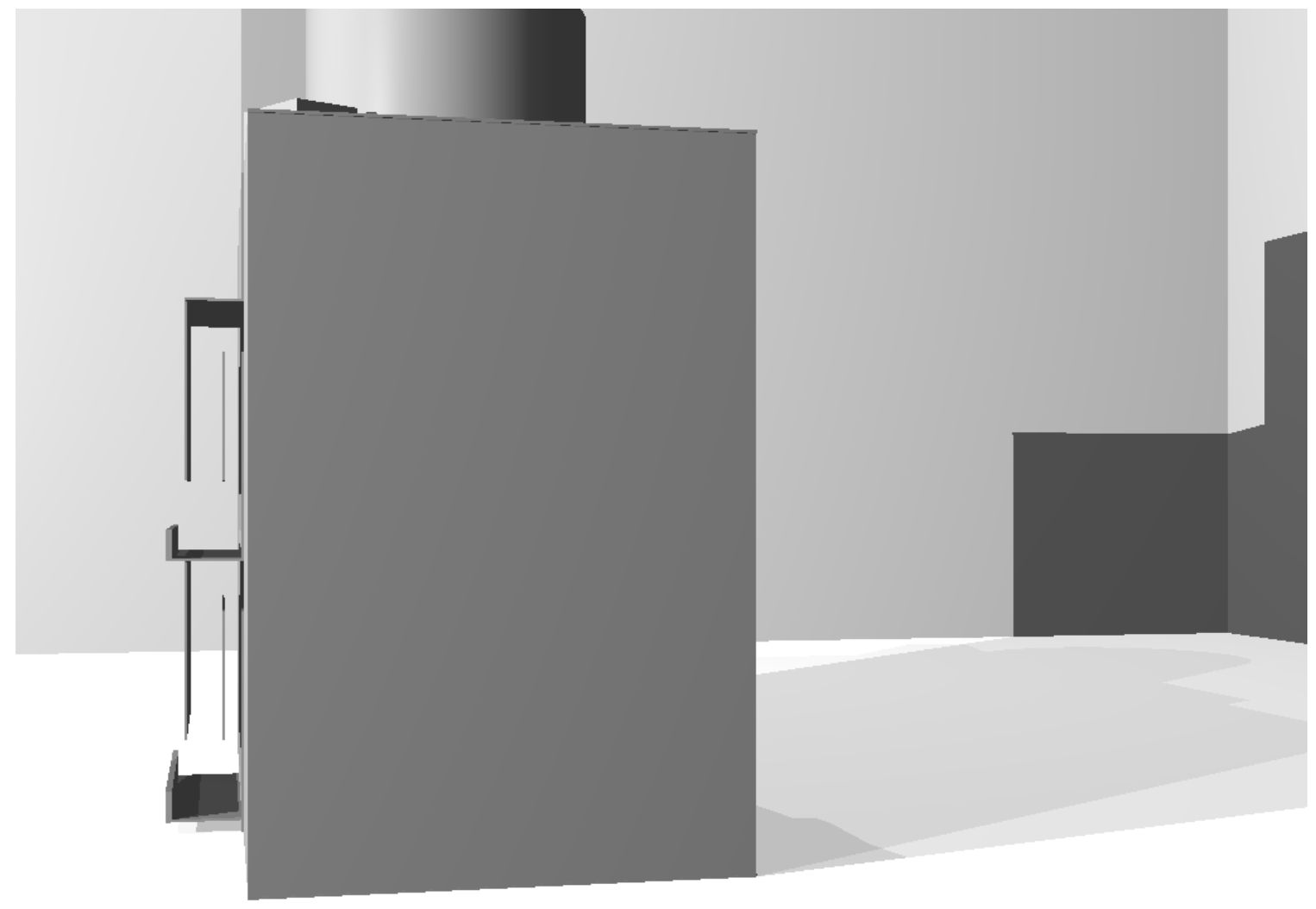

Figure 19: Side View Rendering of Modified Module design; (note: side plates are removed) 


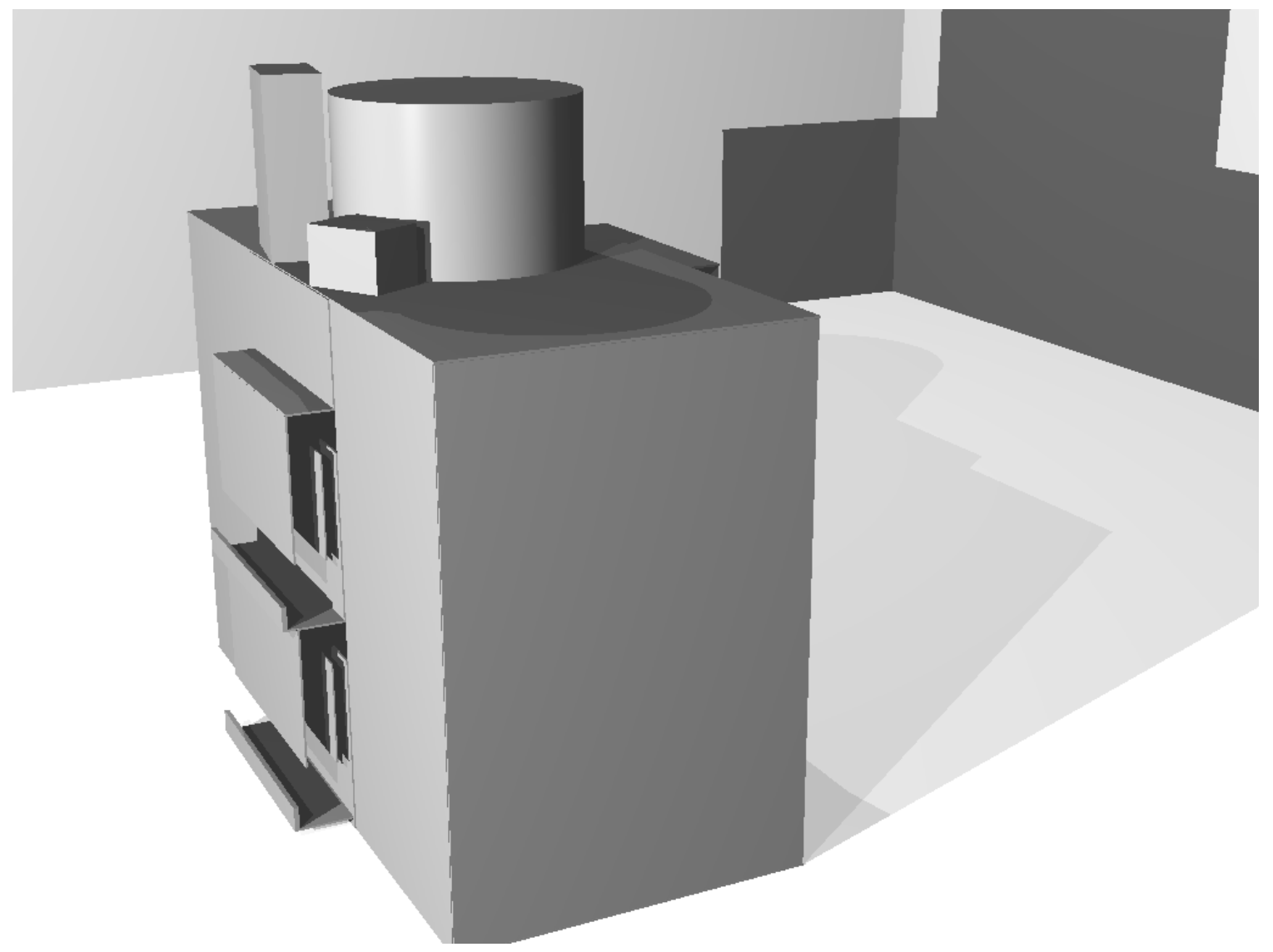

Figure 20: Rendering of Modified Module design; (note: side plates are removed) 
$\underline{\text { Results }}$

Figure 18 shows a POV-Ray Shrapnel Tracker rendering of representative one, two, and three bounce ray paths for hits on the walls for the open module (i.e., no door in place). This visual display of the analysis results identified no specific areas of grouping of shrapnel paths on the walls. However, it did illustrate the broad range of areas of wall that would be expected to be impacted if no attempt was made to restrict the shrapnel paths.

Proposed modifications to the capacitor module were evaluated. The most effective shrapnel containment modification involved cutting 7 inch high slots in each door at two locations to allow pressure venting, and restricting shrapnel escape from the vents by way of horizontal plates above the vents with vertical shield plates stemming downward from the horizontal plates, forming a chute. A "collimator" was placed in the chute to increase the number of impacts experienced by the fragments and to direct them down to the shrapnel trap. The shrapnel trap contains a thickness of shrapnel absorbing material, such as clear pine, to effectively collect the fragments. Alternate trap materials, such as aluminum honeycomb were considered, but found to be cost prohibitive.

The fragments were defined earlier in Section B. Several factors affect the energy the fragments may potentially transfer to the targets. Energy is lost when the fragment bounces off of (and interacts with) the various surfaces (LLNL 1992). Collisions between the shrapnel and most targets are inelastic collisions, with some fraction of the energy causing deformation of the impacted surfaces. We have used an energy absorbing material in the shrapnel traps on the module doors. The depth provided is sufficient to absorb even the most energetic fragment (see Appendix C).

The ray tracing analysis showed the shrapnel trap to be $100 \%$ effective at capturing shrapnel. All fragments exiting the module were directed to the trap. Since the trap was modeled as a pure absorber, all fragments impacting the trap were absorbed by it.

The collimator in each chute was effective at increasing the number of bounces undergone by a fragment before impinging upon the trap. If the trap did not capture the fragment (ie., it did not behave as a pure absorber), fragments could impinge upon the wall after escaping the trap. However, such fragments would have already bounced four times (i.e., fifth impact would be with the wall), and the fragment energy would be severely degraded. The probability of such an impact was estimated to be $\sim 6 \times 10^{-4} /$ fragment. Recall that this assumes the shrapnel trap to be ineffective (i.e., non-absorbing), which is unlikely.

Fragments could escape the module in two other ways:

- module opens up at joints due to pressure, creating new pathways out;

- module door is not returned to its proper position and secured after maintenance. 
The pressure and structural analysis in the previous section indicated that the module should remain intact under anticipated pressure loads from explosive events. Thus, it is not likely that module failure at joints would allow fragments to escape.

Human error could result in a door not being replaced or properly secured after maintenance. This probability can be reduced by:

- requiring door placement back onto the module as a specific step in a procedure;

- having an independent check of all doors to ensure they're properly replaced and secured after a maintenance activity.

\section{Conclusions}

The ray tracing analysis showed the new module concept to be $100 \%$ effective at containing fragments. All fragments have been shown to impact the energy absorbing shrapnel trap on their way out of the module and are trapped. Thus, we have high confidence that energetic fragments will not escape the module with the module doors in place.

Because it cannot be guaranteed that the module doors will be replaced correctly, or that the module pressure analysis was based on the most severe of possible events, consideration should be given to providing some additional protection (e.g., 1.0 inch of high-grade, fire-retardant plywood on the walls). This will act as a secondary containment, giving high confidence that no fragment will escape the capacitor bays.

\section{Section E: Testing Requirements}

Rather than testing the modified module design, a secondary containment for shrapnel can be provided. A test of the module under anticipated conditions during an explosive event would demonstrate the adequacy of the venting area provided, the ability of the module to tolerate the overpressure, and the effectiveness of the shrapnel trap. Since this is not possible (the FANTM facility has been disassembled), a shrapnel barrier on the walls, to act as a secondary containment, should be considered. If the module did break apart during the event, and if shrapnel escaped through pathways other than the chute on the doors, then the shrapnel barrier on the walls would be available as shielding. If this barrier is of sufficient thickness to stop even the most energetic fragment anticipated (e.g., 1.0 inch of high-grade, fire-retardant plywood), then we should have a similarly high level of confidence that fragments will not escape the capacitor bays. 


\section{Section F: Labeling Requirements}

This section does not apply.

\section{Section G: Associated Procedures}

Because this analysis assumes that personnel will not be in the capacitor bays while capacitors are charged or being charged, procedures related to the safety interlock system are associated with this analysis. They will require that the capacitor bays are cleared of personnel prior to charging the capacitors.

To reduce the probability that capacitor module doors are either not replaced or improperly secured after maintenance, procedures related to maintenance are associated with this analysis. Maintenance procedures should require door placement back onto the module as a specific step, and an independent check of all doors to ensure they're properly replaced and secured after a maintenance activity.

After routine maintenance of capacitor modules, a procedure should require that all modules be checked, to ensure that all tools have been removed from the interior of the module. This reduces the potential for shorting. 


\section{Section H: References}

ACE (1999), "Component Failure Testing at American Control Engineering", Photo Book, April 1999.

DOA (1987), "Wood Handbook: Wood as an Engineering Material", USDA Forest Service Handbook, No. 72, Government Printing Office, Washington DC, 1987.

DOE (1992), "A Manual for the Prediction of Blast and Fragment Loadings on Structures", U.S. Department of Energy, DOE/TIC-11268, July 1992.

DOE (1996), “DOE Explosives Safety Manual”, DOE M 440.1-1, March 1996.

Fried, L.E., et al., (1997), Cheetah 2.0, User's Manual,Energetic Materials Center, Lawrence Livermore National Laboratory, 1997.

High, Richard (1968), The Saturn Fireball, NASA Manned Spacecraft Center, Annals of the New York Academy of Sciences, I52, I, 1968, pp441-451.

LLNL (1985), GEMINI Manual, Lawrence Livermore National Laboratory, UCRL-52823, September 1985.

LLNL (1991), SLIC Manual, Lawrence Livermore National Laboratory, UCRLMA-108429, May 1991.

LLNL (1991a), TAURUS Manual, Version 6.16.98, Lawrence Livermore National Laboratory, UCRL-MA-105401, May 1991.

LLNL (1995), "Mechanical Engineering Design Safety Standards", M-012, Lawrence Livermore National Laboratory, September 1995.

LLNL (1995a), LLNL Mechanical Engineering Design Safety Standards, table of bolt yield strengths, Chapter F, Appendix B, Page 16.

LLNL (1999), "National Ignition Facility Final Safety Analysis Report", Preliminary Draft, NIF-00019661, March 31, 1999.

LLNL (1999a), "WBS 1.3.4 Power Conditioning System Reliability, Availability, and Maintainability (RAM) Assessments for Title II 100\% Design Review", Lawrence Livermore National Laboratory, prepared by G. Larson, NIF-0023950OA, June 1999.

Moore, W. (1999), personal communication to S. Brereton, May 1999.

Parsons (1996), "NIF-LTAB, Analyses of Potential Impact of Capacitor/ Shrapnel/ Projectiles", Parsons Technology Section, October 1996. 
Rakaczky, J.A.,(1975) The Suppression of Thermal hazards from Explosions of Munitions: A Literature Survey, BRL Internal Memorandum Report 377, Aberdeen Proving Ground, Maryland.

Smith, D.L. and H.C. Harjes (1999), "FANTM Fault Analysis", memo to D. Bloomquist, May 19,1999.

Staggs, K. et al. (1999), "Fire Risk Analysis for the NIF Capacitor Containment Design", Lawrence Livermore National Laboratory, UCRL-ID-133180, February 1999.

Takemori, H.T. (1989), "Capacitor Bank For the Backward Wave Oscillator Project, Located in Bldg 141", Mechanical Engineering Safety Note, END 89-921, November 1989.

Wilson, M. (1998), "Recent Explosive Failures at the FANTM Facility", November 1998.

Young (1989), Roark's Formulas for Stress \& Strain, 6th edition, McGraw-Hill, 1989. 


\section{List of Contributors}

\begin{tabular}{|l|l|}
\hline Section & Author (s) \\
\hline Summary & Sandra Brereton \\
\hline Introduction & Sandra Brereton \\
\hline Personnel Safety & Dave Prokosch \\
\hline Nature of the Problem & $\begin{array}{l}\text { Sandra Brereton } \\
\text { Bill Moore } \\
\text { Mark Newton } \\
\text { John Pastrnak }\end{array}$ \\
\hline Design Solutions & $\begin{array}{l}\text { Sandra Brereton } \\
\text { Chin Ma }\end{array}$ \\
\hline Calculations & $\begin{array}{l}\text { Sandra Brereton } \\
\text { Russ Greenlaw } \\
\text { Chin Ma }\end{array}$ \\
\hline & John Pastrnak \\
& David Price \\
\hline Appendix A.1 & John Pastrnak \\
\hline Appendix A.2 & John Pastrnak \\
\hline Appendix A.3 & John Pastrnak \\
\hline Appendix A.4 & Chin Ma \\
\hline Appendix A.5 & Chin Ma \\
\hline Appendix A.6 & Sandra Brereton \\
\hline Appendix A.7 & Sandra Brereton \\
\hline Appendix A.8 & Sandra Brereton \\
\hline Appendix A.9 & David Price \\
\hline Appendix B.1 & John Pastrnak \\
\hline Appendix B.2 & Sandra Brereton \\
\hline Appendix B.3 & Sandra Brereton \\
\hline Appendix B.4 & Sandra Brereton \\
\hline Appendix B.5 & David Price \\
\hline Appendix C & Sandra Brereton \\
\hline Appendix D & Sandra Brereton \\
& Chin Ma \\
\hline Appendix E.1 & Madhu Kamath \\
\hline Appendix E.2 & Russ Greenlaw \\
\hline Appendix E.3 & Russ Greenlaw \\
\hline
\end{tabular}




\section{Appendix A: Pressure Calculations}

\section{Appendix A.1}

\section{Calculation for Estimating Module Pressure from Door Bowing}

The purpose of this calculation is to estimate the peak internal quasi-static pressure in the module that could have caused the permanent 2 inch deformation of the module panels.

Due to mounting hooks at the top and seismic restraints at the bottom; the panel is modeled as a simply supported beam where:

$\mathrm{h}=$ thickness $=0.375^{\prime \prime}$

$\mathrm{L}=$ length $=90 "$

$\rho_{\mathrm{g}}=$ weight density $=0.283 \mathrm{lb} / \mathrm{in}^{3}$

$\rho=\frac{0.283 l b}{i n^{3}}\left(\frac{s^{2}}{384 i n}\right)=7.37 E^{-04} \frac{l b-s^{2}}{i n^{4}}$

$\sigma_{\mathrm{y}}=$ yield strength $=36 \mathrm{ksi}$

$\mathrm{w}_{\mathrm{o}}=$ maximum deflection $\sim 2 "$

$\mathrm{i}=$ specific impulse

$\mathrm{M}_{\mathrm{y}}=$ yield moment

S.E.=strain energy

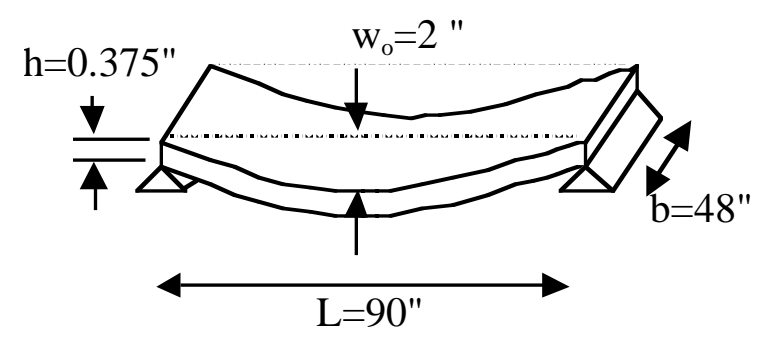

Figure A.1-1: Bowed Access Door Panel 
For a simply supported beam of length $\mathrm{L}$ whose origin is at the midpoint the assumed deformed shape will be a parabola given by:

$$
w=w_{o}\left(1-\frac{4 x^{2}}{L^{2}}\right)
$$

and its derivatives as:

$$
\begin{aligned}
& \frac{d w}{d x}=w_{o}\left(-\frac{8 x}{L^{2}}\right) \\
& \frac{d^{2} w}{d x^{2}}=-w_{o} \frac{8}{L^{2}}
\end{aligned}
$$

The strain energy in a rigid plastic beam is the yield moment times the angle through which it rotates $\left(\frac{d^{2} w}{d x^{2}} d x\right)$ integrated over the length of the beam.

$$
\text { S.E. }=-2 \int_{L / 2}^{0} M_{y} \frac{d^{2} w}{d x^{2}} d x=\frac{-16 M_{y} w_{o}}{L^{2}} \int_{L / 2}^{0} d x=\frac{8 M_{y} w_{o}}{L}
$$

The kinetic energy KE is given by

$$
\text { K.E. }=\frac{1}{2} m v^{2}
$$

the change in momentum is equal to the impulse I:

$$
I=\Delta(m v)=m v
$$

solving for $\mathrm{v}$ and inserting in [2]

$$
\text { K.E. }=\frac{1}{2} m\left(\frac{I^{2}}{m^{2}}\right)=\frac{I^{2}}{2 m}
$$

and in the impulsive loading regime the kinetic energy is

$$
K . E .=\sum_{\text {beam }} \frac{I^{2}}{2 m}=2 \int_{0}^{L / 2} \frac{(i b d x)^{2}}{2(\rho b h d x)}=\frac{i^{2} b L}{2 \rho h}
$$

equating the kinetic energy to the strain energy eqn [1] to [4] gives 


$$
i=\frac{4}{L} \sqrt{\frac{w_{o}}{b} \rho M_{y} h}
$$

substituting for the yield or plastic moment $M_{y}=\sigma_{y} Z=\sigma_{y} \frac{b h^{2}}{4}$

$$
i=\frac{2}{L} \sqrt{w_{o} \rho \sigma_{y} h^{3}}=\frac{2}{90 i n} \sqrt{(2 i n)\left(7.37 E^{-04} \frac{l b-s^{2}}{i n^{4}}\right)\left(\frac{36,000 l b}{i n^{2}}\right)(0.375 i n)^{3}}
$$

\section{$\mathrm{i}=37.1 \mathrm{psi}-\mathrm{ms}$}

This is the impulse over the door panel that would cause the deformation of 2 inches. Given this applied impulse, one can estimate a fictitious equivalent amount of TNT placed in the center of the module that would have produced the same impulse. Assuming a ficticious TNT charge was placed at the center of the module the impulse is matched from a spherical center detonated charge of $0.5 \mathrm{lb}$ (DOE, 1986). The quasi-static pressure on the walls of the capacitor bay walls cannot be estimated directly by the Weibull equation since the charge weight to room volume ratio is below the limits for this equation (Weibull, 1968).

$$
\Delta p=2410\left(\frac{W}{V}\right)^{.72} \quad \text { Weibull Eqn. }
$$

where:

$$
\begin{aligned}
& \Delta \mathrm{p}=\text { gas pressure increase (psig) } \\
& \mathrm{W}=\mathrm{TNT} \text { charge weight }(\mathrm{lb}) \\
& \mathrm{V}=\text { containment volume }\left(\mathrm{ft}^{3}\right) \\
& \text { Limited to: } \quad 0.001 \frac{l b}{f t^{3}} \leq \frac{W}{V} \leq 37 \frac{l b}{f t^{3}}
\end{aligned}
$$

For the capacitor bay $\mathrm{V} \sim 300,000$ cubic feet

$$
\frac{W}{V}=\frac{0.5 l b}{300,000 f t^{3}}=1.66 \times 10^{-06}<.001
$$

However the maximum quasi-static pressure for the free volume of the module (168 cubic feet $=4.75$ cubic meters) is within the limits for the Weibull equation and is calculated below

${ }^{17}$ This result also given in Explosion Hazards and Evaluation (Fundamental Studies in Engineering; 5), W.E. Baker et. al, p308, Elsevier Sciences Publishers, 1986. 


$$
\frac{W}{V}=\frac{0.5 l b}{168 f t^{3}}=.00297
$$

Thus a $0.5 \mathrm{lb}$ charge of TNT in the module would have produced a quasi-static pressure of

$$
\Delta p=2410\left(\frac{W}{V}\right)^{.72}=2410(0.00297)^{.72}=36.5 p s i g
$$

By expanding this gas out to the capacitor bay volume by

$$
p_{1} V_{1}=p_{2} V_{2}
$$

gives a gas over-pressure on the capacitor bay walls of

$$
p_{2}=\frac{p_{1} V_{1}}{V_{2}}=(36.5 p s i)\left(\frac{144 i n^{2}}{f t^{2}}\right)\left(\frac{168 f t^{3}}{300,000 f t^{3}}\right) \approx 3 p s f
$$

This is conservative since it assumes isothermal expansion, rather than entropic expansion. An isothermal calculation is simpler and does not determine problematic results. Further, this calculation neglects the vast heat capacity of the bay, which if taken into account would result in a lower overpressure. In addition, air leakage from the bay is also neglected.

The Safety Factor calculated against structural collapse of the walls if event \#2 had happened in one of the NIF capacitor bays based on a structural wall limit of 30 psf is:

$$
S F=\frac{30 p s f}{3 p s f}=10
$$

\section{$\underline{\text { References }}$}

DOA (1986), Fundamentals of Protective Design for Conventional Weapons, Department of the Army, TM5-855-1, Nov.,11,1986.

Parsons (1996), NIF--LTAB Analysis of Potential Impact of Capacitor/Shrapnel/ Projectiles, Parsons Technology Section,Oct.18, 1996, p2.

Weibull, H.R. (1968), Pressures Recorded in Partially Closed Chambers at Explosion of TNT Charges, Annals of The NY Academy of Sciences, V152,Art. 1, Oct. 28, 1968, p357-361. 


\section{Appendix A.2}

\section{Calculation for Estimating Module Pressure from Bolt Failure}

After two of the FANTM Events (\#2 and \#3), some bolts were found to have failed that were used to attach two module panels to the module frame. Documentation of the exact number and location of the failed bolts was not found. In addition, some anecdotal information was provided that some of the bolts may not have been installed prior to these events. From a "bounding" standpoint, the following calculation is an estimate of the maximum internal static pressure necessary to cause failure of all bolts on a module panel based on the structural capacity of the panel attachment points.

Twenty-two bolt holes are provided in the side panel, to attach the panel to the module frame. [Ref.: preliminary drawing AAA97-103765 dated 8/5/98]

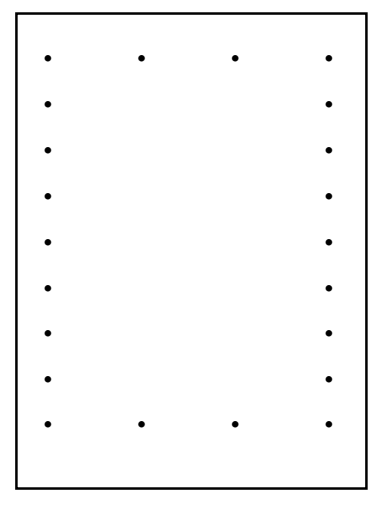

$43^{\prime \prime}$

Panel Thickness $=0.188$ inches steel ASTM A36

Bolt callout $1 / 4 \times 20$ UNC-2B through outside tube wall

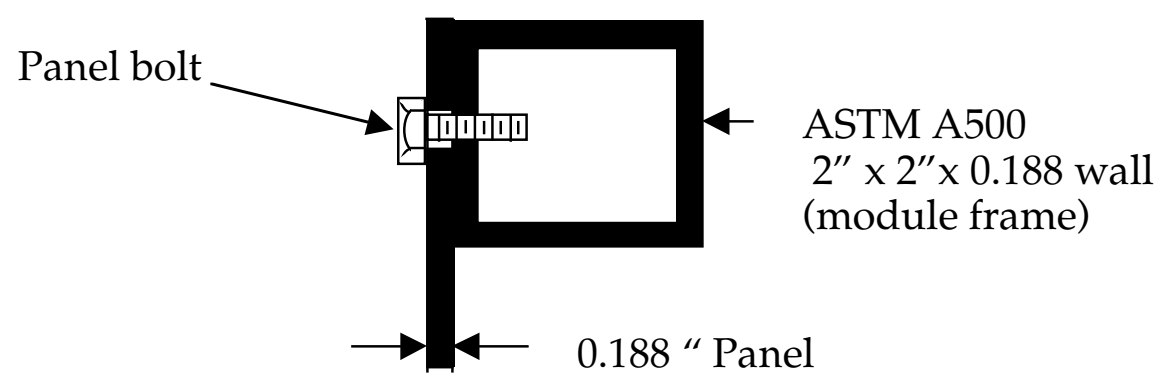

Figure A.2-1 
(1) Check bolt/frame failure by shearing of female threads in tube.

For ASTM-A500, $\mathrm{S}_{\mathrm{u}}{ }^{\max } \sim 50 \mathrm{ksi}$

For 1/4x20 UNC-2B, $\mathrm{A}_{\mathrm{s}}=0.539 \mathrm{in}^{2} / \mathrm{in} \times 0.188 \mathrm{in}=0.101 \mathrm{in}^{2}$

$\mathrm{P} \quad=$ applied uniform static internal pressure

A = panel area

$\mathrm{A}_{\mathrm{s}} \quad=$ shear area

$\mathrm{A}_{\mathrm{t}} \quad=$ tensile area

$\mathrm{S}_{\mathrm{u}} \quad=$ strength (ultimate)

$\mathrm{n} \quad=$ number of fasteners

$\mathrm{P}=\underline{S}_{\underline{\underline{u}}}(\mathrm{n})(\mathrm{A} \underline{\underline{s}})$

$$
\begin{aligned}
& =\frac{50 \mathrm{ksi} \times 22 \times 0.101 \mathrm{in}^{2}}{43 \times 90 \mathrm{in}^{2}} \\
& =28.7 \mathrm{psi}
\end{aligned}
$$

(2) Check tensile failure

Fasteners used at FANTM were Grade 8

$$
\begin{aligned}
\mathrm{P} \quad & =\frac{\underline{S}_{\underline{\underline{u}}}(\mathrm{n})\left(\mathrm{A}_{\underline{s}}\right)}{\mathrm{A}} \\
& =\frac{150 \mathrm{ksi} \times 22 \times 0.0318 \mathrm{in}^{2}}{43 \times 90 \mathrm{in}^{2}} \\
& =27.1 \mathrm{psi}, \text { tensile failure of bolts }
\end{aligned}
$$

Therefore, based on the static strengths of this panel attachment, the maximum static internal pressure in the module is bounded by a maximum of 27.1 to 28.7 psi above atmospheric pressure. Otherwise, static pressures above these estimated would have caused a complete dis-attachment of the side panels which did not occur as a result of events \#2 and \#3. 
By expanding this gas out to the capacitor bay volume using

$$
p_{1} V_{1}=p_{2} V_{2}
$$

where:

$p_{1} \quad=$ pressure in module before venting

$p_{2} \quad=$ pressure in capacitor bay at equilibrium

$V_{1} \quad=$ volume of module, $4.75 \mathrm{~m}^{3}$

$V_{2} \quad=$ volume of capacitor bay, $8.117 \mathrm{~m}^{3}$

gives a gas over-pressure on the capacitor bay walls of

$$
\begin{aligned}
\mathrm{p}_{2} & =\frac{\left(28.7 \mathrm{psi} \times 144 \mathrm{in}^{2} / \mathrm{ft}^{2}\right)}{8117 \mathrm{~m}^{3}} \times 4.75 \mathrm{~m}^{3} \\
& =2.4 \mathrm{psf}
\end{aligned}
$$




\section{Appendix A.3}

\section{Calculation for Estimating Module Pressure from Door Hook Failure}

During two of the FANTM Events (\#2 and \#3), door hooks were found to have failed. This calculation estimates the internal pressure necessary to have caused that failure.

It is assumed that the pressure area of the large panel with the hooks was equal to the panel dimensions minus the area of the small flapper door on the panel (which swung open during the event).

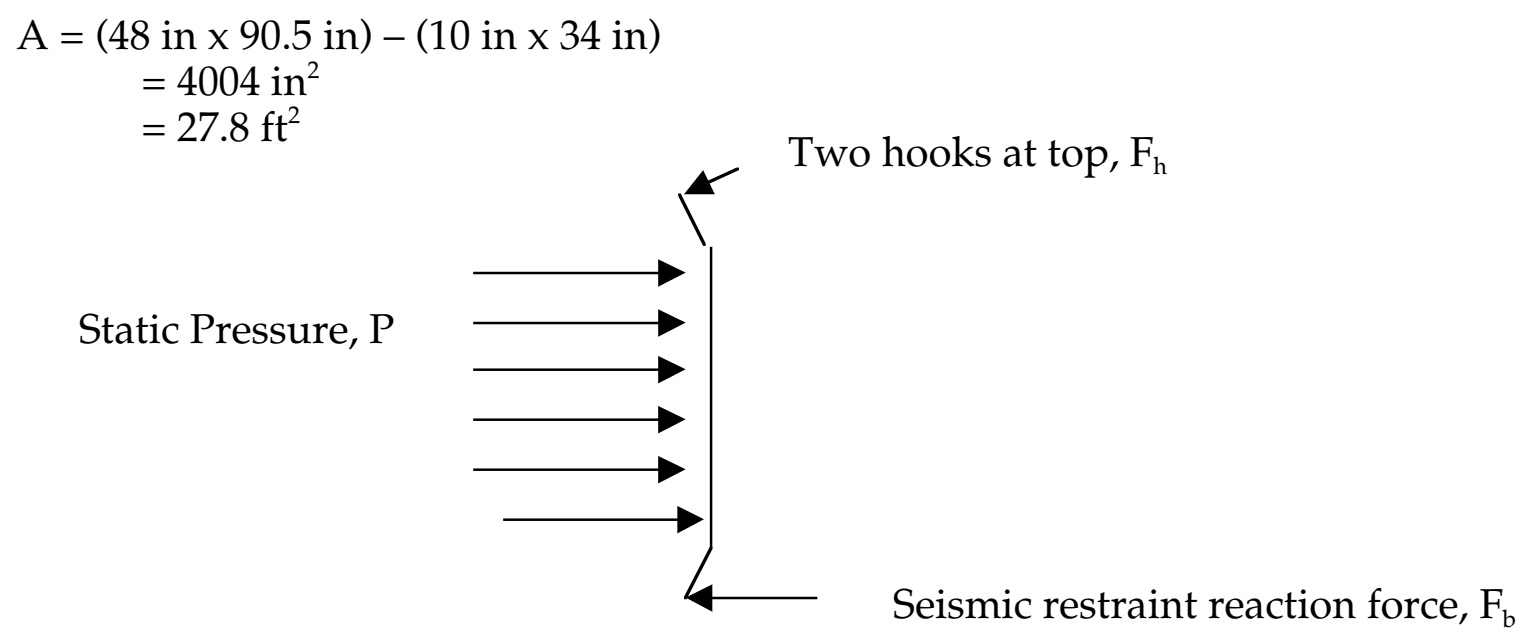

Figure A.3-1

Force in each hook given by $\mathrm{F}_{\mathrm{h}}$

Force in each seismic block given by $\mathrm{F}_{\mathrm{b}}$

$\Sigma \mathrm{F}_{\mathrm{y}} \quad=0$

$\mathrm{PA}=2 \mathrm{~F}_{\mathrm{h}}+2 \mathrm{~F}_{\mathrm{b}}$

Assume at failure of the hook that $\mathrm{F}_{\mathrm{h}}=\mathrm{F}_{\mathrm{b}}$

$\mathrm{PA}=4 \mathrm{~F}_{\mathrm{h}}$

$\mathrm{F}_{\mathrm{h}}=\frac{\mathrm{PA}}{4}$ 
Hook Cross-section

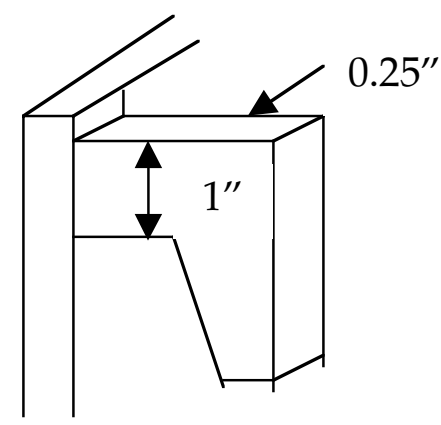

Figure A.3-2

$$
\begin{array}{ll}
\mathrm{A}_{\mathrm{t}} & =\text { tensile area }=0.25 \mathrm{in} \times 1 \mathrm{in}=0.25 \mathrm{in}^{2} \\
\mathrm{~F}_{\mathrm{h}} & =\mathrm{S}_{\mathrm{u}} \times \mathrm{A}_{\mathrm{t}} \\
\mathrm{S}_{\mathrm{u}} \mathrm{A}_{\mathrm{t}} & =\frac{\mathrm{PA}}{4} \\
\mathrm{P} & =\underline{4 \mathrm{~S}_{\underline{u}}} \underline{\mathrm{A}}_{t}
\end{array}
$$

For A36 steel, $\mathrm{S}_{\mathrm{u}}=58-80 \mathrm{ksi}$

$$
\begin{aligned}
\mathrm{P}_{\min } & =4(58000 \mathrm{lb} / \mathrm{in})(0.25 / 4004) \\
& =14.4 \mathrm{psi} \\
\mathrm{P}_{\max } & =4(80000 \mathrm{lb} / \mathrm{in})(0.25 / 4004) \\
& =19.98 \mathrm{psi}
\end{aligned}
$$

By expanding this gas out to the capacitor bay volume using

$$
p_{1} V_{1}=p_{2} V_{2}
$$

gives a gas over-pressure on the capacitor bay walls of

$$
\begin{aligned}
p_{2} & =\frac{\left(19.98 \mathrm{psi} \times 144 \mathrm{in}^{2} / \mathrm{ft}^{2}\right)}{8117 \mathrm{~m}^{3}} \times 4.75 \mathrm{~m}^{3} \\
& =1.7 \mathrm{psf}
\end{aligned}
$$




\section{Appendix A.4}

\section{Calculations Based on the Trajectory of the Small Flapper Door, FANTM Event \#3}

This appendix calculates the travel distance, $\mathrm{D}$, of the small $1^{\prime} \times 3^{\prime}$ flapper door as a function of time after an explosion occurred in a capacitor module (FANTM Event \#3). The peak quasi-static pressure can be determined by comparing the calculated results with the location of the puncture on the east roll-up door resulting from the hit by the flapper door.

At the time of FANTM Event \#3, the module door configuration consisted of: A large, central, west-facing door (CDW), $4^{\prime} \times 8^{\prime}$, with a small flapper door (WFD), $1^{\prime} \times 3^{\prime}$, near the top

A large, central, east-facing door (CDE), $4^{\prime} \times 8^{\prime}$, with a small flapper door (EFD), $1^{\prime} \times 3^{\prime}$, near the bottom.

During FANTM Event \#3, the east flapper door (EFD), was ejected and punctured the roll-up door of the FANTM test cell (see Figure 5, main report).

Following a capacitor explosion (FANTM Event \#3), the quasi-static pressure, $\boldsymbol{P}_{\mathrm{q} s}$, can be expressed as (see Chapter 4 of DOE, 1992):

$$
\boldsymbol{P}_{\mathrm{qs}}(\mathrm{t})=\left(\mathrm{P}_{\mathrm{qs}}+\mathrm{P}_{\mathrm{o}}\right) \exp \left(-\mathrm{c} \mathrm{A}_{\mathrm{tot}} / \mathrm{Vt}\right)-\mathrm{P}_{\mathrm{o}}
$$

Where $\mathrm{P}_{\mathrm{qs}}$ is the peak quasi-static pressure, $\mathrm{P}_{\mathrm{o}}$ is the ambient pressure taken as 14.7 psi, $\mathrm{A}_{\text {tot }}$ is the total venting area of the module, $\mathrm{V}$ is its volume, and the constant $\mathrm{c}$ at standard sea level conditions is

$$
\mathrm{c}=2378 \mathrm{ft} / \mathrm{sec} \quad \text { (see Chapter } 4 \text { of DOE, 1992) }
$$

The travel distance, $\mathrm{D}$, of the east flapper door can be expressed as:

$$
D(t)=\int^{t} v(\tau) d \tau
$$

and

$$
0
$$

$$
m v(t)=\int_{0}^{t} F(\tau) d \tau
$$

where $v(t)$ is the velocity of the east flapper door, $m$ is its mass, and $F(t)$ is the force acting on the east small flapper door due to the pressure.

$$
F(t)=P(t) \times h \times w
$$


where $\mathrm{h}$ and $\mathrm{w}$ are the height and the width of the east flapper door, respectively. The air drag force is neglected in Eq. (4).

The venting area, $\mathrm{A}(\mathrm{t})$, produced by the east flapper door as it moved away from the module can be expressed as:

$$
A(t)=D(t)(2 h+2 w)
$$

Note that $\mathrm{A}(\mathrm{t}) \leq \mathrm{h} \times \mathrm{w}$

Similar equations also hold for the two 4' x 8' central doors, except these doors have contact with the floor, thus Eqs (4) and (5) become

$$
\begin{aligned}
& \mathrm{F}(\mathrm{t})=\mathrm{P}(\mathrm{t}) \times \mathrm{h} \times \mathrm{w}-\mu_{\mathrm{k}} \boldsymbol{W} \\
& \mathrm{A}(\mathrm{t})=\mathrm{D}(\mathrm{t})(2 \mathrm{~h}+\mathrm{w})
\end{aligned}
$$

Where $\boldsymbol{W}$ is the weight of the central door and $\mu_{\mathrm{k}}$ is the kinetic friction coefficient which is taken to be 0.5 . Eq (7) indicates that there will be no venting through the floor. Note that Eq. (7) describes the force acting on the central door after it breaks away from the module. Also, note that the force/energy to fail the hooks was ignored.

Following a capacitor explosion (Event \#3), the east flapper door flew away and hit the roll-up door, the other flapper door swung open, the two central doors moved away from the module and were found leaning against it.

The total venting area in Eq. (1) is the sum of the individual venting areas, i.e.,

$$
\mathrm{A}_{\text {tot }}(\mathrm{t})=\mathrm{A}_{\mathrm{EFD}}(\mathrm{t})+\mathrm{A}_{\mathrm{WFD}}(\mathrm{t})+\mathrm{A}_{\mathrm{CDE}}(\mathrm{t})+\mathrm{A}_{\mathrm{CDW}}(\mathrm{t})+\mathrm{A}_{\mathrm{FIXED}}
$$

Where $\mathrm{A}_{\mathrm{EFD}}, \mathrm{A}_{\mathrm{WFD}}, \mathrm{A}_{\mathrm{CDE}}$, and $\mathrm{A}_{\mathrm{CDW}}$ are the venting areas produced by the east flapper door, the west flapper door, and the two central doors, respectively. $A_{\mathrm{EFD}}$ is expressed by Eq (5), $A_{\mathrm{CDE}}$ and $\mathrm{A}_{\mathrm{CDW}}$ are expressed by Eq (7). The west flapper door is assumed to swing open; its motion is described by Eqs (2) to (6) in Appendix A.5. $\mathrm{A}_{\mathrm{FIXED}}$ is the fixed venting area provided by the gap around the bottom of the module.

For a given peak quasi-static pressure, $\mathrm{P}_{\mathrm{qs}}$, the set of equations (1) to (8), and equations (2) to (6) in Appendix A.5 can be solved numerically by the finite difference method using a spread sheet. Some remarks are in order:

- Eqs (2) to (7) are applied to the east flapper door and the two 4' x 8' central doors separately.

- Eqs (2) to (5) in Appendix A.5 are applied to the west flapper door. 
- The gauge pressure $P_{\mathrm{qs}}(t)$ given in $\mathrm{Eq}(1)$ is always positive.

- The free space inside the module is $168 \mathrm{ft}^{3}$.

- The thickness is $3 / 8$ in. for all doors. These are steel doors with a density of $489.7 \mathrm{lb} / \mathrm{ft}^{3}$.

- The dimensions and weight of the two flapper doors are $1^{\prime} \mathrm{h} \times 3^{\prime} \mathrm{w}$ and $46 \mathrm{lb}$, respectively. The two central doors are $8^{\prime} \mathrm{h} \times 4^{\prime} \mathrm{w}$ and $490 \mathrm{lb}$.

- In the finite difference calculation, a $1 \mathrm{msec}$ time step is used for the time period before ambient pressure is reached. After that, a larger time step is used.

The roll-up door is $8 \mathrm{ft}$ away from the module and the bottom of the east flapper door is 4 in. above the ground. As the flapper door travels horizontally, it will also drop in height due to gravity. There are many ways the flapper door could have traveled. For example, it could have rotated and translated at the same time, or it could have hit the ground and bounced. For the purpose of this calculation, elevation drops of the center-of-mass of the flapper door ranging from $3 \mathrm{in}$. to $5 \mathrm{in}$. at the roll-up door are considered. The elevation drop, $\Delta \mathrm{H}$, was used to estimate the time of flight.

$$
\begin{aligned}
& \Delta \mathrm{H}=1 / 2 \mathrm{~g} \mathrm{t}^{2} \\
& \mathrm{t}=(2 \Delta \mathrm{H} / \mathrm{g})^{1 / 2}
\end{aligned}
$$

Substituting in Eq. (9):

$$
\begin{array}{ll}
\Delta \mathrm{H}=5 \mathrm{in} . & \mathrm{t}=0.161 \mathrm{sec} \\
\Delta \mathrm{H}=4 \mathrm{in} . & \mathrm{t}=0.144 \mathrm{sec} \\
\Delta \mathrm{H}=3 \text { in. } & \mathrm{t}=0.125 \mathrm{sec}
\end{array}
$$

During the time of flight, the east flapper door would have traveled $8 \mathrm{ft}$ to hit the roll-up door. Thus, the calculated results can be used to determine the peak quasi-static pressure corresponding to each of the above elevation drops. For example, in order to determine the peak quasi-static pressure that will lead to an elevation drop of 4 in., a series of calculations with various peak quasi-static pressures were performed. The results show that for $\mathrm{P}_{\mathrm{qs}}=33 \mathrm{psig}$, the flapper door travels $8.09 \mathrm{ft}$ in $0.144 \mathrm{sec}$, which corresponds to an elevation drop of 4 in. The calculated results are summarized below:

$$
\begin{array}{llll}
\Delta \mathrm{H}=5 \text { in. } & \mathrm{t}=0.161 \mathrm{sec} & \mathrm{D}=8.05 \mathrm{ft} & \mathrm{P}_{\mathrm{qs}}=29 \mathrm{psig} \\
\Delta \mathrm{H}=4 \text { in. } & \mathrm{t}=0.144 \mathrm{sec} & \mathrm{D}=8.09 \mathrm{ft} & \mathrm{P}_{\mathrm{qs}}=33 \mathrm{psig} \\
\Delta \mathrm{H}=3 \text { in. } & \mathrm{t}=0.125 \mathrm{sec} & \mathrm{D}=7.95 \mathrm{ft} & \mathrm{P}_{\mathrm{qs}}=38 \mathrm{psig}
\end{array}
$$

As can be seen, the peak quasi-static pressure is uncertain within a wide range depending on the actual drop in elevation and the path traveled. It is nonconservative to assume that the peak chamber pressure is applied to the flapper door across its entire trajectory. 
However, there are many uncertainties in this calculation. Since there is no video data to show the path traveled by the flapper door, FANTM Event \#3 is only used to provide some qualitative conjectures about the peak quasi-static pressure. In all three cases, the pressure reduces to ambient pressure in about 10 msec.

The spread sheets for the three calculations (for $\mathrm{P}_{\mathrm{qs}}=29,33,38 \mathrm{psig}$ ) are provided on the pages to follow. Each calculation includes 2 pages. Explanations to assist with reading the spread sheets are given below:

1. I, h, w, M, W, A, A-max, \#n stand for the door moment of inertia, the door height, the door width, the door mass, the door weight, the door vent area, the door maximum vent area, and the door type identification number (\#)/associated number of doors of that type (n), respectively.

2. The door type identification numbers are as follows:

\#1: west flapper door $\left(1^{\prime} \times 3^{\prime}\right)$

\#2: reserved for calculations in Appendix A.5

\#3: reserved for calculations in Appendix A.5

\#4: east flapper door ( $\left.1^{\prime} \times 3^{\prime}\right)$

\#5: central doors $\left(4^{\prime} \times 8^{\prime}\right)$

3. A-o is the fixed vent area, $\mathrm{V}$ is the free space of the module, $\mathrm{P}_{\mathrm{o}}$ is the ambient pressure, Torque-P is the torque due to the pressure, Torque- $\mathrm{G}$ is the torque due to gravity, and mu-k is the kinetic friction coefficient.

4. The vent area provided by each door should be less than the door's maximum vent area.

5. If the number of doors for a given door identification number is set to zero, the results for that type of door can be ignored. For example when $\mathrm{n} 2=0$, the results corresponding to a Type \#2 door can be ignored. In this appendix, n2 and $\mathrm{n} 3$ are set to zero (used in Appendix A.5). However, the two central doors are modeled in a similar fashion, and so, $\mathrm{n} 5$ is set to 2 .

6. The maximal angle displacement is truncated at $180^{\circ}$.

7. The row highlighted in bold identifies the point in time when the east flapper door has traveled approximately $8 \mathrm{ft}$. 
Appendix A4

Event \#3, Pqs $=29$ psig

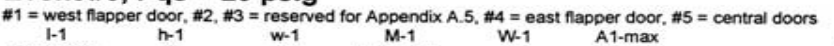

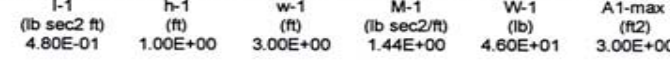

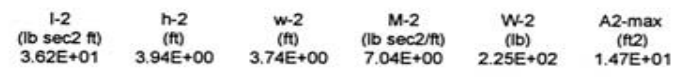

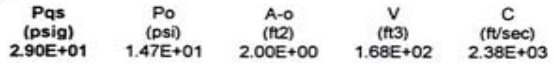

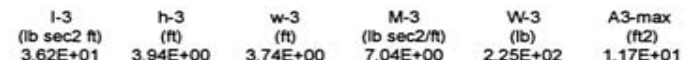

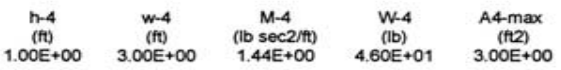

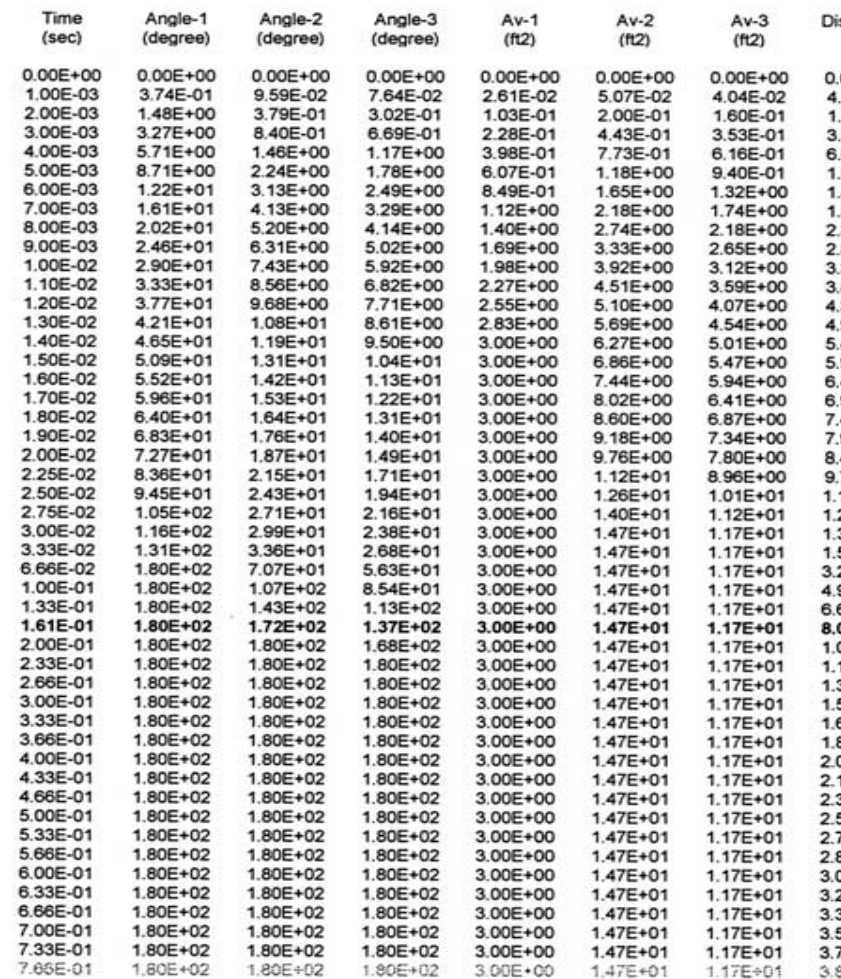

$\begin{array}{lllll}1.00 E+00 & 0.00 E+00 & 0.00 E+\infty 0 & 1.00 E+00 & 2.00 E+00\end{array}$

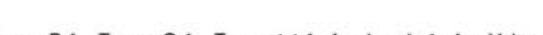

Distance-4 Av-4 Distance-5 Av-5 P1- Po

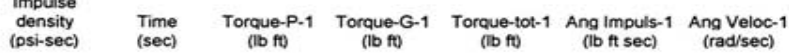

\begin{tabular}{|c|c|}
\hline 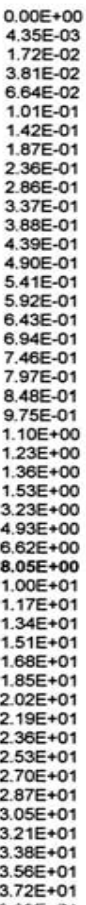 & 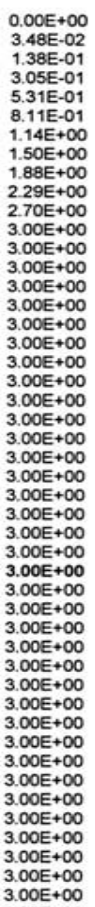 \\
\hline
\end{tabular}

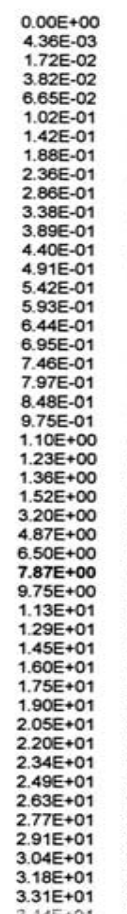

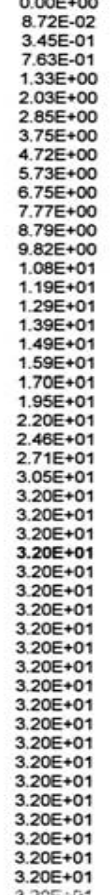

$2.90 \mathrm{E}+01$
$2.76 \mathrm{E}+01$

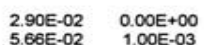

$6.26 \mathrm{E}+03 \quad 0.00 \mathrm{E}+00$

5

$5.26 E+03$
$5.60 E+03$
$5.10 E+03$
$4.47 E+03$
5

$1.31 \mathrm{E}+0$
$2.55 \mathrm{E}+01$

1

(1)

$\begin{array}{lll}3.00 E-03 & 5.11 E+03 & -1.31 E++0 \\ 4.00-03 & 4.47++03 & -2.29++0 \\ 5.00 E-03 & 3.70 E+03 & -3.48 E+00 \\ 7.00 E & 4\end{array}$

\begin{tabular}{ccc}
$6.00 \mathrm{E}-03$ & $2.82 \mathrm{E}+03$ & $-4.86 \mathrm{E}+\infty$ \\
$7.00 \mathrm{E}-03$ & $1.88 \mathrm{E}+03$ & $-6.37 \mathrm{E}+\infty$ \\
\hline & 0.00
\end{tabular}

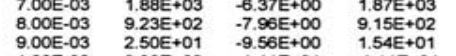

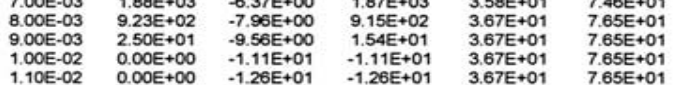

$\begin{array}{lllllll}1.20 E-02 & 0.00 E+\infty 0 & -1.41 E+01 & -1.46 E+01 & 3.67 E+01 & 7.65 E+01 \\ 1.61 E+01 & 3.67 E+01 & 7.64 E+01\end{array}$

$0.00 E+\infty$

$0.00 \mathrm{E}+\infty$
$0.00 \mathrm{E}+\infty$
$0.00 \mathrm{E}+\infty$

$1.70 E-01$
$1.70 E-01$
$1.70 E-01$

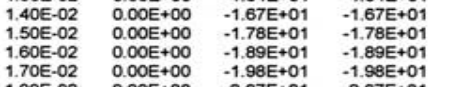

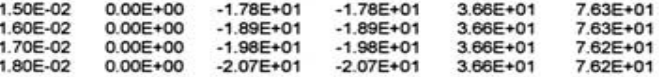

$0.00 E+00$
$0.00 E+00$
$0.000+00$

$1,7.7 E-01$
$1,70 E-01$
$1,70 E-01$

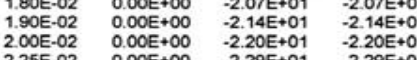

$\begin{array}{lll}2.25 E-02 & 0.00 E++00 & -2.29 E++1 \\ 250 E-02 & 0.00 E+00 & -2.29 E+01 \\ 275 E-02 & 0.00 E & -2.00\end{array}$

$0.00 \mathrm{E}+00$
$0.00 \mathrm{E}+00$
$0.00 \mathrm{E}+00$

$1,70 E-01$
$1.70 E-01$
$1.70 E-01$

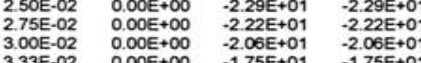

$\begin{array}{lll}3.33 E-02 & 0.00 E+\infty & -1.75 E+11 \\ 6.66 E-02 & 0.00 E+\infty & -2.15 E-06 \\ 1.00 E-01 & 0.00 E+\infty & -2.15 E-06\end{array}$

$\begin{array}{llll}1.33 E-01 & 0.00 E+00 & -2.15 E-06 & -2.15 E-00 \\ 1.20 E & -2.15 E-06\end{array}$

$\begin{array}{llll}1.61 E-01 & 0.00 E+\infty 0 & -2.15 E-06 & -2.15 E-06 \\ 2.00-01 & 0.00+00 & -2.15 E-06 & -2.15-06 \\ 2.33-01 & 0.00+00 & -15 E-06 & -215-06\end{array}$

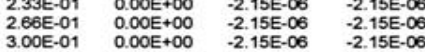

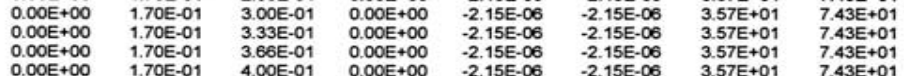

$0.00 E+00$
$0.00 E+00$
$0.00 E+00$

$0.00 E+\infty 0$
$0.00 E+00$
$0.00 E+00$
$0.00 E+00$

$1.70 E-01$
$1.70 E-01$

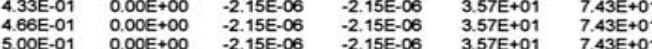

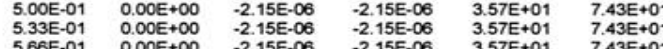

$\begin{array}{llllll}5.66 E-01 & 0.006++00 & -2.15 E-06 & -2.15 E-06 & 3.57 E+01 & 7.43 E+01 \\ 6.00 E-01 & 0.00 E+\infty 0 & -2.15 E-06 & -2.15 E-06 & 3.57 E+01 & 7.43 E+0\end{array}$

$0.00 E+\infty 0$
$0.00 E++0$
$0.00 E++00$

$1.70 \mathrm{E}-01$

$\begin{array}{llll}0.06 E-01 & 0.00 E+00 & -2.15 E-06 & -2.15 E-06 \\ .00 E-01 & 0.00 E+00 & -2.15 E-06 & -2.15 E-06 \\ 7 & 0.06 & \end{array}$

$\begin{array}{llllll}7.33 E-01 & 0.00 E+\infty 0 & -2.15 E-06 & -2.215 E-06 & 3.57 E+01 & 7.43 E+01 \\ 7.06 E-01 & 0.00 E+00 & -2.15 E-06 & -2.15 E-06 & 3.57 E+01 & 7.43 E+01 \\ 7 & -2.15 E-06 & -2.15 E-06 & 3.57 E+01 & 7.43 E+01\end{array}$ 


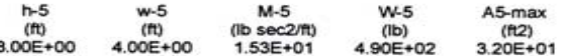

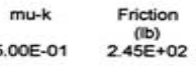

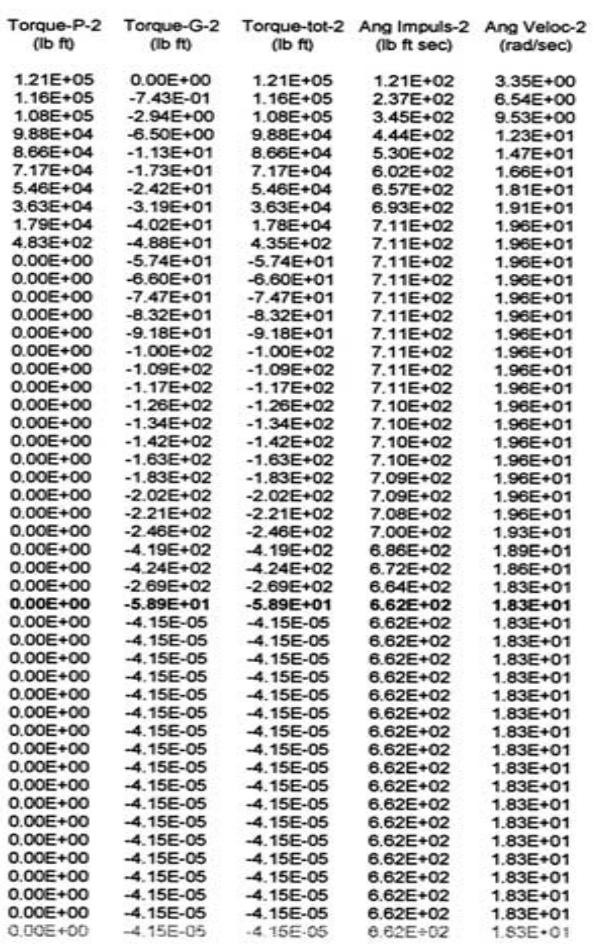

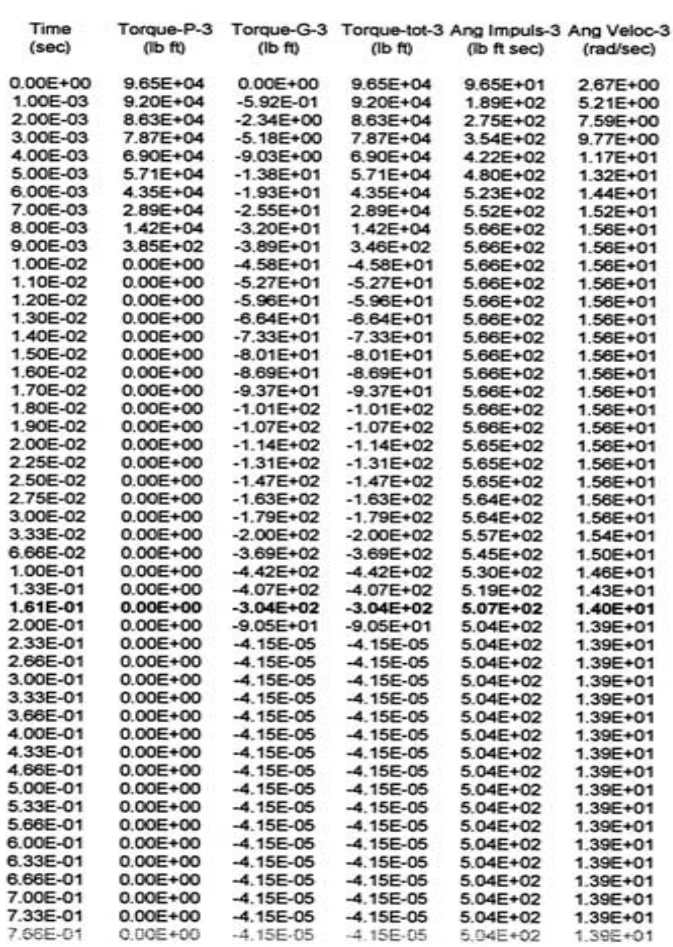

\begin{tabular}{|c|c|c|c|c|c|}
\hline $\begin{array}{l}\text { orces-4 } \\
\text { (ib) }\end{array}$ & $\begin{array}{c}\text { Impulse-4 } \\
\text { (ib-sec) }\end{array}$ & $\begin{array}{l}\text { Veloc-4 } \\
\text { (ft/sec) }\end{array}$ & $\begin{array}{l}\text { Force-5 } \\
\text { (b) }\end{array}$ & $\begin{array}{c}\text { Impulse-5 } \\
\text { (1b-sec) }\end{array}$ & $\begin{array}{l}\text { Veloca-5 } \\
\text { (tt/sec) }\end{array}$ \\
\hline 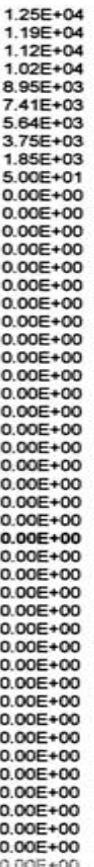 & 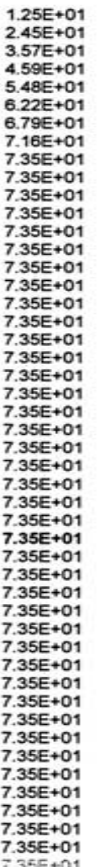 & 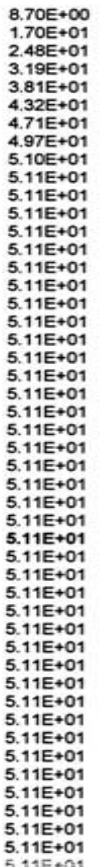 & 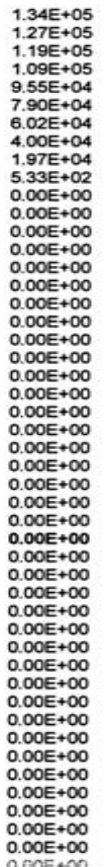 & 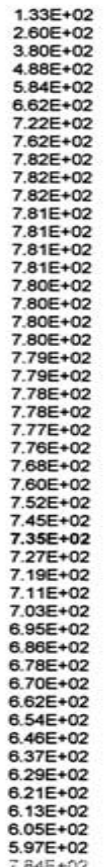 & 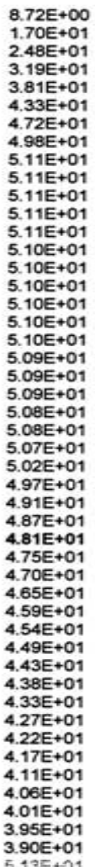 \\
\hline
\end{tabular}


Appendix A4

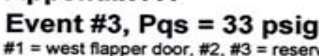

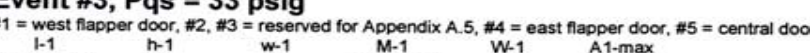

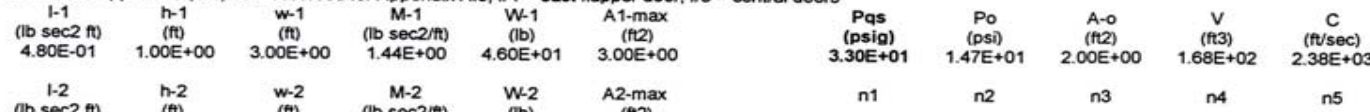

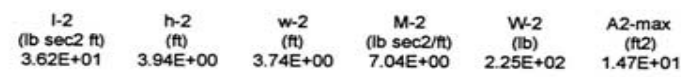

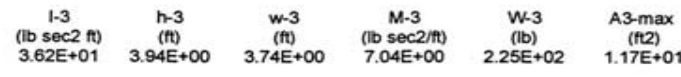

$\begin{array}{lllll}1.00 E+00 & 0.00 E+00 & 0.00 E+00 & 1.00 E+00 & 2.00 E+00\end{array}$

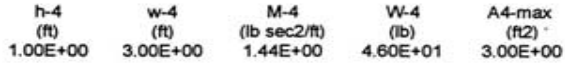

$\begin{array}{llllll}\mathrm{T}_{\text {Time }} & \begin{array}{l}\text { Angle-1 } \\ \text { (sec) }\end{array} & \begin{array}{l}\text { Angle-2 } \\ \text { (degree) }\end{array} & \begin{array}{l}\text { Angle-3 } \\ \text { (degree) }\end{array} & \begin{array}{l}\text { Av-1 } \\ \text { (ft2) }\end{array} & \begin{array}{l}\text { Av-2 } \\ \text { (ft2) }\end{array}\end{array}$

Av-3
(ft2)

Distance-4 Av-4
(ft)

$\underset{\text { Distance-5 }}{\text { Ant }}{ }_{(\mathrm{f}-5)}$

P1. Po
(psi) $\begin{gathered}\text { denonise } \\ \text { (osityec) }\end{gathered}$

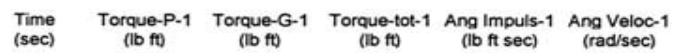

.

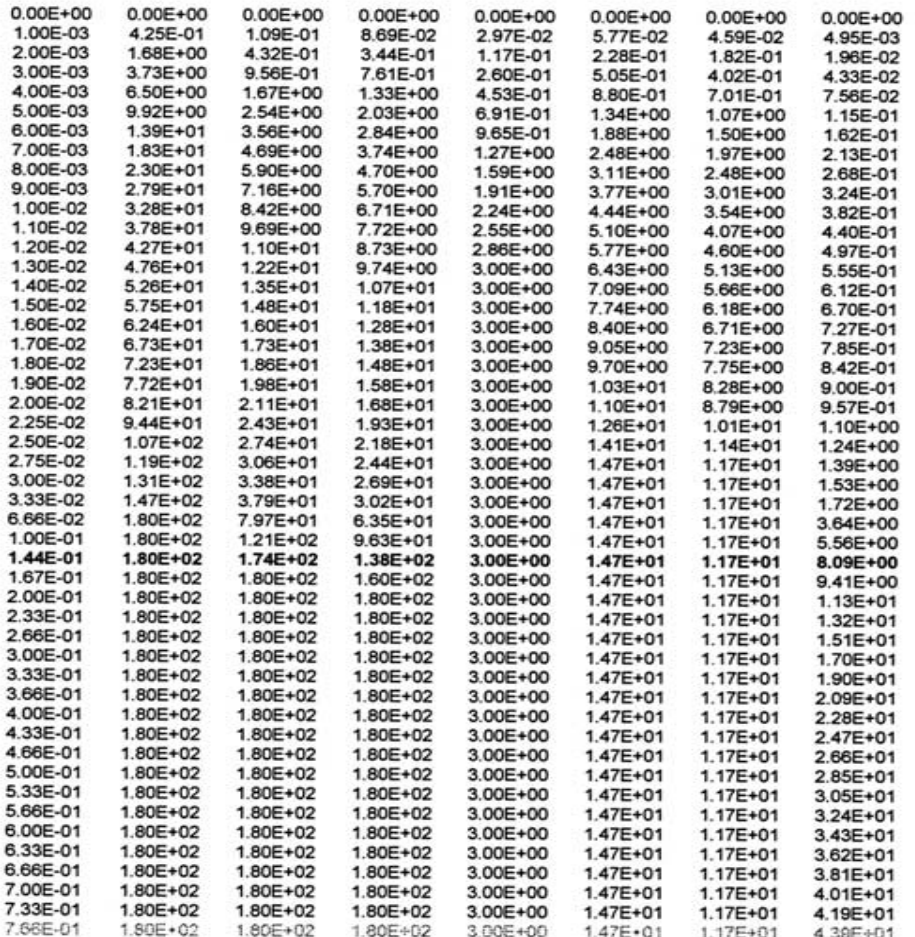

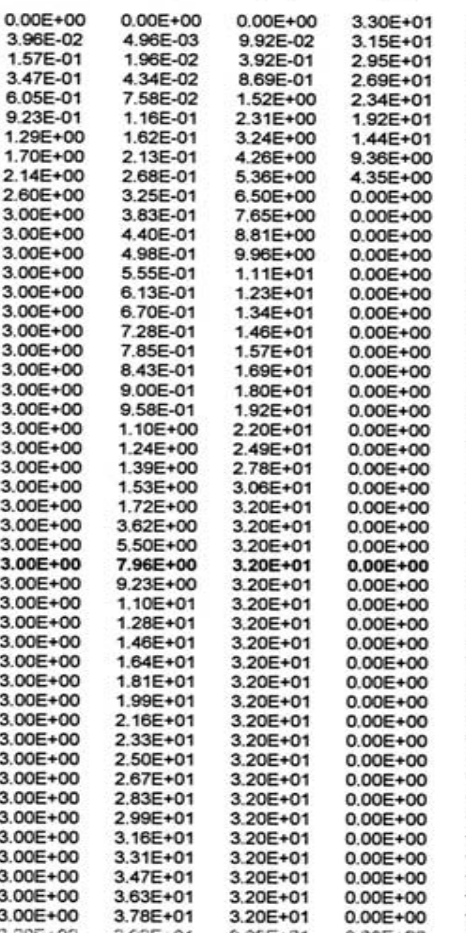

$3.30 E-02$
$6.45 E-02$
$9.400-02$
$1.21 E-01$
$1.44 E-01$
$1.64 E-01$
$1.78 E-01$
$1.87 E-01$
$1.92 E-01$
$1.92 E-01$
$1.92 E-01$
$1.92 E-01$
$1.92 E-01$
$1.92 E-01$
$1.92 E-01$
$1.92 E-01$
$1.92 E-01$
$1.92 E-01$
$1.92 E-01$
$1.92 E-01$
$1.92 E-01$
$1.92 E-01$
$1.92 E-01$
$1.92 E-01$
$1.92 E-01$
$1.92 E-01$
$1.92 E-01$
$1.92 E-01$
$1.92 E-01$
$1.92 E-01$
$1.92 E-01$
$1.92 E-01$
$1.92 E-01$
$1.92 E-01$
$1.92 E-01$
$1.92 E-01$
$1.92 E-01$
$1.92 E-01$
$1.92 E-01$
$1.92 E-01$
$1.92 E-01$
$1.92 E-01$
$1.92 E-01$
$1.92 E-01$
$1.92 E-01$
$1.92 E-01$
$1.92 E-01$
1.925

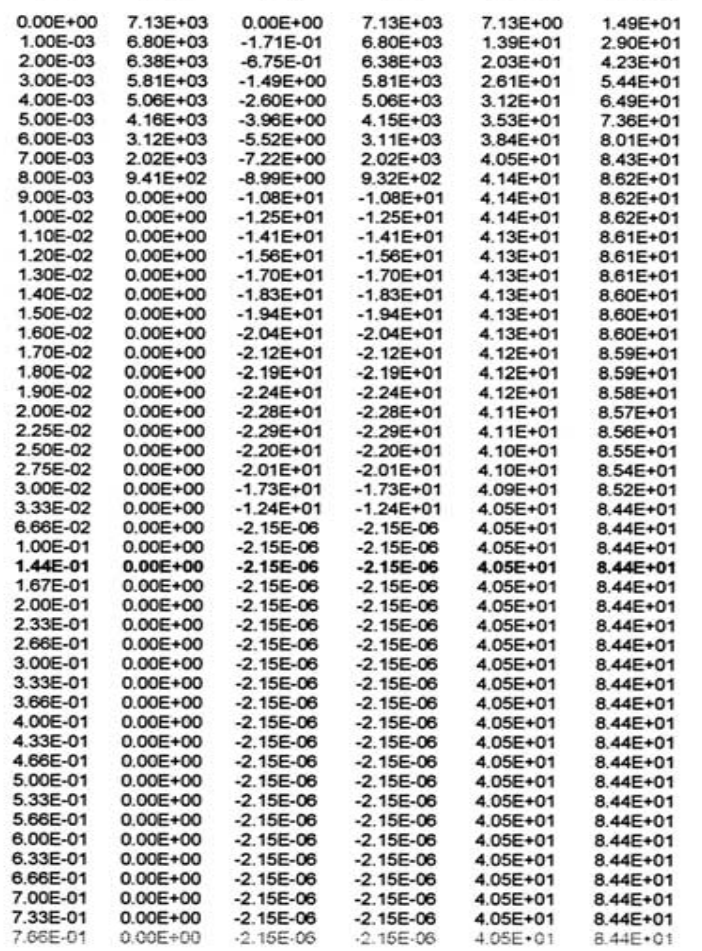




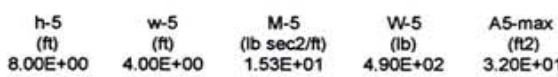

mu-k Friction

5.00E-01 $2.45 E+02$

\begin{tabular}{|c|c|c|c|c|}
\hline $\begin{array}{l}\text { rque- } P-2 \\
\text { (ib fit) }\end{array}$ & $\begin{array}{l}\text { Torque-G-2 } \\
(\mathrm{ib} \text { fit) }\end{array}$ & $\begin{array}{l}\text { Torque-tot-2 } \\
\text { (ib fit) }\end{array}$ & $\begin{array}{c}\text { Ang Impuls-2 } \\
(\mathrm{lb} f t \mathrm{sec})\end{array}$ & $\begin{array}{l}\text { loc-2 } \\
\text { sec) }\end{array}$ \\
\hline $38 E+C$ & & 1.38 & 12 & $3.81 E+00$ \\
\hline $3 \mathrm{~F}+0$ & & & & \\
\hline $\begin{array}{l}E+C \\
E+C\end{array}$ & -3 & & 2 & \\
\hline$E+05$ & & & & \\
\hline+04 & 11 & & & \\
\hline & $-2.76 \mathrm{E}+01$ & & & \\
\hline & $\begin{array}{l}-2.160 \\
-3.63 E\end{array}$ & & & \\
\hline & $-4.56 \mathrm{E}$ & & & \\
\hline & & & & \\
\hline & & & & \\
\hline & & & & \\
\hline & & & & \\
\hline & & & & \\
\hline & & & & \\
\hline & -1.23 & & & \\
\hline & $-1.32 \mathrm{E}$ & & & \\
\hline & & & & \\
\hline $\begin{array}{l}O E+C \\
O E+C\end{array}$ & $\begin{array}{l}-1.51 \mathrm{E} \\
-1.602\end{array}$ & & 8.00 & \\
\hline & $\begin{array}{l}-1.60 E+02 \\
-1.82 E+02\end{array}$ & & $\begin{array}{l}8.9 \\
7.9\end{array}$ & \\
\hline & $-2.04 \mathrm{E}+02$ & & & \\
\hline & -2 & -2.26 & 7.988 & \\
\hline & & & & \\
\hline & $\begin{array}{l}-2.73 \mathrm{E} \\
-2.73\end{array}$ & & 7.88 & \\
\hline & & & & \\
\hline $00 E+0$ & $\begin{array}{l}-3.80 \mathrm{E}+ \\
-4.40 \mathrm{E}\end{array}$ & $\begin{array}{r}-3.80 E \\
-4.40 E\end{array}$ & & \\
\hline+0 & $\begin{array}{l}-4.40+0101 \\
-4.15 \mathrm{E}-05\end{array}$ & $\begin{array}{l}-4.40 \mathrm{E}+01+01 \\
-4.15-05\end{array}$ & $\begin{array}{l}7.566 \mathrm{t} \\
7.56 \mathrm{~s}\end{array}$ & \\
\hline 0.0 & -4 & & & \\
\hline $\begin{array}{l}0.0 \\
0.0\end{array}$ & -4 & $\begin{array}{r}-4.15 \\
-415\end{array}$ & $\begin{array}{l}7.56 \mathrm{E} \\
7.56 \mathrm{E}\end{array}$ & 01 \\
\hline . & $\begin{array}{l}-4.15 \mathrm{E} \\
-4.15 \mathrm{E}\end{array}$ & $\begin{array}{r}-4.1 \\
-4.1\end{array}$ & $\begin{array}{l}7.56 \mathrm{E} \\
7.56 \mathrm{E}\end{array}$ & \\
\hline . & & & & \\
\hline 0. & E-05 & $\begin{array}{l}-4.15 E-05 \\
-15=-05\end{array}$ & $\begin{array}{l}7.568 \\
7.568\end{array}$ & 01 \\
\hline $\begin{array}{l}=0 \\
= \pm 0\end{array}$ & -4 & $\begin{array}{r}-4.155 \\
-4.15\end{array}$ & & \\
\hline 0.00 & & & & \\
\hline . & 05 & -4.15 & & \\
\hline 0. & $\begin{array}{l}-4.45 \mathrm{E}-05 \\
-4.15 \mathrm{E}-05\end{array}$ & $\begin{array}{l}-4.15 \\
-4.15\end{array}$ & $\begin{array}{l}7.566 \mathrm{E} \\
7.56 \mathrm{E}\end{array}$ & \\
\hline & & & & \\
\hline & $\begin{array}{l}-4.15 \mathrm{E} \\
-4.15 \mathrm{E}\end{array}$ & $\begin{array}{l}-4.15 \\
-4.15\end{array}$ & $\begin{array}{l}7.56 \mathrm{E} \\
7.56 \mathrm{E}\end{array}$ & \\
\hline 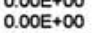 & $-4.15 \mathrm{E}$ & $\begin{array}{l}-4.156 \\
-4.15\end{array}$ & $7.56 \mathrm{E}$ & \\
\hline & & & & \\
\hline & & & & \\
\hline
\end{tabular}

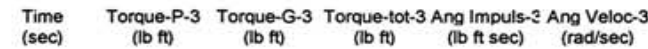

$\begin{array}{llllll}0.00 E+00 & 1.10 E+05 & 0.00 E+00 & 1.10 E+05 & 1.10 E+02 & 3.03 E+00\end{array}$ $\begin{array}{lllllll}1.00 E-03 & 1.05 E+05 & -6.73 E-01 & 1.05 E+05 & 2.15 E+02 & 5.93 E+00 \\ 2.00 E-03 & 9.83 E+04 & -2.66 E+00 & 9.83 E+04 & 3.13 E+02 & 8.65 E+00\end{array}$

$\begin{array}{llllll}3.00 E-03 & 8.95 E+04 & -5.90 E+00 & 8.95 E+04 & 4.02 E+02 & 1.11 E+01 \\ 4.00 E-03 & 7.80 E+04 & -1.03 E+01 & 7.80 E+04 & 4.81 E+02 & 1.33 E+01\end{array}$

$\begin{array}{lllllll}5.00 E-03 & 6.40 E+04 & -1.57 E+01 & 6.40 E+04 & 5.45 E+02 & 1.50 E+01\end{array}$

$\begin{array}{lllllll}6.00 E-03 & 4.81 E+04 & -2.20 E+01 & 4.81 E+04 & 5.93 E+02 & 1.64 E+01 \\ 7.00 & -2.89 E+01 & 3.11 E+04 & 6.24 E+022 & 1.72 E+01\end{array}$

$\begin{array}{lllllll}9.00 E-03 & 1.45 E+04 & -3.64 E+01 & 1.45 E+04 & 6.38 E+02 & 1.76 E+0 \\ 0.00 E+00 & -4.41 E+01 & -4.41 E+01 & 6.38 E+02 & 1.76 E+00\end{array}$

$\begin{array}{llllll}1.00 \mathrm{E}-02 & 0.00 \mathrm{E}+00 & -5.19 \mathrm{E}+01 & -5.19 \mathrm{E}+01 & 6.38 \mathrm{E}+02 & 1.76 \mathrm{E}+01 \\ 1.10 \mathrm{E}-02 & 0.00 \mathrm{E}+00 & -5.96 \mathrm{E}+01 & -5.96 \mathrm{E}+01 & 6.38 \mathrm{E}+02 & 1.76 \mathrm{E}+01\end{array}$

$\begin{array}{llllll}1.20 E-02 & 0.00 E+00 & -6.74 \mathrm{E}+01 & -6.74 \mathrm{E}+01 & 6.38 \mathrm{E}+02 & 1.76 \mathrm{E}+01\end{array}$

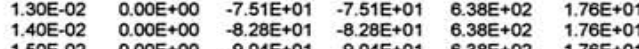

$\begin{array}{llllll}1.60 E-02 & 0.00 E+00 & -9.81 E+01 & -9.81 E+01 & 6.38 E+02 & 1.76 E+01\end{array}$

$\begin{array}{llllll}1.70 E-02 & 0.00 E+00 & -1.06 E+02 & -1.06 E+02 & 6.38 E+02 & 1.76 E+01 \\ 1.80 E-02 & 0.00 E+00 & -1.13 E+02 & -1.13 E+02 & 6.37 E+02 & 1.76 E+01\end{array}$

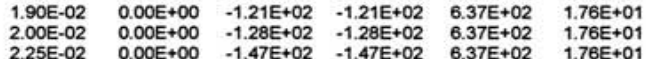

$\begin{array}{llllll}2.25 \mathrm{E}-02 & 0.00 \mathrm{E}+00 & -1.47 \mathrm{E}+02 & -1.47 \mathrm{E}+02 & 6.37 \mathrm{E}+02 & 1.76 \mathrm{E}+01 \\ 2.50 \mathrm{E}-02 & 0.00 \mathrm{E}+00 & -1.65 \mathrm{E}+02 & -1.65 \mathrm{E}+02 & 6.36 \mathrm{E}+02 & 1.76 \mathrm{E}+01\end{array}$

$\begin{array}{lllllll}2.75 E-02 & 0.00 E+00 & -1.83 E+02 & -1.83 E+02 & 6.36 E+02 & 1.76 E+01 \\ 3.00 E-02 & 0.00 E+00 & -2.01 E+02 & -2.01 E+02 & 6.35 E+02 & 1.75 E+01\end{array}$

$\begin{array}{llllll}3.33 \mathrm{E}-02 & 0.00 \mathrm{E}+00 & -2.23 \mathrm{E}+02 & -2.23 \mathrm{E}+02 & 6.28 \mathrm{E}+02 & 1.73 \mathrm{E}+01 \\ 6.66 \mathrm{E}-02 & 0.00 \mathrm{E}+00 & -3.97 \mathrm{E}+02 & -3.97 \mathrm{E}+02 & 6.14 \mathrm{E}+02 & 1.70 \mathrm{E}+01\end{array}$

$\begin{array}{llllll}1.00 E-01 & 0.00 E+00 & -4.41 E+02 & -4.41 E+02 & 5.95 E+02 & 1.64 E+01 \\ 1.44 E-01 & 0.00 E+00 & -2.95 E+02 & -2.95 E+02 & 588 E+02 & 1.62 E+01\end{array}$

$\begin{array}{llllll}1.44 E-01 & 0.00 E+00 & -2.95 E++2 & -2.95 E+02 & 5.88 E+02 & 1.62 E+01 \\ 1.67 E-01 & 0.00 E++00 & -1.52 E+02 & -1.52 E+02 & 5.83 E+02 & 1.61 E+01\end{array}$

$\begin{array}{lllllll}2.33 E-01 & 0.00 E+\infty & -4.15 E-05 & -4.15 E-05 & 5.83 E+02 & 1.61 E+01\end{array}$

$\begin{array}{llllll}2.66 E-01 & 0.00 E+\infty 0 & -4.15 E-05 & -4.15 E-05 & 5.83 E+02 & 1.61 E+01\end{array}$

$-4.15 E-05 \quad 5.83 E+02 \quad 1.61 E+01$

$\begin{array}{llllll}3.66 E-01 & 0.00 E+00 & -4.15 E-05 & -4.15 E-05 & 5.83 E+02 & 1.61 E+01 \\ 4.00 E-01 & 0.00 E+00 & -4.15 E-05 & -4.15 E-05 & 5.83 E+02 & 1.61 E+01 \\ 4.33 E-01 & 0.00 E++0 & -4.15 E-05 & -4.15 E-05 & 5.83 E+022 & 1.61 E+01\end{array}$

$\begin{array}{lllllll}4.66 \mathrm{E}-01 & 0.00 \mathrm{E}+00 & -4.15 \mathrm{E}-05 & -4.15 \mathrm{E}-05 & 5.83 \mathrm{E}+02 & 1.61 \mathrm{E}+01\end{array}$

$\begin{array}{lllllll}5.00 E-01 & 0.00 E+00 & -4.15 E-05 & -4.15 E-05 & 5.83 E+02 & 1.61 E+01 \\ 5.33 E-01 & 0.00 E+00 & -4.15 E-05 & -4.15 E-05 & 5.83 E+02 & 1.61 E+01\end{array}$

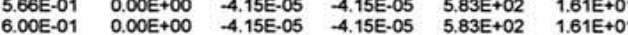

$\begin{array}{llllll}6.33 E-01 & 0.00 E+00 & -4.15 E-05 & -4.15 E-05 & 5.83 E+02 & 1.61 E+01\end{array}$

$\begin{array}{lllllll}7.00 E-01 & 0.00 E+00 & -4.15 E-05 & -4.15 E-05 & 5.83 E+02 & 1.61 E+01 \\ 7.00 E & -4.15 E-05 & -4.15 E-05 & 5.83 E+02 & 1.61 E+01\end{array}$

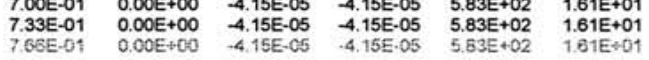

\begin{tabular}{|c|c|c|c|c|c|}
\hline (ID) & $(10-5 e$ & $\begin{array}{l}\text { lloc- } \\
\text { sect } \\
\text { (sec) }\end{array}$ & $\begin{array}{l}\text { Force-5 } \\
\text { (b) }\end{array}$ & e) & $\mathrm{sec})$ \\
\hline & $33 E+$ & 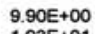 & 05 & 1.52 & $=$ \\
\hline & ${ }_{4}^{2}$ & & & & \\
\hline & $22 \mathrm{E}$ & & & & \\
\hline & 11 & b1 & & 02 & \\
\hline & & & & & \\
\hline 3 & $\begin{array}{l}7.6 \\
8\end{array}$ & b1 & & & \\
\hline 3 & 21 & 01 & & & \\
\hline & & & & & \\
\hline D & & & & & \\
\hline & $\begin{array}{l}8.2 \\
8 .\end{array}$ & & & & \\
\hline & & & & & \\
\hline p & & & & & \\
\hline & & & & & \\
\hline & & & & & \\
\hline & & & & & \\
\hline & & & & & \\
\hline & & & & & \\
\hline & & & & & \\
\hline & & & & & \\
\hline & & & & & \\
\hline & & & & & \\
\hline & & & & & \\
\hline & & & & & \\
\hline & & & & & \\
\hline & & & & & \\
\hline & & & & & \\
\hline & & & & & \\
\hline & & & & & \\
\hline & & & & & \\
\hline & & & & & \\
\hline & & & & & \\
\hline & & & & & \\
\hline & & & & & \\
\hline & & & & & \\
\hline & & & & & \\
\hline & & & & & \\
\hline & & & & & \\
\hline & & & & & \\
\hline & & & & & \\
\hline & & & & & \\
\hline
\end{tabular}




\section{Appendix A4}

Event \#3, Pqs $=38$ psig

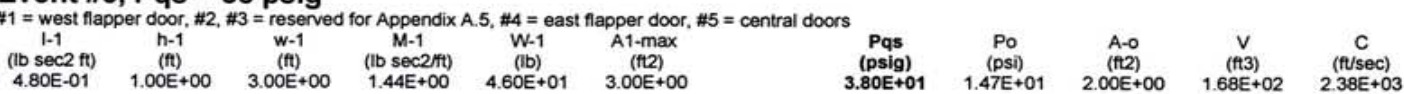

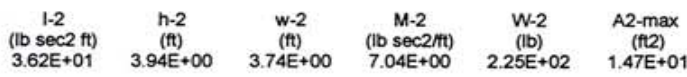

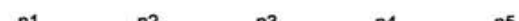

$\begin{array}{lllll}1.00 E+00 & 0.00 E+00 & 0.00 E+00 & 1.00 E+00 & 2.00 E+00\end{array}$

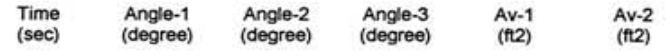

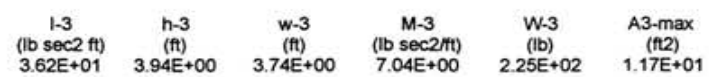

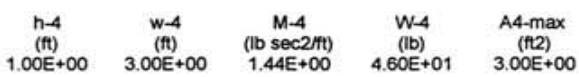

\begin{tabular}{|c|c|c|c|c|c|c|c|c|c|c|c|}
\hline & & & & & & & & & & & \\
\hline & & & & & & & & & & & \\
\hline $10 E-03$ & $7.48 \mathrm{E}+00$ & $2 E+C$ & $\begin{array}{l}8.777-01 \\
1.53 E++0\end{array}$ & $\begin{array}{l}0 E-01 \\
0 E-01 \\
2 E\end{array}$ & $\begin{array}{ll}2=-t \\
1\end{array}$ & 4.63E-01 & $9 E-02$ & DEe-01 & $01 E-02$ & $1.00 \mathrm{E}+\infty 0$ & $3.096+01$ \\
\hline & & $\mathrm{EE}+00$ & 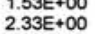 & $\begin{array}{l}5.22 \mathrm{E}-01 \\
7.95-01\end{array}$ & $\begin{array}{l}1.011 \mathrm{E}++00 \\
1.55 \mathrm{E}+0\end{array}$ & $\begin{array}{l}8.08 E-01 \\
1.23 E+00\end{array}$ & $\begin{array}{l}8.71-02-02 \\
133 E-01\end{array}$ & $\begin{array}{l}6.977-01 \\
106 \mathrm{E}+00\end{array}$ & $\begin{array}{l}8.73 \mathrm{E}-02 \\
133 \mathrm{E}-01\end{array}$ & $\begin{array}{l}5 E+00 \\
6 E+\infty\end{array}$ & $\begin{array}{ll}77 E+01 \\
17 F+01\end{array}$ \\
\hline & $0=01$ & 4.10E+ +00 & $3.26 \mathrm{E}+\infty 0$ & $1.11 \mathrm{E}+00$ & $2.16 \mathrm{E}+00$ & $1.72 E+\infty 0$ & $\begin{array}{l}1.33 E=01 \\
1.86 E-01\end{array}$ & . & $\begin{array}{l}01 \\
01\end{array}$ & $\begin{array}{l}00 \\
00 \\
00\end{array}$ & $\begin{array}{l}E+01 \\
E+01 \\
E+01\end{array}$ \\
\hline$E-03$ & $2.10 \mathrm{E}+01$ & $5.39 \mathrm{E}+\infty 0$ & $4.30 \mathrm{E}+00$ & $5 E+00$ & $2.85 \mathrm{E}+00$ & $2.27 \mathrm{E}+00$ & $2.45 E-01$ & $1.96 \mathrm{E}+\infty 0$ & $2.45 E-01$ & 央 & $\begin{array}{l}1.60 \mathrm{E}+01 \\
1.00 \mathrm{E}+01\end{array}$ \\
\hline OE- & $2.64 \mathrm{E}+01$ & $6.77 \mathrm{E}+\infty 0$ & $5.39 \mathrm{E}+\infty$ & $1.81 E+00$ & $3.57 \mathrm{E}+00$ & $2.85 \mathrm{E}+00$ & 3.07E-01 & $2.46 E+00$ & 3.08E-01 & $\infty$ & $4.28 E+00$ \\
\hline OE. & 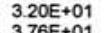 & $8.20 E+\infty 0$ & $6.53 \mathrm{E}+\infty$ & 2. & 4.3 & $3.44 E+00$ & 3.72E-01 & $2.97 \mathrm{E}+\infty 0$ & $3.73 E-01$ & $7.45 \mathrm{E}+00$ & $O E+\infty$ \\
\hline OE & $3.76 \mathrm{E}+01$ & $9.64 \mathrm{E}+\infty 0$ & & & & & & & & & \\
\hline$E-$ & $\begin{array}{l}4.322+01 \\
4.88 E+01\end{array}$ & $\begin{array}{l}1.11 \mathrm{E}+01 \\
1.25 \mathrm{E}+01\end{array}$ & $8.833++00$ & $\begin{array}{l}2.89 \mathrm{E} E+00 \\
3.00 \mathrm{E}+00\end{array}$ & $\begin{array}{l}5.83 \\
6.58\end{array}$ & $\begin{array}{l}4.65 \mathrm{E} \\
5.52 \mathrm{E}\end{array}$ & .03E-01 & $\begin{array}{l}3.00 E+\infty 0 \\
3.00 E+\infty\end{array}$ & $\begin{array}{l}5.04 E-01 \\
5 \text { S }\end{array}$ & 01 & 0 \\
\hline $30 E-02$ & $\begin{array}{l}4.886 \\
5.44 E\end{array}$ & 1.2 & $\begin{array}{l}9.9 .11+00 \\
1.11 E+01\end{array}$ & 20 & $\begin{array}{l}6.5 \\
7.3\end{array}$ & .00 & 001 & & $\begin{array}{l}E-01 \\
E-01\end{array}$ & & 我地 \\
\hline $1.40 \mathrm{E}-$ & $6.00 \mathrm{E}+01$ & $1.54 E+01$ & $1.23 E+01$ & $3.00 \mathrm{E}+00$ & $8.07 E+00$ & $6.45 E+\infty 0$ & 6.99E-01 & $3.00 E++00$ & $\begin{array}{l}E_{0}-01 \\
E-01\end{array}$ & 01 & 我地 \\
\hline SOE- & $6.56 \mathrm{E}+01$ & $1.68 \mathrm{E}+01$ & 1.34 & $3.00 \mathrm{E}++0$ & $8.82 \mathrm{E}+\infty$ & $7.04 \mathrm{E}$ & 7.64 & 3.00 & -01 & $=+01$ & 0 \\
\hline SOE. & 7.12E+01 & $1.83 \mathrm{E}+01$ & $1.46 \mathrm{E}+01$ & $300+\infty$ & $9.55 \mathrm{E}+00$ & & 8005 & & & & \\
\hline$O E$ & $\begin{array}{l}7.68 E+01 \\
\end{array}$ & $1.97 \mathrm{E}+01$ & $1.57 E+01$ & $3.00 E++0$ & 1.03E+01 & 8.23 & 8.9 & 3.00 & $8.96 \mathrm{E}-01$ & & $0 E+\infty$ \\
\hline & & & & & & & & & & & \\
\hline EE-C & $\begin{array}{l}8.80 E+01 \\
9.36 E+01\end{array}$ & $\begin{array}{l}2.26 E+01 \\
2.40 E+01\end{array}$ & $\begin{array}{l}1.80 E+01 \\
1.92 E+01\end{array}$ & $\begin{array}{l}3.00 E E+00 \\
3.00 E+00\end{array}$ & $\begin{array}{l}1.17 E+01 \\
1.25+01\end{array}$ & $\begin{array}{l}9.4119 \\
9.99 \xi\end{array}$ & $\begin{array}{l}1.03 E++0 \\
1.09++\infty\end{array}$ & & & & \\
\hline $5=0$ & $\begin{array}{l}.3 .36+01 \\
1.08 E+02\end{array}$ & $\begin{array}{l}\begin{array}{l}2.40 E+01 \\
2.76 E+01\end{array}\end{array}$ & $\begin{array}{l}1.92 \mathrm{E}+01 \\
2.20 \mathrm{E}+01\end{array}$ & $\begin{array}{l}3.00+00 \\
3.00 E+00\end{array}$ & $\begin{array}{l}1.25 \mathrm{E} E+1 \\
1.42+01\end{array}$ & $1.14 \mathrm{E}+01$ & $1.25 \mathrm{E}+\infty$ & $\begin{array}{l}3.00 \mathrm{E}+00 \\
3.00 \mathrm{E}+0\end{array}$ & $\begin{array}{l}1.009++00 \\
1.26 \mathrm{E}+\infty\end{array}$ & $\begin{array}{l}2.18 E+01 \\
2.51 E+01\end{array}$ & $\begin{array}{l}0.00 E+00 \\
0.00 E+\infty\end{array}$ \\
\hline & $1.21 \mathrm{E}+02$ & & & $3.000+00$ & $\begin{array}{l}1.42 E+01 \\
1.47 E+01\end{array}$ & & $\begin{array}{l}1.25 \mathrm{E}+00 \\
1.42 \mathrm{E}+0\end{array}$ & 00 & & & \\
\hline & 1.35E+02 & $3.48 E+01$ & $2.77 \mathrm{E}+01$ & $3.00 \mathrm{E}+00$ & 1.47E+01 & 1.17 & $1.58 \mathrm{E}$ & 3.0 & 1.58 & 01 & +00 \\
\hline & $1.49 E+02$ & $3.84 \mathrm{E}+01$ & $3.06 \mathrm{E}+01$ & $3.00 \mathrm{E}+00$ & $1.47 \mathrm{E}$ & & & & & & 00 \\
\hline & 1.68E+02 & 4.32E+01 & $\begin{array}{l}3.44 \mathrm{E}+01 \\
7\end{array}$ & $3.00 \mathrm{E}$ & 1.47E+01 & 1.17 & 1.96 & 3.0 & & & $0 E+\infty$ \\
\hline & & $\begin{array}{l}9.07 E+01 \\
1.38 E+01\end{array}$ & & & & & & & & & \\
\hline & $\begin{array}{l}1.800+02+02 \\
1.80 E+02\end{array}$ & $\begin{array}{l}1.38 \mathrm{E}+02 \\
1.72 \mathrm{E}+02\end{array}$ & $\begin{array}{l}1.10 E+02 \\
1.37 E+02\end{array}$ & $\begin{array}{l}3.00 E \\
3.00 E\end{array}$ & $\begin{array}{l}1.47 \\
1.47\end{array}$ & $\begin{array}{l}1.17 \\
1.17\end{array}$ & & & & & \\
\hline & $\begin{array}{l}1.80 \mathrm{EE}+02 \\
1.80 \mathrm{E}+02\end{array}$ & $\begin{array}{l}1.72 \mathrm{EE}+02 \\
1.80 \mathrm{E}+02\end{array}$ & $\begin{array}{l}1.37 \mathrm{E}+02 \\
1.80 \mathrm{E}+02\end{array}$ & $\begin{array}{l}3.00 E \\
3.00 E\end{array}$ & $\begin{array}{l}1.47 \mathrm{E}+01 \\
1.47 \mathrm{E}+01\end{array}$ & $\begin{array}{l}1.177+01 \\
1.17 \mathrm{E}+01\end{array}$ & $\begin{array}{l}7.995 E+00 \\
1.07 E+01\end{array}$ & $\begin{array}{l}3.00 \\
3.00\end{array}$ & & $\begin{array}{l}3.20 \\
3.20\end{array}$ & $\begin{array}{l}0.00 E+00 \\
0.00 E+\infty\end{array}$ \\
\hline & 年 & 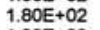 & 100 & & $1.47 \mathrm{E}$ & 1.17E+01 & & & & & $\begin{array}{l}0 \\
0 E+\infty 00 \\
0 E+00\end{array}$ \\
\hline & $0 \mathrm{E}+02$ & $30 E+02$ & $1.80 E$ & $3.00 \mathrm{E}$ & $1.47 \mathrm{E}$ & & 1.5 & & & & 0 \\
\hline & & 2 & 1.80 & & 1.47 & & & & & & \\
\hline & 1. & BOE & $1.80 \mathrm{E}$ & 3.00 & 1.47 & & & & & & .00 \\
\hline & & & 0 & & & & & & & & \\
\hline & $O E_{1}$ & & & & & & & & & & \\
\hline & $\begin{array}{l}.880 \mathrm{E}+ \\
1.80 \mathrm{E}+\end{array}$ & & $\begin{array}{l}1.80 \mathrm{E}+02 \\
1.80 \mathrm{E}+02\end{array}$ & $\begin{array}{l}3.00 E \\
3.00 E \\
3\end{array}$ & $\begin{array}{l}1.47 \\
1.47\end{array}$ & & $\begin{array}{l}1 \\
1\end{array}$ & $\begin{array}{l}3.0 \\
3.0\end{array}$ & & 01 & $+\infty$ \\
\hline & & $1.80 \mathrm{E}+02$ & $1.80 E$ & & 1.47 & & & & & & \\
\hline & 1.80E & 1. $80 \mathrm{E}$ & $1.80 \mathrm{E}$ & 3. & 1.47 & & 3.03 & & & & \\
\hline & $\mathrm{OE}+$ & $30 \mathrm{E}+02$ & $1.80 E$ & 3. & $1.47 \mathrm{E}$ & & 1 & 3.00 & & & \\
\hline & & $0 E+02$ & $1.80 E+02$ & 3. & 1.4 & & & & & & \\
\hline & 02 & $80 E$ & $1.80 \mathrm{E}$ & 3.00 & 1.47 & & 3. & & & & \\
\hline & & & & & & & & & & & \\
\hline & & & & & & & & & & & \\
\hline & & & & & & & & & $\begin{array}{r}4.18 \mathrm{E}+01 \\
436+01\end{array}$ & $\begin{array}{l}3.20 \mathrm{E}+01 \\
3.20 \mathrm{E}+01\end{array}$ & $\begin{array}{l}0.00 E+000 \\
0.00 E+00\end{array}$ \\
\hline & & & & & & & & 3.00 & 4 & $3.20=51$ & OOF FO \\
\hline
\end{tabular}

\begin{tabular}{|c|c|c|c|c|c|c|}
\hline $\begin{array}{l}\text { mpulse } \\
\text { density } \\
\text { sil-sec) }\end{array}$ & $\begin{array}{l}\text { Time } \\
\text { (sec) }\end{array}$ & $\begin{array}{c}\text { Torque-P-1 } \\
(\mathrm{lb} \mathrm{ft})\end{array}$ & $\begin{array}{c}\text { Torque-G-1 } \\
\text { (lb fit) }\end{array}$ & $\begin{array}{c}\text { orque-tot-1 } \\
(\mathrm{lb} f \mathrm{ft})\end{array}$ & $\begin{array}{l}\text { Ang Impuls-1 } \\
\text { (b f f sec) }\end{array}$ & $\begin{array}{c}\text { Ang } \\
\text { (rad }\end{array}$ \\
\hline & & & & & & \\
\hline & & $\begin{array}{l}7.8 \\
7.3\end{array}$ & & & & \\
\hline & $\begin{array}{l}0.0 E-03 \\
D O E-03\end{array}$ & & 0 & 3 & $\begin{array}{l}34 \mathrm{E} E+01 \\
01 \mathrm{E}+01\end{array}$ & \\
\hline & & & & & & \\
\hline & & & & $\begin{array}{l}3 \\
3 \\
3\end{array}$ & & \\
\hline & 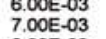 & & -8.2 & & & \\
\hline & & & & & & \\
\hline & & & & & & \\
\hline & 1. & & & & & \\
\hline $2.18 \mathrm{E}$ & 1. & & & & & \\
\hline & & & & & & \\
\hline & 1 & & & & & \\
\hline & 1.60 & & & & & \\
\hline & & & & & & \\
\hline & & & & & & \\
\hline 2. & 2 & & & & & \\
\hline & & & & & & \\
\hline & & & & & & \\
\hline & & & & & & \\
\hline & & & & & & \\
\hline & & & & & & \\
\hline & & & & & & \\
\hline & & & & & & \\
\hline & & & $\begin{array}{l}-2 . \\
-2\end{array}$ & $\begin{array}{l}-2.1 \\
-2.1\end{array}$ & & \\
\hline & & & & & & \\
\hline & & & & & & \\
\hline & & & & & & \\
\hline & & & & & & \\
\hline & & & & & & \\
\hline & & & & & & \\
\hline & & & & & & \\
\hline & & & & & & \\
\hline & & & & & & \\
\hline & & & & & & \\
\hline & $E-01$ & & 6 & & & \\
\hline & & & & & & \\
\hline & Note & & 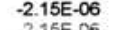 & 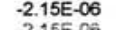 & $4.64 E+01$ & \\
\hline
\end{tabular}




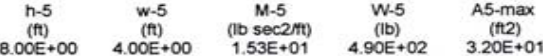

$\begin{array}{cc}\text { mu-k } & \begin{array}{c}\text { Friction } \\ \text { (b) } \\ 5.00 E-01 \\ 2.45 E+02\end{array} \\ & \end{array}$

\begin{tabular}{|c|c|c|c|c|}
\hline $\begin{array}{l}\text { que.p-p-2 } \\
(\mathrm{b}+\mathrm{ti})\end{array}$ & $\begin{array}{l}\text { Torque-G-2 } \\
\text { (ib fit) }\end{array}$ & $\begin{array}{l}\text { Torque-tot-2 } \\
\text { (Ib fit) }\end{array}$ & $\begin{array}{l}\text { Ang Impuls-2 } \\
\text { (Ib ft sec) }\end{array}$ & $\begin{array}{l}\text { eloc-2 } \\
\text { (sec) }\end{array}$ \\
\hline $59 E+05$ & & & $\begin{array}{l}1.59 \mathrm{E}+02 \\
3.11 \mathrm{E}+02\end{array}$ & 0 \\
\hline 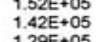 & $\begin{array}{l}-9.7472-01 \\
-3.85 E++\infty\end{array}$ & 25 & 2 & $\begin{array}{l}8.585 \\
1.258\end{array}$ \\
\hline$E+0$ & $\begin{array}{r}8.53 \mathrm{E}+00 \\
-1.4 \mathrm{E}+01\end{array}$ & $\begin{array}{l}1.29 E+05 \\
1.12 E+05\end{array}$ & $\begin{array}{l}5.82 E+02 \\
6.94 E+02\end{array}$ & $\begin{array}{l}1.61 \mathrm{E}+01 \\
1.92 \mathrm{E}+01\end{array}$ \\
\hline$=0$ & $\begin{array}{l}-1.49 E E+01 \\
-2.27 E+01\end{array}$ & $\begin{array}{l}1.12 E+05 \\
9.06 E+04\end{array}$ & 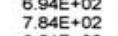 & $\begin{array}{l}1.92 E+01 \\
2.17 E+01\end{array}$ \\
\hline$E+0$ & $\begin{array}{l}-3.17 \mathrm{E} \\
-4.17 \mathrm{E}\end{array}$ & 4 & 22 & $\begin{array}{l}2.35 \mathrm{E}+01 \\
2.47 \mathrm{E}+01\end{array}$ \\
\hline & $-5.23 \mathrm{E}+01$ & $\begin{array}{l}4.78 \mathrm{E}+04 \\
1.794\end{array}$ & & \\
\hline$=0$ & $\begin{array}{l}-6.33 E+01 \\
-7.43 E+01\end{array}$ & & & \\
\hline$=0$ & $\begin{array}{l}-8.53 \mathrm{E} \\
-9.62 \mathrm{E}\end{array}$ & & & \\
\hline$E+0$ & $\begin{array}{l}-1.07 E+02 \\
-1.07 E\end{array}$ & 02 & $9.10 €+02$ & $\begin{array}{l}2.51 \mathrm{E}+01 \\
251 \mathrm{E}+01\end{array}$ \\
\hline $\begin{array}{l}0.00+0 \\
0.00 E+0 \\
0.000+0\end{array}$ & $\begin{array}{l}-1.18 \mathrm{E}+02 \\
-1.29 \mathrm{E}+02\end{array}$ & $\begin{array}{l}-1.188+02 \\
-1.29 \mathrm{E}+02\end{array}$ & $\begin{array}{l}9.10 E+02 \\
9.10 E+02\end{array}$ & $\begin{array}{l}2.512+01 \\
2.51 E+01\end{array}$ \\
\hline $0 E+0$ & $\begin{array}{r}-1.39 E+02 \\
-1.50 E+02\end{array}$ & 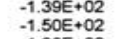 & $\begin{array}{l}9.10 \mathrm{E}+02 \\
9.10 \mathrm{O}+02\end{array}$ & $\begin{array}{l}2.51 \mathrm{E}+01 \\
2.51 \mathrm{E}+01\end{array}$ \\
\hline 0.00 & $\begin{array}{l}-1.60 \mathrm{E}+0202 \\
-1.71 \mathrm{E}+02\end{array}$ & $\begin{array}{l}-1.600+02 \\
-1.71 \mathrm{E}+02\end{array}$ & $\begin{array}{l}+02 \\
+02\end{array}$ & $\begin{array}{l}2.51 \mathrm{E}+01 \\
2.51 \mathrm{E}+01\end{array}$ \\
\hline $\begin{array}{l}0.00 \\
0.00\end{array}$ & $\begin{array}{l}-1.81 \mathrm{E}+02 \\
-206 \mathrm{E}+02\end{array}$ & .02 & $\begin{array}{l}9.09 E+02 \\
9.08 E+02\end{array}$ & \\
\hline $\begin{array}{l}0.00 E+0 \\
0.00 E+0 \\
0.00\end{array}$ & $\begin{array}{l}-2.30 \mathrm{E}+02 \\
-254 \mathrm{E}+02\end{array}$ & $\begin{array}{l}-2.30 E+02 \\
-2544+02\end{array}$ & 02 & \\
\hline $\begin{array}{l}0.00 E+c \\
0.00+c\end{array}$ & $\begin{array}{l}-2.76 \mathrm{E} \\
-30 \mathrm{E}\end{array}$ & $\begin{array}{l}-2.766 \\
-304\end{array}$ & 02 & $\begin{array}{l}2.50 E+01 \\
248 E+01\end{array}$ \\
\hline 年 & $\begin{array}{r}-4.44 \mathrm{E}+02 \\
-4\end{array}$ & $-4.44 \mathrm{E}+02$ & 8.811 & $2.43 E+01$ \\
\hline $\begin{array}{l}0.00 E+0 \\
0.00 E+0\end{array}$ & $\begin{array}{l}-2.5 .5 \\
-5.5\end{array}$ & $\begin{array}{l}-2.99 \\
-5.90\end{array}$ & & \\
\hline & $\begin{array}{l}-4.155 \\
-1.15\end{array}$ & $\begin{array}{l}-4.15 E-05 \\
-155-05\end{array}$ & & $\begin{array}{l}2.41 E+01 \\
2.11\end{array}$ \\
\hline $0.00 E+0$ & $\begin{array}{l}-4.15 E-05 \\
-4.15 E-05\end{array}$ & $\begin{array}{l}4.15-05 \\
-4.15 E-05\end{array}$ & & $2.41 E+01$ \\
\hline $\begin{array}{l}0.00 E+c \\
0.00 E+c\end{array}$ & $\begin{array}{l}-4 . \\
-4 .\end{array}$ & $\begin{array}{l}-4.15 E-05 \\
-415-05\end{array}$ & 02 & \\
\hline 0.0 & $\begin{array}{l}-4.15 E- \\
4.15 E-\end{array}$ & $\begin{array}{l}-4.15 \\
-415\end{array}$ & $8.71 \mathrm{E}+02$ & $\begin{array}{l}2.41 \mathrm{E}+01 \\
2.41\end{array}$ \\
\hline$=+c-c$ & $\begin{array}{l}-4.15 E-c \\
-4.15 E-6\end{array}$ & $\begin{array}{l}-4.15 E-05 \\
-4.15 E-05\end{array}$ & $\begin{array}{l}8.71 \mathrm{E}+02 \\
871 \mathrm{E}+02\end{array}$ & \\
\hline $0.00 E+0$ & 4 & $\begin{array}{r}-4.15 \\
-415\end{array}$ & & $2.41 E+01$ \\
\hline 00 & $\begin{array}{l}-4.15 E-C \\
-4.15 E-C\end{array}$ & $\begin{array}{l}-4.155 \\
-4.15 \mathrm{E}\end{array}$ & $\begin{array}{l}8.716 \\
8.711\end{array}$ & $\begin{array}{l}2.41 \\
2.41\end{array}$ \\
\hline $\begin{array}{l}0.00 E+C \\
0.00 E+C\end{array}$ & $\begin{array}{l}-4.15 \\
-4155\end{array}$ & $\begin{array}{l}-4.15 E-05 \\
-4.15-05\end{array}$ & $\begin{array}{l}8.71 \mathrm{E}+02 \\
871 \mathrm{E}+02\end{array}$ & 01 \\
\hline $\begin{array}{l}0.00 E+4 \\
0.00 t \\
0.00\end{array}$ & $\begin{array}{r}-4.15 E-05 \\
-115\end{array}$ & & 12 & $\begin{array}{l}2.4111+01 \\
2.11\end{array}$ \\
\hline 0 & $-4.15 E-6$ & $\begin{array}{l}-4.415 E \\
-4.15 E\end{array}$ & 8.71 & $\begin{array}{l}01 \\
01\end{array}$ \\
\hline $\begin{array}{l}.00 E+0 \\
.00 E+0\end{array}$ & $5 E-6$ & $\begin{array}{l}15 E-05 \\
15 E-05\end{array}$ & $8.71 \mathrm{E}+02$ & $\begin{array}{l}2.4 \mathrm{E}+01 \\
2.41 \mathrm{E}+01\end{array}$ \\
\hline & & & & \\
\hline
\end{tabular}

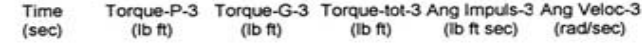

$\begin{array}{llllll}0.00 E+00 & 1.27 E+05 & 0.00 E+00 & 1.27 E+05 & 1.27 E+02 & 3.49 \mathrm{E}+\infty 0 \\ 1.00 E-03 & 1.21 \mathrm{E}+05 & -7.76 E-01 & 1.21 \mathrm{E}+05 & 2.47 \mathrm{E}+02 & 6.83 \mathrm{E}+00\end{array}$

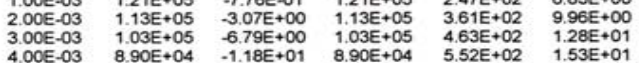

5.006

$5.00 \mathrm{E}-03$

$9.00 \mathrm{E}$

$1.00 \mathrm{E}$
$1.10 \mathrm{E}$
1.02

$1.30 \mathrm{E}$

$1.60 \mathrm{E}$

$2.00 \mathrm{E}$

$2.00 E-02$
$2.55 E-02$
$2.50 E-02$

$2.75 \mathrm{E}-02$
$3.00 \mathrm{E}-02$
$3.33 \mathrm{E}-02$

$3.33 E-02$
$6.66 E-02$
$1.00 E-01$

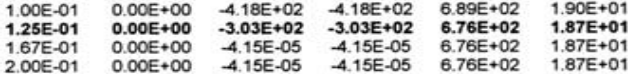

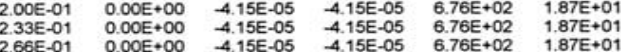

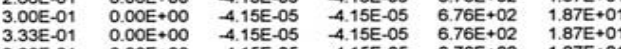

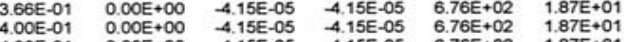

$\begin{array}{lllllll}4.33 E-01 & 0.00 E+00 & -4.15 E-05 & -4.15 E-05 & 6.76 E+02 & 1.87 E+01 \\ 4.66 E-01 & 0.00+00 & -4.15 E-05 & -4.15 E-05 & 6.766+02 & 1.87 E+01 \\ 5 & 000+00 & -415 E-05 & -15 E-05 & 676+02 & 1.87 E+01\end{array}$

$\begin{array}{lllllll}5.00 E-01 & 0.00 E+00 & -4.15 E-05 & -4.15 E-05 & 6.76 E+02 & 1.87 E+01 \\ 533 E-01 & 0.00 E+00 & -4.15 E-05 & -4.15 E-05 & 6.76 E+02 & 1.87 E+01\end{array}$

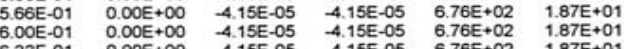

$\begin{array}{lllllll}6.33 E-01 & 0.00 E+00 & -4.15 E-05 & -4.15 E-05 & 6.76 E+02 & 1.87 E+01 \\ 6.66 E-01 & 0.00 E+00 & -4.15 E-05 & -4.15 E-05 & 6.76 E+02 & 1.877+01\end{array}$

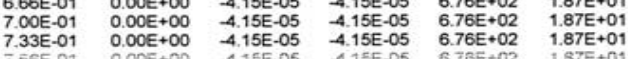

\begin{tabular}{|c|c|c|c|c|c|}
\hline & & & rece-5 & & \\
\hline 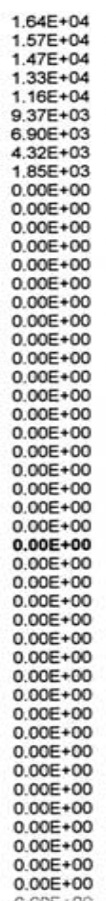 & 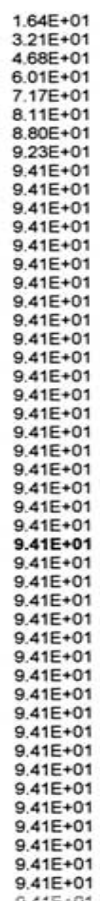 & $\begin{array}{l}01 \\
01\end{array}$ & 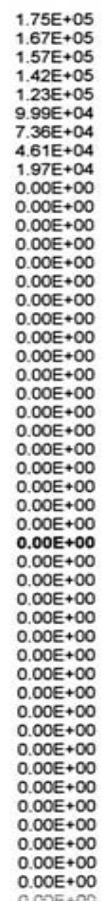 & 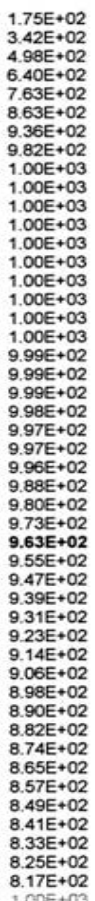 & \\
\hline
\end{tabular}




\section{Appendix A.5}

\section{Calculations for the Double Swinging Doors, FANTM Event \#5}

This appendix calculates the swing angle $\theta$ of the bottom half-door, the top half-door, and the flapper door (on the top-half door) as a function of time after an explosion occurred in a capacitor module (FANTM Event \#5). The peak quasi-static pressure can be determined by comparing the calculated results with the positions of the doors recorded on video film.

At the time of FANTM Event \#5, the module door configuration consisted of:

Two west-facing large swinging doors $\left(\sim 4^{\prime} \times 4^{\prime}\right)$, the bottom half-door (BHD) and the top half-door (THD)

A small flapper door (WFD), 1'x3', on the top half-door

A large, central, east-facing door (CDE), 4'x8', with a small flapper door (EFD), 1'x3', near the bottom.

Following a capacitor explosion (Event \#5), the quasi-static pressure, $\boldsymbol{P}_{\mathrm{qs}}$, can be expressed as (see Chapter 4 of DOE, 1992):

$$
\boldsymbol{P}_{\mathrm{qs}}(\mathrm{t})=\left(\mathrm{P}_{\mathrm{qs}}+\mathrm{P}_{\mathrm{o}}\right) \exp \left(-\mathrm{c} \mathrm{A}_{\mathrm{tot}} / \mathrm{Vt}\right)-\mathrm{P}_{\mathrm{o}}
$$

Where $\mathrm{P}_{\mathrm{qs}}$ is the peak quasi-static pressure, $\mathrm{P}_{\mathrm{o}}$ is the ambient pressure taken as $14.7 \mathrm{psi}$, $\mathrm{A}_{\text {tot }}$ is the total venting area of the module, $\mathrm{V}$ is its volume, and the constant $\mathrm{c}$ at standard sea level conditions is

$$
\mathrm{c}=2378 \mathrm{ft} / \mathrm{sec} \quad(\text { see Chapter } 4 \text { of DOE, 1992) }
$$

The swing angle $\theta$ of the bottom half-door can be expressed as:

$$
\theta(t)=\int_{0}^{t} \omega(\tau) d \tau
$$

and

$$
\Im \omega(t)=\int_{0}^{t} \Gamma(\tau) d \tau
$$

Where $\omega(t)$ is the angular velocity of the bottom half-door, $\mathfrak{\Im}$ is its moment of inertia, and $\Gamma(t)$ is the torque acting on the bottom half-door due to the pressure and gravity:

$$
\begin{aligned}
& \Gamma(\mathrm{t})=\mathrm{P}_{\mathrm{qs}}(\mathrm{t}) \times \mathrm{h} w \times \mathrm{h} / 2-\mathrm{m} \times \mathrm{g} \times \sin \theta \times \mathrm{h} / 2 \\
& \Im=1 / 3 \times \mathrm{m} \times \mathrm{h}^{2}
\end{aligned}
$$

Where $h$ and $w$ are the height and the width of the bottom half-door, respectively; $m$ is its mass, and $\mathrm{g}$ is the gravitational acceleration of $32 \mathrm{ft} / \mathrm{sec}^{2}$. Air drag force and friction are neglected in Eq. (4). 
The venting area, $\mathrm{A}(\theta)$, produced by the bottom half-door as it swings open can be expressed as:

$$
\begin{aligned}
& \mathrm{A}(\theta)=2 \times \mathrm{A}_{1}(\theta)+\mathrm{A}_{2}(\theta) \\
& \begin{aligned}
& \mathrm{a}=2 \times \mathrm{h} \times \sin (\theta / 2) \\
& \mathrm{A}_{1}(\theta)=0.5 \times 2 \mathrm{~h} \sin (\theta / 2) \times \mathrm{h} \times \cos (\theta / 2) \\
&=0.5 \times \mathrm{h}^{2} \times \sin \theta \\
& \mathrm{A}_{2}(\theta)=\mathrm{a} \times \mathrm{W} \\
&=2 \times \mathrm{h} \times \mathrm{w} \times \sin (\theta / 2)
\end{aligned} \\
& \mathrm{A}(\theta)=\mathrm{h}^{2} \sin \theta+2 \mathrm{hw} \sin (\theta / 2)
\end{aligned}
$$

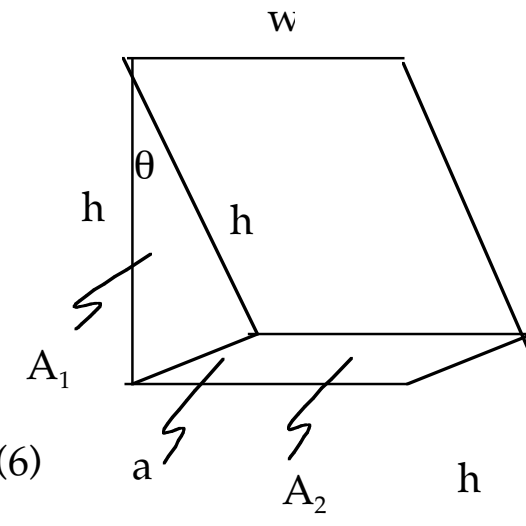

$\operatorname{hcos}(\theta / 2)$

Note that $A(\theta) \leq h \times W$

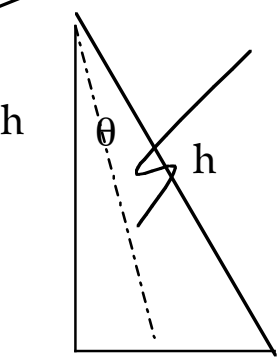

a

Similar equations also hold for the flapper door (WFD) and the top half-door, with minor modifications for the top half-door as follows:

- The area of the top half-door is equal to $\mathrm{hxw}-3 \mathrm{ft}^{2}$, where $3 \mathrm{ft}^{2}$ is the area of the west flapper door.

- The hinge bar of the west flapper door is attached to the top half-door. The swinging west flapper door contributes little to the moment of inertia of the top half-door (about 1\%). Thus, the moment of inertia of the top half-door is taken to be the same as that of the bottom half-door.

Following a capacitor explosion (Event \#5), the bottom half-door, the top halfdoor, and the west flapper door all swung open. In addition, the $4^{\prime} \times 8^{\prime}$ east central door (CDE) moved away from the module, and the east flapper door also swung open. The total venting area in Eq. (1) is the sum of the individual venting areas, i.e.,

$$
\mathrm{A}_{\text {tot }}(\mathrm{t})=\mathrm{A}_{\mathrm{BHD}}(\mathrm{t})+\mathrm{A}_{\mathrm{THD}}(\mathrm{t})+\mathrm{A}_{\mathrm{WFD}}(\mathrm{t})+\mathrm{A}_{\mathrm{EFD}}(\mathrm{t})+\mathrm{A}_{\mathrm{CDE}}(\mathrm{t})+\mathrm{A}_{\mathrm{FIXED}}
$$

Where $A_{B H D}, A_{T H D}, A_{W F D}$, and $A_{E F D}$ are the venting areas produced by the bottom half-door, the top half-door, the west flapper door (on the top half-door), and the east flapper door (on the east central door), respectively. They are all expressed by equation (6), except their angles and dimension are different. $\mathrm{A}_{\mathrm{CDE}}$ is the venting area produced by the $4^{\prime} \times 8^{\prime}$ east central door as it moved away from the module; equations describing its motion are given by Eqs (2) to (7) of Appendix A.4 and will not be repeated here. $\mathrm{A}_{\mathrm{FIXED}}$ is the fixed venting area, provided around the bottom of the module.

For a given peak quasi-static pressure, $\mathrm{P}_{\mathrm{qs}}$, the set of equations (1) to (6) and equations (2) to (7) of Appendix A.4 can be solved numerically by the finite difference method using a spread sheet. Some remarks are in order: 
- Eqs (2) to (5) are applied to each swinging door separately.

- Eqs (2) to (7) in Appendix A.4 are applied to the east central door (CDE).

- The gauge pressure $\mathrm{P}(\mathrm{t})$ given in $\mathrm{Eq}(1)$ is always positive.

- The free space inside the module is $168 \mathrm{ft}^{3}$.

- The thickness is $3 / 8$ in. for all doors. These are steel doors with a density of $489.7 \mathrm{lb} / \mathrm{ft}^{3}$.

- The dimensions and weight of the bottom half-door and the top half-door are $3.94^{\prime} \mathrm{h} \times 3.74^{\prime} \mathrm{w}$ and $225 \mathrm{lb}$, respectively. The two flapper doors are $1^{\prime} \mathrm{h} \times 3^{\prime} \mathrm{w}$ and $46 \mathrm{lb}$, and the east central door is $8^{\prime} \mathrm{h} \times 4^{\prime} \mathrm{w}$ and $490 \mathrm{lb}$.

- In the finite difference calculation, a $1 \mathrm{msec}$ time step is used for the time period before ambient pressure is reached. After that, a larger time step is used.

The angle displacement of the swinging doors depends on the peak quasi-static pressure, which is the only parameter in the calculation. The calculation considered several peak quasi-static pressures, such as 10,11, and 12 psig. The results indicate that the angular displacements of the bottom half-door, the top half-door, and the west flapper door can be best overall reproduced by a peak quasi-static pressure of 11 psig.

The calculated results of the angular displacements of the bottom and top halfdoors for the peak quasi-static pressures of 11 psig are depicted in Figure A.5-1. For comparison, Figure A.5-1 also shows the swing angles of the bottom and top half-doors estimated from the video as a function of time (data are taken from (Smith 1999)). Figure A.5-1 indicates that the swing angles of the bottom and top half-doors shown on the video could be well reproduced by a peak quasi-static pressure of $11 \mathrm{psig}$. It should be noted that the video data of the positions of the bottom and top half-doors within the first 0.1 second have large uncertainty (video over-exposed); therefore, the comparison within the first 0.1 second is less significant. The maximum calculated swing angle of the bottom half-door is about $180^{\circ}$, which is within the range of the estimated maximum angle (of $160^{\circ}$ to $180^{\circ}$ ) as determined by the video (Smith 1999). The calculation shows that the quasi-static pressure drops to the ambient pressure in about $9 \mathrm{msec}$, the total impulse due to the quasi-state pressure over this $9 \mathrm{msec}$ period is $63 \mathrm{psi}-\mathrm{ms}$. This is consistent with the findings given in (Smith 1999), where by considering gravitational effects, they determined that the swing could have been caused by an initial impulse of 50 psi-ms.

For a peak quasi-static pressure of $11 \mathrm{psig}$, the calculation shows that the west flapper door reaches $48^{\circ}$ at $33.3 \mathrm{msec}$ and $100^{\circ}$ at $66.6 \mathrm{msecond}$. These results are consistent with the video data (first and second frames). The calculated total venting area of the module increases from $2 \mathrm{ft}^{2}$ at 0 seconds to $7.4 \mathrm{ft}^{2}$ at 9 msec. At that point, the quasi-static pressure reduces to the ambient pressure. A similar venting effect may be provided by a fixed venting area less than $7.4 \mathrm{ft}^{2}$.

The calculated results for a peak quasi-static pressure of 10 psig are depicted in Figure A.5-2. The results fits the video data better than those of 11 psig for time less than 0.5 seconds. However, the maximum swing angle of the bottom half- 
door is only $142^{\circ}$ in this case. Thus, the overall results are best represented by an overpressure of 11 psig.

Pressure venting following a capacitor explosion is an important consideration in the design of a capacitor module. The double swing doors are used to vent the overpressure in the case of FANTM Event \#5. A comparison between the pressure venting of the double swinging doors and that of a constant venting area of $8.75 \mathrm{ft}^{2}$ is depicted in Figure A.5-3. Figure A.5-3 shows that the pressure venting of the constant $8.75 \mathrm{ft}^{2}$ venting area is much faster than that of the double swinging doors. For a peak quasi-static pressure of $11 \mathrm{psig}$, the pressure drops to the ambient pressure in $4.5 \mathrm{msec}$ (using Eq. 1) in the former case, while it takes 9 msec in the latter case. A comparison of the venting areas associated with the above two cases is depicted in Figure A.5-4.

A similar comparison of pressure venting for a peak pressure of 40 psig for the above two cases is depicted in Figure A.5-5. Figure A.5-5 shows that overall the constant venting area of $8.75 \mathrm{ft}^{2}$ still provides faster venting than the double swinging doors; although it takes $10.6 \mathrm{msec}$ for the pressure to drop to ambient pressure in the former case, while it takes $9 \mathrm{msec}$ in the latter case. A comparison of the venting areas associated with the above two cases for a peak quasi-static pressure of 40 psig is depicted in Figure A.5-6.

The spread sheets for the three calculations (for $\mathrm{P}_{\mathrm{qs}}=10,11,12 \mathrm{psig}$ ) are provided on the pages to follow. Each calculation includes 2 pages. Explanations to assist with reading the spread sheets are given below:

1. I, h, w, M, W, A, A-max, \#n stand for the door moment of inertia, the door height, the door width, the door mass, the door weight, the door vent area, the door maximum vent area, and the door type identification number (\#)/associated number of doors of that type (n), respectively.

2. The door type identification numbers are as follows:

\#1: west flapper door $\left(1^{\prime} \times 3^{\prime}\right)$

\#2: bottom half-door

\#3: top half-door

\#4: east flapper door $\left(1^{\prime} \times 3^{\prime}\right)$

\#5: east central door $\left(4^{\prime} \times 8^{\prime}\right)$

3. A-o is the fixed vent area, $\mathrm{V}$ is the free space of the module, $\mathrm{P}_{\mathrm{o}}$ is the ambient pressure, Torque-P is the torque due to the pressure, Torque-G is the torque due to gravity, and mu-k is the kinetic friction coefficient.

4. The vent area provided by each door should be less than the door's maximum vent area.

5. If the number of doors for a given door identification number is set to zero, the results for that type of door can be ignored. For example when $\mathrm{n} 2=0$, the results corresponding to a Type \#2 door can be ignored. In this appendix, n2 
and $\mathrm{n} 3$ are set to zero (used in Appendix A.5). However, the two central doors are modeled in a similar fashion, and so, n5 is set to 2 .

6. The maximal angle displacement is truncated at $180^{\circ}$.

\section{$\underline{\text { References }}$}

DOE (1992), "A Manual for the Prediction of Blast and Fragment Loadings on Structures", U.S. Department of Energy, DOE/TIC-11268, July 1992.

Smith, D.L. and Harjes, H.C. (1999), "FANTM Fault Analysis", memo from D. L. Smith and H.C. Harjes to D. Bloomquist, Sandia National Laboratoty, May 19, 1999. 
Figure A.5-1:Comparison between theoretical calculations (at $\mathrm{P}_{\mathrm{qs}}=11 \mathrm{psig}$ ) and video data for the swinging doors

(Video data are taken from (Smith, 1999))

Solid curve represents calculated results for the bottom door.

Dotted curve represents calculated results for the top door.

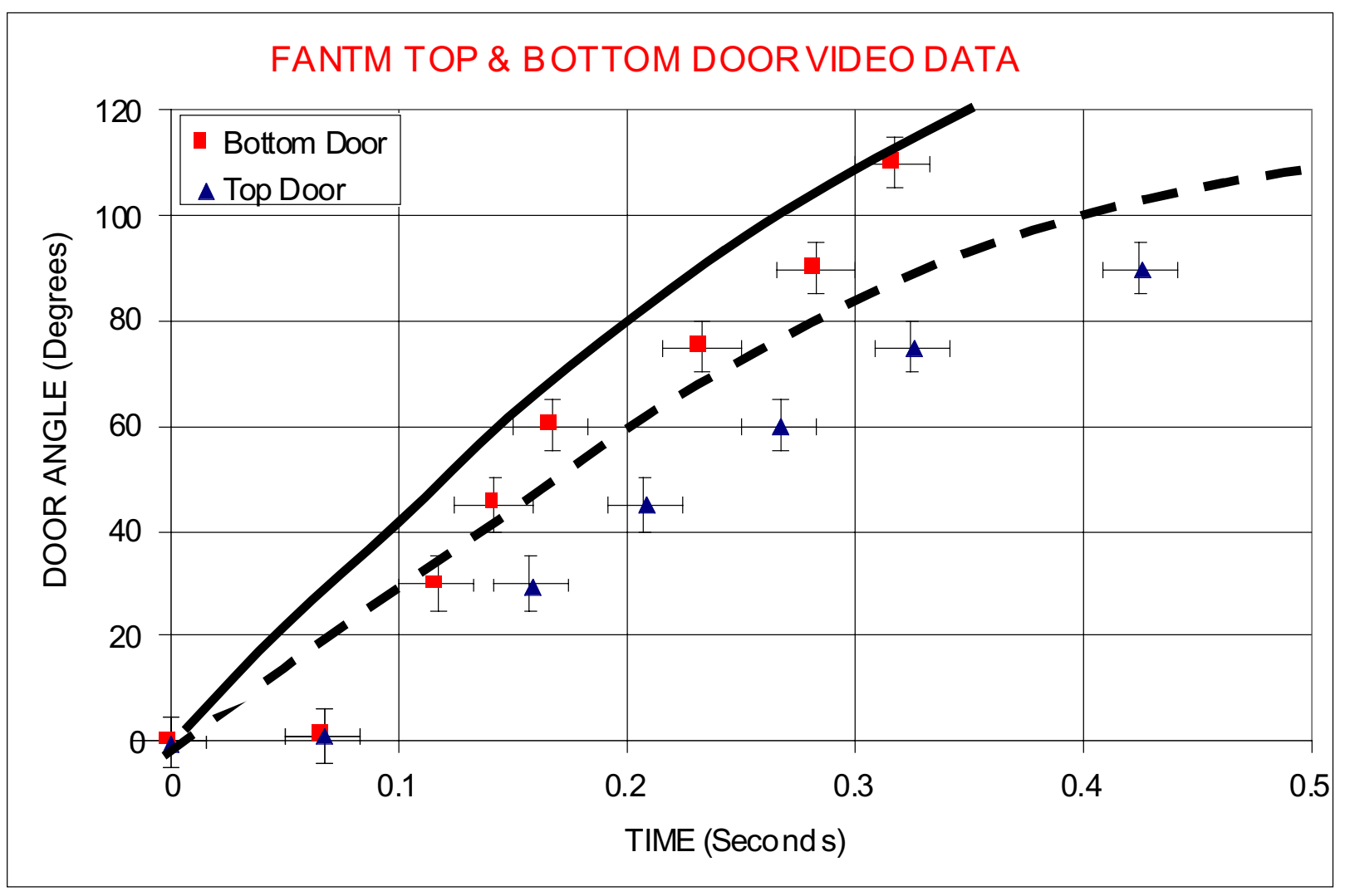


Figure A.5-2:Comparison between theoretical calculations (at $P{ }_{q s}=10 \mathrm{psig}$ ) and video data for the swinging doors

(Video data are taken from (Smith, 1999))

Solid curve r epresents calculated results for the bottom door.

Dotted curve represents calculated results for the top door.

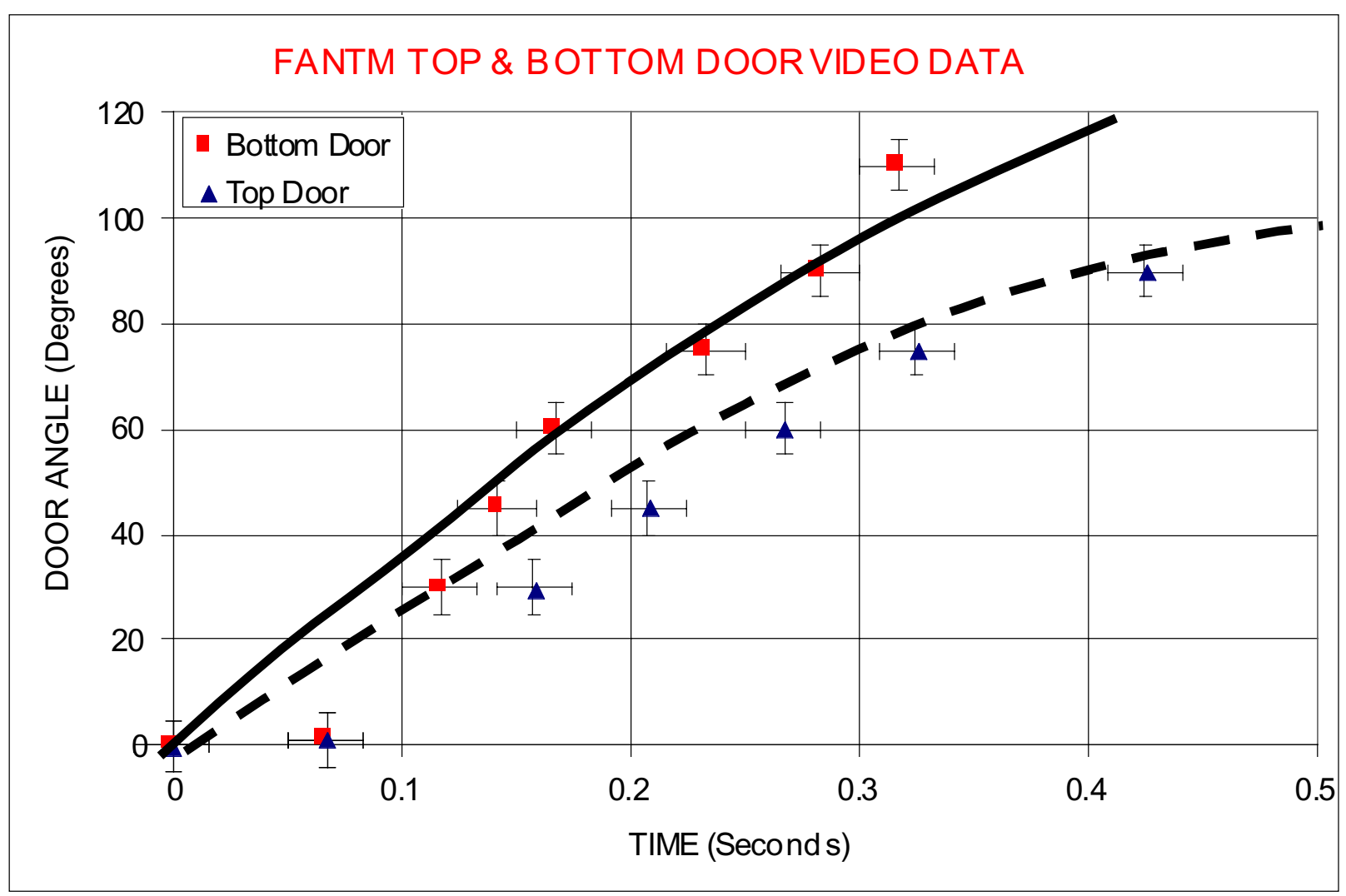




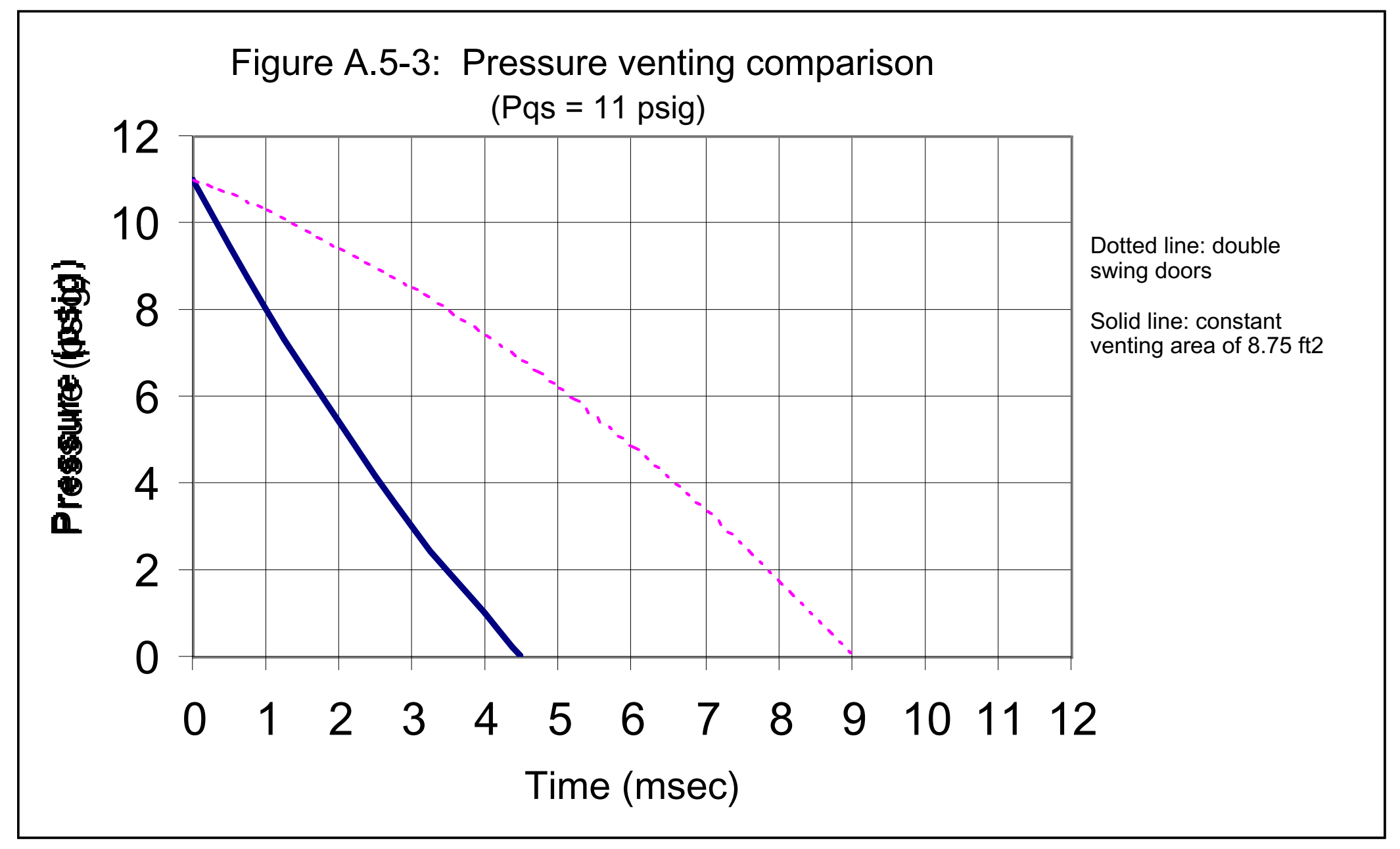


Figure A.5-4: Venting area comparison

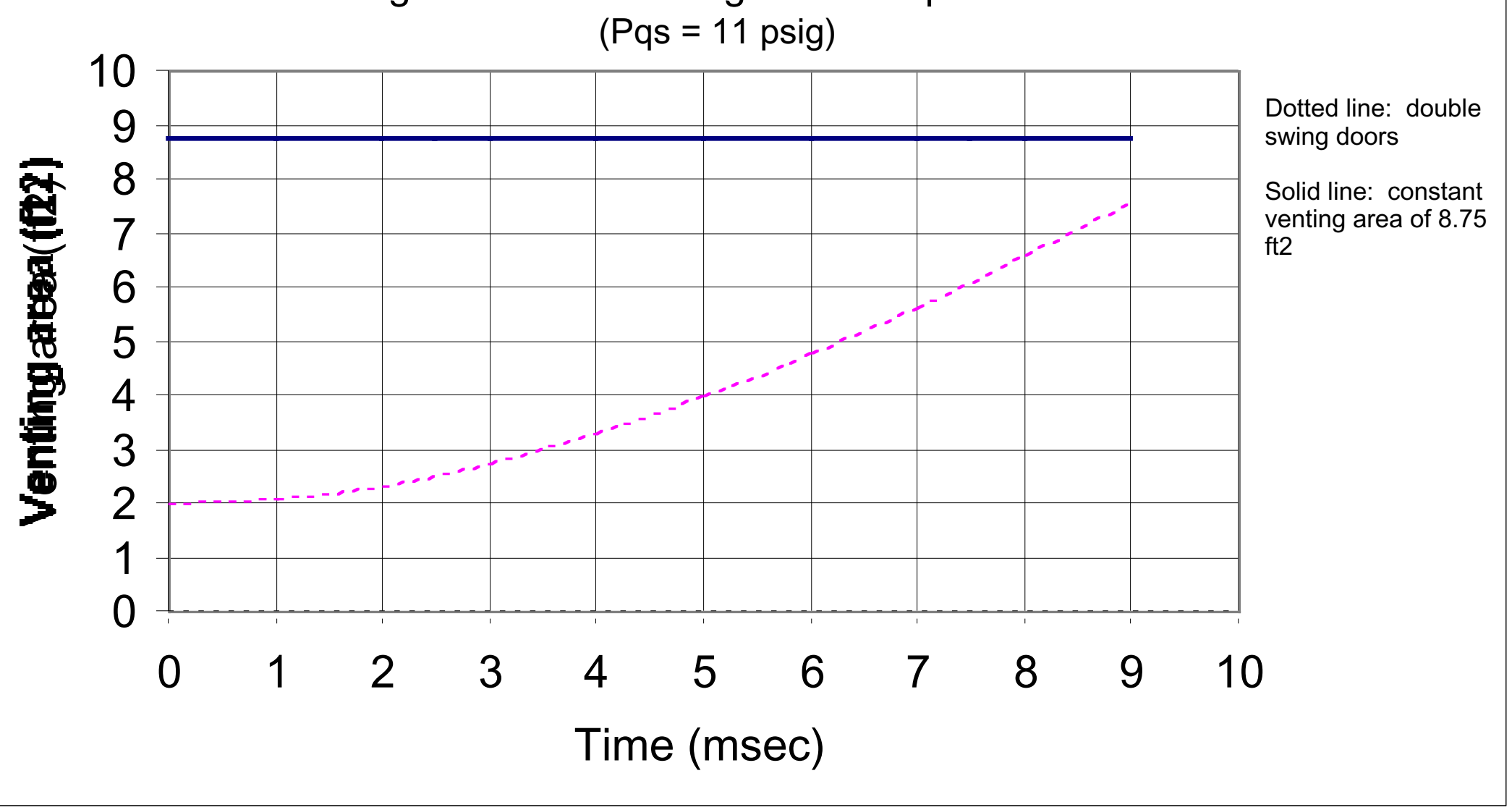




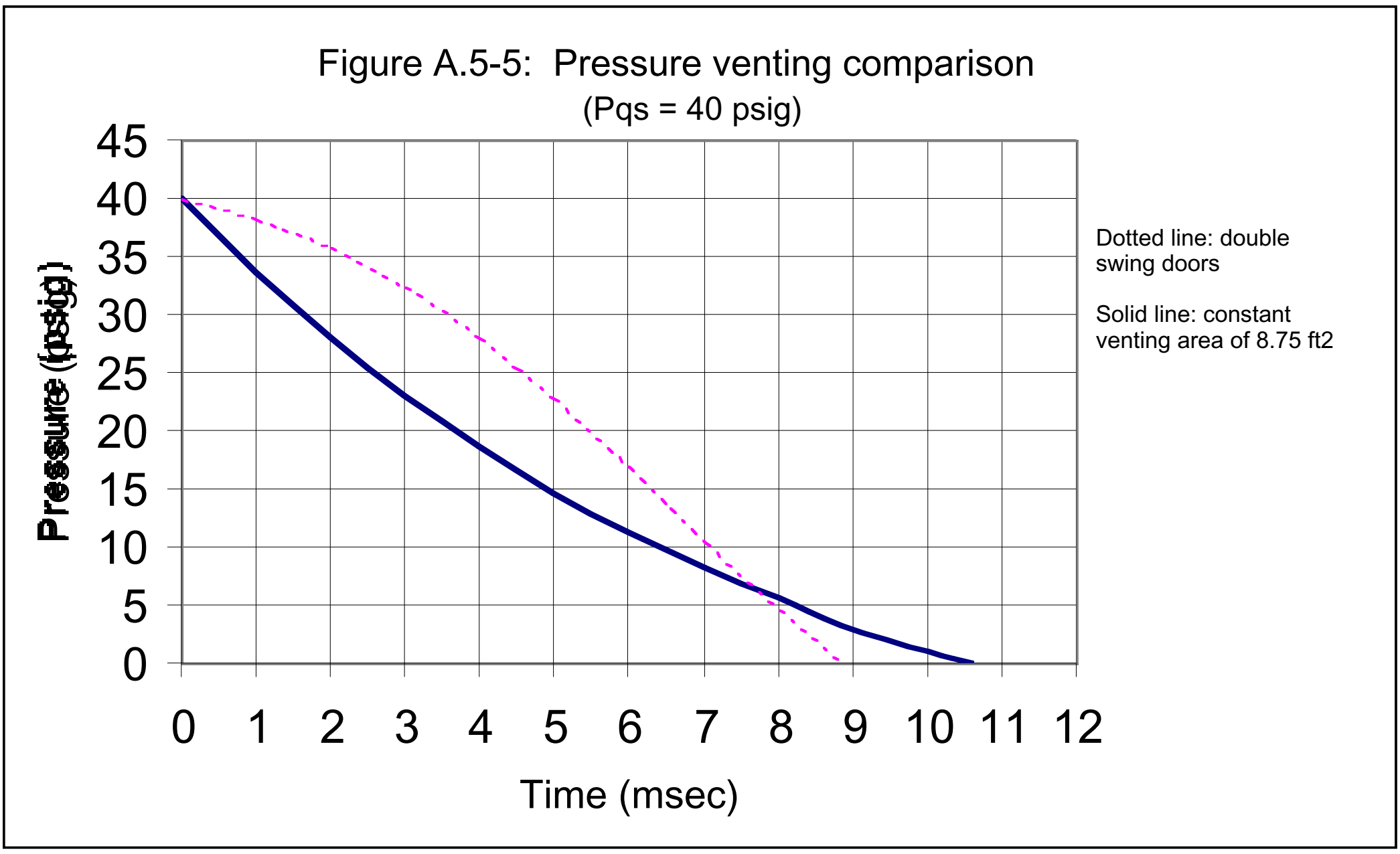




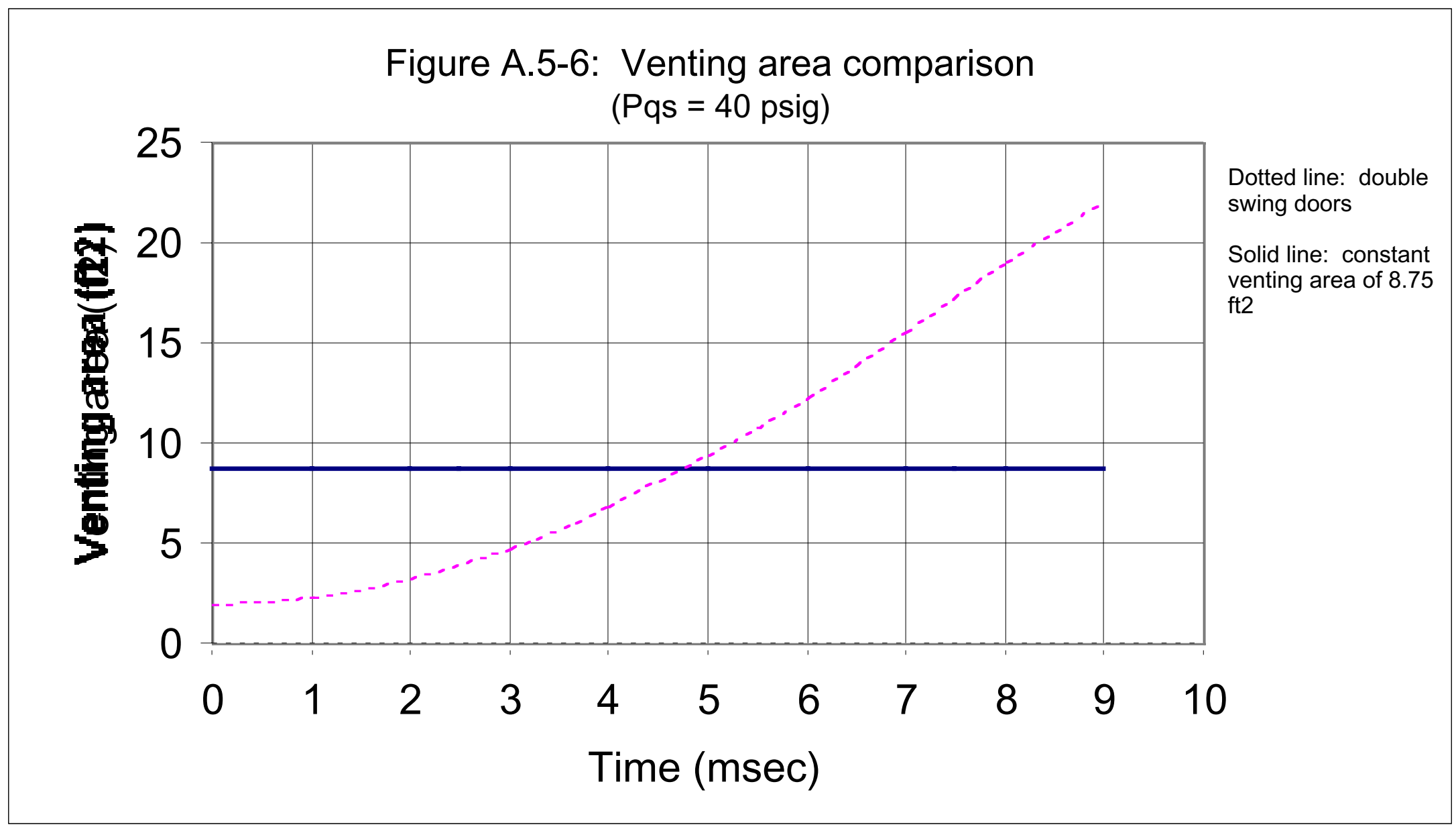




\section{Appendix A5}

Event \#5, Pqs $=10 \mathrm{psig}$

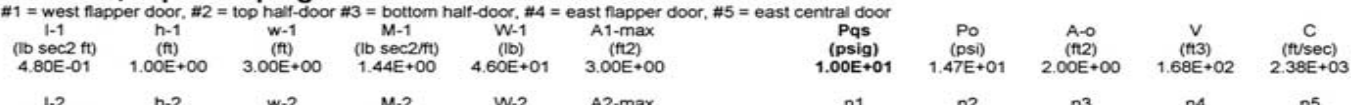

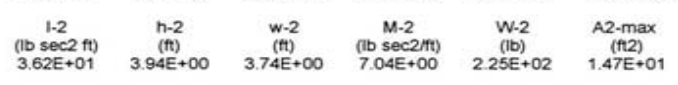

$$
2.00 E+00 \quad 1.00 E+00 \quad 1.00 E+\infty 0 \quad 0.00 E+00 \quad 1.00 E+00
$$

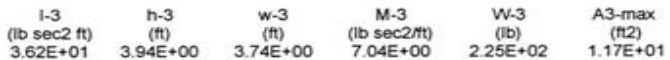

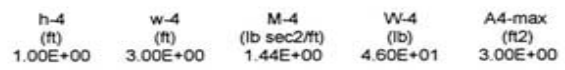

\begin{tabular}{|c|c|c|c|c|}
\hline $\begin{array}{l}\text { Time } \\
\text { sec) }\end{array}$ & $\begin{array}{l}\text { gle-1 } \\
\text { greee) }\end{array}$ & $\begin{array}{l}\text { Angle-2 } \\
\text { (degree) }\end{array}$ & $\begin{array}{l}\text { gle-3 } \\
\text { garee) }\end{array}$ & $\begin{array}{l}\text { Av-1 } \\
(\text { (112) }\end{array}$ \\
\hline 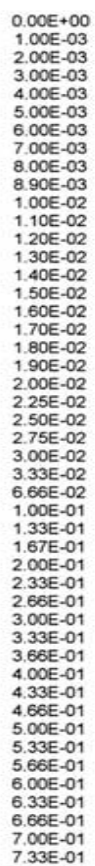 & 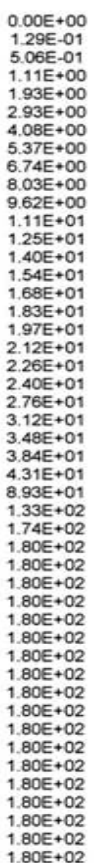 & 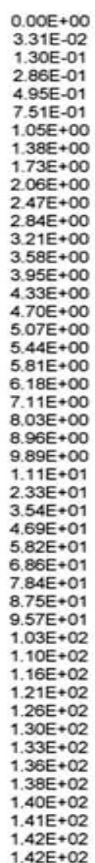 & 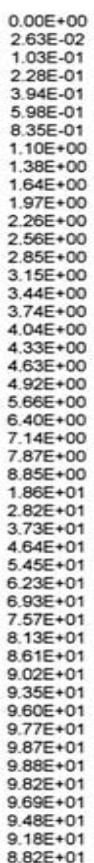 & 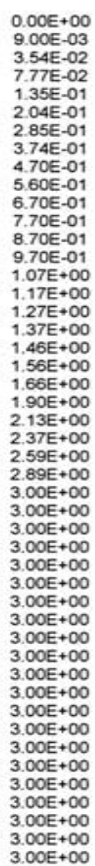 \\
\hline
\end{tabular}

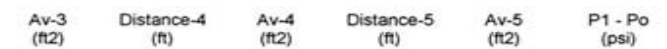

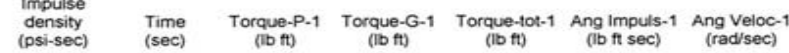

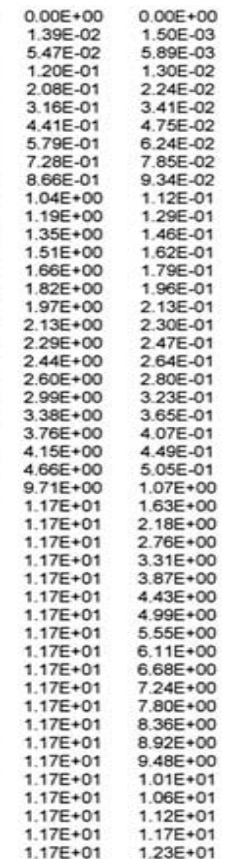

\begin{tabular}{|c|}
\hline 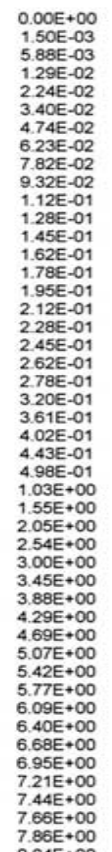 \\
\hline
\end{tabular}

\begin{tabular}{|c|}
\hline 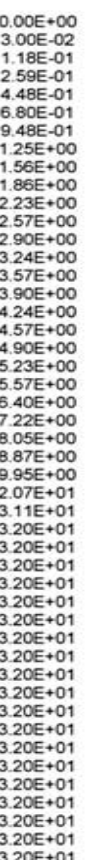 \\
\hline
\end{tabular}

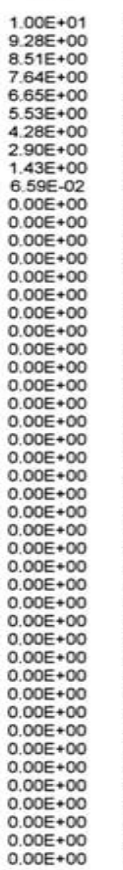

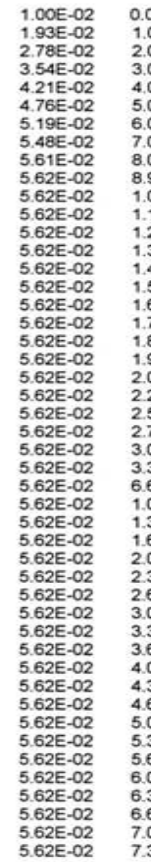

\begin{tabular}{|c|c|c|c|c|c|}
\hline 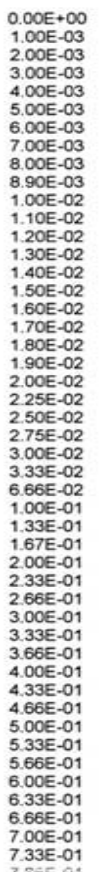 & 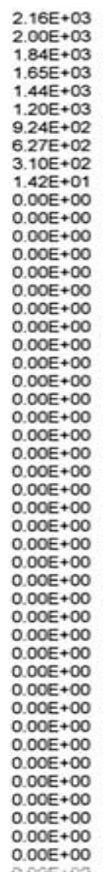 & 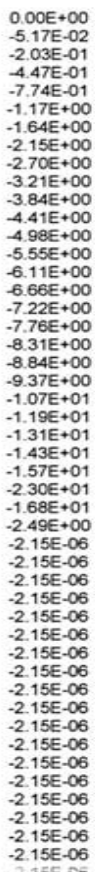 & 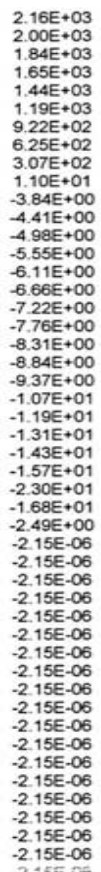 & 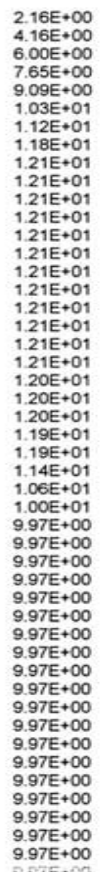 & 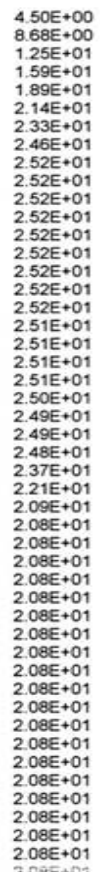 \\
\hline
\end{tabular}




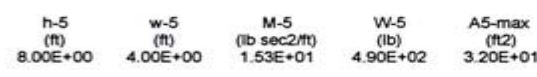

$\begin{array}{cc}\text { mu-k } & \begin{array}{c}\text { Friction } \\ \text { (Ib) } \\ 5.00 E-01 \\ 2.45 E+02\end{array}\end{array}$

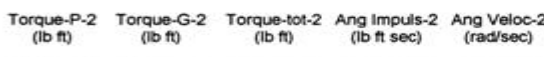

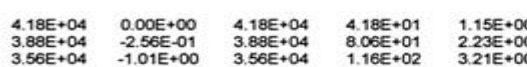

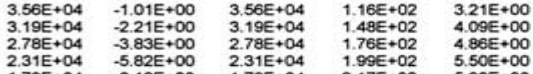

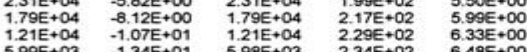

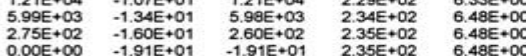

$\begin{array}{llllll}0.00 E+\infty & -2.49 E+01 & -2.49 E+01 & 2.35 E+02 & 6.48 E+00 \\ 0.00 E+\infty & -2.77+01 & -2.77 E+01 & 2.35 E+02 & 6.48 E+00\end{array}$

$0.00 E+\infty$
$0.00 E+\infty$

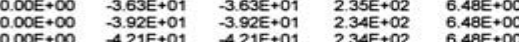

\begin{tabular}{llllll}
$0.00 E+\infty$ & $-4.211+01$ & $-4.211 E+01$ & $2.34 E+02$ & $6.48 E+00$ \\
\hline$-4.49 E+01$ & $-4.49 E+01$ & $2.34 E+02$ & $6.47 E+00$
\end{tabular}

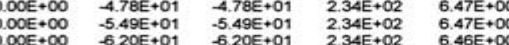

$\begin{array}{llllll}000 E+\infty & -6.91 E+01 & -6.91 E+01 & 2.34 E+02 & 6.46 E+\infty\end{array}$

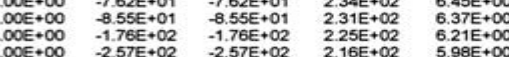

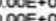

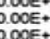

.

$0.00 e^{2}$

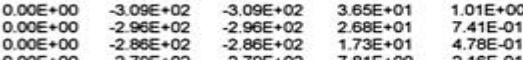

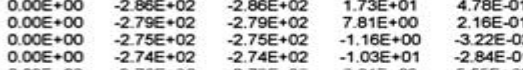

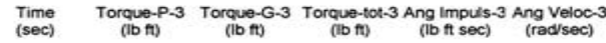

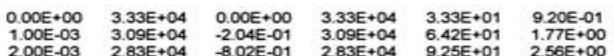

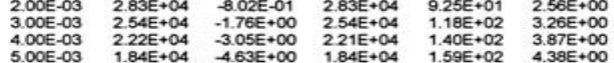

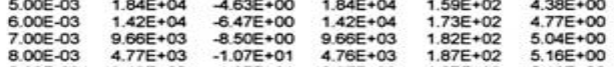

$\begin{array}{llllll}8.90 E-03 & 2.19 E+02 & -1.27 E+01 & 2.07 E+02 & 1.877+02 & 5.16 E+00 \\ 1.00 E-02 & 0.00 E+\infty 0 & -1.52 E+01 & -1.52 E+01 & 1.87 E+02 & 5.16 E++00\end{array}$

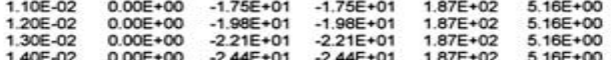

$1.50 E-02$
$1.50 E-02$
1.000

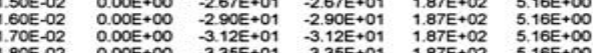

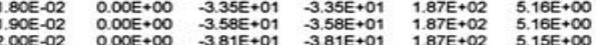

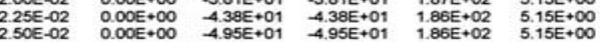

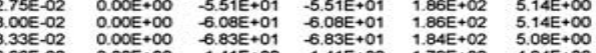

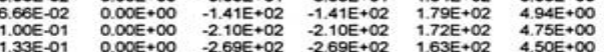

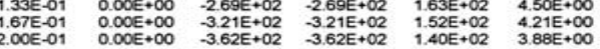

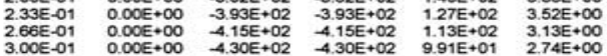

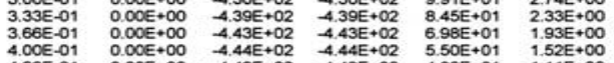

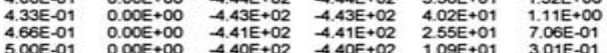

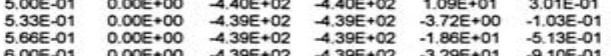

$\begin{array}{llllll}6.33 E-01 & 0.00 E+00 & -4.41 E+02 & -4.41 E+02 & -4.76 E+01 & -9.10 E E+01 \\ & -1.32 E+00\end{array}$

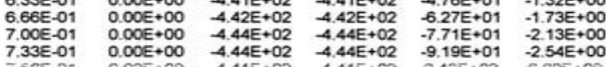

\begin{tabular}{|c|c|c|c|c|c|}
\hline (b)e- & $\begin{array}{l}\text { Impulse } \\
\text { nb-sec }\end{array}$ & $\begin{array}{l}\text { loc } 4 \\
\text { (sec) }\end{array}$ & $\begin{array}{c}\begin{array}{c}\text { Forcee-5 } \\
\text { (b) }\end{array} \\
\text { (a) }\end{array}$ & $\begin{array}{c}\text { Impulse-5 } \\
\text { (b-sec) }\end{array}$ & $\begin{array}{l}\text { oc-s } \\
\text { sec) }\end{array}$ \\
\hline 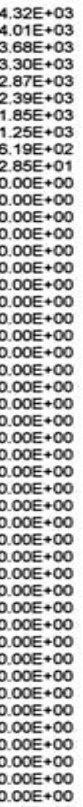 & 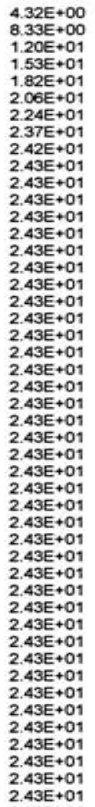 & 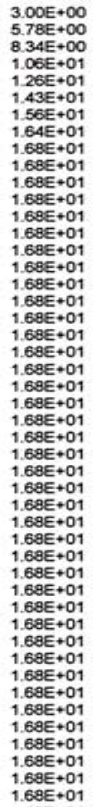 & 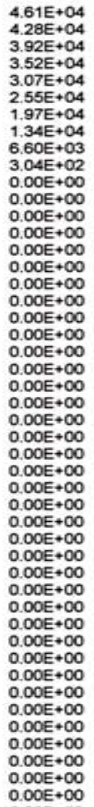 & 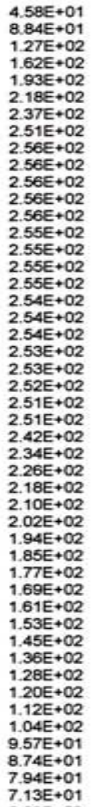 & 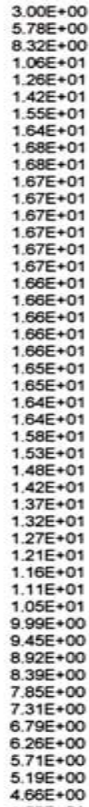 \\
\hline
\end{tabular}




\section{Appendix A5}

Event \#5, Pqs $=11$ psig

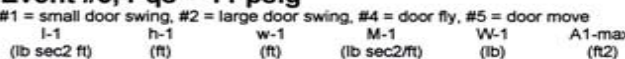

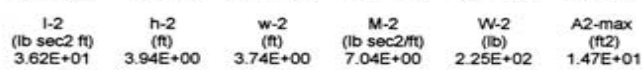

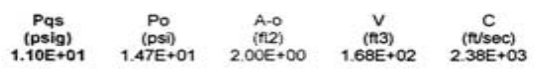

$\begin{array}{ccccc}n 1 & n 2 & n 3 & n 4 & n 5 \\ 2.00 E+\infty 0 & 1.00 E+\infty 0 & 1.00 E+\infty 0 & 0.00 E+\infty & 1.00 E+\infty\end{array}$

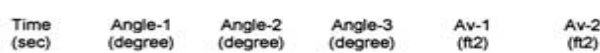

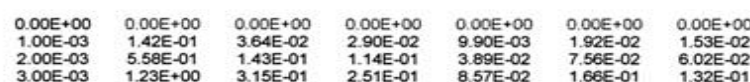

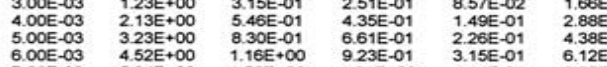

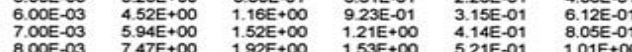

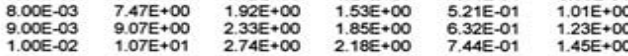

$\begin{array}{lll}1.10 \mathrm{E}-02 & 1.23 \mathrm{E} \\ 1.20 \mathrm{E}-02 & 1.39 \mathrm{E}+01\end{array}$

$\begin{array}{lll}1.40 E-02 & 1.75 E+01 & 3.99 E+\infty \\ 1.72 E+01 & 4.41 E+\infty\end{array}$

$\begin{array}{lll}1.50 E-02 & 1.88 E+01 & 4.82 E+\infty \\ 1.60 E-02 & 2.04 \mathrm{E}+01 & 5.24 \mathrm{E}+\infty\end{array}$

$\begin{array}{lll}1.70 E-02 & 220 E+01 \\ 1.80 E-02 & 2.36 E+0\end{array}$

$\begin{array}{llll}2.50 E-02 & 3.49 E+01 & 7.94 E++ \\ 275 E-02 & 8.97+0\end{array}$

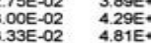

$\begin{array}{ll}6.66 \mathrm{E}-02 & 9.99 \mathrm{E}+0 \\ .00 \mathrm{E}-01 & 1.49 \mathrm{E}+0 \\ .33 \mathrm{E}-01 & 1.80 \mathrm{E}+02\end{array}$

$1.80 \mathrm{E}+02$

$\begin{array}{llll}233 E-01 & 1.80 E+02 & 7.68 E+0 \\ 8.79 E+0\end{array}$

$\begin{array}{lll}3.00 E-01 & 1.80 \mathrm{E}+02 \\ 3.33 \mathrm{E}-01 & 1.80 \mathrm{E}+02\end{array}$

$\begin{array}{ll}3.66 \mathrm{E}-01 & 1.80 \mathrm{E}+ \\ 4.00 \mathrm{E}-01 & 1.80 \mathrm{E}+ \\ 433 \mathrm{E} & 1.01\end{array}$

$1.32 E+0$
$1.39+0$
$1.45+0$

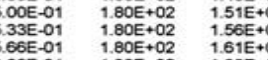

$\begin{array}{ll}.33 E-01 & 1.80 E+02 \\ 6.66 E-01 & 1.80 E+02 \\ 7.00 E-01 & 1.80 E+02 \\ 7 & \end{array}$

$\begin{array}{lll}7.33 E-01 & 1.80 E+02 & 1.790+02 \\ 7.00 E+02 & 1.80 E+02\end{array}$

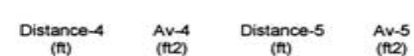

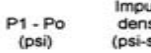

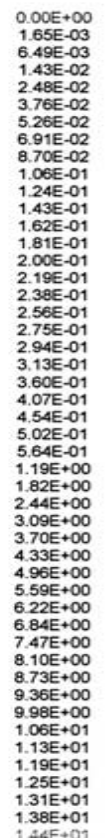

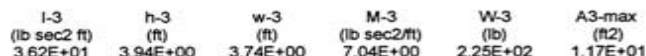

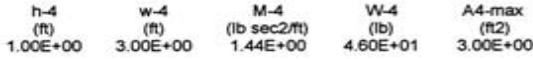

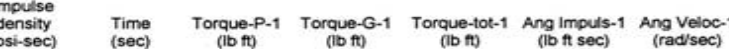

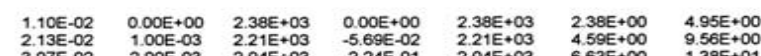

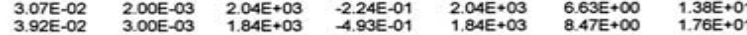

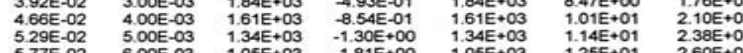
$\begin{array}{llllllll}5.777-02 & 6.00 E-03 & 1.05 E+03 & -1.81 E++00 & 1.05 E+03 & 1.25 E+11 & 2.60 E+0 \\ 6.11 E-02 & 7.00 E=-03 & 7.23 E+02 & -2.38 E++00 & 7.20 E+02 & 1.32 E+01 & 2.75 E+01\end{array}$

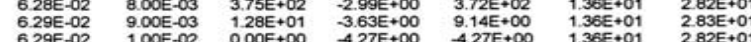

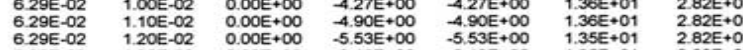

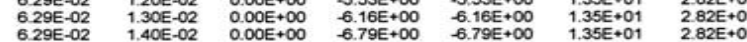

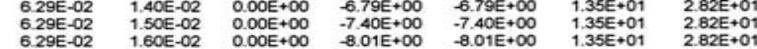

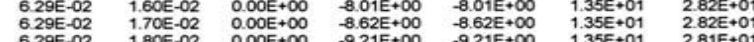

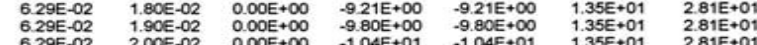

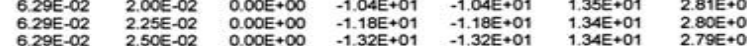

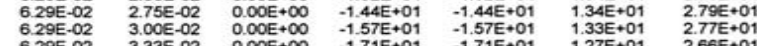

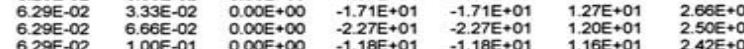

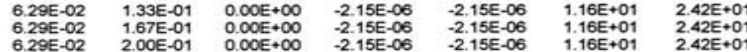

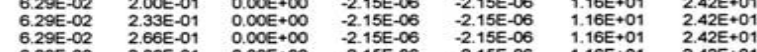

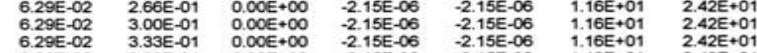

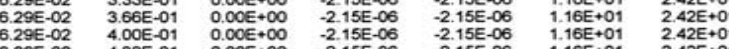

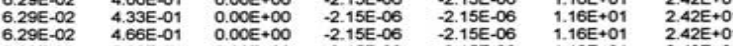

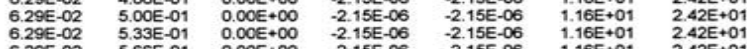
$\begin{array}{llllllll}6.296-02 & 5.66 E-01 & 0.00 E++0 & -2.15 E-06 & -2.15 E-06 & 1.16 E+01 & 2.42 E+01 \\ 6.226-02 & 6.00 E-01 & 0.00 E++00 & -2.15 E-06 & -2.15 E-06 & 1.16 E+01 & 2.42 E+01\end{array}$

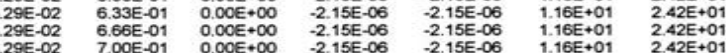

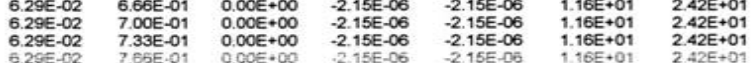




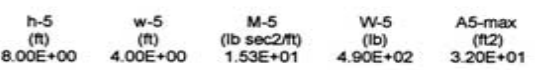

$\begin{array}{cc}\text { mu-k } & \begin{array}{c}\text { Friction } \\ \text { (it) } \\ 5.00 E-01 \\ 2.45 E+02\end{array}\end{array}$

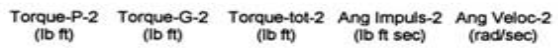

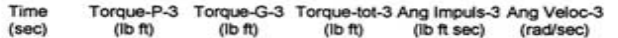

$\begin{array}{llllll}4.60 E+04 & 0.00 E+00 & 4.60 E+04 & 4.60 E+01 & 1.27 E+00 \\ 4.28 E+04 & -2.82 E-01 & 4.28 E+04 & 8.88 E+01 & 2.45 E+00\end{array}$

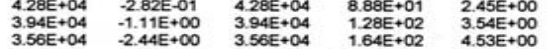

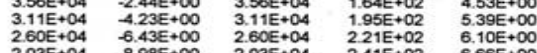

$1.40 \mathrm{E}+$

$1.40 E+04$
$725 E+\infty$
$2.47 E++0$
$0.00 E+\infty$

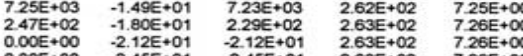

$0.00 E+\infty$

0.006

$0.00 E$

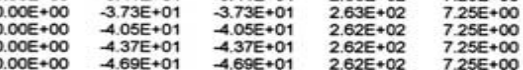

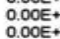

$0.00 E+\infty$
$0.00 E+\infty$
$0.00 E+\infty$

$0.005+\infty$
$0.00 E+\infty$

$0.00 \mathrm{E}$

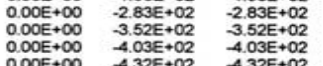

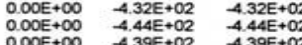

$0.00 E+\infty$

$0.00 E+\infty$
$0.00 E+\infty$

$0.00 \mathrm{E}+\infty$

$\begin{array}{llllll}00 E+00 & -1.45 E+02 & -1.45 E+02 & 8.65 E+01 & 2.52 E++\infty\end{array}$

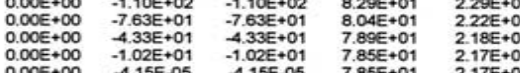

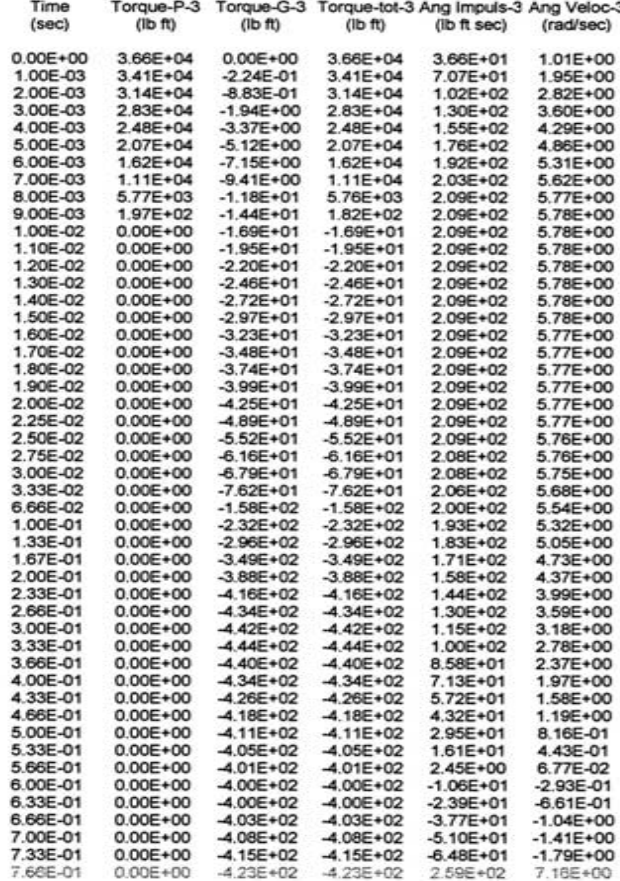

\begin{tabular}{|c|c|c|c|c|c|}
\hline $\begin{array}{l}\text { orcee-4 } \\
\text { (bi) }\end{array}$ & $\begin{array}{l}\text { pulse-4 } \\
\text { b-sec) }\end{array}$ & $\begin{array}{l}\text { Veloc-4 } \\
\text { (it/sec) }\end{array}$ & $\begin{array}{c}\text { Forcee.5 } \\
\text { (ib) }\end{array}$ & $\begin{array}{l}\text { mpulse-5 } \\
\text { (bi-sec) }\end{array}$ & 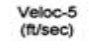 \\
\hline 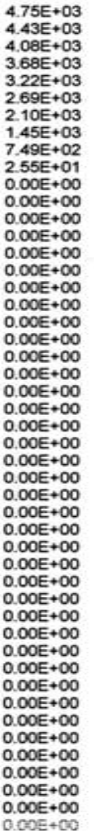 & 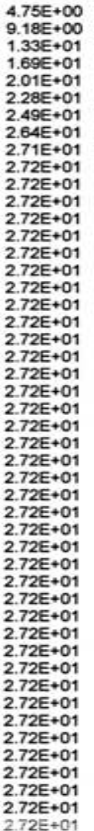 & 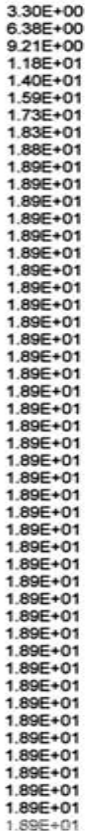 & 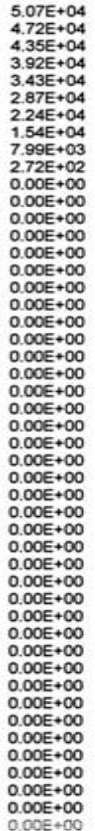 & 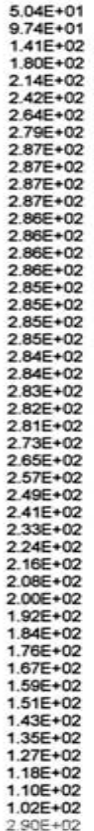 & 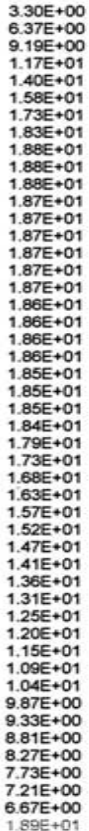 \\
\hline
\end{tabular}




\section{Appendix A5}

Event \#5, Pqs $=12$ psig
$\# 1=$ west flapper $d 00 x, \# 2=100$ halt-do

\begin{tabular}{|c|c|c|c|c|c|c|c|c|c|c|c|c|c|c|c|c|c|c|}
\hline 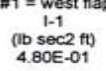 & $\begin{array}{c}h-1 \\
(f) \\
1.00 \mathrm{E}+\infty\end{array}$ & $\begin{array}{c}w-1 \\
(\pi) \\
3.00 \mathrm{E}+00\end{array}$ & $\begin{array}{l}\text { M M-1 } \\
\text { (1) secmit) } \\
1.44 \mathrm{E}+\infty\end{array}$ & $\begin{array}{l}\text { W-1 } \\
\text { (b) } \\
\text { SOE }\end{array}$ & $\begin{array}{l}\text { A1-max } \\
\text { (172) } \\
3.00 E+\infty 0\end{array}$ & & $\begin{array}{c}\text { (psig) } \\
1.20 \mathrm{~g} \text { +01 }\end{array}$ & $\begin{array}{c}\text { Po } \\
\text { (PSi) } \\
47 E+01\end{array}$ & 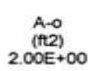 & $\begin{array}{l}v \\
(\mathrm{~N} / 3) \\
68 \mathrm{E}+02\end{array}$ & $\begin{array}{c}\text { C } \\
\text { Wsec) } \\
38 E+03\end{array}$ & & $\begin{array}{l}1-3 \\
\text { sece } \mathrm{ft} \\
22 \mathrm{E}+01\end{array}$ & $\begin{array}{c}h-3 \\
\text { (ffi) } \\
3.94 \mathrm{E}+\infty\end{array}$ & $\begin{array}{c}w-3 \\
(7) \\
3.74 \mathrm{E}+\infty\end{array}$ & $\begin{array}{c}M-3 \\
\text { (il } \mathrm{sec} 2 \mathrm{~m}) \\
7.04 \mathrm{E}+00\end{array}$ & $\begin{array}{c}W \cdot 3 \\
(1 \mathrm{~B}) \\
2.25 \mathrm{E}+02\end{array}$ & $\begin{array}{c}A_{3-\max }(\mathrm{m2}) \\
1.17 \mathrm{E}+01\end{array}$ \\
\hline $\begin{array}{c}1-2 \\
100 \\
3.62 E+2 t \\
3.62 E+0\end{array}$ & $\begin{array}{l}h-2 \\
\text { (f) } \\
.94 \mathrm{E}+\infty\end{array}$ & $\begin{array}{c}w-2 \\
(f i) \\
74 E+\infty 0\end{array}$ & 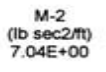 & $\begin{array}{l}W-2 \\
(\text { Di) } \\
25 E+02\end{array}$ & $\begin{array}{l}\text { A2-max } \\
\text { (ff2) } \\
1.47 \mathrm{E}+01\end{array}$ & & $\begin{array}{l}{ }^{\mathrm{n} 1} \\
\mathrm{DOE}+\infty\end{array}$ & $\begin{array}{c}n 2 \\
1.00 E+00\end{array}$ & $\begin{array}{c}n 3 \\
1.00 E+\infty 0\end{array}$ & $\begin{array}{c}n 4 \\
0.00 E+\infty 00\end{array}$ & $\begin{array}{c}n 5 \\
1.00 E+\infty\end{array}$ & & & $\begin{array}{l}\text { h-A } \\
\text { (ff) } \\
.0 O E\end{array}$ & $\begin{array}{l}w-4 \\
(1) \\
(00 E+00\end{array}$ & $\begin{array}{c}\text { M-4 } \\
\text { (becentm } \\
1.44 E+00\end{array}$ & $\begin{array}{c}W-4 \\
\text { (b) } \\
4.60 \mathrm{E}+01\end{array}$ & \\
\hline $\begin{array}{l}\text { Tit } \\
\text { (s }\end{array}$ & gree & $\begin{array}{l}\text { Angle-s } \\
\text { (degree }\end{array}$ & $\begin{array}{l}\begin{array}{l}\text { Angle--3 } \\
\text { (degree) }\end{array}\end{array}$ & $\begin{array}{l}\text { A Av-1 } \\
(f+2)\end{array}$ & $A v-2$ & $\begin{array}{l}\mathrm{A} v-3 \\
(\mathrm{I} 2 \mathrm{2})\end{array}$ & $\begin{array}{l}\text { tance-4 } \\
\text { (ft) }\end{array}$ & $\begin{array}{l}\text { Av-4 } \\
(122)\end{array}$ & ince & $\begin{array}{l}\text { Av-5 } \\
\text { (ft2) }\end{array}$ & $\begin{array}{l}\text { P1 - po } \\
\text { (psi) }\end{array}$ & & & $\begin{array}{l}\text { rave-P-1 } \\
(\mathrm{b} \text { f ft) }\end{array}$ & $\begin{array}{l}\text { que-G-1 } \\
\text { (ib ti) }\end{array}$ & $\begin{array}{l}\text { Torque-tot-1 } \\
\text { (ib fit) }\end{array}$ & c) & $\begin{array}{l}\text { Ang veloc- } \\
\text { (rad/sec) }\end{array}$ \\
\hline 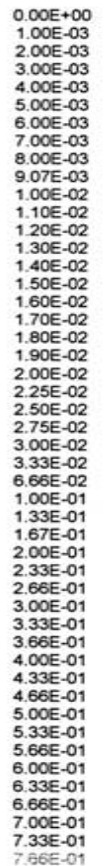 & 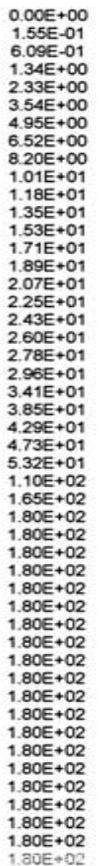 & 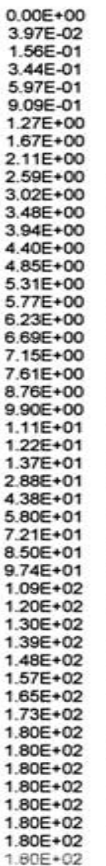 & 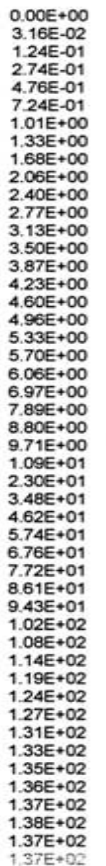 & 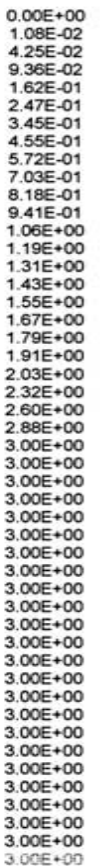 & 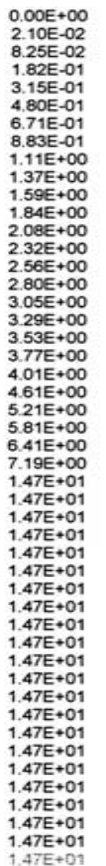 & 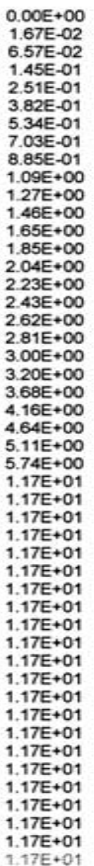 & 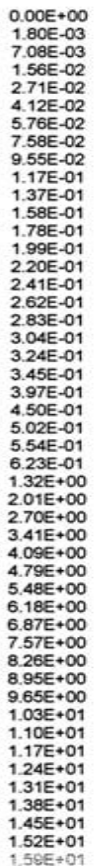 & 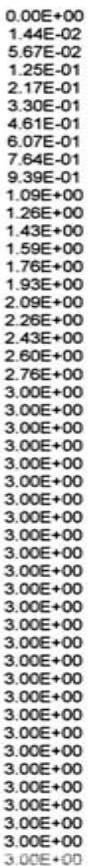 & 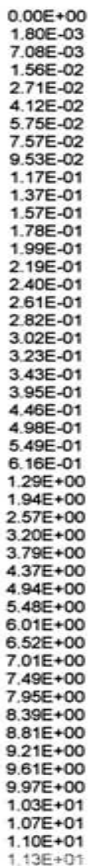 & 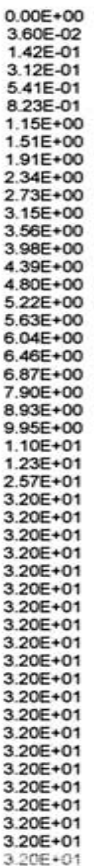 & 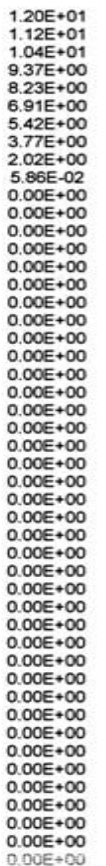 & 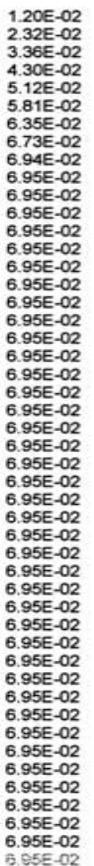 & 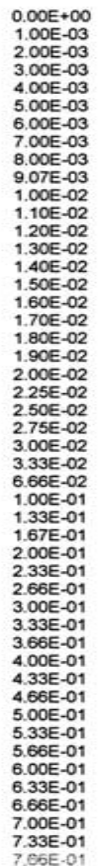 & 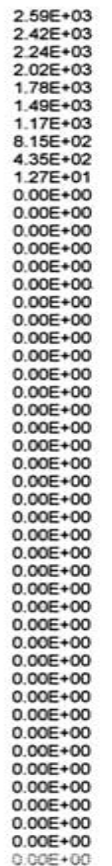 & 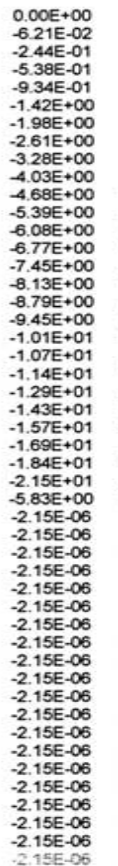 & 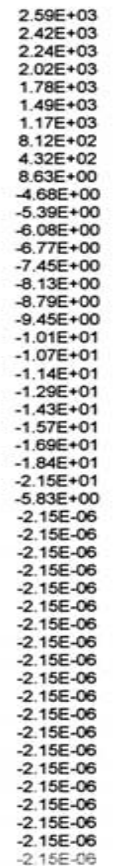 & 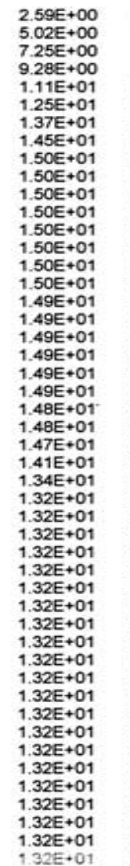 & $\begin{array}{l}+01 \\
+011 \\
+01 \\
+01 \\
+01 \\
+01 \\
+01 \\
+01 \\
+01 \\
+01 \\
+01\end{array}$ \\
\hline
\end{tabular}




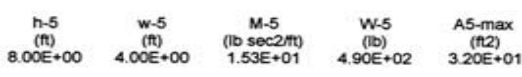

$\begin{array}{cc}\text { mu-k } & \begin{array}{c}\text { Friction } \\ \text { (ID) } \\ 5.00 E-01 \\ 2.45 E+02\end{array}\end{array}$

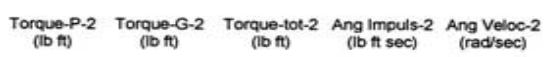

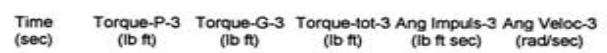

\begin{tabular}{|c|c|c|c|}
\hline 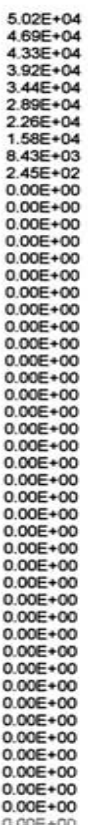 & 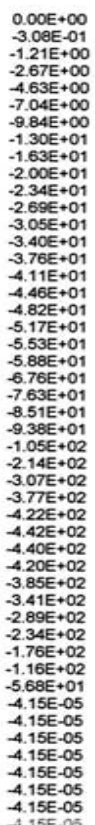 & 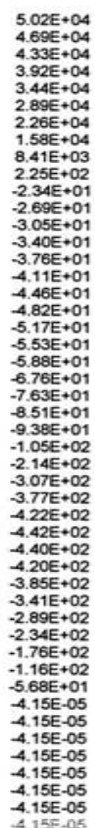 & 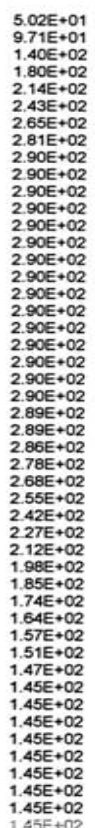 \\
\hline
\end{tabular}

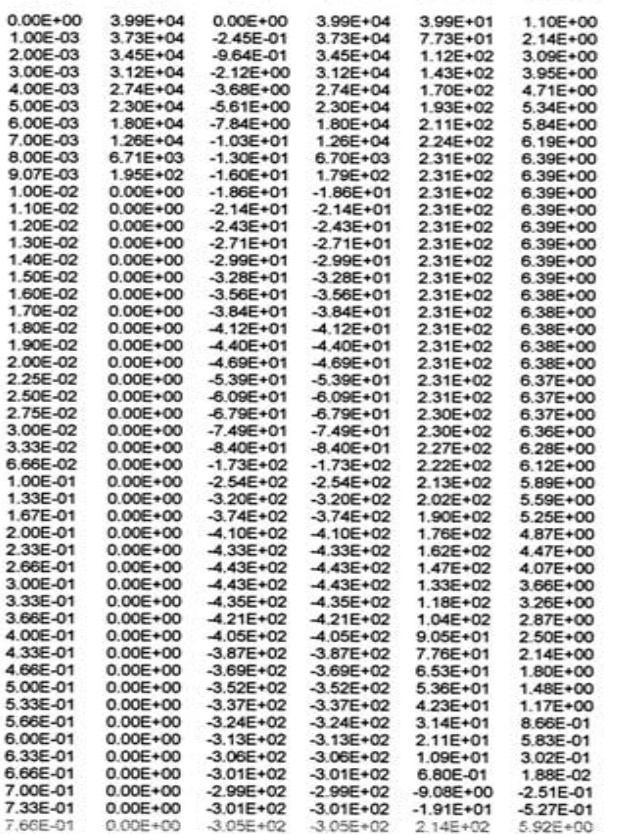

\begin{tabular}{|c|c|c|c|c|c|}
\hline $\begin{array}{l}\text { orce }-4 \\
\text { (bi) }\end{array}$ & $\begin{array}{c}\text { Impulse-4 } \\
(\text { (b-sec) }\end{array}$ & $\begin{array}{l}\text { Veloc } 4 \\
\text { (t/sec) }\end{array}$ & $\begin{array}{l}\begin{array}{c}\text { Force-5 } \\
(\text { (D) }\end{array} \\
\text { (a) }\end{array}$ & $\begin{array}{c}\text { Impulse-5 } \\
(\text { (b-sec) }\end{array}$ & $\begin{array}{l}\text { Veloc-5 } \\
\text { (IN/sec) }\end{array}$ \\
\hline 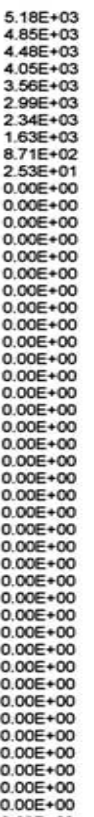 & 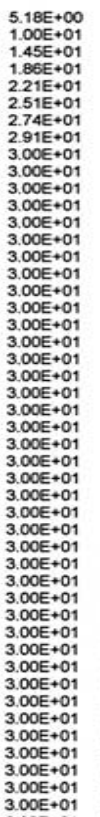 & 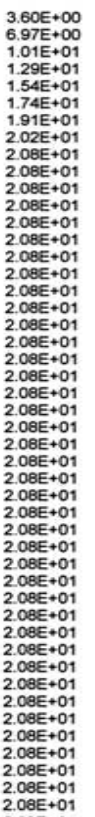 & 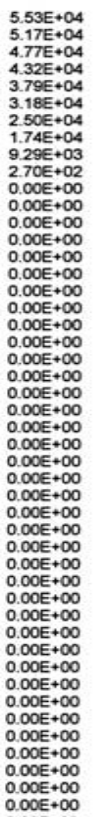 & 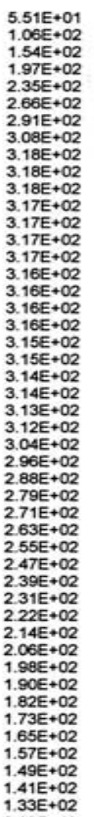 & 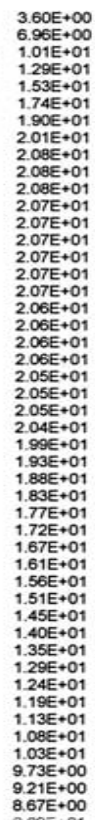 \\
\hline
\end{tabular}




\section{Appendix $\mathrm{A5}$}

Event \#5, Pqs $=40$ psig

\begin{tabular}{|c|c|c|c|c|c|c|c|c|c|c|c|c|c|c|c|c|c|c|}
\hline $\begin{array}{l}-1 \\
-1 \\
e-2 \pi \\
E-01\end{array}$ & $\begin{array}{l}n-1 \\
(n) \\
.00 E+0 C\end{array}$ & 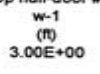 & 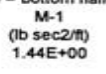 & 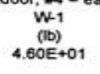 & 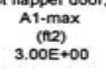 & & $\begin{array}{c}\text { Pqs } \\
\text { (psig) } \\
4.00 E+01\end{array}$ & $\begin{array}{c}P_{0} \\
\text { (PS5) } \\
47 E+01\end{array}$ & 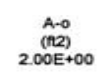 & 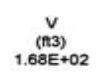 & $\begin{array}{c}c \\
\text { C } \\
\text { (1.sec) } \\
2.38 \mathrm{BE}+03\end{array}$ & & $\begin{array}{c}1 \text { 1.3 } \\
\text { (ib secan } \\
3.62 E+01\end{array}$ & 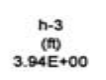 & $\begin{array}{c}w-3 \\
(\pi) \\
3.74 E+00\end{array}$ & $\begin{array}{c}\text { Me-3 } \\
\text { chb secermm } \\
7.04 \mathrm{E}+00\end{array}$ & 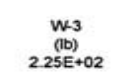 & $\begin{array}{l}\text { A3-max } \\
\text { (fR2) } \\
1.17 \mathrm{E}+01\end{array}$ \\
\hline $\begin{array}{l}1-2 \\
\text { sec2s) } \\
32 E+01\end{array}$ & $\begin{array}{c}\mathrm{h}-2 \\
\text { (fi) } \\
3.94 \mathrm{E} \\
3.94 \mathrm{E}\end{array}$ & 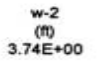 & $\begin{array}{c}M-2 \\
\text { (bi secenm) } \\
7.04 E+00\end{array}$ & $\begin{array}{c}W-2 \\
\text { (D) } \\
2.25 E+02\end{array}$ & $\begin{array}{c}\text { A2-max } \\
\text { (172) } \\
1.47 \mathrm{E}+01\end{array}$ & & $\begin{array}{c}n 1 \\
2.00 E+00\end{array}$ & $\begin{array}{c}n 2 \\
1.00 E+\infty 0\end{array}$ & $\begin{array}{c}{ }^{n 3} \\
1.00 E+00\end{array}$ & $\begin{array}{c}n 4 \\
0.00 E+00\end{array}$ & $\begin{array}{c}{ }^{n 5} \\
1.00 E+\infty\end{array}$ & & & $\begin{array}{c}\mathrm{h}-4 \\
(10) \\
1.00 E+0\end{array}$ & $\begin{array}{c}W-4 \\
w(0) \\
.00 E+00\end{array}$ & $\begin{array}{c}\text { M-4 } \\
\text { ib secermm } \\
1.44 E+00\end{array}$ & & \\
\hline $\begin{array}{l}\text { Time } \\
\text { (sec) }\end{array}$ & $\begin{array}{l}\text { Angle-1 } \\
\text { (Negree) }\end{array}$ & $\begin{array}{l}\text { nogle-2 } \\
\text { egree) }\end{array}$ & $\begin{array}{l}\text { Angle-3 } \\
\text { (degree) }\end{array}$ & $\begin{array}{l}A-1 \\
\text { (n2) }\end{array}$ & $\begin{array}{l}\text { Av-2 } \\
(122)\end{array}$ & $\begin{array}{l}\text { Ave-3 } \\
(n 22)\end{array}$ & $\begin{array}{l}\text { tonce } \\
(\pi)\end{array}$ & $\begin{array}{l}A v-4 \\
(122)\end{array}$ & $\begin{array}{l}\text { stance-s } \\
(70)\end{array}$ & $\begin{array}{l}\text { An-5 } \\
\text { (n2) }\end{array}$ & 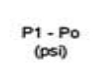 & $\begin{array}{l}\text { Impulse } \\
\text { densty } \\
\text { (esi-sec) }\end{array}$ & $\begin{array}{l}\underbrace{}_{\text {Time }} \\
\text { (sec) }\end{array}$ & $\begin{array}{l}\text { Torque-p-1 } \\
\text { (bi if) }\end{array}$ & (a) & 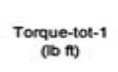 & $\begin{array}{l}\text { Ang Impuls-1 } \\
\text { (b) } \mathrm{n} \text { sec) }\end{array}$ & $\begin{array}{c}\text { Ang Veloce } 1 \\
\text { (rad/sec) }\end{array}$ \\
\hline 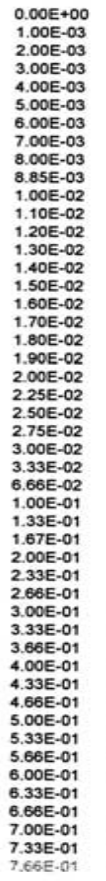 & 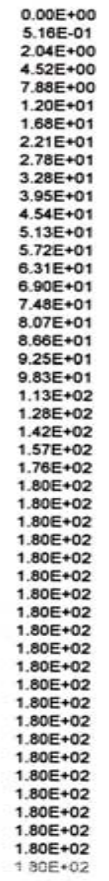 & 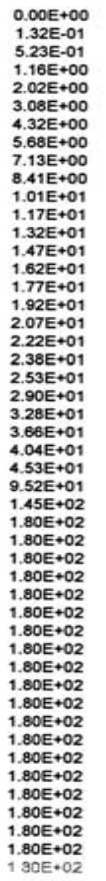 & 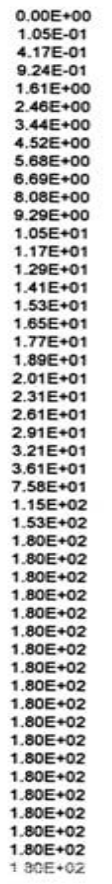 & 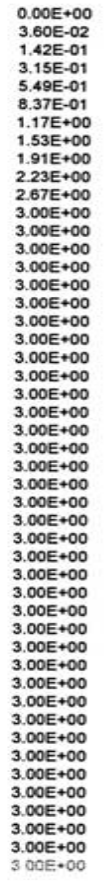 & 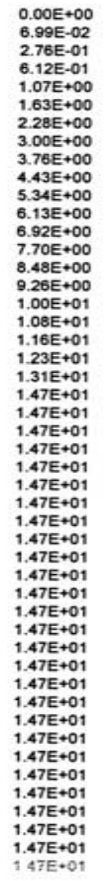 & 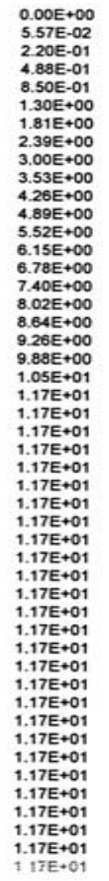 & 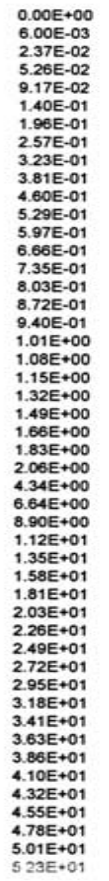 & 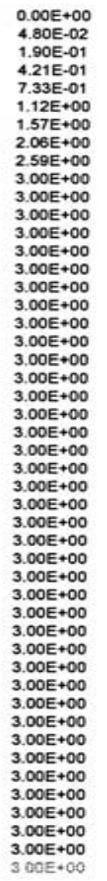 & 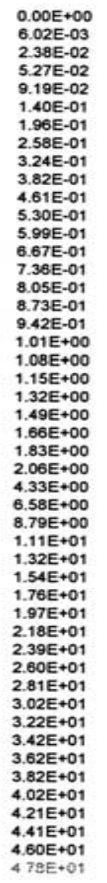 & 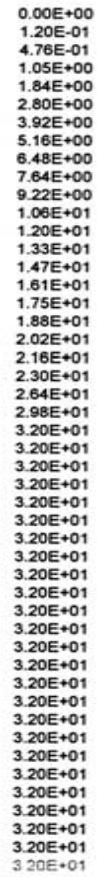 & 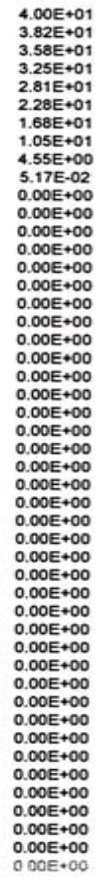 & 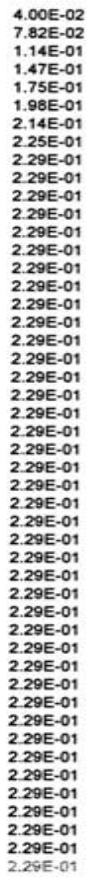 & 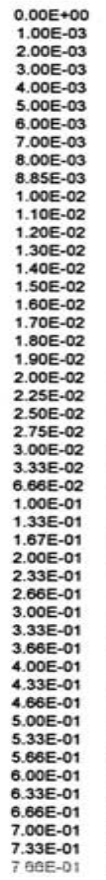 & 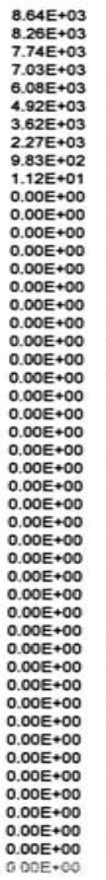 & 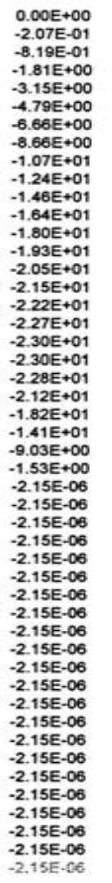 & 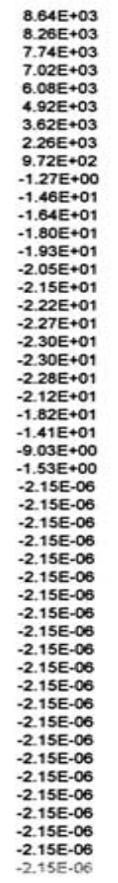 & 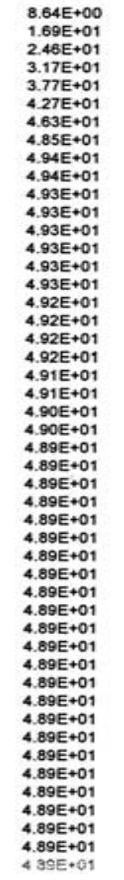 & 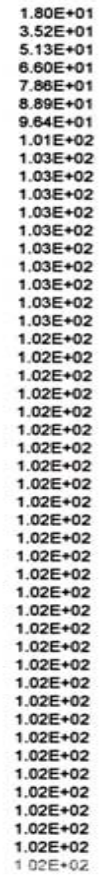 \\
\hline
\end{tabular}




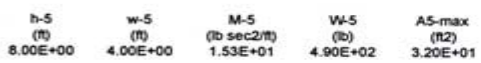

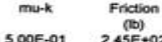

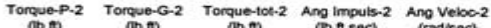

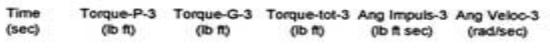

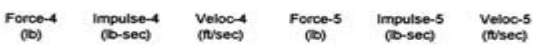

Antot

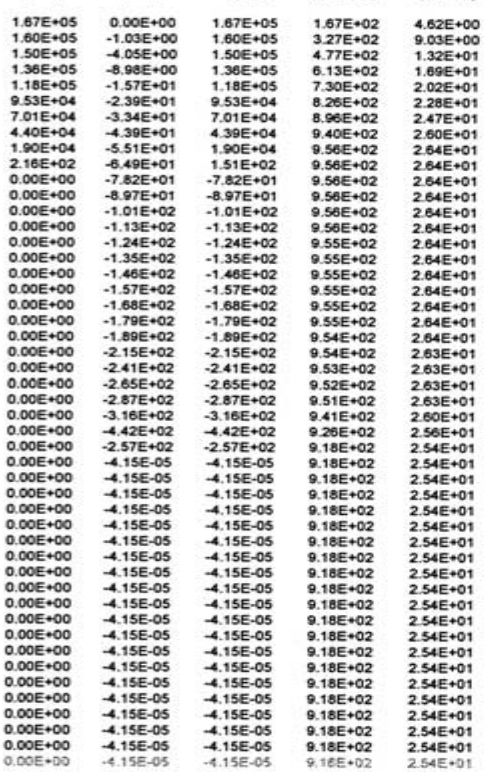

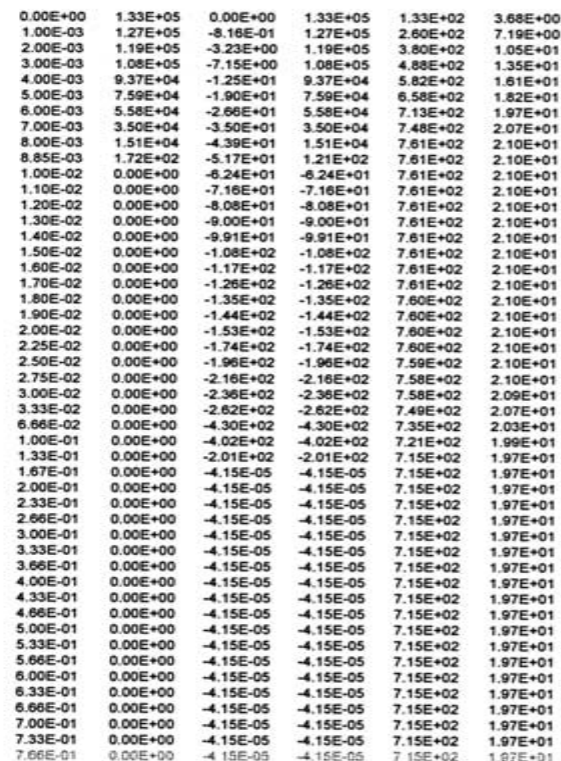

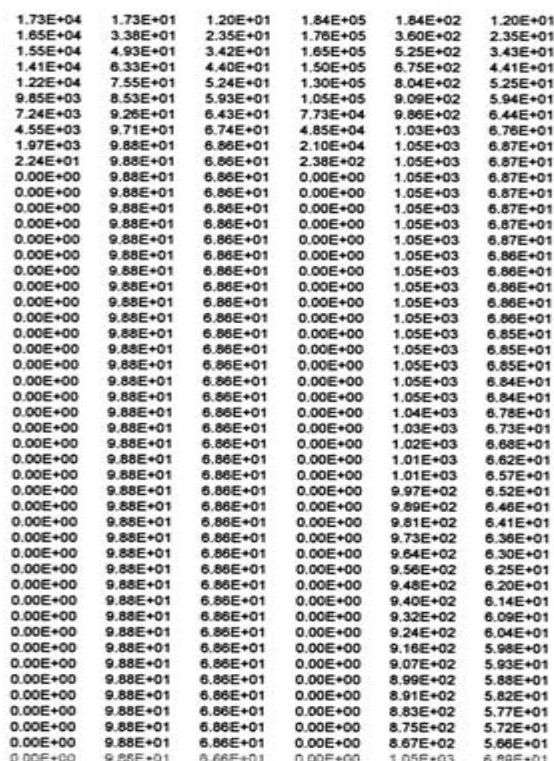

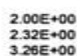

$3.79 E+00$
$6.85 E+00$

1.24 $1.56=0 .+01$

$1.91 E+01$
$2.21 E+01$
$2.62 E+01$

$2.206 E+01$
$3.245+0.9$

$3.806=01$
$4.08 E+01$

4.63E:

and 1

ast

ast

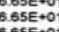

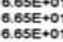

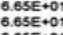

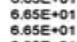

-1
S

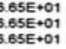




\section{Appendix A.6}

\section{Calculation of Energy Release Based on Fireball Size}

The purpose of this calculation is to estimate the amount of oil that would be burned in a fireball, $10 \mathrm{ft}(3 \mathrm{~m})$ in diameter. A fireball of approximately this size was thought to be observed on the video of the FANTM events.

With a diameter of $3 \mathrm{~m}$, radius of $1.5 \mathrm{~m}$, the fireball volume (if assumed to be a sphere) would be $14.137 \mathrm{~m}^{3}$. If $\mathrm{y}$ is the volume of air in the sphere, the volume fraction of air would be

$\mathrm{v}_{\text {air }}=\frac{\mathrm{y}}{14137 \mathrm{~L}}$

and the volume fraction of oil would be

$\mathrm{v}_{\text {oil }}=1-\frac{\mathrm{y}}{14137 \mathrm{~L}}$

The average density of the fireball can be found from

$$
\begin{aligned}
& \mathrm{v}_{\text {air }} \rho_{\text {air }}+\mathrm{v}_{\text {oil }} \rho_{\text {oil }}=\rho^{\text {av }}{ }_{\text {mixture }}=\frac{\mathrm{M}_{\text {mixture }}}{14137 \mathrm{~L}} \\
& \mathrm{M}_{\text {mixture }}=\left[\mathrm{v}_{\text {air }} \rho_{\text {air }}+\left(1-\frac{\mathrm{y}}{14137} \mathrm{~L}\right) \rho_{\text {oil }}\right] \times 14137 \mathrm{~L}
\end{aligned}
$$

At the stoichiometric mixture, the ratio of masses of air to oil is 11.6 to 1 (see Appendix A.7). Therefore, the mass fraction of air in a stoichiometric burn would be

$$
\begin{aligned}
\mathrm{m}_{\text {air }} & =\frac{11.6}{11.6+1}=0.921 \\
& =\frac{\mathrm{M}_{\text {air }}}{\mathrm{M}_{\text {mixture }}} \\
& \left.=\frac{\rho_{\text {air }} \mathrm{y}}{\left[\mathrm{v}_{\text {air }} \rho_{\text {air }}+\left(1-\frac{\mathrm{y}}{14137} \mathrm{~L}\right.\right.} \rho_{\text {oil }}\right] \times 14137 \mathrm{~L}
\end{aligned}
$$


Solving for the volume of air in the sphere,

$y=\frac{0.921 \times 14137 \mathrm{~L} \times \rho_{\text {oil- }}}{(1-0.921) \rho_{\text {air }}+0.921 \rho_{\text {oil }}}$

In the fireball, the oil would likely become vaporized because of the temperature rise resulting from the event. The densities of the oil and the air are described by:

$\rho_{\text {oil }}=\frac{\mathrm{P} \mathrm{M}_{\mathrm{oil}}}{\mathrm{R} \mathrm{T}}$

$\rho_{\text {air }}=\frac{\mathrm{P} \mathrm{M}_{\text {air }}}{\mathrm{R} \mathrm{T}}$

Where $\mathrm{M}_{\text {oil }}$ and $\mathrm{M}_{\text {air }}$ are the molecular weights of oil vapor $\left(\mathrm{C}_{18} \mathrm{H}_{34} \mathrm{O}_{3}, 298 \mathrm{~g} / \mathrm{mole}\right.$, see Appendix A.7) and air, respectively.

The fireball is assumed to burn at the flame temperature (2000 K, Skaggs et al., (1999)):

$$
\begin{aligned}
\rho_{\text {oil }} & =\frac{101325 \mathrm{~Pa} \times 298 \mathrm{~g} / \mathrm{mole}}{8.314 \mathrm{~Pa} \mathrm{~m}^{3} / \mathrm{mole} \mathrm{K} \times 2000 \mathrm{~K} \times 1000 \mathrm{~L} / \mathrm{m}^{3}} \\
& =1.816 \mathrm{~g} / \mathrm{L} \\
\rho_{\text {air }} & =\frac{101325 \mathrm{~Pa} \times 28.84 \mathrm{~g} / \mathrm{mole}}{8.314 \mathrm{~Pa} \mathrm{~m} / \mathrm{mole} \mathrm{K} \times 2000 \mathrm{~K} \times 1000 \mathrm{~L} / \mathrm{m}^{3}} \\
& =0.176 \mathrm{~g} / \mathrm{L}
\end{aligned}
$$

Substituting and solving for the volume of air in the sphere, $y=14020 \mathrm{~L}$.

Therefore, the volume of oil in a fireball at $2000 \mathrm{~K}$ would be $(14137 \mathrm{~L}-14020 \mathrm{~L})$

$=117 \mathrm{~L}$. The mass of oil in a fireball at $2000 \mathrm{~K}$ would be $117 \mathrm{~L} \times 1.816 \mathrm{~g} / \mathrm{L}=212$ g. The mass of air in the fireball at $2000 \mathrm{~K}$ would be $14020 \mathrm{~L} \times 0.176 \mathrm{~g} / \mathrm{L}=$ $2.47 \times 10^{3} \mathrm{~g}$.

The oil in the fire ball is assumed to completely burn. The heat of combustion of castor oil is $37.1 \mathrm{MJ} / \mathrm{kg}$. If $212 \mathrm{~g}$ of oil is burned, the total energy release would be $7.87 \mathrm{MJ}$. If the $2 \mathrm{MJ}$ of electrical energy is added in, the total energy release would be $9.87 \mathrm{MJ}(\Delta \mathrm{H})$ (this is conservative, since much of the electrical energy would be consumed in creating the conditions allowing for combustion of the oil, i.e., atomizing the oil). 
The capacitor bay air volume is approximately $8120 \mathrm{~m}^{3}$, assuming $10 \%$ equipment occupancy and dimensions of $250 \mathrm{ft} \times 49 \mathrm{ft} \times 26 \mathrm{ft}$. Using the ideal gas equation, the number of moles of oxygen and nitrogen in the capacitor bay air can be determined:

$\mathrm{N}_{\mathrm{O} 2}=7.1 \times 10^{4}$ gmole

$\mathrm{N}_{\mathrm{N} 2}=2.67 \times 10^{5}$ gmole

The temperature rise of the air in the bay can be determined using the following:

$\Delta \mathrm{H}=\mathrm{N}_{\mathrm{O} 2} \mathrm{Cv}_{\mathrm{O} 2} \Delta \mathrm{T}+\mathrm{N}_{\mathrm{N} 2} \mathrm{Cv}_{\mathrm{N} 2} \Delta \mathrm{T}$

$\mathrm{Cv}_{\mathrm{O} 2}=26.3 \mathrm{~J} /$ gmole $\mathrm{K}$

$\mathrm{Cv}_{\mathrm{N} 2}=20.0 \mathrm{~J} /$ gmole $\mathrm{K}$

With a fireball temperature of $2000 \mathrm{~K}, \Delta \mathrm{H}^{2000}=9.87 \mathrm{MJ}$. Solving for the resulting temperature rise, $\Delta \mathrm{T}^{2000}=1.37 \mathrm{~K}$. The final bay pressure can be obtained from:

$$
\begin{aligned}
& \frac{\underline{P}_{\text {initial }}}{\mathrm{T}_{\text {initial }}}=\frac{\underline{P}_{\text {final }}}{\mathrm{T}_{\text {final }}} \\
& \begin{aligned}
\mathrm{P}_{\text {final }}= & \frac{\left(\underline{T}_{\text {initial }}+\Delta \mathrm{T}\right)}{\mathrm{T}_{\text {initial }}} \mathrm{P}_{\text {initial }} \\
& =\frac{294.37}{293} \times 14.7 \mathrm{psi} \\
& =14.77 \mathrm{psi} \\
\text { Overpressure } & =(14.77-14.7) \times 144 \\
& =9.9 \mathrm{psf}
\end{aligned}
\end{aligned}
$$

This is below the wall structural limit of $30 \mathrm{psf}$.

A second calculation related to the fireball was performed. Formulas relating the mass of a munition vs fireball diameter (Rakaczky, 1975) and mass of propellant vs fireball diameter (High, 1968) were used to estimate the ballpark quantity of material involved.

Fireball size $(D)=f($ munition mass $)($ Rakaczky, 1975)

$\mathrm{D} \quad=3.76 \mathrm{M}^{0.325}$, with $\mathrm{D}$ in $\mathrm{m}, \mathrm{M}$ in $\mathrm{kg}$

$\underline{\mathrm{D}}=\mathrm{M}^{0.325}$

3.76

$\mathrm{M} \quad=(\mathrm{D} / 3.76)^{1 / 0.325}$ 
For a $3 \mathrm{~m}$ fireball, $\mathrm{M}=(3 / 3.76)^{1 / 0.325}=0.499 \mathrm{~kg}=1.10 \mathrm{lb}$

Duration:

$$
\begin{aligned}
\mathrm{t} \quad & =0.258 \mathrm{M}^{0.349} \\
& =0.258(0.499)^{0.349} \\
& =0.202 \mathrm{sec}
\end{aligned}
$$

In the video, the fireball duration was about 6 frames $=0.2$ seconds. This is close to the 0.202 seconds estimated using the above formula.

Fireball size $(D)=f($ propellant mass $)($ High,1968)

D $\quad=9.82 \mathrm{~W}^{0.32}$, with $\mathrm{D}$ in $\mathrm{ft}, \mathrm{W}$ in $\mathrm{lb}$

$\mathrm{W} \quad=(\mathrm{D} / 9.82)^{1 / 0.32}$

For a $3 \mathrm{~m}$ fireball, $\mathrm{W}=(9.84 / 9.82)^{1 / 0.32}=1.01 \mathrm{lb}=0.459 \mathrm{~kg}$

Duration:

$$
\begin{aligned}
\mathrm{t} & =0.232 \mathrm{~W}^{0.34} \\
& =0.232(1.01 \mathrm{lb})^{0.34} \\
& =0.232 \mathrm{sec}
\end{aligned}
$$

For a 2 meter fireball the munition estimate gives $0.31 \mathrm{lb}$, while the propellant estimate gives $0.275 \mathrm{lb}$. For a 3 meter fireball, the munition amount is $1.10 \mathrm{lb}$, while the propellant amount is $1.01 \mathrm{lb}$. Although the NIF capacitor modules will not contain munitions or propellants, empirical evidence from this single failure puts the range of equivalent explosive material in the $0.3-1 \mathrm{lb}$ range, consistant with other estimates in this document. Note, however, that the burning of the oil actually occurs much more slowly (msecs) compared to explosive reactions (usecs). Thus, care must be taken when referring to a TNT equivalent, which may generate the same peak pressure, but the shock wave phenomenon is very different.

\section{$\underline{\text { References }}$}

High, Richard, The Saturn Fireball, NASA Manned Spacecraft Center, Annals of the New York Academy of Sciences, I52, I, 1968, pp441-451.

Rakaczky, J.A.,(1975) The Suppression of Thermal hazards from Explosions of Munitions: A Literature Survey, BRL Internal Memorandum Report 377, Aberdeen Proving Ground, Maryland. 


\section{Appendix A.7}

\section{Calculation of Energy Release Based on Oxygen Limited Conditions}

The purpose of this calculation is to determine the maximum amount of oil that could combust, assuming the reaction is limited by the amount of oxygen contained in the free space of the module.

Vmod $=11.88 \mathrm{~m}^{3}$

Vair $=0.4 \times \operatorname{Vmod}=4.75 \mathrm{~m}^{3}$

The number of moles of air contained in the free space of the module can be determined from the ideal gas equation:

$$
\begin{aligned}
\text { Nair } & =\underline{\mathrm{P} \text { Vair }} \\
& =\frac{101325 \mathrm{~Pa} \times 4.75 \mathrm{~m}^{3}}{8.314{\mathrm{~Pa} . \mathrm{m}^{3}}^{3} / \mathrm{mole} \mathrm{K}^{\mathrm{K}} \times 293 \mathrm{~K}} \\
& =197.6 \text { moles }
\end{aligned}
$$

Air is $21 \%$ oxygen, so the number of moles of oxygen available is:

$$
\begin{aligned}
\mathrm{N}_{\mathrm{O} 2} & =0.21 \times 197.6 \\
& =41.5 \text { moles }
\end{aligned}
$$

The stoichiometry for the reaction for complete combustion of castor oil $\left(\mathrm{C}_{18} \mathrm{H}_{34} \mathrm{O}_{3}\right)$ is:

$1.66 \mathrm{C}_{18} \mathrm{H}_{34} \mathrm{O}_{3}+41.5 \mathrm{O}_{2}--\ddagger$ combustion products

$$
\begin{gathered}
\frac{\text { air mass }}{\text { oil mass }}=\frac{41.5 \times 32+0.79 / 0.21 \times 28}{1.66 \times 298} \\
=11.6
\end{gathered}
$$

The molecular weight of castor oil is $298 \mathrm{~g} /$ mole. So for complete consumption of the oxygen, 1.66 moles, or $495 \mathrm{~g}$ of oil would be consumed.

The heat of combustion of castor oil is $37.1 \mathrm{MJ} / \mathrm{kg}$. If $495 \mathrm{~g}$ of oil is burned, the total energy release would be $18.4 \mathrm{MJ}$. If the $2 \mathrm{MJ}$ of electrical energy is added in, the total energy release would be $20.4 \mathrm{MJ}(\Delta \mathrm{H})$ (this is conservative, since much of the electrical energy would be consumed in creating the conditions allowing for combustion of the oil, i.e., atomizing the oil). 
The capacitor bay air volume is approximately $8120 \mathrm{~m}^{3}$, assuming $10 \%$ equipment occupancy and dimensions of $250 \mathrm{ft} \times 49 \mathrm{ft} \times 26 \mathrm{ft}$. Using the ideal gas equation, the number of moles of oxygen and nitrogen in the capacitor bay air can be determined:

$\mathrm{N}_{\mathrm{O} 2}=7.09 \times 10^{4}$

$\mathrm{N}_{\mathrm{N} 2}=2.67 \times 10^{5}$

The temperature rise of the air in the bay can be determined using the following:

$\Delta \mathrm{H} \quad=\mathrm{N}_{\mathrm{O} 2} \mathrm{Cv}_{\mathrm{O} 2} \Delta \mathrm{T}+\mathrm{N}_{\mathrm{N} 2} \mathrm{Cv}_{\mathrm{N} 2} \Delta \mathrm{T}$

$\mathrm{Cv}_{\mathrm{O} 2}=26.3 \mathrm{~J} /$ gmole $\mathrm{K}$

$\mathrm{Cv}_{\mathrm{N} 2}=20.0 \mathrm{~J} /$ gmole $\mathrm{K}$

Solving, $\Delta \mathrm{T}=2.8 \mathrm{~K}$

$$
\begin{aligned}
& \begin{aligned}
& P_{\text {final }}= \frac{(\mathrm{To}+\Delta \mathrm{T})}{\mathrm{To}} \mathrm{P}_{\text {initial }} \\
&=\frac{295.8}{293} \times 14.7 \mathrm{psi} \\
&=14.84 \mathrm{psi} \\
& \\
& \text { Overpressure } \quad=(14.84-14.7) \times 144 \\
& \quad=20.2 \mathrm{psf}
\end{aligned}
\end{aligned}
$$

This is below the wall structural limit of 30 psf. 


\section{Appendix A.8}

\section{Calculation of Energy Release Due to Vaporization of Oil in Capacitor Can}

The purpose of this calculation is to estimate the amount of oil that could be vaporized by the electrical energy deposited in the capacitor can. The vaporized oil is then assumed to be available for combustion.

The first step is to estimate the amount of energy that could be deposited in the oil. At total of $2 \mathrm{MJ}$ of electrical energy is available. When the fault begins to occur, the electrical energy will start to dump into the oil. The fraction that can be dumped is determined from the ratio of resistance of the arc $(\sim 3 \mathrm{ohm})$ to the resistance of the damping element $(\sim 20 \mathrm{ohm})$. This allows a maximum of $0.3 \mathrm{MJ}$ to be deposited in the oil.

Properties of oil:

$\mathrm{C}_{\mathrm{p}}=2088 \mathrm{~J} / \mathrm{kg} \mathrm{K}$

$\Delta \mathrm{H}_{\text {vap }}=3.36 \times 10^{5} \mathrm{~J} / \mathrm{kg}$

$\rho=962 \mathrm{~kg} / \mathrm{m}^{3}$

$\mathrm{T}_{\text {boil }}=586 \mathrm{~K}$

The system can be viewed as follows:

\section{Figure A.8-1}

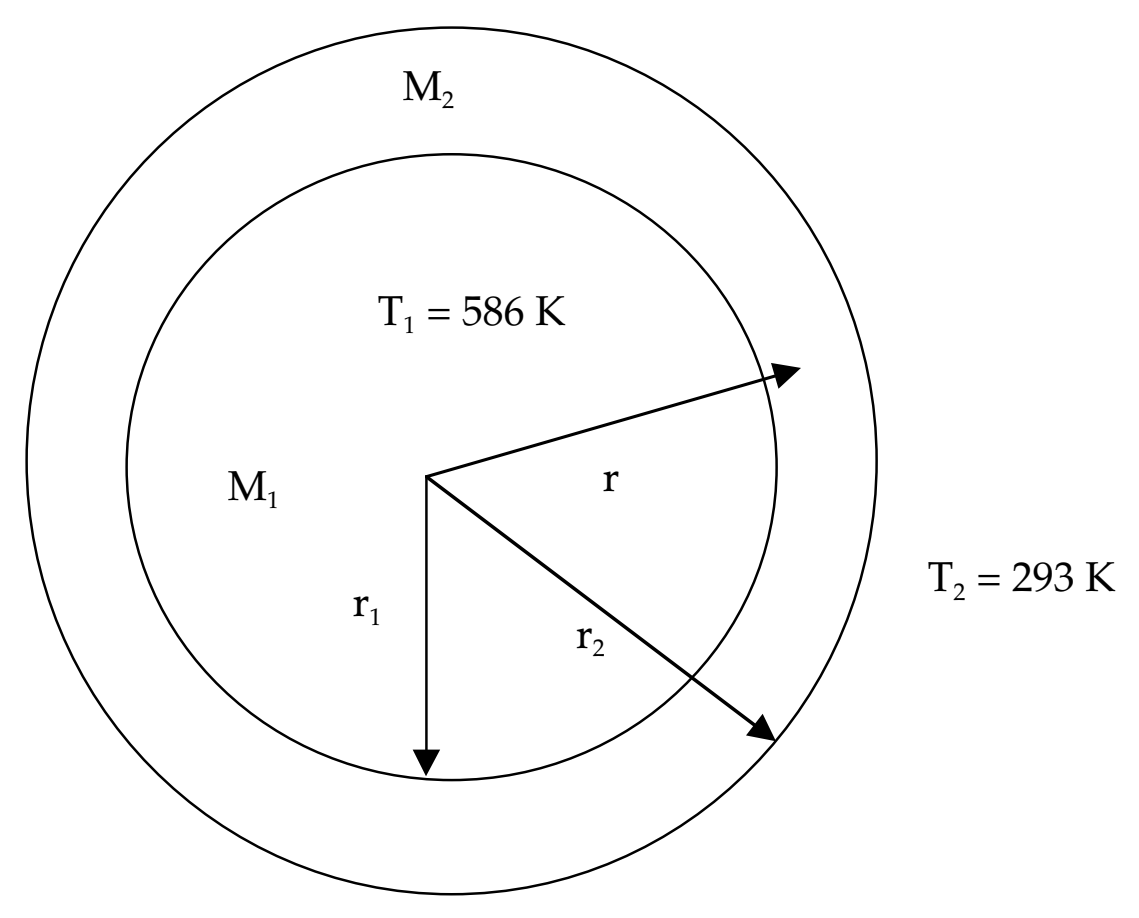


The analysis assumes that the arc dumps its energy at a point, such that a sphere of vapor is created. The vapor is assumed to remain at the boiling point, at ambient pressure. In reality, the sphere of vapor would be surrounded by a layer of liquid, over which a temperature gradient from boiling $(586 \mathrm{~K})$ to ambient $(293 \mathrm{~K})$ would exist. Conservatively, for this calculation, the energy to heat up this shell of liquid is ignored (i.e., $r_{1}=r_{2}=r$ ). Rather, the energy is assumed to be consumed in creating vapor, which is then assumed to ignite.

Calculate the energy to heat and vaporize M1, within the volume $4 / 3 \pi r 1^{3}$ :

$$
\begin{aligned}
\mathrm{E}_{1} & =\mathrm{M}_{1} \mathrm{C}_{\mathrm{p}} \Delta \mathrm{T}+\mathrm{M}_{1} \Delta \text { Hvap } \\
& =\mathrm{M}_{1} \times 2088(586-293)+\mathrm{M}_{1} \times 3.36 \times 10^{5} \\
& =9.48 \times 10^{5} \mathrm{M}_{1} \\
& =9.48 \times 10^{5} \times \rho \times 4 / 3 \pi \mathrm{r}_{1}^{3} \\
& =3.82 \times 10^{9} \mathrm{r}_{1}^{3}
\end{aligned}
$$

The energy to heat and vaporize is derived from the arc, which contains $3 \times 10^{5} \mathrm{~J}$ of energy.

$$
\begin{array}{ll}
3 \times 10^{5} & =3.82 \times 10^{9} \mathrm{r}_{1}{ }^{3} \\
\mathrm{r}_{1}{ }^{3} & =7.85 \times 10^{-5} \\
\mathrm{r}_{1} & =0.0428 \mathrm{~m} \\
\mathrm{~V}_{1} & =3.28 \times 10^{-4} \mathrm{~m}^{3} \\
\mathrm{M}_{1} & =0.316 \mathrm{~kg}
\end{array}
$$

The heat of combustion of castor oil is $37.1 \mathrm{MJ} / \mathrm{kg}$. If $316 \mathrm{~g}$ of oil burn, the total energy release would be $11.7 \mathrm{MJ}$. If the $2 \mathrm{MJ}$ of electrical energy is added in, the total energy release would be 13.7 $\mathrm{MJ}(\Delta \mathrm{H})$ (this is conservative, since much of the electrical energy would be consumed in creating the conditions allowing for combustion of the oil, i.e., vaporizing the oil).

From the energy release, the temperature rise, and resultant overpressure can be determined as in Appendix A.6. 


\section{Appendix A.9}

\section{Calculation of Energy Released Based on the Cheetah Code}

To follow is input data for Cheetah:

Moist air density: $1.185 \mathrm{~g} / \mathrm{L} @ 25^{\circ} \mathrm{C}$

Free air volume in the module: $173.5 \mathrm{ft}^{3} \times 28.3168 \mathrm{~L} / \mathrm{ft}^{3}=4912.971 \mathrm{~L}$

Mass of air in module: $4912.971 \mathrm{~L} \times 1.185 \mathrm{~g} / \mathrm{L}=5.82 \mathrm{~kg}$

Three gallons of oil available: 3 gal x $8.337 \mathrm{lb} /$ gal x $0.962=24 \mathrm{lb}, 10.89 \mathrm{~kg}$

Adding the masses of available constituents, the total mixture mass is: $16.71 \mathrm{~kg}$, $65.17 \%$ oil by weight.

Stoichiometric mixture would be (Staggs, 1999): $\quad 5.82 \mathrm{~kg}$ air $\underline{0.502 \mathrm{~kg} \text { oil }}$

$6.322 \mathrm{~kg}$ total, $7.94 \%$ oil, $92.059 \%$ air

To follow is output from Cheetah:

Mixture specific volume: $432 \mathrm{~cm}^{3} / \mathrm{g}$

$6322 \mathrm{~g} \times 432 \mathrm{~cm}^{3} / \mathrm{g}=2.73 \times 10^{6} \mathrm{~cm}^{3}$

Mixture energy density: $0.004 \mathrm{~kJ} / \mathrm{cm}^{3}$

$2.73 \times 10^{6} \mathrm{~cm}^{3} \times 0.004 \mathrm{~kJ} / \mathrm{cm}^{3}=10,900 \mathrm{~kJ}=10.9 \mathrm{MJ}$

\section{$\underline{\text { References }}$}

Staggs, K. et al., (1999), "Fire Risk Analysis for the NIF Capacitor Containment Design", Lawrence Livermore National Laboratory, UCRL-ID-133180, February 1999. 


\section{Appendix A.9}

\section{Calculation of Energy Released Based on the Cheetah Code}

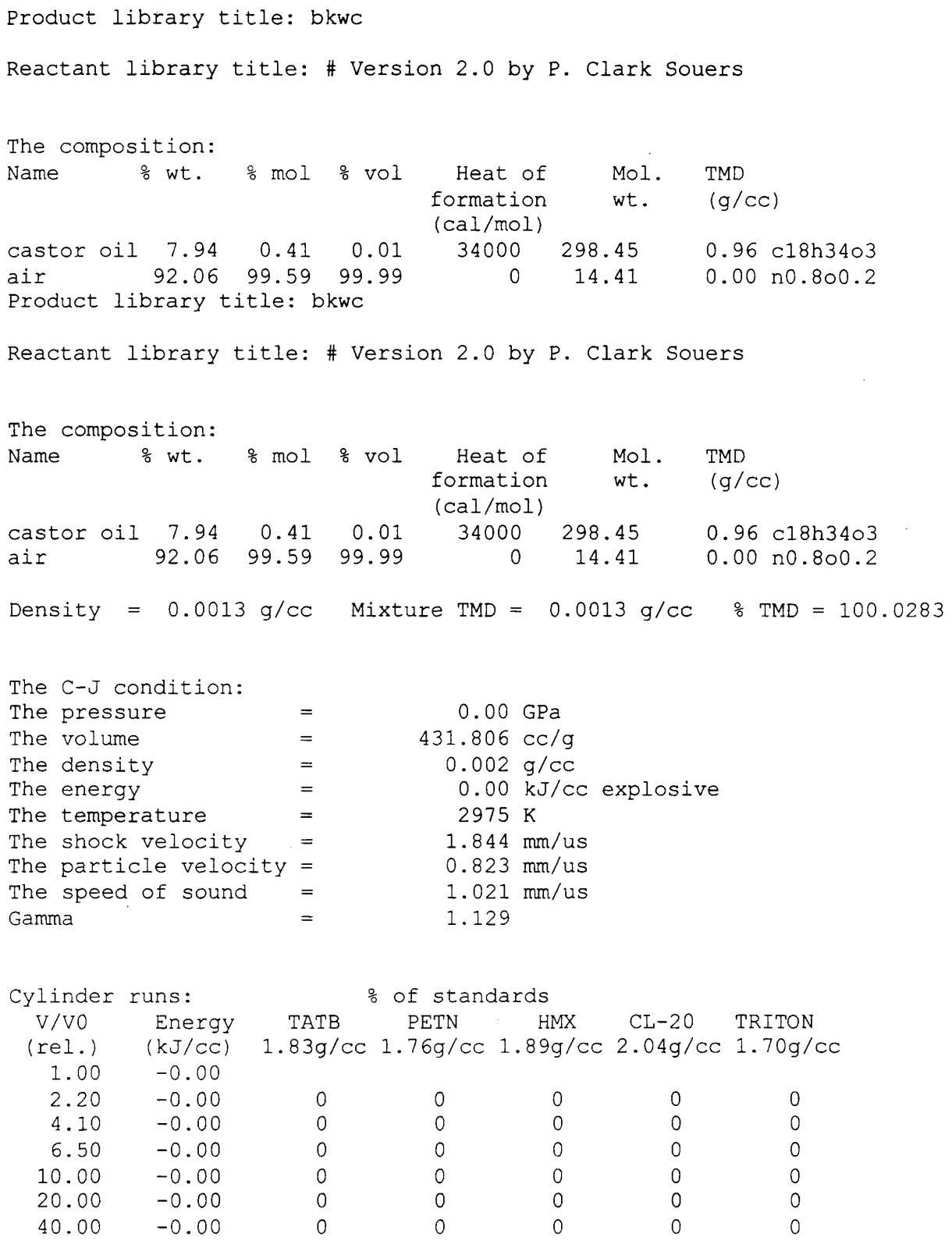

$\begin{array}{ccccccc}\text { Cylinder } & \text { runs: } \\ \text { V/VO } & \text { Energy } & \text { TATB } & \text { PETN } & \text { HMX } & \text { CL-20 } & \text { TRITON } \\ \text { (rel.) } & \text { (kJ/cc) } & 1.83 \mathrm{~g} / \mathrm{cc} & 1.76 \mathrm{~g} / \mathrm{cc} & 1.89 \mathrm{~g} / \mathrm{cc} & 2.04 \mathrm{~g} / \mathrm{cc} & 1.70 \mathrm{~g} / \mathrm{cc} \\ 1.00 & -0.00 & & & & 0 & \\ 2.20 & -0.00 & 0 & 0 & 0 & 0 & 0 \\ 4.10 & -0.00 & 0 & 0 & 0 & 0 & 0 \\ 6.50 & -0.00 & 0 & 0 & 0 & 0 & 0 \\ 10.00 & -0.00 & 0 & 0 & 0 & 0 & 0 \\ 20.00 & -0.00 & 0 & 0 & 0 & 0 & 0 \\ 40.00 & -0.00 & 0 & 0 & 0 & 0 & 0\end{array}$


MESN99-066-OA

NIF-0063594

N.M. 6.4 .

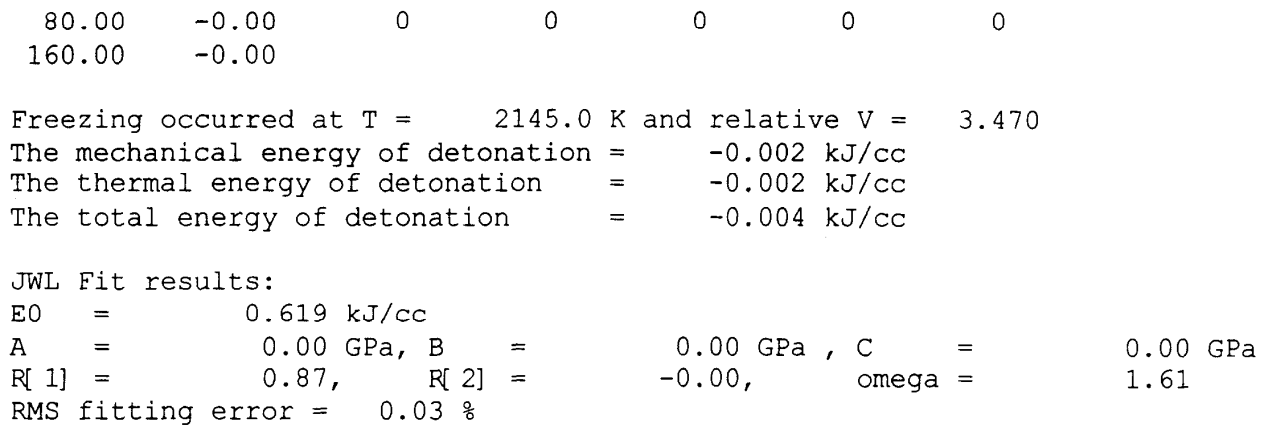


The Composition

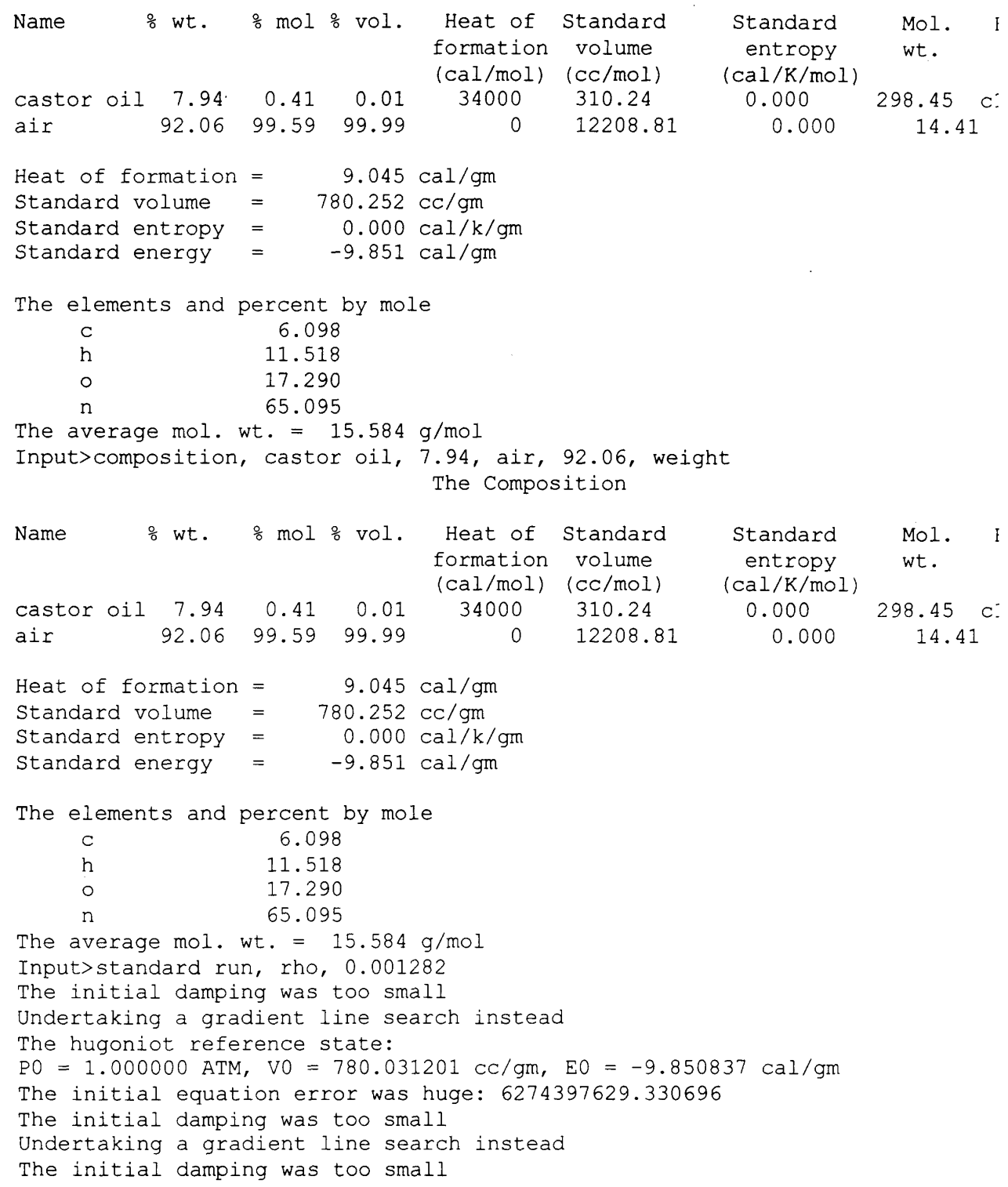


Undertaking a gradient line search instead Too many iterations in the etanewt solver Failed to find equilibrium. Will try again. Too many iterations in the etanewt solver Failed to find equilibrium. Will try again. Too many iterations in the etanewt solver Failed to find equilibrium. Will try again. Too many iterations in the etanewt solver Failed to find equilibrium. Will try again. Too many iterations in the etanewt solver Failed to find equilibrium. Will try again. Too many iterations in the etanewt solver Failed to find equilibrium. Will try again. Too many iterations in the etanewt solver Failed to find equilibrium. Will try again. Too many iterations in the etanewt solver

Failed to find equilibrium. Will try again. Too many iterations in the etanewt solver Failed to find equilibrium. Will try again. Too many iterations in the etanewt solver Failed to find equilibrium. Will try again. An attempt to find a thermo point failed. Error in find equilibrium, continuing ... The initial equation error was huge: 43038033.995459

Using 10 ATM as a lower bound for the C-J pressure

Using 26 ATM as an upper bound for the C-J pressure

The C-J point was bracketed in cjbrent

The $\mathrm{CJ}$ state was found in 6 iterations

The $\mathrm{C}-\mathrm{J}$ condition

The shock velocity $=1.84390 \mathrm{e}+003 \mathrm{~m} / \mathrm{s}$

The particle velocity $=8.23163 \mathrm{e}+002 \mathrm{~m} / \mathrm{s}$

The speed of sound $=1.02074 \mathrm{e}+003 \mathrm{~m} / \mathrm{s}$

$\mathrm{PO}=\quad 1 \mathrm{~atm}, \mathrm{VO}=780.03120 \mathrm{cc} / \mathrm{gm}, \mathrm{E} 0=-9.85084 \mathrm{cal} / \mathrm{gm}$

Reference state $=$ reactants

$H(R)=H-9.05, E(R)=E--9.85, S(R)=S-0.00$

$\begin{array}{cccccccc} & \mathrm{P} & \mathrm{V} & \mathrm{T} & \mathrm{H}(\mathrm{R}) & \mathrm{E}(\mathrm{R}) & \mathrm{S}(\mathrm{R}) & \mathrm{VGS} \\ & (\mathrm{ATM}) & (\mathrm{CC} / \mathrm{GM}) & (\mathrm{K}) & (\mathrm{CAL} / \mathrm{GM}) & (\mathrm{CAL} / \mathrm{GM}) & (\mathrm{CAL} / \mathrm{K} / \mathrm{GM}) & (\mathrm{CC} / \mathrm{GM}) \\ 1 .) & 20.2 & 431.8058 & 2974.7 & 281.80 & 89.41 & 2.199 & 431.8058\end{array}$

Product concentrations

Name (mol/kg) (mol gas/mol explosive)

n2 Gas 2.534e+001 3.950e-001 
MESN99-066-OA

NIF-0063594

N.M. 6.4.

\begin{tabular}{|c|c|c|c|}
\hline h2o & Gas & $4.207 e+000$ & $6.556 \mathrm{e}-002$ \\
\hline $\mathrm{CO} 2$ & Gas & $3.098 e+000$ & $4.828 e-002$ \\
\hline $\mathrm{CO}$ & Gas & $1.691 \mathrm{e}+000$ & $2.635 e-002$ \\
\hline 02 & Gas & $5.257 e-001$ & $8.193 e-003$ \\
\hline 11 & Gas & $4.330 e-001$ & $6.748 e-003$ \\
\hline h & Gas & $3.159 \mathrm{e}-001$ & $4.922 e-003$ \\
\hline no2 & Gas & $2.685 e-004$ & $4.185 e-006$ \\
\hline n3n & Gas & $3.714 e-006$ & $5.788 e-008$ \\
\hline & Gas & $1.524 \mathrm{e}-006$ & $2.374 \mathrm{e}-008$ \\
\hline & Gas & $1.705 e-007$ & $2.656 \mathrm{e}-009$ \\
\hline c & Gas & De-011 & $2.883 e-013$ \\
\hline & Gas & $2 e-012$ & 14 \\
\hline $\operatorname{ch} 3$ & Gas & $5.509 e-013$ & $8.585 e-015$ \\
\hline $\mathrm{c} 2 \mathrm{~h} 4$ & Gas & $2.676 e-019$ & $4.170 e-021$ \\
\hline $\mathrm{c} 2 \mathrm{~h} 6$ & Gas & $2.011 \mathrm{e}-024$ & $3.134 \mathrm{e}-026$ \\
\hline & solid & $0.000 e+000$ & $0.000 e+000$ \\
\hline & & & \\
\hline & & & $0 \Omega$ \\
\hline
\end{tabular}

The C-J Adiabat

Reference state $=$ reactants

$H(R)=H-9.05, E(R)=E--9.85, S(R)=S-0.00$

$\begin{array}{ccccccc}\mathrm{P} & \mathrm{V} & \mathrm{T} & \mathrm{H}(\mathrm{R}) & \mathrm{E}(\mathrm{R}) & \mathrm{S}(\mathrm{R}) & \mathrm{VGS} \\ (\mathrm{ATM}) & (\mathrm{CC} / \mathrm{GM}) & (\mathrm{K}) & (\mathrm{CAL} / \mathrm{GM}) & (\mathrm{CAL} / \mathrm{GM}) & (\mathrm{CAL} / \mathrm{K} / \mathrm{GM}) & (\mathrm{CC} / \mathrm{GM}) \\ 10.1 & 780.0312 & 2703.8 & 142.03 & -29.17 & 2.199 & 780.0312\end{array}$

Product concentrations

\begin{tabular}{rccc}
\multicolumn{2}{c}{ Name } & $(\mathrm{mol} / \mathrm{kg})$ & (mol gas $/ \mathrm{mol}$ \\
$\mathrm{n} 2$ & Gas & $2.544 \mathrm{e}+001$ & $3.965 \mathrm{e}-001$ \\
$\mathrm{~h} 20$ & Gas & $4.311 \mathrm{e}+000$ & $6.719 \mathrm{e}-002$ \\
$\mathrm{co} 2$ & Gas & $3.608 \mathrm{e}+000$ & $5.623 \mathrm{e}-002$ \\
$\mathrm{co}$ & Gas & $1.180 \mathrm{e}+000$ & $1.839 \mathrm{e}-002$ \\
$\mathrm{o} 2$ & Gas & $3.177 \mathrm{e}-001$ & $4.951 \mathrm{e}-003$ \\
$\mathrm{n} 0$ & Gas & $2.342 \mathrm{e}-001$ & $3.650 \mathrm{e}-003$ \\
$\mathrm{~h} 2$ & Gas & $2.112 \mathrm{e}-001$ & $3.291 \mathrm{e}-003$ \\
$\mathrm{n} 22$ & Gas & $1.011 \mathrm{e}-004$ & $1.575 \mathrm{e}-006$ \\
$\mathrm{~h} 3 \mathrm{n}$ & Gas & $1.257 \mathrm{e}-006$ & $1.960 \mathrm{e}-008$ \\
$\mathrm{ch} 202$ & Gas & $5.400 \mathrm{e}-007$ & $8.415 \mathrm{e}-009$ \\
$\mathrm{ch} 20$ & Gas & $4.085 \mathrm{e}-008$ & $6.366 \mathrm{e}-010$ \\
$\mathrm{ch} 3$ & Gas & $1.618 \mathrm{e}-012$ & $2.521 \mathrm{e}-014$
\end{tabular}


MESN99-066-OA

NIF-0063594

N.M. 6.4 .

$\begin{array}{rlll}\text { ch4 } 4 \text { Gas } & 2.974 \mathrm{e}-013 & 4.634 \mathrm{e}-015 \\ \text { ch3oh } & \text { Gas } & 6.104 \mathrm{e}-014 & 9.513 \mathrm{e}-016 \\ \mathrm{c} 2 \mathrm{~h} 4 & \text { Gas } & 7.619 \mathrm{e}-021 & 1.187 \mathrm{e}-022 \\ \mathrm{c} 2 \mathrm{~h} 6 & \text { Gas } & 3.315 \mathrm{e}-026 & 5.167 \mathrm{e}-028 \\ { }^{\star} \mathrm{C} \text { solid } & 0.000 \mathrm{e}+000 & 0.000 \mathrm{e}+000 \\ & & & \\ \text { Total Gas } & 3.531 \mathrm{e}+001 & 5.502 \mathrm{e}-001 \\ \text { Total Cond. } & 0.000 \mathrm{e}+000 & 0.000 \mathrm{e}+000\end{array}$

Reference state $=$ reactants

$\mathrm{H}(\mathrm{R})=\mathrm{H}-9.05, \mathrm{E}(\mathrm{R})=\mathrm{E}-\mathbf{- 9} .85, \mathrm{~S}(\mathrm{R})=\mathrm{S}-0.00$

$\begin{array}{llll}\text { 1.) (ATM) } & \text { (K) } / G M) & \text { (CAL/GM) }\end{array}$

Product concentrations

\begin{tabular}{|c|c|c|c|}
\hline \multicolumn{2}{|c|}{ Name } & \multicolumn{2}{|c|}{$(\mathrm{mol} / \mathrm{kg}) \quad(\mathrm{mol}$ gas $/ \mathrm{mol} \mathrm{e}$} \\
\hline n2 & Gas & $2.553 e+001$ & $78 e-001$ \\
\hline h2o & Gas & $4.402 e+000$ & $59 e-002$ \\
\hline $\mathrm{CO} 2$ & Gas & $4.135 e+000$ & $6.444 e-002$ \\
\hline $\mathrm{co}$ & Gas & $6.536 e-001$ & $1.019 e-00$ \\
\hline h2 & Gas & $1.211 \mathrm{e}-001$ & $388 e-003$ \\
\hline 02 & Gas & $9.176 e-002$ & $1.430 e-003$ \\
\hline no & Gas & $6.959 e-002$ & $1.084 e-00$ \\
\hline no2 & Gas & $1.480 e-005$ & $2.307 e-0 c$ \\
\hline h3n & Gas & $3.060 e-007$ & $4.769 e-00$ \\
\hline $\operatorname{ch} 202$ & Gas & $1.212 e-007$ & $1.889 e-0$ \\
\hline ch2o & Gas & $5.374 \mathrm{e}-009$ & $8.375 \mathrm{e}-$ \\
\hline $\operatorname{ch} 3$ & Gas & $5.360 e-014$ & $8.353 e-$ \\
\hline $\operatorname{ch} 4$ & Gas & $2.041 e-014$ & $3.181 \mathrm{e}-$ \\
\hline ch3oh & Gas & $3.131 e-015$ & $4.880 \mathrm{e}$ \\
\hline $\mathrm{c} 2 \mathrm{~h} 4$ & Gas & $6.529 e-023$ & $1.017 \mathrm{e}-$ \\
\hline c2h 6 & Gas & $1.588 e-028$ & $2.475 \mathrm{e}-$ \\
\hline${ }^{\star} \mathrm{C}$ & sol & $0.000 e+000$ & $0.000 \mathrm{e}+$ \\
\hline ta & & +0 & \\
\hline
\end{tabular}

Total Cond. $0.000 \mathrm{e}+000 \quad 0.000 \mathrm{e}+000$

The initial equation error was huge: 10795.835530

The initial equation error was huge: 11447.395269

Reference state $=$ reactants

$H(R)=H-9.05, E(R)=E--9.85, S(R)=S-0.00$ 


$\begin{array}{cccccccc} & \mathrm{P} & \mathrm{V} & \mathrm{T} & \mathrm{H}(\mathrm{R}) & \mathrm{E}(\mathrm{R}) & \mathrm{S}(\mathrm{R}) & \mathrm{VGS} \\ & (\mathrm{ATM}) & (\mathrm{CC} / \mathrm{GM}) & (\mathrm{K}) & (\mathrm{CAL} / \mathrm{GM}) & (\mathrm{CAL} / \mathrm{GM}) & (\mathrm{CAL} / \mathrm{K} / \mathrm{GM}) & (\mathrm{CC} / \mathrm{GM}) \\ 1 .) & 2.3 & 2706.3828 & 2145.0 & -109.96 & -239.93 & 2.1992706 .3828\end{array}$

Product concentrations

Name (mol/kg) (mol gas/mol explosive)

n2 Gas 2.555e+001 3.982e-001

h2o Gas $4.425 e+000 \quad 6.896 e-002$

$\mathrm{CO} 2$ Gas $4.305 e+000 \quad 6.709 e-002$

co Gas $4.837 e-001 \quad 7.538 e-003$

h2 Gas $9.791 \mathrm{e}-002 \quad 1.526 \mathrm{e}-003$

no Gas $2.056 \mathrm{e}-002 \quad 3.204 \mathrm{e}-004$

02 Gas $1.977 \mathrm{e}-002 \quad 3.080 \mathrm{e}-004$

no2 Gas $2.054 \mathrm{e}-006 \quad 3.201 \mathrm{e}-008$

h3n Gas $1.682 \mathrm{e}-007 \quad 2.622 \mathrm{e}-009$

ch2o2 Gas $5.323 e-008 \quad 8.296 e-010$

ch2o Gas $1.937 \mathrm{e}-009 \quad 3.019 \mathrm{e}-011$

ch3 Gas $1.012 \mathrm{e}-014 \quad 1.577 \mathrm{e}-016$

ch4 Gas $8.093 e-015$ 1.261e-016

ch3oh Gas $8.062 \mathrm{e}-016 \quad 1.256 \mathrm{e}-017$

c2h4 Gas $9.065 \mathrm{e}-024 \quad 1.413 \mathrm{e}-025$

c2h6 Gas $2.063 e-029 \quad 3.215 e-031$

${ }^{*} \mathrm{C}$ solid $0.000 e+000 \quad 0.000 e+000$

Total Gas $3.490 \mathrm{e}+001 \quad 5.439 \mathrm{e}-001$

Total Cond. $0.000 \mathrm{e}+000 \quad 0.000 \mathrm{e}+000$

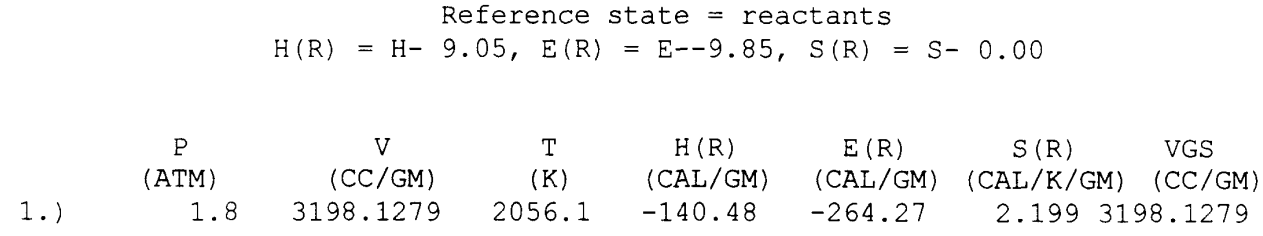

Product concentrations

\begin{tabular}{|c|c|c|c|}
\hline \multicolumn{2}{|c|}{ Name } & \multicolumn{2}{|c|}{$(\mathrm{mol} / \mathrm{kg}) \quad(\mathrm{mol} \mathrm{gas} / \mathrm{mol} \mathrm{e}$} \\
\hline $\mathrm{n} 2$ & Gas & $2.555 e+001$ & $3.982 e-001$ \\
\hline h2o & Gas & $4.425 e+000$ & $6.896 e-00$ \\
\hline $\operatorname{co} 2$ & Gas & $4.305 e+000$ & $6.709 e-0$ \\
\hline $\mathrm{co}$ & Gas & $4.837 e-001$ & $7.538 e-00$ \\
\hline h2 & Gas & $9.791 e-002$ & $1.526 \mathrm{e}$ \\
\hline no & Gas & $2.056 e-002$ & $3.204 e-00$ \\
\hline 02 & Gas & $1.977 \mathrm{e}-002$ & $3.080 e-00$ \\
\hline no2 & Gas & $2.054 e-006$ & $3.201 e-00$ \\
\hline$h 3 n$ & Gas & 007 & $2 e$ \\
\hline
\end{tabular}




$\begin{array}{ccccccc}P & \mathrm{~V} & \mathrm{~T} & \mathrm{H}(\mathrm{R}) & \mathrm{E}(\mathrm{R}) & \mathrm{S}(\mathrm{R}) & \mathrm{VGS} \\ (\mathrm{ATM}) & (\mathrm{CC} / \mathrm{GM}) & (\mathrm{K}) & (\mathrm{CAL} / \mathrm{GM}) & (\mathrm{CAL} / \mathrm{GM}) & (\mathrm{CAL} / \mathrm{K} / \mathrm{GM}) & (\mathrm{CC} / \mathrm{GM}) \\ 0.6 & 7800.3120 & 1632.2 & -283.59 & -377.93 & 2.1997800 .3120\end{array}$

\section{Product concentrations}

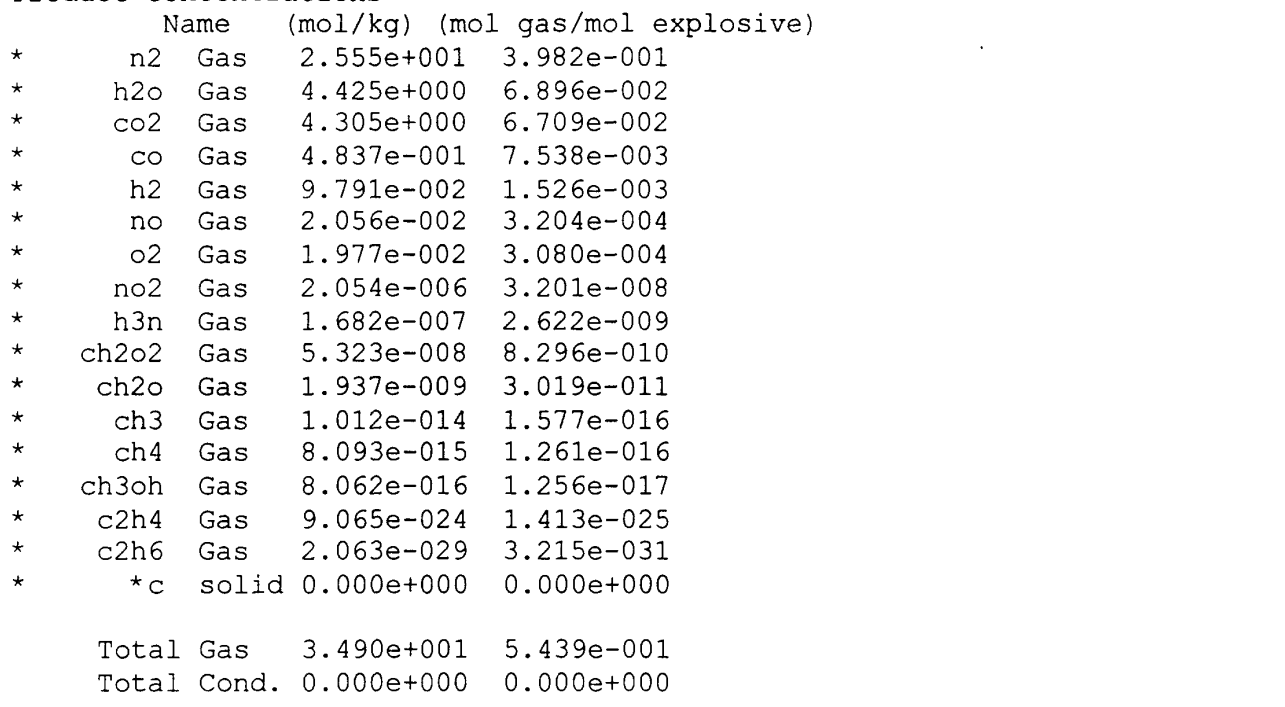

Reference state $=$ reactants

$H(R)=H-9.05, E(R)=E--9.85, S(R)=S-0.00$

$\begin{array}{cccccccc} & (\mathrm{ATM}) & (\mathrm{CC} / \mathrm{GM}) & (\mathrm{K}) & (\mathrm{CAL} / \mathrm{GM}) & (\mathrm{CAL} / \mathrm{GM}) & (\mathrm{CAL} / \mathrm{K} / \mathrm{GM}) & (\mathrm{CC} / \mathrm{GM}) \\ 1 .) & 0.2 & 15600.6240 & 1354.5 & -374.51 & -449.57 & 2.19915600 .6240\end{array}$

Product concentrations

\begin{tabular}{|c|c|c|c|c|}
\hline & \multicolumn{2}{|c|}{ Name } & \multicolumn{2}{|c|}{ (mol/kg) (mol gas/mol explosive) } \\
\hline * & $\mathrm{n} 2$ & Gas & $2.555 e+001$ & $3.982 e-001$ \\
\hline$\star$ & h2o & Gas & $4.425 e+000$ & $6.896 e-002$ \\
\hline * & $\mathrm{CO} 2$ & Gas & $4.305 e+000$ & $6.709 e-002$ \\
\hline$\star$ & $\mathrm{CO}$ & Gas & $4.837 e-001$ & $7.538 e-003$ \\
\hline * & h2 & Gas & $9.791 e-002$ & $1.526 e-003$ \\
\hline * & no & Gas & $2.056 e-002$ & $3.204 e-004$ \\
\hline * & o2 & Gas & $1.977 e-002$ & $3.080 e-004$ \\
\hline * & no2 & Gas & $2.054 e-006$ & $3.201 e-008$ \\
\hline * & $h 3 n$ & Gas & $1.682 e-007$ & $2.622 e-009$ \\
\hline$\star$ & $\operatorname{ch} 202$ & Gas & $5.323 e-008$ & $8.296 e-010$ \\
\hline
\end{tabular}




\begin{tabular}{|c|c|c|c|}
\hline ch2o & Gas & $1.937 e-009$ & $3.019 e-011$ \\
\hline $\operatorname{ch} 3$ & Gas & $1.012 e-014$ & $1.577 e-016$ \\
\hline $\operatorname{ch} 4$ & Gas & $8.093 e-015$ & $1.261 e-016$ \\
\hline ch3oh & Gas & $8.062 e-016$ & $1.256 e-017$ \\
\hline c2h4 & Gas & $9.065 e-024$ & $1.413 e-025$ \\
\hline $\mathrm{c} 2 \mathrm{~h} 6$ & Gas & $2.063 e-029$ & $3.215 e-031$ \\
\hline$\star \sigma$ & solid & $0.000 e+000$ & $0.000 e+000$ \\
\hline & & 3.4 & 5.4 \\
\hline & & 000 & $0.000 e+00$ \\
\hline
\end{tabular}

\begin{tabular}{|c|c|c|c|c|c|c|c|}
\hline & & $H(R)=H-$ & $\begin{array}{l}\text { ference } \\
05, E(R)\end{array}$ & $\begin{array}{l}\text { tate }=r e c \\
=E--9.85\end{array}$ & $\begin{array}{l}\text { tants } \\
S(R)=S\end{array}$ & 0.00 & \\
\hline & $\begin{array}{c}\mathrm{P} \\
\text { (ATM) }\end{array}$ & $\begin{array}{c}V \\
(\mathrm{CC} / \mathrm{GM})\end{array}$ & $\begin{array}{c}T \\
(K)\end{array}$ & $\begin{array}{c}H(R) \\
(\mathrm{CAL} / \mathrm{GM})\end{array}$ & $\begin{array}{c}E(R) \\
(\mathrm{CAL} / \mathrm{GM})\end{array}$ & $\begin{array}{c}S(R) \\
(C A L / K / G M)\end{array}$ & $\begin{array}{l}\text { VGS } \\
\text { (CC/GM) }\end{array}$ \\
\hline .) & 0.1 & 31201.2480 & 1115.2 & -450.34 & -508.80 & 2.1993120 & 1.2480 \\
\hline
\end{tabular}

Product concentrations

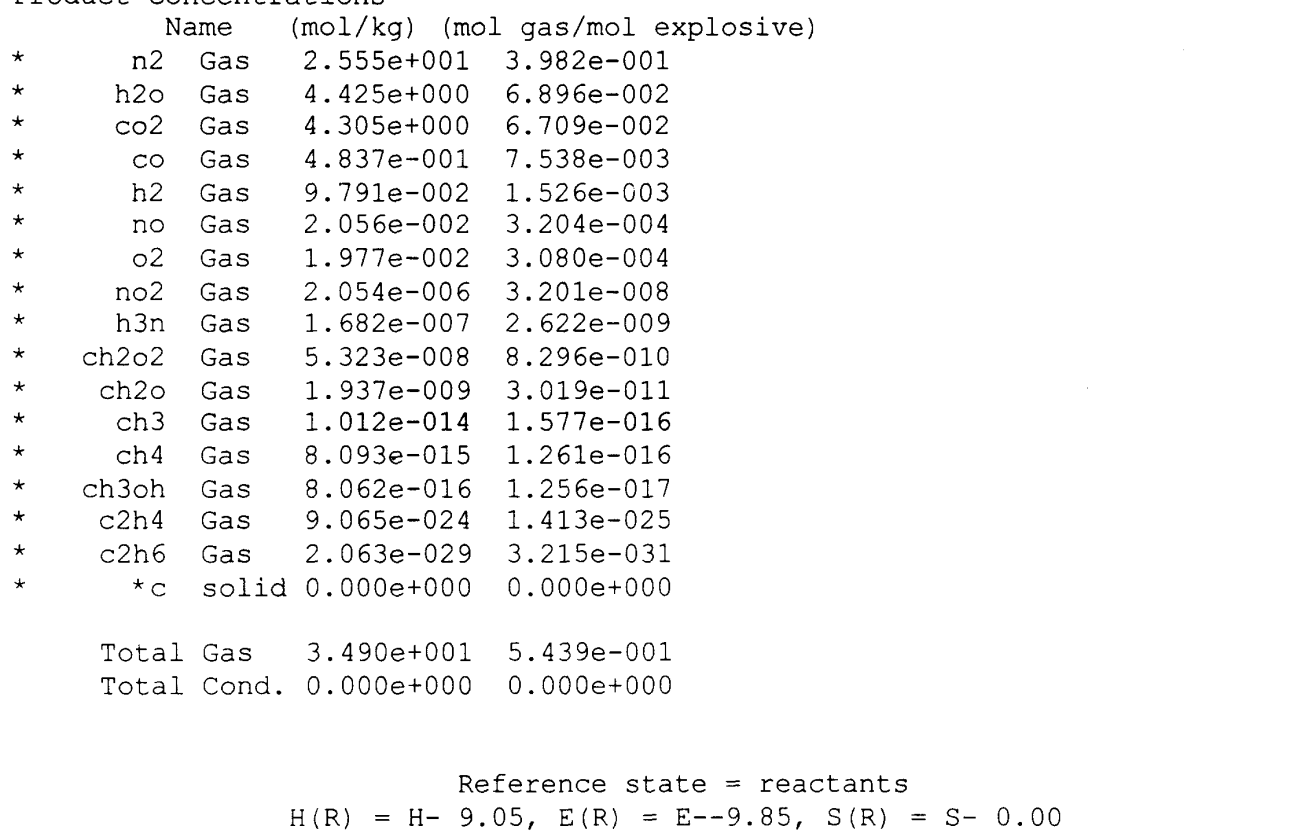




$\begin{array}{cccccccc} & \mathrm{P} & \mathrm{V} & \mathrm{T} & \mathrm{H}(\mathrm{R}) & \mathrm{E}(\mathrm{R}) & \mathrm{S}(\mathrm{R}) & \mathrm{VGS} \\ & (\mathrm{ATM}) & (\mathrm{CC} / \mathrm{GM}) & (\mathrm{K}) & (\mathrm{CAL} / \mathrm{GM}) & (\mathrm{CAL} / \mathrm{GM}) & (\mathrm{CAL} / \mathrm{K} / \mathrm{GM}) & (\mathrm{CC} / \mathrm{GM}) \\ 1 .) & 0.0 & 62402.4961 & 909.2 & -513.17 & -557.34 & 2.19962402 .4961\end{array}$

Product concentrations

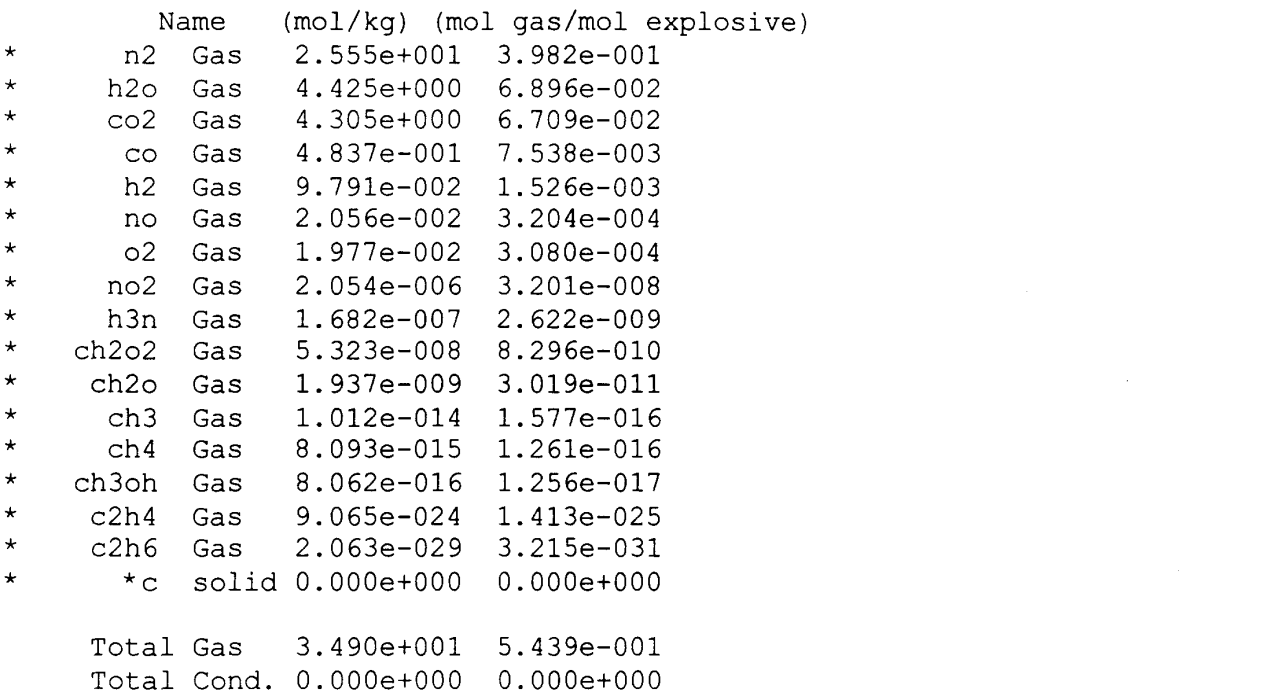

Reference state $=$ reactants

$H(R)=H-9.05, E(R)=E--9.85, S(R)=S-0.00$

$\begin{array}{cccccccc} & \mathrm{P} & \mathrm{V} & \mathrm{T} & \mathrm{H}(\mathrm{R}) & \mathrm{E}(\mathrm{R}) & \mathrm{S}(\mathrm{R}) & \mathrm{VGS} \\ & (\mathrm{ATM}) & (\mathrm{CC} / \mathrm{GM}) & (\mathrm{K}) & (\mathrm{CAL} / \mathrm{GM}) & (\mathrm{CAL} / \mathrm{GM}) & (\mathrm{CAL} / \mathrm{K} / \mathrm{GM}) & (\mathrm{CC} / \mathrm{GM}) \\ 1 .) & 0.0 & 124804.9922 & 732.6 & -564.78 & -596.69 & 2.199124804 .9922\end{array}$

Product concentrations

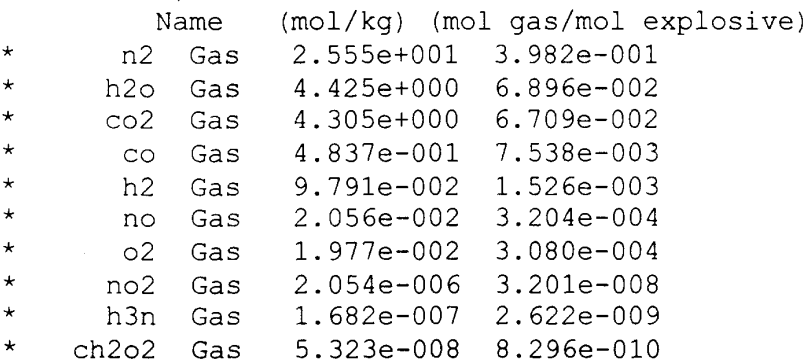




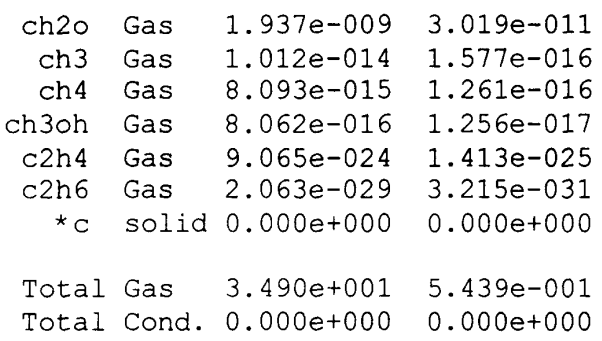

The End of the Adiabat

Reference state $=$ reactants

$H(R)=H-9.05, E(R)=E--9.85, S(R)=S-0.00$

$\begin{array}{cccccccc} & \mathrm{P} & \mathrm{V} & \mathrm{T} & \mathrm{H}(\mathrm{R}) & \mathrm{E}(\mathrm{R}) & \mathrm{S}(\mathrm{R}) & \mathrm{VGS} \\ & (\mathrm{ATM}) & (\mathrm{CC} / \mathrm{GM}) & (\mathrm{K}) & (\mathrm{CAL} / \mathrm{GM}) & (\mathrm{CAL} / \mathrm{GM}) & (\mathrm{CAL} / \mathrm{K} / \mathrm{GM}) & (\mathrm{CC} / \mathrm{GM}) \\ 1.1 & 1.0 & 5199.6208 & 1815.0 & -222.44 & -329.47 & 2.1995199 .6208\end{array}$

Product concentrations

\begin{tabular}{|c|c|c|c|}
\hline \multicolumn{2}{|c|}{ Name } & $(\mathrm{mol} / \mathrm{kg})$ & $\mathrm{gas} / \mathrm{mol} \epsilon$ \\
\hline $\mathrm{n} 2$ & Gas & $2.555 e+001$ & $3.982 e-001$ \\
\hline h2o & Gas & $4.425 e+000$ & $6.896 e-002$ \\
\hline $\mathrm{CO} 2$ & Gas & $4.305 e+000$ & $6.709 e-002$ \\
\hline $\mathrm{CO}$ & Gas & $4.837 e-001$ & $7.538 e-003$ \\
\hline h2 & Gas & $9.791 e-002$ & $1.526 \mathrm{e}-003$ \\
\hline no & Gas & $5 e-002$ & $3.204 e-004$ \\
\hline 02 & Gas & $7 e-002$ & $3.080 e-004$ \\
\hline no2 & Gas & $2.054 e-006$ & $3.201 e-008$ \\
\hline h3n & Gas & $2 e-007$ & $2 e-009$ \\
\hline 202 & Gas & $e-008$ & $2-010$ \\
\hline $\operatorname{ch} 20$ & Gas & $e-009$ & $19 e-011$ \\
\hline $\operatorname{ch} 3$ & Gas & $e-014$ & $1.577 e-016$ \\
\hline ch 4 & Gas & $8.093 e-015$ & $1.261 e-01$ \\
\hline sh $30 h$ & Gas & $e-016$ & $1.256 e-01$ \\
\hline $\mathrm{c} 2 \mathrm{~h} 4$ & Gas & $j e-024$ & $1.413 e-025$ \\
\hline c2h 6 & Gas & $2.063 e-029$ & $3.215 e-031$ \\
\hline$\star C$ & solid & $0.000 \mathrm{e}+000$ & $0.000 e+000$ \\
\hline al & & +001 & 5 \\
\hline Total & ond & $e+000$ & \\
\hline
\end{tabular}

The Products at room temperature and pressure 
Reference state $=$ reactants

$$
\mathrm{H}(\mathrm{R})=\mathrm{H}-9.05, \mathrm{E}(\mathrm{R})=\mathrm{E}-\mathbf{9} .85, \mathrm{~S}(\mathrm{R})=\mathrm{S}-0.00
$$

$\begin{array}{cccccccc} & \mathrm{P} & \mathrm{V} & \mathrm{T} & \mathrm{H}(\mathrm{R}) & \mathrm{E}(\mathrm{R}) & \mathrm{S}(\mathrm{R}) & \mathrm{VGS} \\ & (\mathrm{ATM}) & (\mathrm{CC} / \mathrm{GM}) & (\mathrm{K}) & (\mathrm{CAL} / \mathrm{GM}) & (\mathrm{CAL} / \mathrm{GM}) & (\mathrm{CAL} / \mathrm{K} / \mathrm{GM}) & (\mathrm{CC} / \mathrm{GM}) \\ 1 .) & 1.0 & 855.3121 & 298.0 & -682.00 & -683.82 & 1.674 & 855.3121\end{array}$

Product concentrations

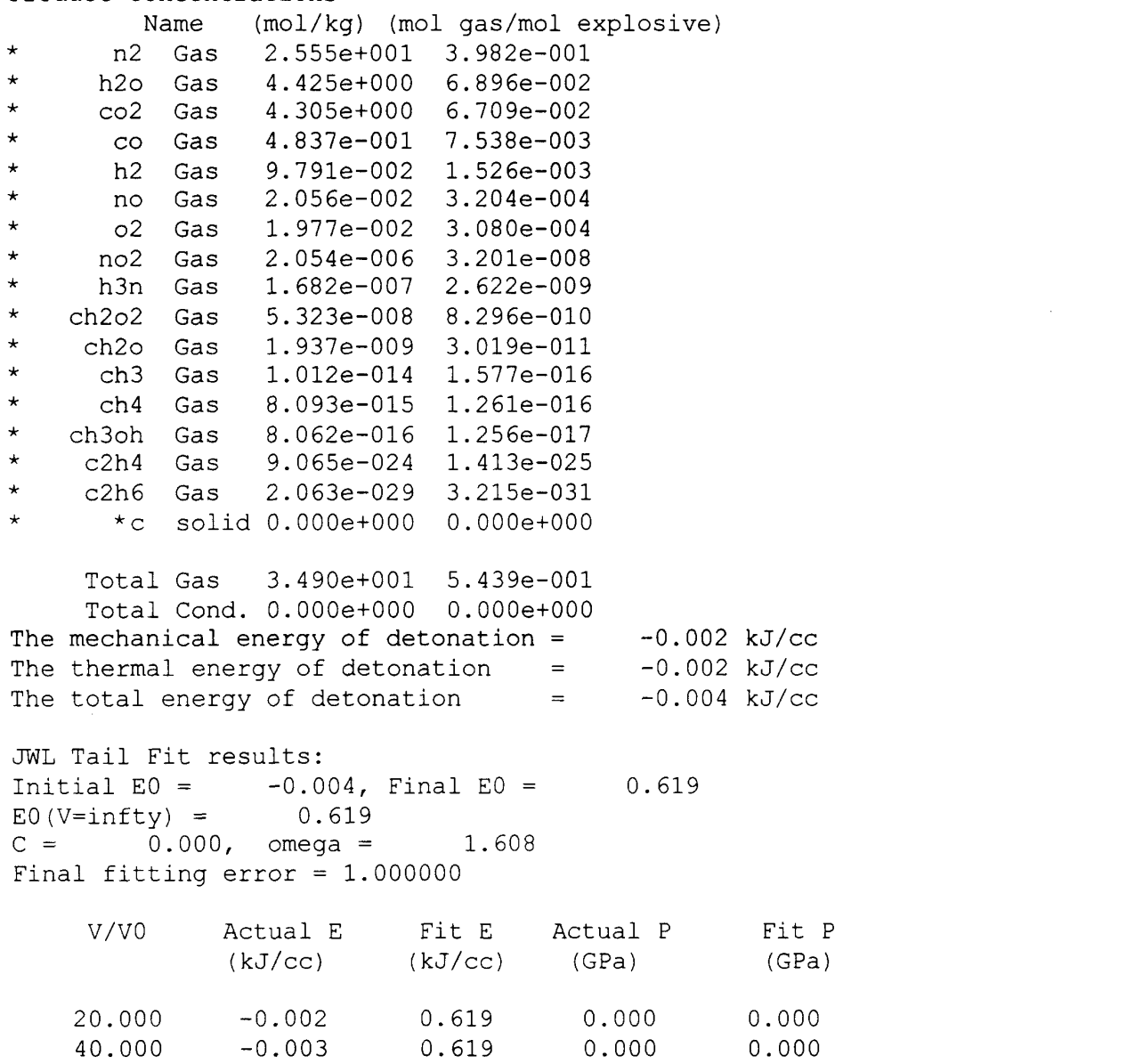


MESN99-066-OA

NIF-0063594

N.M. 6.4.

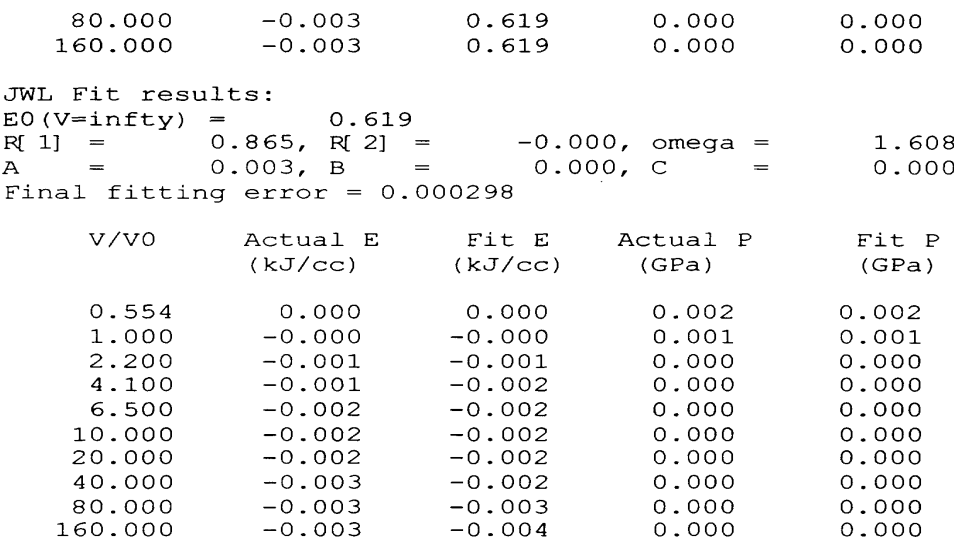




\section{Appendix B: Fragment Calculations}

\section{Appendix B.1}

\section{Calculation of Velocity of Resistor Fragments}

To estimate the maximum velocity of the dump resistor fragments that could result from an internal short or fault within a dump resistor, the following simplified electrical circuit of a capacitor module is used:

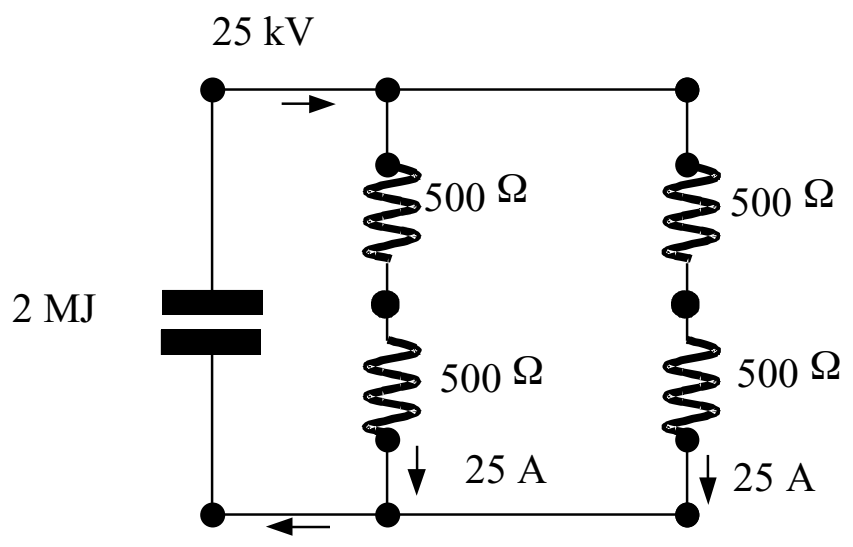

Figure B.1-1

Two series pairs of dump resistors are used in each capacitor module. Each individual resistor is capable of dissipating the entire energy stored in a module. When the energy stored in a module is to be dumped, two switches, each one in series with a pair of dump resistors, are closed resulting in the circuit in Figure B.1-1.

If one of the $500 \Omega$ resistors fails by internal arcing, its resistance goes to essentially zero $(\sim 3 \mathrm{~m} \Omega)$. The failure of a single resistor results in doubling the energy deposition in the remaining series resistor as shown in Figure B.1-2. But the increase in energy deposited in the remaining single resistor is still well within the capability of the resistor. 


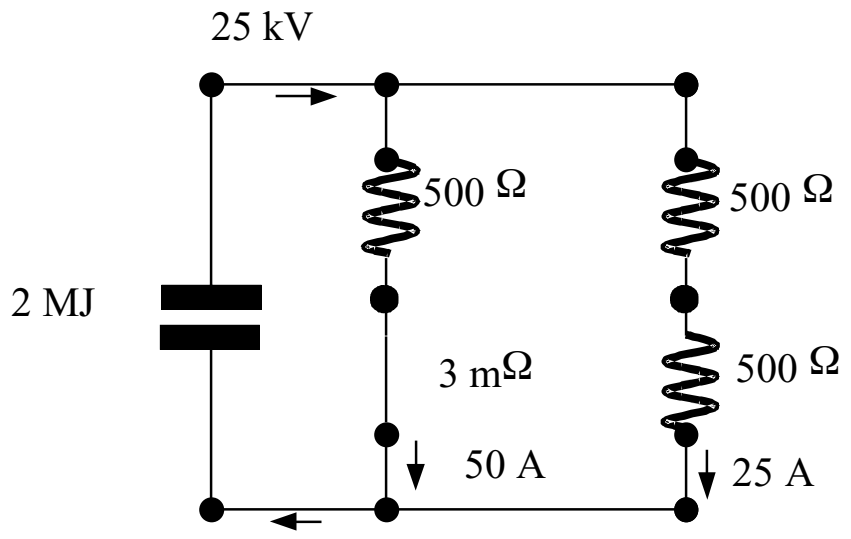

Figure B.1-2

While it is highly unlikely that the second series resistor will fail by internal arcing at essentially the same time as the first resistor, there is no guarantee that it would not happen. Simultaneous failures of the two resistors in series would result in the circuit shown in Figure B.1-3, which is equivalent to the circuit that existed during the FANTM event \#3 except then the full voltage was $17 \mathrm{kV}$ and the stored energy was only $0.84 \mathrm{MJ}$.

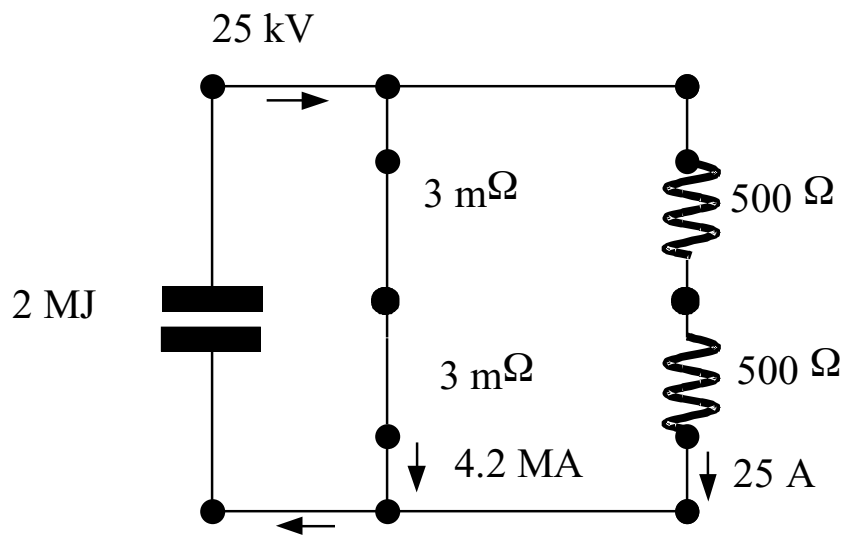

Figure B.1-3

It is further assumed that essentially all of the $2 \mathrm{MJ}$ of the available stored energy is dissipated in the two 12 inch long series dump resistors that have failed by internal arcing as shown in Figure B.1-3. 
To estimate the velocity of the hollow cored dump resistor fragments, the Gurney equation for a right circular cylinder was used. The Gurney equation is normally used to estimate the velocities of bomb casing fragments that result from the detonation of explosives that are surrounded by a metallic casing. It is believed that velocities obtained in this manner are conservative since any electrical energy dissipated is dispersed throughout the ceramic case thickness as opposed to internal to the case per the Gurney methodology. The geometry of the resistor is depicted below:

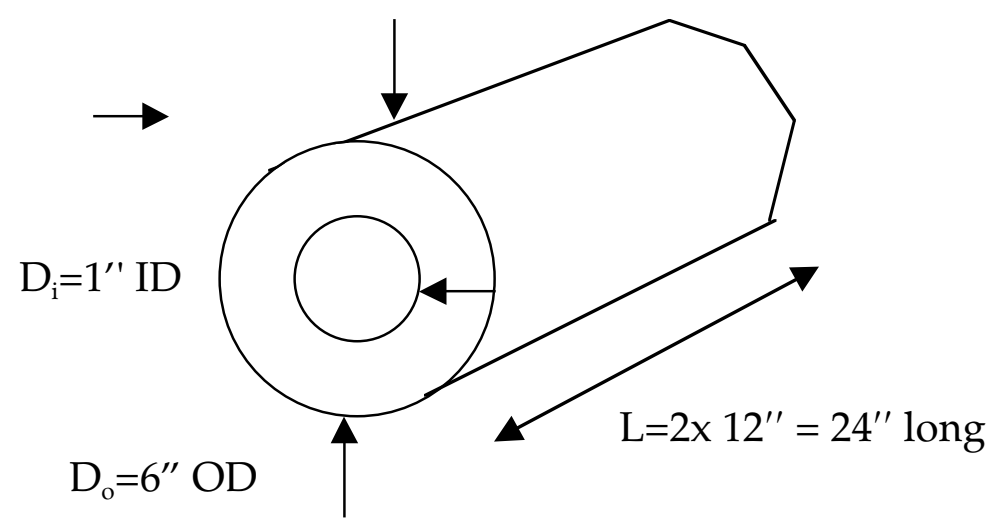

\section{Figure B.1-4}

Resistor density $($ Vandervalde, 1999$)=2.25 \mathrm{~g} / \mathrm{cm}^{3}=140 \mathrm{lb} / \mathrm{ft}^{3}$

$$
\mathrm{v}_{0}=\left(2 \mathrm{E}^{\prime}\right)^{0.5} \frac{\left[\mathrm{W} / \mathrm{W}_{\mathrm{c}}\right]^{0.5}}{\left[1+0.5 \mathrm{~W} / \mathrm{W}_{\mathrm{c}}\right]^{0.5}}
$$

where:

$$
\begin{aligned}
& \mathrm{v}_{0} \quad=\text { initial fragment velocity } \\
& \sqrt{2 E^{\prime}}=\text { Gurney Energy Constant (8,000 fps for TNT } \\
& \text { (DOE, 1992b)) } \\
& \mathrm{W} \text { = weight of explosive } \\
& \mathrm{W}_{\mathrm{c}} \quad \text { = weight of casing } \\
& W_{c}=\frac{\pi\left(D_{0}^{2}-D_{i}^{2}\right)}{4} L \rho_{c} g \\
& =\frac{\pi\left(36 \mathrm{in}^{2}-1 \mathrm{in}^{2}\right)}{4} \times 24 \mathrm{in} \times 140 \mathrm{lb} / \mathrm{ft}^{3} \times \mathrm{ft}^{3} / 1728 \mathrm{in}^{3} \\
& =53.5 \mathrm{lb}
\end{aligned}
$$


Max. Energy released into resistors $=2.0 \mathrm{MJ}$

Equivalent TNT weight if all the electrical energy was released :

$$
W=2.0 M J \frac{1 l b(T N T)}{2.67 M J}=0.75 l b(T N T)
$$

$$
\begin{aligned}
\frac{\mathrm{W}}{\mathrm{W}_{\mathrm{c}}} & =\frac{0.75 \mathrm{lb}}{53.5 \mathrm{lb}} \\
& =0.0140 \\
\mathrm{v}_{0} & =8000 \mathrm{fps} \quad \frac{[0.0140]^{0.5}}{[1+0.5 \times 0.0140]^{0.5}} \\
& =943 \mathrm{fps}
\end{aligned}
$$

\section{$\underline{\text { References }}$}

DOE(1992a), "A Manual for the Prediction of Blast and Fragment Loadings on Structures", U.S. Department or Energy, Figure 6.4, cylinder type, DOE/TIC11268, July 1992.

DOE(1992b), "A Manual for the Prediction of Blast and Fragment Loadings on Structures", U.S. Department or Energy, Table 6.1, DOE/TIC-11268, July 1992.

Vandervalde, Dave (1999), phone conversation with John Pastrnak, 4/28/99. 


\section{Appendix B.2}

\section{Velocity of Copper Fragments}

In the review of methods for calculating fragment impact damage, one of the more applicable approaches for calculating copper fragment velocity on steel targets was provided in DOE (1992). This considers the properties of both the fragment (density, size, velocity) and the properties of the target (density, yield strength, thickness). This approach was utilized to back-calculate fragment velocity based on observed penetration depths in the FANTM module. The deepest penetration in the module enclosure was found to be no greater than 0.125 inches. This was assumed to be caused by fragments similar to Fragment 2 . Fragment 3 was found to have just penetrated a capacitor can, 0.07 inches thick.

To utilize this approach to estimate velocity, one must first estimate the dimensionless target thickness, DOE (1992) (Page 6-129):

$$
\begin{aligned}
& \mathrm{H}=(\mathrm{h} / \mathrm{a}) \\
& \text { Where, } \\
& \mathrm{H}=\text { dimensionless target thickness } \\
& \mathrm{h}=\text { target thickness (inches) } \\
& \text { a } \quad=\text { radius of fragment (assuming sphere) } \\
& =(3 \mathrm{~V} / 4 \pi)^{1 / 3} \\
& \mathrm{~V} \quad=\text { fragment volume }
\end{aligned}
$$

Therefore,

$\mathrm{h}_{2}=0.125 \mathrm{in}$.

$\mathrm{h}_{3}=0.07 \mathrm{in}$.

$\mathrm{a}_{2}=(3 \times 0.0625 / 4 \pi)^{1 / 3}=0.25 \mathrm{in}$.

$\mathrm{a}_{3}=(3 \times 0.0078 / 4 \pi)^{1 / 3}=0.12 \mathrm{in}$

$\mathrm{H}_{2}=0.125 / 0.25=0.5$

$\mathrm{H}_{3}=0.07 / 0.12=0.58$

The next step is to utilize the curve in DOE (1992) (Page 6-131) with H to estimate the corresponding dimensionless projectile velocity. The values taken from the curve are:

$\mathrm{V}_{2}=2$

$\mathrm{V}_{3}=2.4$

The dimensionless projectile velocity is given by:

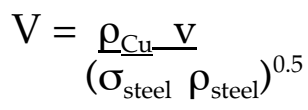


where

$\mathrm{V} \quad=$ dimensionless projectile velocity

$\mathrm{v} \quad=$ projectile velocity $(\mathrm{ft} / \mathrm{s})$

$\rho_{\mathrm{Cu}} \quad=$ copper (fragment) density, $\left(555 \mathrm{lb} / \mathrm{ft}^{3}\right) /\left(32.2 \mathrm{ft} / \mathrm{s}^{2}\right)$

$\rho_{\text {Steel }}=$ steel (target) density, $\left(499 \mathrm{lb} / \mathrm{ft}^{3}\right) /\left(32.2 \mathrm{ft} / \mathrm{s}^{2}\right)$

$\sigma_{\text {steel }}=$ steel (target) yield strength $(36,000 \mathrm{psi})$

Solving,

$$
\begin{aligned}
\mathrm{v}_{2} & =\frac{2 \times\left(36,000 \mathrm{psi} \times 144 \mathrm{in}^{2} / \mathrm{ft}^{2} \times 499 \mathrm{lb} / \mathrm{ft}^{3} \times 32.2 \mathrm{lb} \mathrm{ft} / \mathrm{lb} \mathrm{s}^{2}\right)^{0.5}}{555 \mathrm{lb} / \mathrm{ft}^{3}} \\
& =1040 \mathrm{ft} / \mathrm{s} \\
\mathrm{v}_{3} \quad & =\frac{2.4 \times\left(36,000 \mathrm{psi} \times 144 \mathrm{in}^{2} / \mathrm{ft}^{2} \times 499 \mathrm{lb} / \mathrm{ft}^{3} \times 32.2 \mathrm{lb} \mathrm{ft} / \mathrm{lb} \mathrm{s}\right)^{0.5}}{555 \mathrm{lb} / \mathrm{ft}^{3}} \\
& =1248 \mathrm{ft} / \mathrm{s}
\end{aligned}
$$

\section{$\underline{\text { References }}$}

DOE(1992), "A Manual for the Prediction of Blast and Fragment Loadings on Structures", U.S. Department or Energy, DOE/TIC-11268, July 1992. 


\section{Appendix B.3}

\section{Estimated Penetration Depths of Fragments}

Estimated penetration depths of fragments into various NIF building materials and candidate shielding materials are provided in this appendix. A variety of formulations were utilized to estimate the penetration of fragments into materials. Not all are summarized here. For steel, it was found that the method in DOE (1992; P.6-127) provided reasonable results because the properties of both the fragment and the target are considered. An alternate formula, known as the Saville formula (LLNL, 1995) also gave bounding results for most fragments impinging on steel. For Fragment 2, the Thor formulation provided bounding results for steel. No formulae were found specifically for gypsum board. Strawboard and fibreboard were used as approximations. The formula for concrete found in DOE (1992) was used. For plywood, the approach used in Parsons (1996) was applied here.

Penetration depths of fragments using these formulations are calculated in this appendix. A summary of the fragment properties used is given below.

\begin{tabular}{|c|c|c|c|}
\hline & Fragment 1 & Fragment 2 & Fragment 3 \\
\hline Material & $\begin{array}{l}\text { Resistor } \\
\text { (ceramic) }\end{array}$ & Copper & Copper \\
\hline Weight (oz) & $\begin{array}{l}2 \\
(0.0568 \mathrm{~kg})\end{array}$ & $\begin{array}{l}0.32 \\
(0.0091 \mathrm{~kg})\end{array}$ & $\begin{array}{l}0.04 \\
(0.0011 \mathrm{~kg})\end{array}$ \\
\hline $\begin{array}{l}\text { Cross } \\
\text { Section }\left(\mathrm{in}^{2}\right)\end{array}$ & 1.125 & 0.5 & 0.0625 \\
\hline $\begin{array}{l}\text { Volume } \\
\left(\text { in }^{3}\right)\end{array}$ & 1.125 & 0.0625 & 0.0078 \\
\hline $\begin{array}{l}\text { Weight } \\
\text { Density } \\
\left(\mathrm{lb} / \mathrm{ft}^{3}\right)\end{array}$ & 140 & 555 & 555 \\
\hline $\begin{array}{l}\text { Velocity } \\
\text { (ft/s) }\end{array}$ & $\begin{array}{l}943 \\
(287 \mathrm{~m} / \mathrm{s})\end{array}$ & $\begin{array}{l}1040 \\
(317 \mathrm{~m} / \mathrm{s})\end{array}$ & $\begin{array}{l}1248 \\
(380 \mathrm{~m} / \mathrm{s})\end{array}$ \\
\hline
\end{tabular}

\section{Steel}

Method \#1 (DOE, 1992; P.6-129)

This approach utilizes the properties of both the fragment and the target. First, the dimensionless fragment velocity must be estimated:

$$
\mathrm{V}=\frac{\rho_{\mathrm{f}} \times \mathrm{V}}{\left(\sigma_{\text {steel }} \times \rho_{\text {steel }}\right)^{0.5}}
$$


where

$\mathrm{V} \quad=$ dimensionless projectile velocity

$\mathrm{v} \quad=$ projectile velocity $(\mathrm{ft} / \mathrm{s})$

$\rho_{\mathrm{f}} \quad=$ fragment density $\left(\mathrm{lb} / \mathrm{ft}^{3}\right) /\left(\mathrm{ft} / \mathrm{s}^{2}\right)$

$\rho_{\text {Steel }}=$ steel (target) density, $\left(499 \mathrm{lb} / \mathrm{ft}^{3}\right) /\left(32.2 \mathrm{ft} / \mathrm{s}^{2}\right)$

$\sigma_{\text {steel }}=$ steel (target) yield strength $(36,000 \mathrm{psi})$

$\mathrm{V}_{1} \quad=\left(140 \mathrm{lb} / \mathrm{ft}^{3} \times 943 \mathrm{ft} / \mathrm{s}\right)$

$\left(36000 \mathrm{psi} \times 144 \mathrm{in}^{2} / \mathrm{ft}^{2} \times 499 \mathrm{lb} / \mathrm{ft}^{3} \times 32.2 \mathrm{ft} / \mathrm{s}^{2}\right)^{0.5}$

$=0.46$

$\mathrm{V}_{2} \quad=\frac{\left(555 \mathrm{lb} / \mathrm{ft}^{3} \times 1040 \mathrm{ft} / \mathrm{s}\right)}{\left(36000 \mathrm{psi} \times 144 \mathrm{in}^{2} / \mathrm{ft}^{2}\right.}$

$\left.\frac{\left(36000 \mathrm{psi} \times 144 \mathrm{in}^{2} / \mathrm{ft}^{2}\right.}{(39} 499 \mathrm{lb} / \mathrm{ft}^{3} \times 32.2 \mathrm{ft} / \mathrm{s}^{2}\right)^{0.5}$

$=2$

$\mathrm{V}_{3} \quad=\frac{\left(555 \mathrm{lb} / \mathrm{ft}^{3} \times 1248 \mathrm{ft} / \mathrm{s}\right)}{\left(36000 \mathrm{psin} 144 \mathrm{in}^{2} / \mathrm{ft}^{2}\right.}$

$\left(36000 \mathrm{psi} \times 144 \mathrm{in}^{2} / \mathrm{ft}^{2} \times 499 \mathrm{lb} / \mathrm{ft}^{3} \times 32.2 \mathrm{ft} / \mathrm{s}^{2}\right)^{0.5}$

$=2.4$

The penetration depth of the fragment, $h$, can be calculated by the formula given in DOE (1992; P.6-129):

$\mathrm{H}=(\mathrm{h} / \mathrm{a})$

Where,

$\mathrm{H}=$ dimensionless target thickness

$\mathrm{h}=$ target penetration depth (inch)

a $\quad=$ radius of fragment (assuming sphere):

$=(3 \mathrm{~V} / 4 \pi)^{1 / 3}$

$V \quad=$ fragment volume

Based on the dimensionless projectile velocity, $\mathrm{V}$, the dimensionless target thickness H can be read from the curve in DOE (1992; P.6-131):

$\mathrm{H}_{1}=0.08$

$\mathrm{H}_{2}=0.5$

$\mathrm{H}_{3}=0.58$

The corresponding target penetration depth can be found as follow:

$\mathrm{h}_{1} \quad=0.08 \times(3 \times 1.125 / 4 \pi)^{1 / 3}=0.052$ in

$\mathrm{h}_{2} \quad=0.5 \times(3 \times 0.0625 / 4 \pi)^{1 / 3}=0.123 \mathrm{in}$

$\mathrm{h}_{3} \quad=0.58 \times(3 \times 0.0078 / 4 \pi)^{1 / 3}=0.071$ in 
Method \#2, Saville Formula LLNL (1995):

The Saville formula is given by:

$\mathrm{T}(\mathrm{m})=6 \times 10^{-5} \mathrm{~m}_{\mathrm{f}}^{0.33} \mathrm{v}_{\mathrm{f}}$

where

$\mathrm{T} \quad=$ penetration depth $(\mathrm{m})$

$\mathrm{m}_{\mathrm{f}} \quad=$ fragment mass $(\mathrm{kg})$

$\mathrm{v}_{\mathrm{f}} \quad=$ fragment velocity $(\mathrm{m} / \mathrm{s})$

This was applied to Fragments 1, 2, and 3.

$$
\begin{aligned}
\mathrm{T}_{1} & =6 \times 10^{-5}(0.0568)^{0.33} \times 287 \\
& =0.0067 \mathrm{~m} \\
& =0.26 \mathrm{in} \\
\mathrm{T}_{2 \mathrm{~b}} \quad & =6 \times 10^{-5}(0.0091)^{0.33} \times 317 \\
& =0.004 \mathrm{~m} \\
& =0.16 \mathrm{in} \\
\mathrm{T}_{3} & =6 \times 10^{-5}(0.0011)^{0.33} \times 380 \\
& =0.0024 \mathrm{~m} \\
& =0.095 \mathrm{in}
\end{aligned}
$$

\section{Gypsum Board}

Method \#1: Strawboard Approximation (DOE, 1992, P.6-169):

$\mathrm{v}=59010(\mathrm{~h} \mathrm{~A})^{0.606}\left(7000 \mathrm{~W}_{\mathrm{f}}\right)^{-0.674}$

$\mathrm{v}=$ fragment velocity $(\mathrm{ft} / \mathrm{s})$

$\mathrm{h} \quad=$ fragment penetration depth (in)

A = average impact area $\left(\mathrm{in}^{2}\right)$

$\mathrm{W}_{\mathrm{f}} \quad$ = fragment weight $(\mathrm{lb})$

Substituting the values from the table into the formula, the following results are obtained:

$\mathrm{h}_{1} \quad=1.8 \mathrm{in}$

$\mathrm{h}_{2} \quad=0.62$ in

$\mathrm{h}_{3} \quad=0.67 \mathrm{in}$ 
Method \#2: Fibreboard Approximation (DOE, 1992; P.6-169):

$\mathrm{V}=44740(\mathrm{~h} \mathrm{~A})^{0.75}\left(7000 \mathrm{~W}_{\mathrm{f}}\right)^{-0.75}$

$\mathrm{V}=$ fragment velocity $(\mathrm{ft} / \mathrm{s})$

$\mathrm{h} \quad=$ fragment penetration depth (in)

A = average impact area $\left(\mathrm{in}^{2}\right)$

$\mathrm{W}_{\mathrm{f}} \quad$ = fragment weight $(\mathrm{lb})$

Substituting the values from the table into the formula, the following results are obtained:

$\begin{array}{ll}\mathrm{h}_{1} & =4.5 \mathrm{in} \\ \mathrm{h}_{2} & =1.9 \mathrm{in} \\ \mathrm{h}_{3} & =2.4 \mathrm{in}\end{array}$

Concrete (DOE, 1992; P.6-156)

$\mathrm{h}=5.36 \times 10^{-3} \mathrm{~W}_{\mathrm{f}}^{0.37} \mathrm{v}_{\mathrm{f}}^{0.9}$

$\mathrm{h} \quad=$ fragment penetration depth (in)

$\mathrm{W}_{\mathrm{f}} \quad$ = fragment weight $(\mathrm{lb})$

$\mathrm{v}_{\mathrm{f}} \quad=$ fragment velocity $(\mathrm{ft} / \mathrm{s})$

Substituting the values from the table into the formula, the following results are obtained:

$\mathrm{h}_{1} \quad=1.2 \mathrm{in}$

$\mathrm{h}_{2}=0.65$ in

$\mathrm{h}_{3}=0.36$ in

\section{Plywood (Amman and Whitney, as given in Parsons (1996)):}

The penetration depth in plywood is described by

$$
\mathrm{h}=\left[282 \times \mathrm{N} \times \mathrm{W} \times \mathrm{D}^{0.2} /\left(\mathrm{f}_{\mathrm{cp}}{ }^{0.5} \times \mathrm{D}^{2}\right)\right]\left(\mathrm{V}_{\mathrm{s}} / 1000\right)^{1.8}
$$

Where

$$
\begin{aligned}
\mathrm{h} & =\text { penetration depth (in) } \\
\mathrm{N} & =\text { nose factor } \\
& =0.72+0.25(\mathrm{n}-0.25)^{0.5} \\
& =0.85 \text { (for } \mathrm{n}=\mathrm{r} / \mathrm{d}=0.5 \text { for stubby fragments) } \\
\mathrm{f}_{\mathrm{cp}} \quad & =\text { property of plywood, compression perpendicular to the grain } \\
& =160 \text { psi for low grade plywood } \\
& =340 \text { psi for high grade plywood } \\
\mathrm{D} \quad & =\text { fragment diameter (in) } \\
\mathrm{V}_{\mathrm{s}} \quad & =\text { fragment velocity }(\mathrm{ft} / \mathrm{s})
\end{aligned}
$$


Based on the fragment volume, the fragment diameters are obtained as follow:

$\mathrm{D}_{1}=2 \times(3 \mathrm{~V} / 4 \pi)^{1 / 3}=2 \times(3 \times 1.125 / 4 \pi)^{1 / 3}=1.3 \mathrm{in}$

$\mathrm{D}_{2}=2 \times(3 \mathrm{~V} / 4 \pi)^{1 / 3}=2 \times(3 \times 0.0625 / 4 \pi)^{1 / 3}=0.49$ in

$\mathrm{D}_{3}=2 \times(3 \mathrm{~V} / 4 \pi)^{1 / 3}=2 \times(3 \times 0.0078 / 4 \pi)^{1 / 3}=0.25$ in

Substituting values for low grade plywood, the penetration depths are obtained as follow:

$$
\begin{aligned}
\mathrm{h}_{1} & =\left[282 \times 0.85 \times 2 / 16 \times 1.3^{0.2} /\left(160^{0.5} \times 1.3^{2}\right)\right](943 / 1000)^{1.8} \\
& =1.3 \mathrm{in} \\
\mathrm{h}_{2} & =\left[282 \times 0.85 \times 0.32 / 16 \times 0.49^{0.2} /\left(160^{0.5} \times 0.49^{2}\right)\right](1040 / 1000)^{1.8} \\
& =1.5 \mathrm{in} \\
\mathrm{h}_{3} \quad & =\left[282 \times 0.85 \times 0.04 / 16 \times 0.25^{0.2} /\left(160^{0.5} \times 0.25^{2}\right)(1248 / 1000)^{1.8}\right. \\
& =0.86 \mathrm{in}
\end{aligned}
$$

Substituting values for high grade plywood, the penetration depths are obtained as follow:

$$
\begin{aligned}
\mathrm{h}_{1} & =\left[282 \times 0.85 \times 2 / 16 \times 1.3^{0.2} /\left(340^{0.5} \times 1.3^{2}\right)\right](943 / 1000)^{1.8} \\
& =0.91 \mathrm{in} \\
\mathrm{h}_{2} & =\left[282 \times 0.85 \times 0.32 / 16 \times 0.49^{0.2} /\left(340^{0.5} \times 0.49^{2}\right)\right](1040 / 1000)^{1.8} \\
& =1.01 \mathrm{in} \\
\mathrm{h}_{3} \quad & =\left[282 \times 0.85 \times 0.04 / 16 \times 0.25^{0.2} /\left(340^{0.5} \times 0.25^{2}\right)\right](1248 / 1000)^{1.8} \\
& =0.58 \mathrm{in}
\end{aligned}
$$

\section{Lumagard}

The required shielding thickness based on this material was obtained from the chart on the following page. Since the penetration formulations are a stronger function of fragment velocity than of fragment mass, use of the tabulated information based on velocity should be reasonably appropriate. It is estimated from the chart that a lumagard thickness of $7 / 32$ inch should provide adequate shielding. 


\section{Appendix B.4}

\section{Calculation of Vertical Momentum of Fragments}

The vertical momentum of each fragment was calculated to estimate the impact on the exterior roof. The vertical component of the velocity was estimated using the formulation given in DOE (1992):

$$
\begin{aligned}
& \mathrm{V}_{\mathrm{yf}}=\left(\mathrm{Mg} / \mathrm{k}_{\mathrm{y}}\right)^{0.5} \sin \left[\tan ^{-1}\left(\mathrm{~V}_{\mathrm{y} 0}\left(\mathrm{k}_{\mathrm{y}} / \mathrm{Mg}\right)^{0.5}\right)\right] \quad \text { DOE (1992) (P.6-174) } \\
& \mathrm{k}_{\mathrm{y}}=\mathrm{C}_{\mathrm{D}} \mathrm{A} \rho_{\text {air }} / 2 \\
& \text { where } \\
& \mathrm{V}_{\mathrm{yf}} \quad \text { = vertical component of velocity }(\mathrm{ft} / \mathrm{s}) \\
& \mathrm{V}_{\mathrm{y} 0} \quad=\text { initial vertical component of velocity }(\mathrm{ft} / \mathrm{s}) \\
& \mathrm{Mg} \quad=\text { fragment weight }(\mathrm{lb}) \\
& \mathrm{C}_{\mathrm{D}} \quad=\text { drag coefficient }(\text { assumed to be } 1) \\
& \mathrm{A} \quad=\text { fragment area presented in vertical direction }\left(\mathrm{in}^{2}\right) \\
& \rho_{\text {air }} \quad=\text { air density }\left(0.0748 \mathrm{lb} / \mathrm{ft}^{3}\right) /\left(32.2 \mathrm{ft} / \mathrm{s}^{2}\right)
\end{aligned}
$$

Substituting values,

$$
\begin{array}{rl}
\mathrm{k}_{\mathrm{y} 1}= & \left(2.92 \times 10^{-4} \mathrm{lb} / \mathrm{ft}\right) /\left(32.2 \mathrm{ft} / \mathrm{s}^{2}\right) \\
\mathrm{k}_{\mathrm{y} 2}= & \left(1.30 \times 10^{-4} \mathrm{lb} / \mathrm{ft}\right) /\left(32.2 \mathrm{ft} / \mathrm{s}^{2}\right) \\
\mathrm{k}_{\mathrm{y} 3}= & \left(1.62 \times 10^{-5} \mathrm{lb} / \mathrm{ft}\right) /\left(32.2 \mathrm{ft} / \mathrm{s}^{2}\right) \\
\mathrm{V}_{\mathrm{y} 1}= & \left(2 / 16 \mathrm{lb} 32.2 \mathrm{ft} / \mathrm{s}^{2} / 2.92 \times 10^{-4} \mathrm{lb} / \mathrm{ft}\right)^{0.5} \sin \left[\operatorname { t a n } ^ { - 1 } \left(943 \mathrm{ft} / \mathrm{s}\left(2.92 \times 10^{-4} \mathrm{lb} / \mathrm{ft} /\right.\right.\right. \\
& \left.\left.\left.\left(32.2 \mathrm{ft} / \mathrm{s}^{2} \times 2 / 16 \mathrm{lb}\right)\right)^{0.5}\right)\right] \\
= & 117 \mathrm{ft} / \mathrm{s} \\
\mathrm{V}_{\mathrm{y} 2}= & \left(0.32 / 16 \mathrm{lb} \times 32.2 \mathrm{ft} / \mathrm{s}^{2} / 1.30 \times 10^{-4} \mathrm{lb} / \mathrm{ft}\right)^{0.5} \sin \left[\operatorname { t a n } ^ { - 1 } \left(1040 \mathrm{ft} / \mathrm{s}\left(1.30 \times 10^{-4}\right.\right.\right. \\
& \left.\left.\left.1 \mathrm{~b} / \mathrm{ft} /\left(32.2 \mathrm{ft} / \mathrm{s}^{2} \times 0.32 / 16 \mathrm{lb}\right)\right)^{0.5}\right)\right] \\
= & 70.2 \mathrm{ft} / \mathrm{s} \\
= & \left(0.04 / 16 \mathrm{lb} \times 32.2 \mathrm{ft} / \mathrm{s}^{2} / 1.62 \times 10^{-5} \mathrm{lb} / \mathrm{ft}\right)^{0.5} \sin \left[\operatorname { t a n } ^ { - 1 } \left(1248 \mathrm{ft} / \mathrm{s}\left(1.62 \times 10^{-5}\right.\right.\right. \\
& \left.\left.\left.1 \mathrm{~b} / \mathrm{ft} /\left(32.2 \mathrm{ft} / \mathrm{s}^{2} \times 0.04 / 16 \mathrm{lb}\right)\right)^{0.5}\right)\right] \\
\mathrm{V}_{\mathrm{y} 3} & 70.4 \mathrm{ft} / \mathrm{s}
\end{array}
$$

Momemtum $=\mathrm{p}=\mathrm{mv}$

$$
\begin{array}{ll}
\mathrm{p}_{1} & =2 / 16 \mathrm{lb} \times 117 \mathrm{ft} / \mathrm{s} / 32.2 \mathrm{ft} / \mathrm{s}^{2} \\
& =0.45 \mathrm{lb} \mathrm{s} \\
\mathrm{p}_{2} \quad & =0.32 / 16 \mathrm{lb} \times 70.2 \mathrm{ft} / \mathrm{s} / 32.2 \mathrm{ft} / \mathrm{s}^{2} \\
& =0.044 \mathrm{lb} \mathrm{s} \\
\mathrm{p}_{3} \quad & =0.04 / 16 \mathrm{lb} \times 70.4 \mathrm{ft} / \mathrm{s} / 32.2 \mathrm{ft} / \mathrm{s}^{2} \\
& =0.0055 \mathrm{lb} \mathrm{s}
\end{array}
$$




\section{Appendix B.5}

\section{Ray Tracing, Sample POV-Ray Tracing Results}

\section{Partial Output}

Listing of angular distribution of impacts on surfaces defined in the model:

\begin{tabular}{|c|c|c|c|c|c|}
\hline Object 0 & 0 & 0 & 0 & 13 & 15 \\
\hline $0.0-5.0$ & 0 & 0 & 0 & 0 & 0 \\
\hline $5.0-10.0$ & 0 & 0 & 0 & 0 & 0 \\
\hline $10.0-15.0$ & 0 & 0 & 0 & 0 & 0 \\
\hline $15.0-20.0$ & 0 & 0 & 0 & 13 & 15 \\
\hline $20.0-25.0$ & 0 & 0 & 0 & 0 & 0 \\
\hline $25.0-30.0$ & 0 & 0 & 0 & 0 & 0 \\
\hline $30.0-35.0$ & 0 & 0 & 0 & 0 & 0 \\
\hline $35.0-40.0$ & 0 & 0 & 0 & 0 & 0 \\
\hline $40.0-45.0$ & 0 & 0 & 0 & 0 & 0 \\
\hline $45.0-50.0$ & 0 & 0 & 0 & 0 & 0 \\
\hline $50.0-55.0$ & 0 & 0 & 0 & 0 & 0 \\
\hline $55.0-60.0$ & 0 & 0 & 0 & 0 & 0 \\
\hline $60.0-65.0$ & 0 & 0 & 0 & 0 & 0 \\
\hline $65.0-70.0$ & 0 & 0 & 0 & 0 & 0 \\
\hline $70.0-75.0$ & 0 & 0 & 0 & 0 & 0 \\
\hline $75.0-80.0$ & 0 & 0 & 0 & 0 & 0 \\
\hline $80.0-85.0$ & 0 & 0 & 0 & 0 & 0 \\
\hline $85.0-90.0$ & 0 & 0 & 0 & 0 & 0 \\
\hline \multirow{2}{*}{\multicolumn{6}{|c|}{ 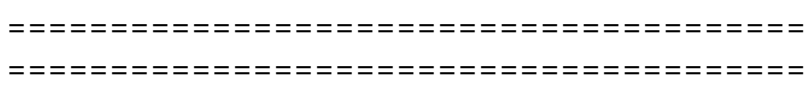 }} \\
\hline & & & & & \\
\hline Object 3 & 0 & 0 & 0 & 0 & 29 \\
\hline $0.0-5.0$ & 0 & 0 & 0 & 0 & 0 \\
\hline $5.0-10.0$ & 0 & 0 & 0 & 0 & 0 \\
\hline $10.0-15.0$ & 0 & 0 & 0 & 0 & 0 \\
\hline $15.0-20.0$ & 0 & 0 & 0 & 0 & 0 \\
\hline $20.0-25.0$ & 0 & 0 & 0 & 0 & 0 \\
\hline $25.0-30.0$ & 0 & 0 & 0 & 0 & 0 \\
\hline $30.0-35.0$ & 0 & 0 & 0 & 0 & 0 \\
\hline $35.0-40.0$ & 0 & 0 & 0 & 0 & 29 \\
\hline $40.0-45.0$ & 0 & 0 & 0 & 0 & 0 \\
\hline $45.0-50.0$ & 0 & 0 & 0 & 0 & 0 \\
\hline $50.0-55.0$ & 0 & 0 & 0 & 0 & 0 \\
\hline $55.0-60.0$ & 0 & 0 & 0 & 0 & 0 \\
\hline $60.0-65.0$ & 0 & 0 & 0 & 0 & 0 \\
\hline $65.0-70.0$ & 0 & 0 & 0 & 0 & 0 \\
\hline $70.0-75.0$ & 0 & 0 & 0 & 0 & 0 \\
\hline $75.0-80.0$ & 0 & 0 & 0 & 0 & 0 \\
\hline $80.0-85.0$ & 0 & 0 & 0 & 0 & 0 \\
\hline $85.0-90.0$ & 0 & 0 & 0 & 0 & 0 \\
\hline
\end{tabular}




\begin{tabular}{|c|c|c|c|c|c|}
\hline Object 4 & 0 & 0 & 0 & 0 & 17 \\
\hline $0.0-5.0$ & 0 & 0 & 0 & 0 & 0 \\
\hline $5.0-10.0$ & 0 & 0 & 0 & 0 & 0 \\
\hline $10.0-15.0$ & 0 & 0 & 0 & 0 & 0 \\
\hline $15.0-20.0$ & 0 & 0 & 0 & 0 & 0 \\
\hline $20.0-25.0$ & 0 & 0 & 0 & 0 & 0 \\
\hline $25.0-30.0$ & 0 & 0 & 0 & 0 & 0 \\
\hline $30.0-35.0$ & 0 & 0 & 0 & 0 & 15 \\
\hline $35.0-40.0$ & 0 & 0 & 0 & 0 & 2 \\
\hline $40.0-45.0$ & 0 & 0 & 0 & 0 & 0 \\
\hline $45.0-50.0$ & 0 & 0 & 0 & 0 & 0 \\
\hline $50.0-55.0$ & 0 & 0 & 0 & 0 & 0 \\
\hline $55.0-60.0$ & 0 & 0 & 0 & 0 & 0 \\
\hline $60.0-65.0$ & 0 & 0 & 0 & 0 & 0 \\
\hline $65.0-70.0$ & 0 & 0 & 0 & 0 & 0 \\
\hline $70.0-75.0$ & 0 & 0 & 0 & 0 & 0 \\
\hline $75.0-80.0$ & 0 & 0 & 0 & 0 & 0 \\
\hline $80.0-85.0$ & 0 & 0 & 0 & 0 & 0 \\
\hline $85.0-90.0$ & 0 & 0 & 0 & 0 & 0 \\
\hline \multicolumn{6}{|c|}{ 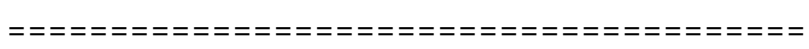 } \\
\hline Object 6 & 0 & 0 & 0 & 10 & 13 \\
\hline $0.0-5.0$ & 0 & 0 & 0 & 0 & 0 \\
\hline $5.0-10.0$ & 0 & 0 & 0 & 0 & 0 \\
\hline $10.0-15.0$ & 0 & 0 & 0 & 0 & 0 \\
\hline $15.0-20.0$ & 0 & 0 & 0 & 10 & 13 \\
\hline $20.0-25.0$ & 0 & 0 & 0 & 0 & 0 \\
\hline $25.0-30.0$ & 0 & 0 & 0 & 0 & 0 \\
\hline $30.0-35.0$ & 0 & 0 & 0 & 0 & 0 \\
\hline $35.0-40.0$ & 0 & 0 & 0 & 0 & 0 \\
\hline $40.0-45.0$ & 0 & 0 & 0 & 0 & 0 \\
\hline $45.0-50.0$ & 0 & 0 & 0 & 0 & 0 \\
\hline $50.0-55.0$ & 0 & 0 & 0 & 0 & 0 \\
\hline $55.0-60.0$ & 0 & 0 & 0 & 0 & 0 \\
\hline $60.0-65.0$ & 0 & 0 & 0 & 0 & 0 \\
\hline $65.0-70.0$ & 0 & 0 & 0 & 0 & 0 \\
\hline $70.0-75.0$ & 0 & 0 & 0 & 0 & 0 \\
\hline $75.0-80.0$ & 0 & 0 & 0 & 0 & 0 \\
\hline $80.0-85.0$ & 0 & 0 & 0 & 0 & 0 \\
\hline $85.0-90.0$ & 0 & 0 & 0 & 0 & 0 \\
\hline \multirow{2}{*}{\multicolumn{6}{|c|}{ 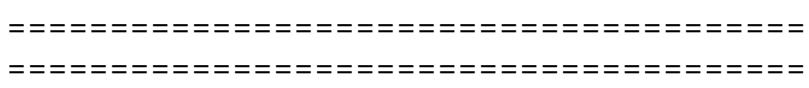 }} \\
\hline & & & & & \\
\hline Object 8 & 0 & 0 & 0 & 0 & 3 \\
\hline $0.0-5.0$ & 0 & 0 & 0 & 0 & 0 \\
\hline $5.0-10.0$ & 0 & 0 & 0 & 0 & 0 \\
\hline $10.0-15.0$ & 0 & 0 & 0 & 0 & 0 \\
\hline $15.0-20.0$ & 0 & 0 & 0 & 0 & 3 \\
\hline $20.0-25.0$ & 0 & 0 & 0 & 0 & 0 \\
\hline $25.0-30.0$ & 0 & 0 & 0 & 0 & 0 \\
\hline $30.0-35.0$ & 0 & 0 & 0 & 0 & 0 \\
\hline $35.0-40.0$ & 0 & 0 & 0 & 0 & 0 \\
\hline $40.0-45.0$ & 0 & 0 & 0 & 0 & 0 \\
\hline
\end{tabular}




\begin{tabular}{|c|c|c|c|c|}
\hline $45.0-50.0$ & 0 & 0 & 0 & 0 \\
\hline $50.0-55.0$ & 0 & 0 & 0 & 0 \\
\hline $55.0-60.0$ & 0 & 0 & 0 & 0 \\
\hline $60.0-65.0$ & 0 & 0 & 0 & 0 \\
\hline $65.0-70.0$ & 0 & 0 & 0 & 0 \\
\hline $70.0-75.0$ & 0 & 0 & 0 & 0 \\
\hline $75.0-80.0$ & 0 & 0 & 0 & 0 \\
\hline $80.0-85.0$ & 0 & 0 & 0 & 0 \\
\hline $85.0-90.0$ & 0 & 0 & 0 & 0 \\
\hline
\end{tabular}

\section{Listing of ray trajectories, locations of impact:}

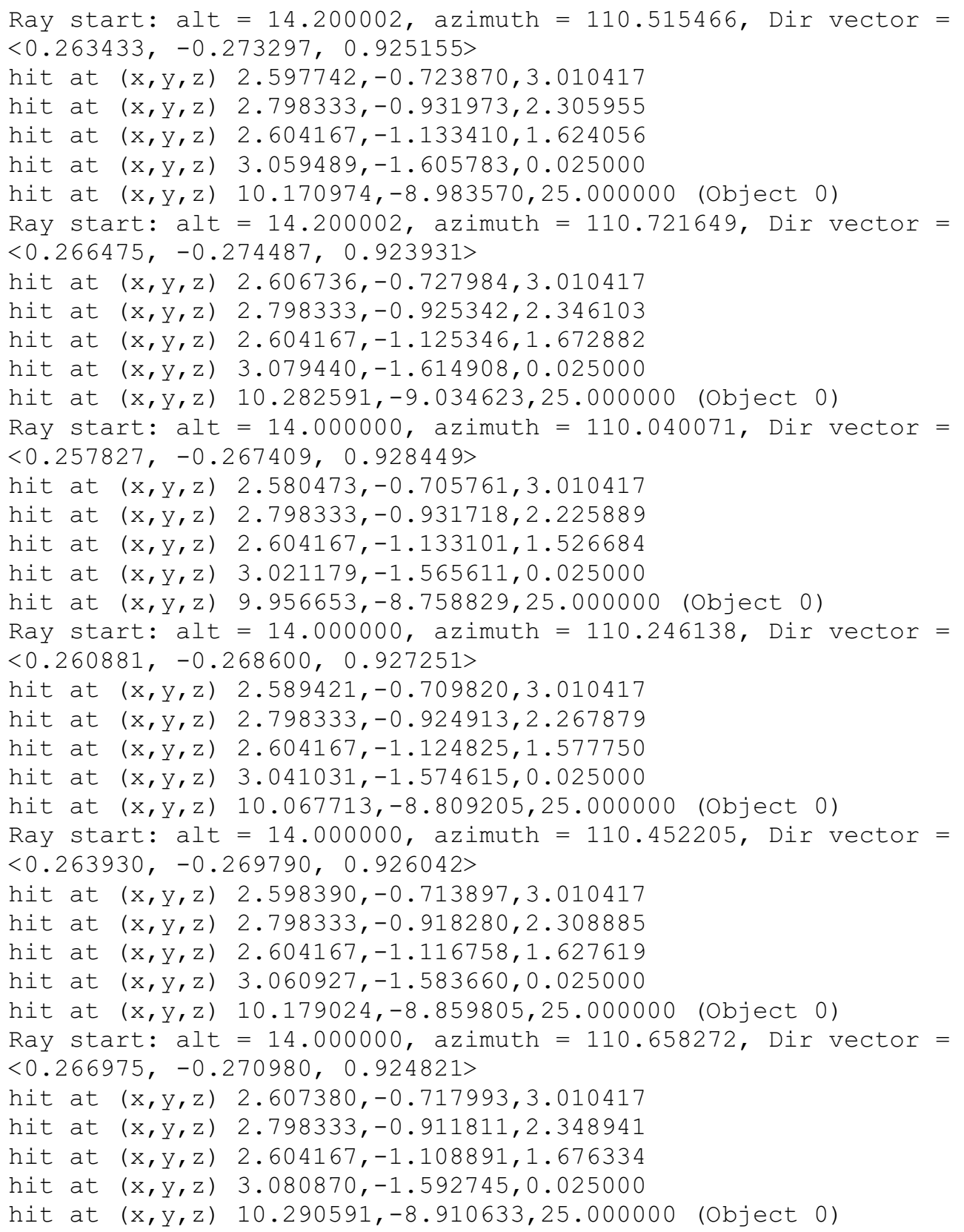


Ray start: alt $=13.799999$, azimuth $=109.708404$, Dir vector $=$ $<0.254322,-0.262342,0.930858>$

hit at $(x, y, z) 2.569485,-0.690597,3.010417$

hit at $(x, y, z) 2.798333,-0.926661,2.172798$

hit at $(x, y, z) 2.604167,-1.126951,1.462119$

hit at $(x, y, z) 2.996806,-1.531971,0.025000$

hit at $(x, y, z) 9.820296,-8.570631,25.000000$ (Object 0)

Ray start: alt $=13.799999$, azimuth $=109.914239$, Dir vector $=$ $<0.257382,-0.263534,0.929680>$

hit at $(\mathrm{x}, \mathrm{Y}, \mathrm{z}) 2.578399,-0.694613,3.010417$

hit at $(x, y, z) 2.798333,-0.919803,2.216002$

hit at $(x, y, z) 2.604167,-1.118610,1.514660$

hit at $(x, y, z) 3.016580,-1.540880,0.025000$

hit at $(\mathrm{x}, \mathrm{y}, \mathrm{z}) 9.930921,-8.620472,25.000000$ (Object 0$)$

Ray start: alt $=13.799999$, azimuth $=110.120066$, Dir vector $=$ $<0.260438,-0.264725,0.928490>$

hit at $(x, y, z) 2.587332,-0.698646,3.010417$

hit at $(x, y, z) 2.798333,-0.913120,2.258175$

hit at $(x, y, z) 2.604167,-1.110483,1.565950$

hit at $(x, y, z) 3.036397,-1.549828,0.025000$

hit at $(\mathrm{x}, \mathrm{y}, \mathrm{z}) 10.041789,-8.670531,25.000000$ (Object 0 )

Ray start: alt $=13.799999$, azimuth $=110.325901$, Dir vector $=$ $<0.263489,-0.265915,0.927288>$

hit at $(x, y, z) 2.596286,-0.702698,3.010417$

hit at $(x, y, z) 2.798333,-0.906605,2.299360$

hit at $(x, y, z) 2.604167,-1.102560,1.616035$

hit at $(x, y, z) 3.056260,-1.558816,0.025000$

hit at $(\mathrm{x}, \mathrm{y}, \mathrm{z}) 10.152910,-8.720813,25.000000$ (Object 0)

Ray start: alt $=13.799999$, azimuth $=110.531736$, Dir vector $=$ $<0.266536,-0.267105,0.926074>$

hit at $(\mathrm{x}, \mathrm{y}, \mathrm{z}) 2.605261,-0.706767,3.010417$

hit at $(x, y, z) 2.798333,-0.900253,2.339589$

hit at $(x, y, z) 2.604167,-1.094834,1.664960$

hit at $(x, y, z) 3.076168,-1.567844,0.025000$

hit at $(\mathrm{x}, \mathrm{y}, \mathrm{z}) 10.264285,-8.771319,25.000000$ (Object 0 )

Ray start: alt $=13.599997$, azimuth $=109.645717$, Dir vector $=$ $<0.254805,-0.258827,0.931710>$

hit at $(x, y, z) 2.570143,-0.680720,3.010417$

hit at $(x, y, z) 2.798333,-0.912513,2.176024$

hit at $(x, y, z) 2.604167,-1.109744,1.466042$

hit at $(x, y, z) 2.998265,-1.510062,0.025000$

hit at $(\mathrm{x}, \mathrm{y}, \mathrm{z}) 9.828456,-8.448062,25.000000$ (Object 0 )

Ray start: alt $=13.599997$, azimuth $=109.851428$, Dir vector $=$ $<0.257867,-0.260019,0.930535>$

hit at $(\mathrm{x}, \mathrm{y}, \mathrm{z}) 2.579052,-0.684719,3.010417$

hit at $(x, y, z) 2.798333,-0.905830,2.219123$

hit at $(\mathrm{x}, \mathrm{Y}, \mathrm{z}) 2.604167,-1.101617,1.518457$

hit at $(x, y, z) 3.018029,-1.518933,0.025000$

hit at $(\mathrm{x}, \mathrm{y}, \mathrm{z})$ 9.939029,-8.497687,25.000000 (Object 0)

Ray start: alt $=13.599997$, azimuth $=110.057140$, Dir vector $=$ $<0.260925,-0.261210,0.929348>$

hit at $(x, y, z) 2.587982,-0.688735,3.010417$

hit at $(x, y, z) 2.798333,-0.899317,2.261198$

hit at $(x, y, z) 2.604167,-1.093696,1.569625$

hit at $(x, y, z) 3.037837,-1.527842,0.025000$

hit at $(x, y, z) 10.049847,-8.547529,25.000000$ (Object 0 ) 


\section{Appendix C: Calculation of Required Thickness of Energy Absorbing Material}

This appendix determines the required thickness of energy absorbing material used in the shrapnel trap proposed for the new module concept. The proposed material for use in the trap is clear pine (i.e., no knots). The orientation of the wood grain relative to the imposed stress is important. Energy absorption is much greater if the grain is oriented parallel to the direction of the stress. It is therefore assumed that the grain of the wood in the trap will be oriented vertically, so that it will be parallel to the direction of the incoming fragments.

The required thickness of energy absorbing material is described by (DOE, 1992, Chapter 7):

$\mathrm{t}=\frac{\mathrm{KE}}{\mathrm{f}_{\mathrm{cr}} \mathrm{A}_{\mathrm{p}}}$

Where

$\mathrm{t}=$ required thickness of absorbing material $(\mathrm{ft})$

$\mathrm{KE} \quad=$ kinetic energy of incident fragment $(\mathrm{ft}-\mathrm{lb})$

$\mathrm{f}_{\mathrm{cr}} \quad=$ crush strength of energy absorbing material (psi)

$\mathrm{A}_{\mathrm{p}} \quad=$ projected area of fragment $\left(\mathrm{in}^{2}\right)$

The crush strength of pine varies, but 3500 psi is a representative value for several varieties of pine (DOE, 1992, Table 7.12).

The properties of the various projectiles considered in this work are summarized below:

\begin{tabular}{|l|l|l|l|}
\hline & Fragment 1 & Fragment 2 & Fragment 3 \\
\hline Weight (oz) & 2 & 0.32 & 0.04 \\
\hline $\begin{array}{l}\text { Cross } \\
\left.\text { Section (in }{ }^{2}\right)\end{array}$ & 1.125 & 0.5 & 0.0625 \\
\hline $\begin{array}{l}\text { Energy } \\
\text { (ft-lb) }\end{array}$ & 1726 & 336 & 60.5 \\
\hline
\end{tabular}

Substituting values, the required thickness of pine to stop each of the fragments is:

$\begin{array}{lll}\mathrm{t}_{1} & =0.44 \mathrm{ft} & =5.3 \text { inches } \\ \mathrm{t}_{2} & =0.19 \mathrm{ft} & =2.3 \text { inches } \\ \mathrm{t}_{3} & =0.27 \mathrm{ft} & =3.3 \text { inches }\end{array}$


Assume 3.5 inches of pine are provided in the trap. This will completely absorb the energy of fragments 2 and 3 . Fragment 1 will still have some residual energy once it reaches the bottom of the trap. This fragment could either penetrate into the steel bottom of the shrapnel trap, or be reflected by it.

The residual velocity of Fragment 1 after traveling 3.5 inches in the pine would be:

$\mathrm{KE}_{\text {abs }}{ }^{1} \quad=3.5 / 12 \mathrm{ft} \times 3500 \mathrm{psi} \times 1.125 \mathrm{in}^{2}$

$=1148 \mathrm{ft}-\mathrm{lb}$

$\mathrm{KE}_{\mathrm{r}}{ }^{1} \quad=(1726-1148) \mathrm{ft}-\mathrm{lb}$

$=578 \mathrm{ft}-\mathrm{lb}$

$\mathrm{v}_{\mathrm{r}}{ }^{1} \quad=\left(578 \mathrm{ft}-1 \mathrm{~b} \times 2 \times 16 /(2 \mathrm{lb}) \times 32.2 \mathrm{ft} / \mathrm{s}^{2}\right)^{0.5}$

$=546 \mathrm{ft} / \mathrm{s}$

At this velocity, the penetration depth into the steel bottom of the trap would be approximately 0.15 inches (using, for example, the Saville formula given in Appendix B.3). The bottom of the shrapnel trap will be at least 0.25 inch steel. If fragment 1 penetrates into the steel, it will come to a stop before completely penetrating the bottom of the trap.

If the fragment is reflected off the bottom of the trap, it would have at least another 3.5 inches of pine to travel through. At the velocity of $546 \mathrm{ft} / \mathrm{s}$, the penetration depth into the pine would be approximately 1.8 inches, thus it would come to a stop in the pine on the way back out. 


\section{Appendix D: Calculation of Maximum Credible Number of Simultaneous Events}

The capacitor module explosion rate is estimated based on data from FANTM at Sandia National Laboratory, Albuquerque. At the end of the test program in July of 1999, 17112 shots had been conducted. During the test program, there were 5 events of various types. The last failure occurred in January of 1999. After that, an additional 9545 shots were fired without incident.

The failure rate for the module can be calculated in a number of ways:

(1) Based on the total data set:

$\underline{5 \text { explosions }}=2.9 \times 10^{-4}$ explosions $/$ module - shot 17112 shots

(2) Based on the data up until January of 1999:

$$
\frac{5 \text { explosions }}{(17112-9545) \text { shots }}=6.6 \times 10^{-4} \text { explosions } / \text { module }- \text { shot }
$$

(3) Based on the data after January of 1999:

The predicted failure rate, $\mathrm{P}$, for 0 failures after $\mathrm{n}$ trials is:

$$
\mathrm{P}=1-(1-\mathrm{CL})^{1 /(\mathrm{n}+1)}
$$

where CL is the confidence level.

At 99\% confidence level, the failure rate would be:

$$
\begin{aligned}
\mathrm{P} & =1-(1-0.99)^{1 /(9545+1)} \\
& =4.8 \times 10^{-4} \text { explosions } / \text { module }- \text { shot }
\end{aligned}
$$

At 95\% confidence level, the failure rate would be:

$$
\begin{aligned}
\mathrm{P} & =1-(1-0.95)^{1 /(9545+1)} \\
& =3.1 \times 10^{-4} \text { explosions } / \text { module }- \text { shot }
\end{aligned}
$$

At $90 \%$ confidence level, the failure rate would be:

$$
\begin{aligned}
\mathrm{P} & =1-(1-0.90)^{1 /(9545+1)} \\
& =2.4 \times 10^{-4} \text { explosions } / \text { module }- \text { shot }
\end{aligned}
$$


At $50 \%$ confidence level, the failure rate would be:

$$
\begin{aligned}
\mathrm{P} & =1-(1-0.50)^{1 /(9545+1)} \\
& =7.3 \times 10^{-5} \text { explosions } / \text { module }- \text { shot }
\end{aligned}
$$

Based on these various ways of calculating a failure rate, the values are within an order of magnitude. Because modifications were made to the capacitors and other components throughout the test program, the second half of the data is perhaps more representative of the situation. At the $95 \%$ confidence level, the failure rate would be $3.1 \times 10^{-4}$ per module per shot.

The events at FANTM occurred during a two-minute time period during each shot, when the capacitors were charging or were charged. Note that the FANTM rate is a conservative explosion rate for NIF, as it is expected that additional knowledge will be gained, modifications made, and the failure rate reduced.

In a NIF capacitor bay, there will be 48 operating modules. It is of interest to know the probability of more than one module exploding simultaneously. To determine the probability of two events occurring simultaneously, the number of combinations of two modules, given there are 48 available, must be determined. This is described by:

$$
\begin{aligned}
\mathrm{C}(2, \mathrm{~N}) & =\frac{\mathrm{N} !}{(\mathrm{N}-2) ! 2 !} \\
& =\frac{48 !}{46 ! 2 !} \\
& =1128
\end{aligned}
$$

Thus, there are 1,128 ways one can combine 48 modules into pairs of two modules. The probability on a shot of more than one explosion would be determined from the probability of each module exploding individually, times the number of ways two events could occur together. Mathematically, this would be expressed as:

$$
\begin{aligned}
& \mathrm{P}(2 \text { explosions within a shot charge period })=1128 \times\left(3.1 \times 10^{-4}\right)^{2} \\
& \quad=1.08 \times 10^{-4} \text { two explosions } / \text { shot }
\end{aligned}
$$

The period of time when the modules are charging or are charged is approximately 2 minutes. Simultaneous explosions are of interest from the standpoint that their pressure pulses in the capacitor bay could overlap. The duration of the capacitor bay overpressure is estimated as follows:

A typical air leakage rate for a commercial building with average walls was found to be $1500 \mathrm{~cm}^{3} / \mathrm{s} \mathrm{m}^{2}$ at $75 \mathrm{~Pa}$ overpressure (ASHRAE, 1997, P. 25.19). The capacitor bay walls provide approximately $1450 \mathrm{~m}^{2}$ of area $(2 \times 250 \mathrm{ft} \times 26 \mathrm{ft}+2 \times$ $50 \mathrm{ft} \times 26 \mathrm{ft}$ ). This gives a leak rate of $2.2 \mathrm{~m}^{3} / \mathrm{s}$ at $75 \mathrm{~Pa}$. At other pressures, the leak rate can conservatively be described by (ASHRAE, 1981, P.22.8): 


$$
\mathrm{Q}=\mathrm{C} \Delta \mathrm{P}^{0.5}
$$

where

$\mathrm{Q} \quad=$ leakage flow rate $\left(\mathrm{m}^{3} / \mathrm{s}\right)$

$\mathrm{C}=$ constant

$\Delta \mathrm{P} \quad=$ overpressure $(\mathrm{Pa})$

Note that at higher pressures $(>10 \mathrm{~Pa})$, the pressure coefficient is often larger than 0.5. This would give a larger leakage flow rate (and a shorter time for the capacitor bay to reach ambient after being pressurized). However, since an appropriate coefficient could not be justified, 0.5 was conservatively used here.

Using the data of $2.2 \mathrm{~m}^{3} / \mathrm{s}$ at $75 \mathrm{~Pa}$, a value for $\mathrm{C}$ can be estimated:

$$
\begin{aligned}
C & =\frac{2.2 \mathrm{~m}^{3} / \mathrm{s}}{(75 \mathrm{~Pa})^{0.5}} \\
& =0.25 \mathrm{~m}^{3} / \mathrm{Pa}^{0.5} \mathrm{~s}
\end{aligned}
$$

Thus,

$$
\mathrm{Q}=0.25 \Delta \mathrm{P}^{0.5}
$$

Assuming the peak bay pressure is 30 psf (structural limit of the walls), $\Delta \mathrm{P}=30$ psf $=1436 \mathrm{~Pa}$ at the start of the transient. The excess volume $\left(\Delta \mathrm{V}_{\text {tot }}\right)$ needed for the bay pressure to return to ambient can be estimated:

$$
\left(\mathrm{P}_{\mathrm{a}}+\Delta \mathrm{P}_{\mathrm{o}}\right) \mathrm{V}_{\mathrm{b}}=\mathrm{P}_{\mathrm{a}}\left(\mathrm{V}_{\mathrm{b}}+\Delta \mathrm{V}_{\text {tot }}\right)
$$

where:

$\mathrm{P}_{\mathrm{a}} \quad=$ ambient pressure $(1.013 \mathrm{E}+5 \mathrm{~Pa})$

$\Delta \mathrm{P}_{\mathrm{o}} \quad$ = initial overpressure $(1436 \mathrm{~Pa})$

$\mathrm{V}_{\mathrm{b}} \quad$ = capacitor bay volume (8117 $\mathrm{m}^{3}$, corrected for equipment occupancy)

$\Delta \mathrm{V}_{\text {tot }}=$ total excess volume required to bring the pressure back to ambient $\left(\mathrm{m}^{3}\right)$

Solving, $\Delta \mathrm{V}_{\mathrm{tot}}=115 \mathrm{~m}^{3}$.

Knowing the total volume that must be vented to return the bay to ambient pressure, the initial pressure, and the relationship between leakage rate and overpressure, the time to return the capacitor bay to ambient pressure can be estimated. This was done using a spreadsheet and the following basic equations:

$$
\left(\mathrm{P}_{\mathrm{a}}+\Delta \mathrm{P}(\mathrm{t})\right) \mathrm{V}_{\mathrm{b}}=\mathrm{P}_{\mathrm{a}}\left(\mathrm{V}_{\mathrm{b}}+\Delta \mathrm{V}(\mathrm{t})\right)
$$

where:

$\Delta \mathrm{P}(\mathrm{t})=$ remaining overpressure at time step $\mathrm{t}$

$\Delta \mathrm{V}(\mathrm{t})=$ excess volume that still must be vented at time step $\mathrm{t}$ for the bay pressure to return to ambient 
Thus,

$$
\Delta \mathrm{P}(\mathrm{t})=\Delta \mathrm{V}(\mathrm{t}) \mathrm{P}_{\mathrm{a}} / \mathrm{V}_{\mathrm{b}}
$$

Consider:

$\mathrm{Q}(\mathrm{t})=0.25 \Delta \mathrm{P}(\mathrm{t})^{0.5}$, exhaust rate during time step $\mathrm{t}$

$\Delta \mathrm{v}(\mathrm{t})=\mathrm{Q}(\mathrm{t}) \Delta \mathrm{t}$, volume exhausted during time step $\mathrm{t}$

One observes:

$$
\Delta \mathrm{V}(\mathrm{t})=\Delta \mathrm{V}_{\text {tot }}-\Sigma_{\mathrm{i}} \Delta \mathrm{v}\left(\mathrm{t}_{\mathrm{i}}\right), \quad \mathrm{t}_{\mathrm{i}}<\mathrm{t}
$$

(Note: the sum of $\Delta v\left(t_{i}\right)$ is over time steps $t_{i}$ to the point $t$. In addition, $\Delta v\left(t_{i}\right)$ is the exhausted volume at overpressure $\Delta \mathrm{P}\left(\mathrm{t}_{\mathrm{i}}\right)$ while $\Delta \mathrm{V}_{\text {tot }}$ is the exhausted volume at the ambient pressure $\mathrm{P}_{\mathrm{a}}$. However, due to the small overpressure, if $\Delta v\left(t_{\mathrm{i}}\right)$ is converted to the corresponding volume at $\mathrm{P}_{\mathrm{a}}$ in the above summation, the following resulting time will not change significantly.)

The results of the calculation are shown in Table D-1. Time steps ( 1 second) were taken until the remaining overpressure was essentially zero. As can be seen in the table, this occurred within about 22 seconds. For there to be a potential overpressure issue from simultaneous explosions, they would have to occur within 22 seconds of each other. During any two minute shot charge period, the chance of two explosions occurring within 22 seconds of each other would be $22 / 120=0.18$. Thus, the chance of two events occurring within any 22 second time window would be:

$$
\begin{aligned}
\mathrm{P}_{2} & =\mathrm{P}(2 \text { explosions within a shot charge period }) \times 22 / 120 \\
& =1.08 \times 10^{-4} \times 0.18 \\
& =2.0 \times 10^{-5} \text { two-overlap-explosions } / \text { shot } \quad \text { (this is credible) }
\end{aligned}
$$

Note that during a two minute shot charge period, the probability of three events occurring within any 22 second time window is described by:

$$
\begin{aligned}
& \mathrm{P}_{3}=\frac{48 !}{(48-3) ! 3 !} \times\left(3.1 \times 10^{-4}\right)^{3}(22 / 120)^{2} \\
& =1.7 \times 10^{-8} \text { three-overlap-explosions / shot }
\end{aligned}
$$


Table D-1: Decay of Overpressure in Capacitor Bay

\begin{tabular}{|c|c|c|c|}
\hline Time (sec) & $\begin{array}{c}\text { Remaining } \\
\text { Overpressure } \\
\Delta P(t)(P a)\end{array}$ & $\begin{array}{c}\text { Remaining } \\
\text { Overvolume } \\
\Delta \mathrm{V}(\mathrm{t})\left(\mathrm{m}^{3}\right) \\
\end{array}$ & $\begin{array}{c}\text { Exhaust Rate } \\
\text { during time step } \\
Q\left(\mathrm{~m}^{3} / \mathrm{s}\right)\end{array}$ \\
\hline 0 & 1436 & 115 & 9.47364766 \\
\hline 1 & 1317.70297 & 105.526352 & 9.07504467 \\
\hline 2 & 1204.38329 & 96.4513077 & 8.67605644 \\
\hline 3 & 1096.04575 & 87.7752512 & 8.2766454 \\
\hline 4 & 992.695634 & 79.4986058 & 7.87676819 \\
\hline 5 & 894.338773 & 71.6218376 & 7.47637434 \\
\hline 6 & 800.981611 & 64.1454633 & 7.07540463 \\
\hline 7 & 712.631341 & 57.0700587 & 6.67378894 \\
\hline 8 & 629.296029 & 50.3962697 & 6.27144336 \\
\hline 9 & 550.984788 & 44.1248264 & 5.86826629 \\
\hline 10 & 477.708002 & 38.2565601 & 5.46413306 \\
\hline 11 & 409.47761 & 32.792427 & 5.05888828 \\
\hline 12 & 346.307492 & 27.7335387 & 4.65233471 \\
\hline 13 & 288.213991 & 23.081204 & 4.24421659 \\
\hline 14 & 235.216643 & 18.8369874 & 3.83419355 \\
\hline 15 & 187.339235 & 15.0027939 & 3.42179809 \\
\hline 16 & 144.611391 & 11.5809958 & 3.00636191 \\
\hline 17 & 107.07108 & 8.57463387 & 2.58687892 \\
\hline 18 & 74.7688358 & 5.98775496 & 2.16172437 \\
\hline 19 & 47.7754777 & 3.82603059 & 1.72799518 \\
\hline 20 & 26.1980769 & 2.09803541 & 1.27960143 \\
\hline 21 & 10.2197496 & 0.81843398 & 0.79920858 \\
\hline 22 & 0.24006683 & 0.01922541 & 0.12249154 \\
\hline 23 & -1.2894797 & -0.1032661 & 0 \\
\hline
\end{tabular}

\section{$\underline{\text { References }}$}

ASHRAE, 1981, ASHRAE Handbook, 1981 Fundamentals, American society of Heating, Refrigeration, and Air-Conditioning Engineers, Include., 1981.

ASHRAE, 1997, ASHRAE Handbook, 1997 Fundamentals, , American society of Heating, Refrigeration, and Air-Conditioning Engineers, Include., 1997. 


\title{
Appendix E: Module Structural Calculations
}

\section{Appendix E.1}

\section{NIF Capacitor Module Blast Door Dynamic Load Calculation}

Originator: Madhu Kamath

Date: $06 / 28 / 01$

Check: $\quad$ David W. Coats

\author{
Date: 06/29/01
}

From Ref.1, Equation 5-2 ( pages 5-10 \& 5-11),

$$
\mathrm{f}_{\mathrm{ds}}=\mathrm{f}_{\mathrm{dy}}=\mathrm{c}^{*} \mathrm{a} * \mathrm{f}_{\mathrm{y}}
$$

$\mathrm{f}_{\mathrm{y}}=$ static yield stress (= $36 \mathrm{ksi}$ for ASTM A36 steel)

$\mathrm{f}_{\mathrm{dy}}=$ dynamic yield stress

$\mathrm{f}_{\mathrm{ds}}=$ dynamic design stress

$\mathrm{c}=$ dynamic increase factor on the yield stress (=1.29, Ref.1, P.5-15).

$\mathrm{a}=$ average strength increase factor $(=1.1$ for steels with specified

minimum yield stress of $50 \mathrm{ksi}$ or less ; 1.0 otherwise, Ref.1, P.5-15 )

$$
\begin{aligned}
& \mathrm{f}_{\mathrm{ds}}=1.29 * 1.1 * 36 \mathrm{ksi} \\
& \quad=51.08 \mathrm{ksi}
\end{aligned}
$$

$\mathrm{r}_{\mathrm{E}}=12$ psi (see Appendix E.2, based on fy=36 ksi).

$\mathrm{r}_{\mathrm{u}}=\mathrm{r}_{\mathrm{E}}^{*} \mathrm{k} \mathrm{f}_{\mathrm{ds}} / \mathrm{f}_{\mathrm{y}}$

$\mathrm{k}=$ ratio of plastic modulus to elastic modulus (=1.5, Ref. 2, P.213)

$\mathrm{r}_{\mathrm{u}}=12 * 1.5 * 51.08 / 36=25.5$ psi capacity

$\mathrm{T}_{\mathrm{N}}=21.7 \mathrm{~m}$-sec (the first important fundamental period of the front door, see Appendix E.2).

$\mathrm{T}=10 \mathrm{msec}$ (decay time of the dynamic pressure)

From Ref. 1, Fig 3-54, we use $T / T_{N}=10 / 21.7=0.46, X_{m} / X_{E}=10, r_{u} / P=0.29$, and obtain: 
40

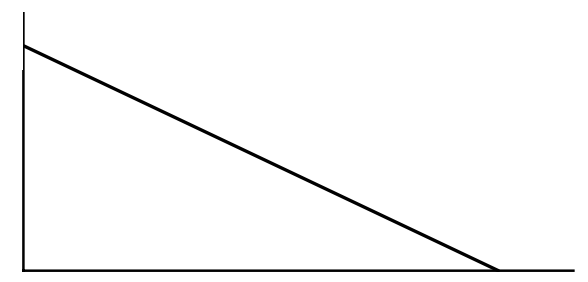

$\mathrm{T}=10 \mathrm{msec}$

Figure E.1-1: Dynamic load on the blast door, the pressure decay time is $10 \mathrm{msec}$.

$$
\begin{aligned}
& \mathrm{r}_{\mathrm{u}}(\text { required resistance })=\mathrm{P} * 0.29 \mathrm{psi} \\
& =40 * 0.29 \mathrm{psi}=11.6 \mathrm{psi}<25.5 \text { psi capacity. O.K }
\end{aligned}
$$

(where $X_{m}$ and $X_{E}$ are the maximum displacement and elastic displacement, respectively; $u=X_{m} / X_{E}$ is the ductility ratio, and $P=40$ psi is the peak dynamic pressure inside the vessel).

Note: The maximum $X_{m} / X_{E}$ is 26 , this calculation uses $X_{m} / X_{E}=10$ (Ref. 1, P.5-19).

$\mathrm{T}_{\mathrm{N}}=3.5 \mathrm{~m}$-sec (the $10^{\text {th }}$ important mode of the front door, see Appendix E.2)

From Fig 3-54, for $\mathrm{T} / \mathrm{T}_{\mathrm{N}}=10 / 3.5=2.86, \mathrm{X}_{\mathrm{m}} / \mathrm{X}_{\mathrm{E}}=26, \mathrm{r}_{\mathrm{u}} / \mathrm{P}=0.62$, and we obtain :

$$
\begin{aligned}
\left.\mathrm{r}_{\mathrm{u}} \text { (required resistance }\right) & =\mathrm{P}^{*} 0.62 \mathrm{psi} \\
= & 40^{*} 0.62=24.8 \mathrm{psi}<25.5 \text { psi. } \quad \text { O.K }
\end{aligned}
$$

The rear door with the lowest period of $3.9 \mathrm{~m}$-sec (the $10^{\text {th }}$ important, see Appendix E.2) is also okay from the above figure (Fig. 3-54); $r_{u}$ (required resistance $)=40 * 0.6=24.0 \mathrm{psi}<25.5 \mathrm{psi}$ O.K

Hence both the front and back blast doors are O.K.

\section{$\underline{\text { References }}$}

Ref.1: Structures to resist the effects of accidental explosions-Army TM 5-1300, 1990.

Ref.2: L. S. Beedle, Structural Steel Design, 1964. 


\section{Appendix E.2}

\section{Door Structural Analysis}

The capacitor module cabinet design has two removable panels, called the front and rear doors. These panels are not hinged as in conventional doors, but are instead slid into place over hooks at the top of each door opening, and dropped into slots at the bottom of each opening.

At the waist, or mid-height, position, each door has two latches, comprising a steel bar that is slid between the door and a fixed bracket, then bolted to the bracket. As it turns out, these waist latches carry most of the force that would be seen by each door in the event of internal pressure. This is due to their position midway between the top and bottom of the openings and also to the fact that the doors are continuous under the latch -- thus the latches accrue load similarly to the center support of a three-support continuous beam with simple ends: substantially more than $1 / 2$ of the total load.

The current door design comprises a large steel plate, roughly 8 feet high by 4 feet wide, and $3 / 8$ inch thick. Mounted on the exterior of each door are two large, vertical vent chutes, designed to allow venting of internal pressure while preventing fragments of electrical components from exiting with substantial velocity. Each chute has an entrance opening in the door plate, an internal baffle, and an exit opening guarded by a piece of soft wood to absorb particle energy with minimal rebound.

On each door is a small, hinged access panel, called the "window", which will be opened to access a particular electrical part within the cabinet (and without having to remove the main doors). On the "front door" the window is at the top, while on the "rear door" the window is at the bottom. The rear door is located on the side of the cabinet which also has the attached "control rack", which is also the side of the cabinet with welded side panels. The front door is on the side of the cabinet with bolted side panels. 


\section{Finite Element Model}

The following drawings were among those used in constructing and revising the finite ele-ment models for the analysis:

AAA99-120485-0A NIF Power Conditioning, Module Configuration Layout, PCS Module sub-system

AAA97-103881-0B PCS Module sub-system, Front Door Assembly

AAA97-103882-0C PCS Module sub-system, Front Door Assembly, Front Door Weldment

AAA97-103883-0B PCS Module sub-system, Rear Door Assembly

AAA97-103884-0C PCS Module sub-system, Rear Door Assembly, Rear Door

Weldment

AAA99-120452-0A PCS Main Energy Storage Module, Module PPN Assembly, Energy Storage Assembly

AAA99-120453-0A Module PPN Assembly, Energy Storage Assembly, Module

Frame.

The finite element models (one model for each door) were constructed using the SLIC modeling program, running on both PC and SUN Sparc computers. Due to the small dimensions in certain locations on both doors, the models required fairly fine element spacing. The front door model (model version 32f) comprises 10451 nodes, 78 beam elements, and 10574 shell elements, each with a size of approximately 1 inch by 1 inch. The rear door model (version 24r) is slightly smaller, with 10378 nodes, 81 beam elements, and 10452 shell elements.

The main door plates, chute covers, baffles, and other plate structure, and most reinforce-ments were modeled as plate-and-shell elements, while some reinforcing pieces (in the vicinity of the window) were modeled with beam elements. Spring elements were used at the points of restraint of the doors to the cabinets in order to determine reactions.

Figure E.2-1 illustrates one of the models (SLIC graphic) and Figures E.2-2 and E.2-3 show the deformed shape (front and back views, respectively) of the front door due to "blast" pressure (TAURUS graphics), while Figures E.2-4 and E.2-5 show the deformed shape of the rear door (TAURUS graphics). 


\section{Analysis}

Pressures. The door structures were analyzed, using conventional finite element procedures, for gravity loads and a superimposed blast pressure of 12 psig applied to the inside surface of the door. A reduced pressure of 2 psig was applied to the inside of the chutes, producing a net of 10 psig on the portions of the door panels that are overlain by the vent chutes, and 2 psig on the chute cover plates.

The value of 2 psig for the chute pressure was determined by calculating the approximate pressure drops that could be expected to occur if a flow of hot, pressurized air were to vent through a chute, including the entrance loss on entering the chute, the Venturi effect due to the reduced area within the chute, and the effect of expansion due to these pressure drops (expansion works to increase the velocity-related pressure drops mentioned). The mass rate of flow that would approx-imately dissipate the 12 psig of pressure by means of chute entrance and exit losses was determined by trial and error. Since the velocities are expected to reach sonic, the flow analysis is considered to be only approximate.

The GEMINI analysis program (version of 20Jun00) as running on DEC (now Compaq) compass cluster was used for static analysis of gravity and pressure loads in a single case. Static solution times were approximately $560 \mathrm{cpu}$ seconds (single processor) per run.

Frequencies of Vibration. Natural frequencies and mode shapes of each door (including the proposed modifications) were computed, using the compass cluster machines; each computation run produced 40 frequencies and mode shapes using the Lanczos method, and required approximately $1200 \mathrm{cpu}$ seconds per run. The results of these computations are shown in Tables E.2-5 and E.2-6 and graphics of the modes that are most significant with respect to potential separation of the door appear as Figures E.2-8, E.2-9 and E.2-10.

Analysis of Doubler Plates. Doubler plates can be attached to main plates in two different ways, and can also be included in a finite element analysis in two different ways:

Method \# 1: Increased Thickness. A doubler plate can be modeled by increasing the thickness of the plate to which the doubler is applied. For this approximation to correctly model the structure, the doubler plate must be welded to the original plate in such a manner as to cause the two plates to act as a single plate of greater thickness -that is, simply welding the perimeter of the doubler to the main plate is not sufficient since this would not assure the two plates would act as one. To get full composite action, the interior of the doubler must be periodically plug-welded to the main plate. If this is the case, then the main and doubler plates may be modeled as a single plate with the combined thickness of the two plates. Otherwise, the analysis would be overstating both the stiffness and strength of the combination. 
For example, a 3/8" main plate with a 3/8" doubler (periodically plug-welded) would be analyzed as one plate of $3 / 4^{\prime \prime}$ thickness (which has 8 times the stiffness and 4 times the strength of one $3 / 8^{\prime \prime}$ plate) if the doubler is adequately attached to the main plate with periodic plug welds.

Method \# 2: Two Plates. A doubler plate may also be modeled as a second plate, co-located with the main plate (that is, sharing the same plane). Analyzing the two plates as two plates acting somewhat independently generally understates both the stiffness and strength of the combination by a factor of nearly two (and is therefore generally conservative). If the analysis shows this model to have adequate strength and stiffness, then the doubler plate may be perimeter fillet-welded to the main plate, with few or no interior plug welds.

For example, a $3 / 8^{\prime \prime}$ main plate with a $3 / 8^{\prime \prime}$ doubler (not periodically plugwelded) would be analyzed as two plates of $3 / 8^{\prime \prime}$ thickness (which have twice the stiffness and twice the strength of a single $3 / 8^{\prime \prime}$ plate).

Welding of Door Reinforcing Doubler Plates. For the capacitor rack doors, it is necessary for only two sets of doublers to be plug welded for extra strength:

1. The waist latch cutout doublers (those external to the vent chutes -- that is those directly under the latches) need to be both perimeter and plug-welded to the door main plates so as to act as a single plate of double thickness. Due to the limited width of this doubler (approximately 1" wide at its narrowest) a line of $3 / 8$ " plug welds, spaced 1" down the vertical centerline will be all that can be accomplished.

2. The rear door, lower vent chute inlet side plate doublers also need to be plug welded as well as perimeter welded -- and these doublers also need to be made of slightly stronger steel, ASTM A529 (42 ksi yield).

All other doublers may be applied with only perimeter welds (fillet welds or single-groove welds as convenient) of depth equal to the material thickness.

\section{Results}

Minimum Factors of Safety. Governing factors of safety for ductile materials (such the steel being used for this design) are specified in the LLNL Mechanical Engineering Design Safety Standards (MEDSS), Chapter E, page 5 as:

for normal loads: $\quad 3.0$ against yield

for rare events: $\quad 1.0$ against yield

Since the failure of a capacitor is a rare event, the minimum factor of safety of von Mises stresses compared with yield is 1.0

Yield Stresses. The square tube steel is ASTM A500, Grade B, which has a yield of $46 \mathrm{ksi}$, and (with the exception of one set of doubler plates) the steel plate and doublers are ASTM A36 with a yield of 36. The rear door vent chute side plate doublers, at the lower vent inlet only, must be ASTM A529 (42 ksi yield). 
Stresses. Maximum stresses and actual factors of safety for both doors (as modified) and all mater-ials are shown in Table I (from a spreadsheet). The proposed design modifications mitigate high stresses at points of stress concentration previously evident and bring the design into conformance with the intent of the LLNL MEDSS factors of safety, as shown in Table E.2-1.

Table E.2-1: Stresses and Factors of Safety for Front and Rear Doors

Front Door (results from run 32f)

\begin{tabular}{|c|c|c|c|}
\hline $1--S$ & ses, & KSI-- & Safety \\
\hline Beam Materials ... & Yield & Maximum & Factor \\
\hline 1 Door Top Reinforcement & 46 & 23.13 & 1.99 \\
\hline 2 unused & 46 & -- & -- \\
\hline 3 Window cover hinges, latch & 46 & 19.87 & 2.31 \\
\hline 4 Window opening rein. & 46 & 10.60 & 4.34 \\
\hline 5 Window cover rein. Beam & 46 & 23.96 & 1.92 \\
\hline
\end{tabular}

$\begin{array}{lllll} & \text { /--Stresses, } & \text { KSI-- } & \text { Safety } & \\ \text { Shell Materials ... } & \text { Yield } & \text { Maximum } & \text { Factor } & \text { Note } \\ 1 \text { Main door Plate A36 } & 36 & 38.58 & .93 & 1 \\ \text { 2 Chute Cover Plates A36 } & 36 & 20.09 & 1.79 & \\ \text { 3 Chute Exit Lip strips A36 } & 36 & 6.04 & 5.96 & \\ 4 \text { Chute Side Plates A36 } & 36 & 36.50 & .99 & 1 \\ 5 \text { Chute Bottom Plates A36 } & 36 & 24.96 & 1.44 & \\ 6 \text { Chute Baffles A36 } & 36 & 8.53 & 4.22 & \\ 7 \text { Window Cover Plate A36 } & 36 & 28.06 & 1.28 & \\ \text { 8 Bottom and Side Doublers } & 36 & 32.64 & 1.10 & \\ \text { 9 Waist Latch Interior Dblrs } & 36 & 25.67 & 1.40 & \\ \text { 10 Vent Inlet Doublers A36 } & 36 & 38.58 & .93 & 1\end{array}$

Rear Door (results from run 24r)

\begin{tabular}{|c|c|c|c|c|}
\hline \multicolumn{2}{|c|}{ /--Stresses, } & KSI-- \ & \multicolumn{2}{|l|}{ Safety } \\
\hline Beam Materials ... & Yield & Maximum & Factor & \\
\hline 1 Door Bottom Reinforcement & 46 & 19.12 & 2.41 & \\
\hline 2 unused & 46 & -- & -- & \\
\hline 3 Window cover hinges \& latch & 46 & 20.86 & 2.21 & \\
\hline 4 Window opening reinf. & 46 & 15.30 & 3.01 & \\
\hline 5 Window cover reinf. Beam & 46 & 24.69 & 1.86 & \\
\hline /--Str & esses, & KSI-- \ & Safety & \\
\hline Shell Materials ... & Yield & Maximum & Factor & Note \\
\hline 1 Main door Plate A36 & 36 & 37.50 & .96 & \\
\hline 2 Chute Cover Plates A36 & 36 & 14.99 & 2.40 & \\
\hline 3 Chute Exit Lip strips A36 & 36 & 6.17 & 5.84 & \\
\hline 4 Chute Side Plates, A36 & 36 & 25.53 & 1.41 & \\
\hline 5 Chute Bottom Plates A36 & 36 & 25.35 & 1.42 & \\
\hline 6 Chute Baffles A36 & 36 & 5.98 & 6.02 & \\
\hline
\end{tabular}


Notes:

1. This stress exceeds the allowable (yield) but occurs in only one element (extent less than 1 square inch) at each side of each vent inlet, in the main door plate (and doubler) and front door side plates.

The doubler plates in these regions were modeled as two plates of one thickness sharing the same plane, which understates both their stiffness and strength, and these stresses are therefore overstated.

Modeling the doubler plates as doubling the thickness of the main plate (instead of as a second plate of like thickness) would be less conservative and reduce the calculated stress by a factor of nearly two.

2. This stress is maximum in the doubler plate on the inside of the side plates at the lower vent inlet only, and requires A529 steel (42 yield) doubler plates -- with plug welding to make the plates act as one. The maximum stress in the side plate is less than 36 , allowing A36 to be used for the side plates (material \#4).

The upper vent inlet is lower stressed and can use A36 doubler plates without plug-welding (material \# 8).

Beam Materials. The front and rear door beam materials are shown in Table E.22 (from the model input file).

\section{Table E.2-2: Beam Materials}

Mat Use

1 reinforcing beam at top of front door

1 reinforcing beam at bottom of rear door

2 (unused)

3 beams used as links for attaching window cover

4 vertical beam on door plate at window opening

5 vertical beam on window cover

\section{Description}

$1.5 \times 1.5 \times 1 / 4$ sq tube

$1.5 \times 1.5 \times 1 / 4$ sq tube

$1 \times 1$ square bar.

$1.5 \times 1.5 \times 1 / 4$ sq tube

$1 \times 1 \times 1 / 4$ angle

Door Restraint Reactions. The spring elements used to model the door restraints (top hooks, waist latches, and bottom restraints) provide reaction results that have been used in the capacitor rack cabinet frame analysis, reported in a separate document. 
The front door restraint reactions (pounds-force) at various nodes are shown in Table E.2-3.

Table E.2-3: Front Door Support Point Reactions

Node $\underline{X} \quad \underline{Y} \quad \underline{Z} \quad \underline{\text { Group } X}$ Group $Y$ Group Z Bottom, left restraint ...

$2 \quad-3,328.20 \quad-90.19$

$3 \quad-4,826.55 \quad 2,011.40$

Bottom, right restraint ...

47

48

$$
-5,054.92 \quad 1,907.37
$$

$-3,529.91-1,022.58$

Left waist latch ...

$\begin{array}{llll}1752 & 3,972.11 & -9,677.13 & 10,612.90 \\ 1799 & 2,336.43 & -1,035.36 & 377.80 \\ 1846 & 1,093.95 & 537.91 & 1,419.14 \\ 1893 & 786.62 & 1,399.95 & 952.08 \\ 1940 & 689.40 & 2,234.33 & 801.77 \\ 1987 & 245.76 & 3,226.72 & 61.48 \\ 2034 & 1,023.33 & 10,874.90 & 3,834.05\end{array}$

Right waist latch ...

$\begin{array}{llll}1798 & -3,953.97 & -9,952.20 & 10,287.90 \\ 1845 & -2,352.47 & -1,068.23 & 392.21 \\ 1892 & -1,107.60 & 535.15 & 1,403.59 \\ 1939 & -803.19 & 1,426.60 & 972.00 \\ 1986 & -711.13 & 2,303.25 & 865.94 \\ 2033 & -254.13 & 3,355.77 & 54.73 \\ 2080 & 1,081.57 & 11,397.20 & 4,413.22\end{array}$

Top, left hook ...

3690

3641

Top, right hook ...

3736

3687

$-2,561.22$

$4,911.89$
$-2,886.51$

$5,454.14$

$8100.94 \quad 7,561.32 \quad 18,059.21$

$$
\begin{array}{lll}
-8,100.92 & 7,997.54 & 18,389.59
\end{array}
$$

$-8,584.83 \quad 884.79$

Net Reactions ........ 
Figures E.2-2 and E.2-3, as well as E.2-4 and E.2-5 show the deformed shapes of the front and rear doors, respectively, as viewed from the front and back sides of each door. Note that in the views from the front side, the deformed scale factors have been set to 15 in order to see the deformed shapes, and in the views from the rear sides, the deformed scale factors have been reduced to 4 but the vent chute inlet panels appear to still touch the baffle plates at this modest magnification.

The rear door restraint reactions (pounds-force) at various nodes are shown in Table E.2-4.

Table E.2-4: Rear Door Support Point Reactions

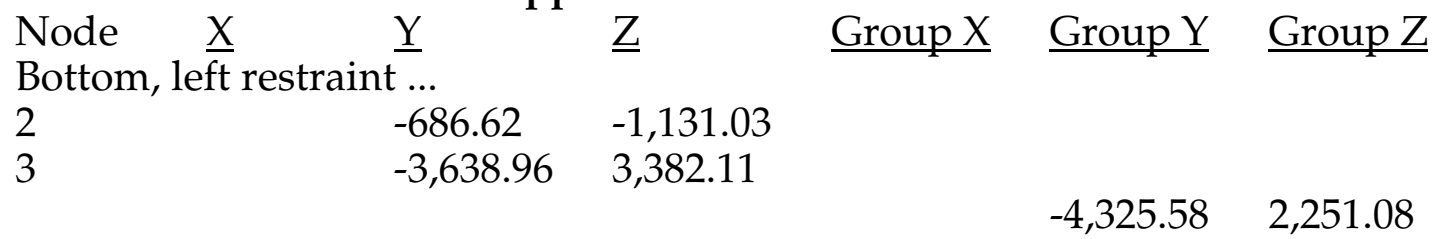

Bottom, right restraint ...

47

48
$-2,666.53 \quad 3,373.99$

$-1,583.10 \quad-1,283.65$

Left waist latch ...

$\begin{array}{llll}1794 & 2,971.00 & -6,668.87 & 11,417.90 \\ 1841 & 3,294.66 & -1,688.97 & 1,794.60 \\ 1888 & 2,589.24 & -597.32 & 2,527.85 \\ 1935 & 2,353.37 & 170.70 & 1,531.97 \\ 1982 & 2,419.88 & 790.28 & 670.05 \\ 2029 & 1,800.99 & 1,487.26 & 42.87 \\ 2076 & 527.12 & 10,234.70 & 277.48\end{array}$

Right waist latch ...

$\begin{array}{llll}1840 & 2,806.25 & -7,136.80 & 12,011.00 \\ 1887 & -3,286.58 & -1,822.63 & 1,830.66 \\ 1934 & -2,583.20 & -682.27 & 2,587.84 \\ 1981 & -2,356.04 & 133.29 & 1,511.68 \\ 2028 & -2,467.66 & 792.84 & 585.85 \\ 2075 & -1,865.05 & 1,489.42 & -8.10 \\ 2079 & 462.77 & 10,889.80 & 36.36\end{array}$

Top, left hook ...

3715

$-893.33$

3666

$2,925.74$

$14,902.02 \quad 3,727.78 \quad 18,262.72$

$\begin{array}{lll}-14,902.01 & 3,663.66 & 18,555.28\end{array}$

Top, right hook ...

3761

3712

$-824.70$

$2,726.43$ 
Front Door Frequencies and Modes. The first ten most significant front door frequencies and modes are tabled below in Table E.2-5 (from the GEMINI results).

\section{Table E.2-5: Front Door Z-direction Modes}

for direction $\quad Z$ (normal to door)

$\begin{array}{ccccc}\begin{array}{c}\text { order of } \\ \text { importance }\end{array} & \begin{array}{c}\text { mode } \\ \text { number }\end{array} & \begin{array}{c}\text { frequency } \\ \text { (hertz) }\end{array} & \begin{array}{c}\text { period } \\ \text { (seconds) }\end{array} & \begin{array}{c}\text { part of total } \\ \text { mass }\end{array} \\ 1 & 4 & 0.46112 \mathrm{E}+02 & 0.21686 \mathrm{E}-01 & 0.2341 \mathrm{E}+00 \\ 2 & 14 & 0.98307 \mathrm{E}+02 & 0.10172 \mathrm{E}-01 & 0.1295 \mathrm{E}+00 \\ 3 & 22 & 0.12901 \mathrm{E}+03 & 0.77515 \mathrm{E}-02 & 0.1058 \mathrm{E}+00 \\ 4 & 2 & 0.39120 \mathrm{E}+02 & 0.25562 \mathrm{E}-01 & 0.9937 \mathrm{E}-01 \\ 5 & 26 & 0.15739 \mathrm{E}+03 & 0.63536 \mathrm{E}-02 & 0.5817 \mathrm{E}-01 \\ 6 & 12 & 0.88443 \mathrm{E}+02 & 0.11307 \mathrm{E}-01 & 0.4606 \mathrm{E}-01 \\ 7 & 6 & 0.48020 \mathrm{E}+02 & 0.20825 \mathrm{E}-01 & 0.4458 \mathrm{E}-01 \\ 8 & 23 & 0.13246 \mathrm{E}+03 & 0.75493 \mathrm{E}-02 & 0.2775 \mathrm{E}-01 \\ 9 & 20 & 0.11488 \mathrm{E}+03 & 0.87048 \mathrm{E}-02 & 0.2555 \mathrm{E}-01 \\ 10 & 33 & 0.28353 \mathrm{E}+03 & 0.35270 \mathrm{E}-02 & 0.2385 \mathrm{E}-01\end{array}$

Notes:

Mode 4: Top and bottom chute inlet panels and chute cover plates flexing in-phase (all panels flexing same direction).

This mode is important since inlet panel yielding could lead to door buckling and separation from cabinet.

Mode 14: Lower inlet panel flexing (1st mode, possible failure mode), and window region flexing (in second mode -- not important).

Mode 22: Inlet panels flexing in second mode and out-of-phase, window region flexing horizontally in 1st mode (could be a failure mode for coming off the top hooks).

Mode 2: Top and bottom chute baffles flexing in-phase. This mode is not important since baffle yielding would not lead to door failure.

Mode 26: Inlet panels flexing in second mode and in-phase, window region flexing vertically in 1st mode (could be a failure mode for coming off the top hooks).

Figure E.2-8 shows mode 4 for the front door. In this mode, both vent chute inlet panels are flexing, in-phase, making this mode the mode most significant for yielding of the door main plate in the vicinity of its waist latch restraints. Note in 
Figure E.2-8 that the normalized scale of the mode causes the vent chute inlet panels to appear to pass-through the baffle plates.

Rear Door Frequencies and Modes. The first ten most significant rear door frequencies and modes are tabled below in Table E.2-6 (from the GEMINI results).

\section{Table E.2-6: $\quad$ Rear Door Z-direction Modes}

$\begin{array}{ccccc}\begin{array}{c}\text { for direction } \\ \text { order of } \\ \text { importance }\end{array} & \begin{array}{c}\text { mode number } \\ \text { frequency } \\ \text { (hertz) }\end{array} & \begin{array}{c}\text { period } \\ \text { (seconds) }\end{array} & \begin{array}{c}\text { part of total } \\ \text { mass }\end{array} \\ 2 & 28 & 0.19379 \mathrm{E}+03 & 0.51602 \mathrm{E}-02 & 0.1189 \mathrm{E}+00 \\ 3 & 3 & 0.45952 \mathrm{E}+02 & 0.21762 \mathrm{E}-01 & 0.1149 \mathrm{E}+00 \\ 4 & 5 & 0.47273 \mathrm{E}+02 & 0.21154 \mathrm{E}-01 & 0.9978 \mathrm{E}-01 \\ 5 & 10 & 0.83648 \mathrm{E}+02 & 0.21154 \mathrm{E}-01 & 0.9978 \mathrm{E}-01 \\ 6 & 27 & 0.17967 \mathrm{E}+03 & 0.55659 \mathrm{E}-02 & 0.7479 \mathrm{E}-01 \\ 7 & 2 & 0.39607 \mathrm{E}+02 & 0.25248 \mathrm{E}-01 & 0.5657 \mathrm{E}-01 \\ 8 & 16 & 0.10925 \mathrm{E}+03 & 0.91533 \mathrm{E}-02 & 0.4324 \mathrm{E}-01 \\ 9 & 20 & 0.12721 \mathrm{E}+03 & 0.78610 \mathrm{E}-02 & 0.4154 \mathrm{E}-01 \\ 10 & 1 & 0.39067 \mathrm{E}+02 & 0.25597 \mathrm{E}-01 & 0.3585 \mathrm{E}-01 \\ & 32 & 0.25793 \mathrm{E}+03 & 0.38770 \mathrm{E}-02 & 0.3411 \mathrm{E}-01\end{array}$

Notes:

Mode 28: Involves second mode horizontal flexure of the top inlet panel, second mode horizontal and vertical flexure of the bottom inlet panel, and first mode flexure of the regions above and below the vent chutes. Second mode flexure of the inlet panels is not likely to be excited nor lead to door failure.

Mode 3: Involves top chute inlet panel flexing in-phase with the top chute cover. This is a mode of flexure that would produce door failure due to main door plate buckling and escape from under the waist restraints.

Mode 5: Bottom chute inlet and cover flexing in-phase with eachother and could buckle the main door panel in the region below the waist latch and lead to separation of the door from the cabinet frame as with mode 3 .

Mode 10: Flexure in the vicinity of the window and could cause window failure or door coming off bottom hooks.

Mode 27: Up- and down-flexing of the lip above the upper chute; could lead to door coming off the top hooks.

Figure E.2-9 shows mode 3 for the rear door. In this mode, the top vent chute inlet panel is flexing, making this mode a significant mode for yielding of the 
door main plate in the vicinity of its waist latch restraints. Note in Figure E.2-9 that the normalized scale of the mode causes the vent chute inlet panel to appear to pass-through the upper vent chute baffle plate.

Figure E.2-10 shows mode 5 for the rear door. In this mode, the bottom vent chute inlet panel is flexing, making this mode a significant mode for yielding of the door main plate in the vicinity of its waist latch restraints. Note in Figure E.210 that the normalized scale of the mode causes the vent chute inlet panel to appear to be flexing away from the vent chute baffle plate. 


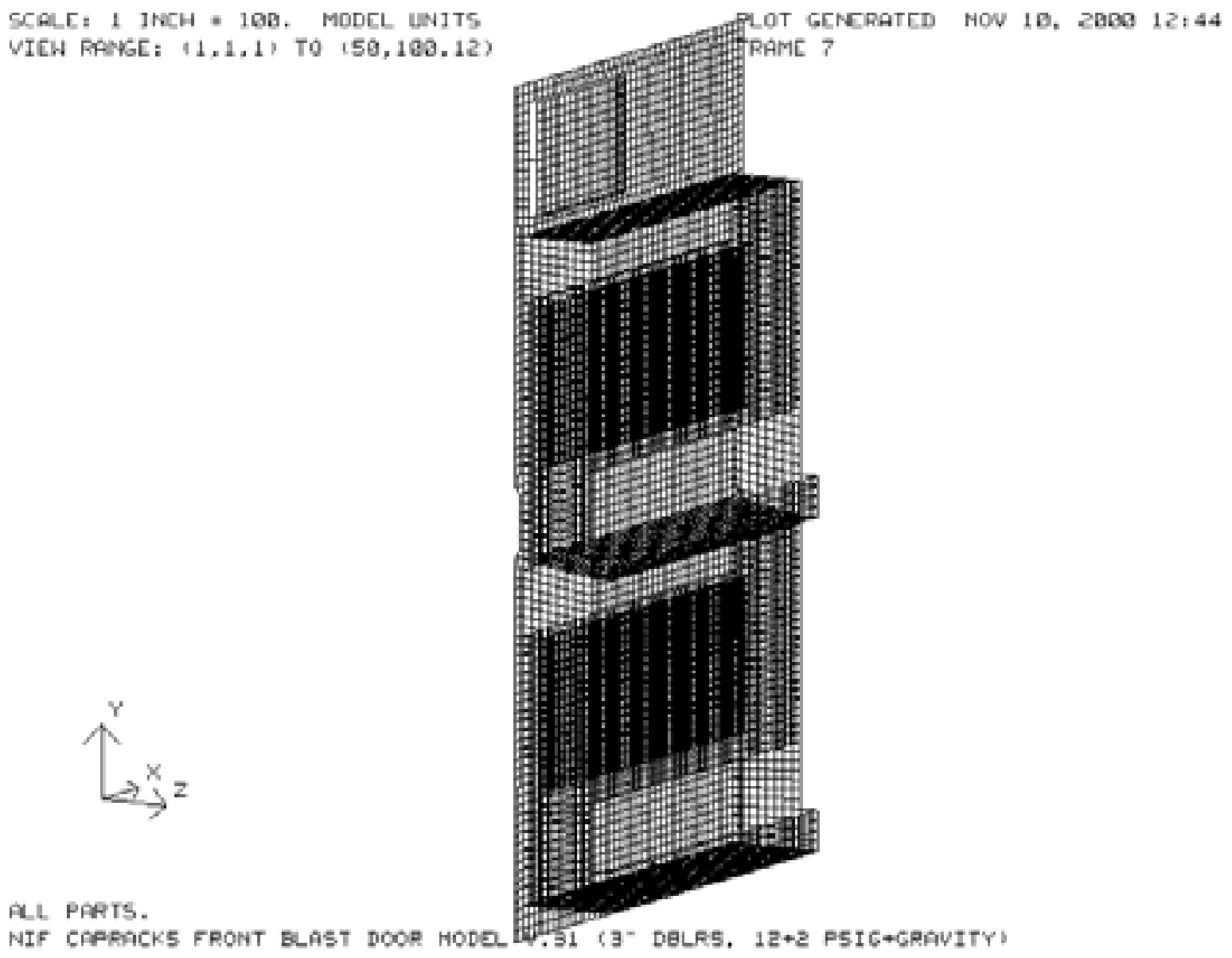

Figure E.2-1: SLIC model of the front door, showing all parts transparently. 
MESN99-066-OA

NIF-0063594

N.M. 6.4.

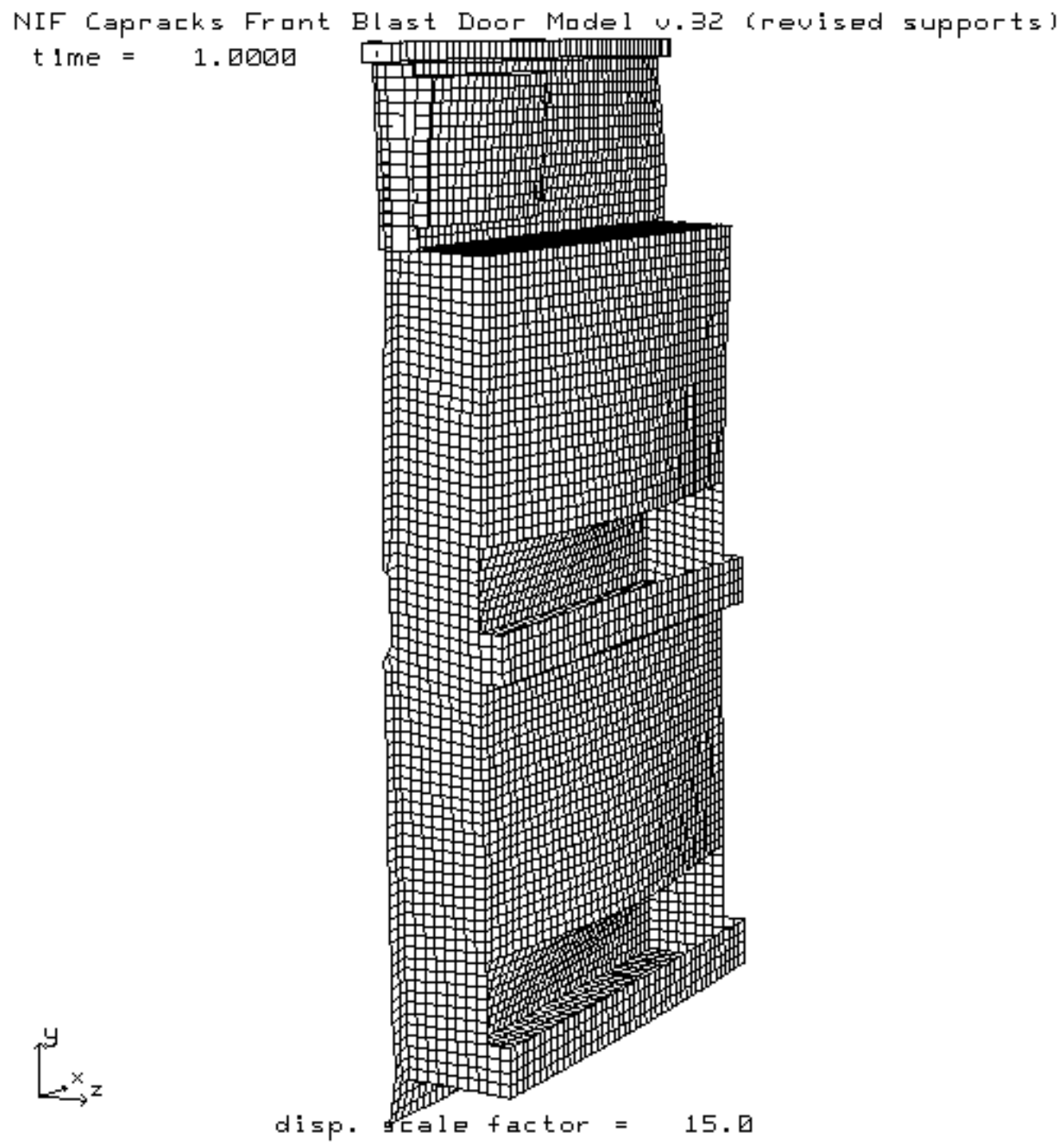

Figure E.2-2: Deformed shape of the front side of the front door. 
MESN99-066-OA

NIF-0063594

N.M. 6.4.

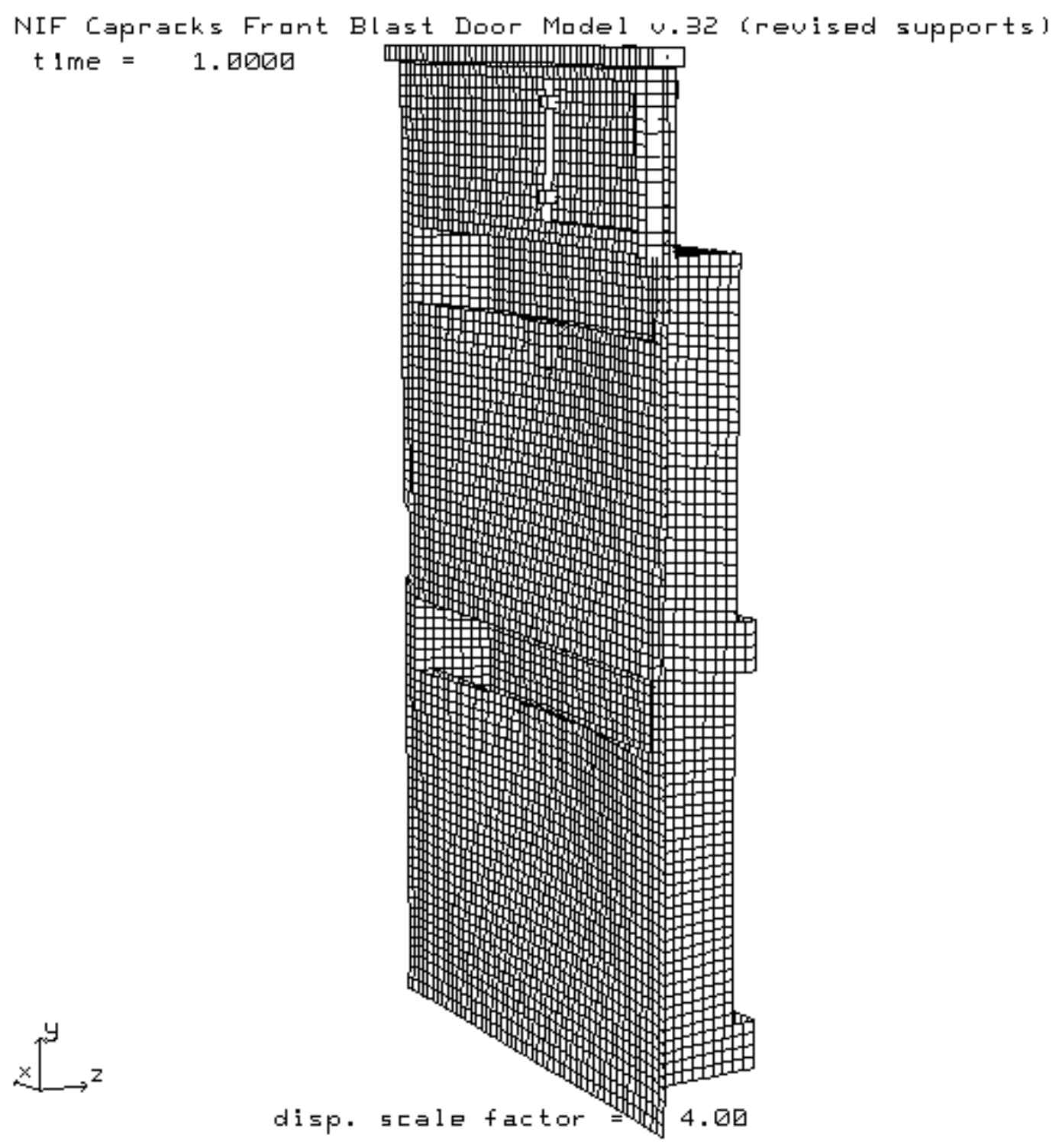

Figure E-2.3: Deformed shape of back side of the front door. 
MESN99-066-OA

NIF-0063594

N.M. 6.4.

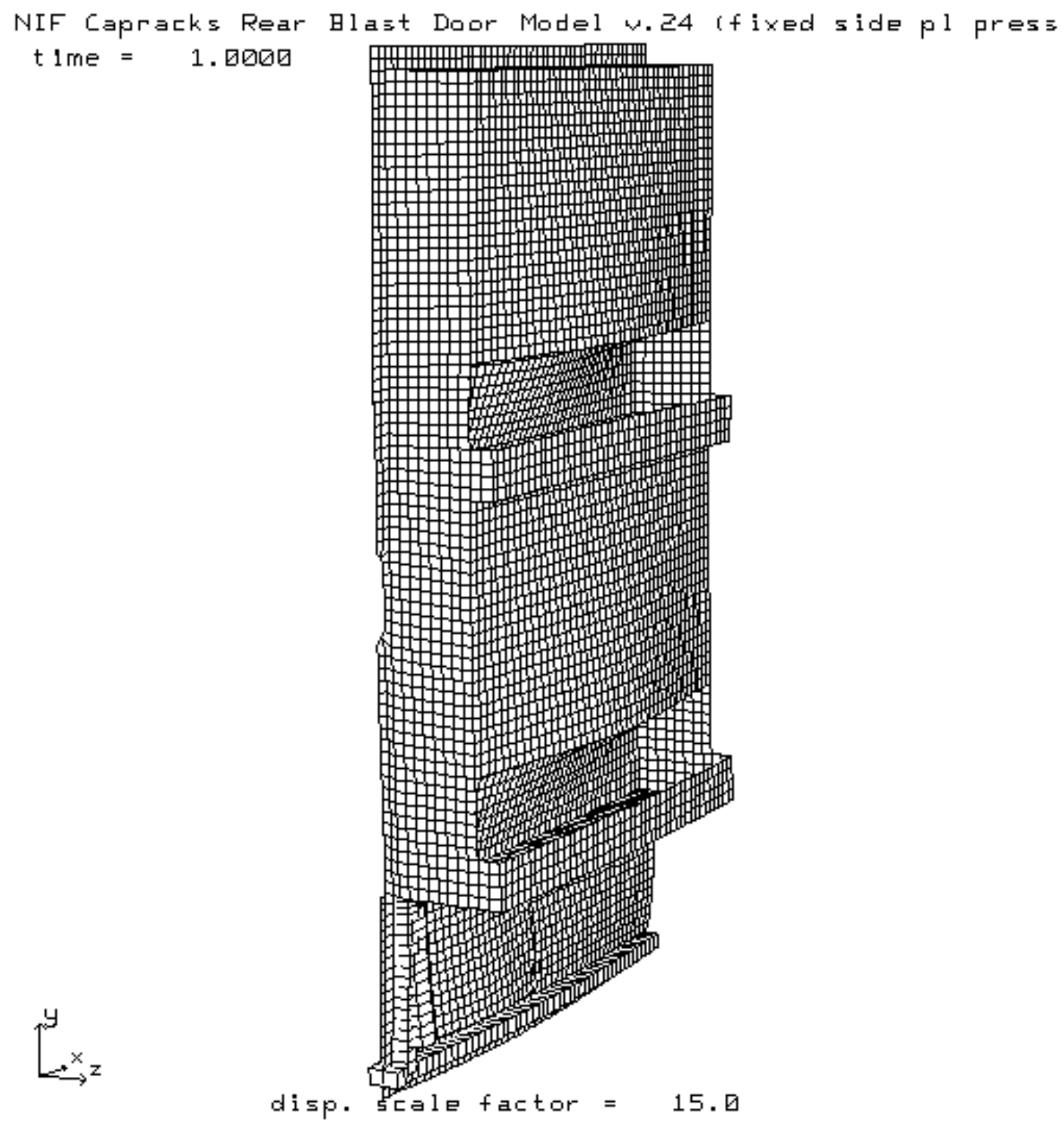

Figure E.2-4: Deformed shape of the front side of the rear door. 
MESN99-066-OA

NIF-0063594

N.M. 6.4.

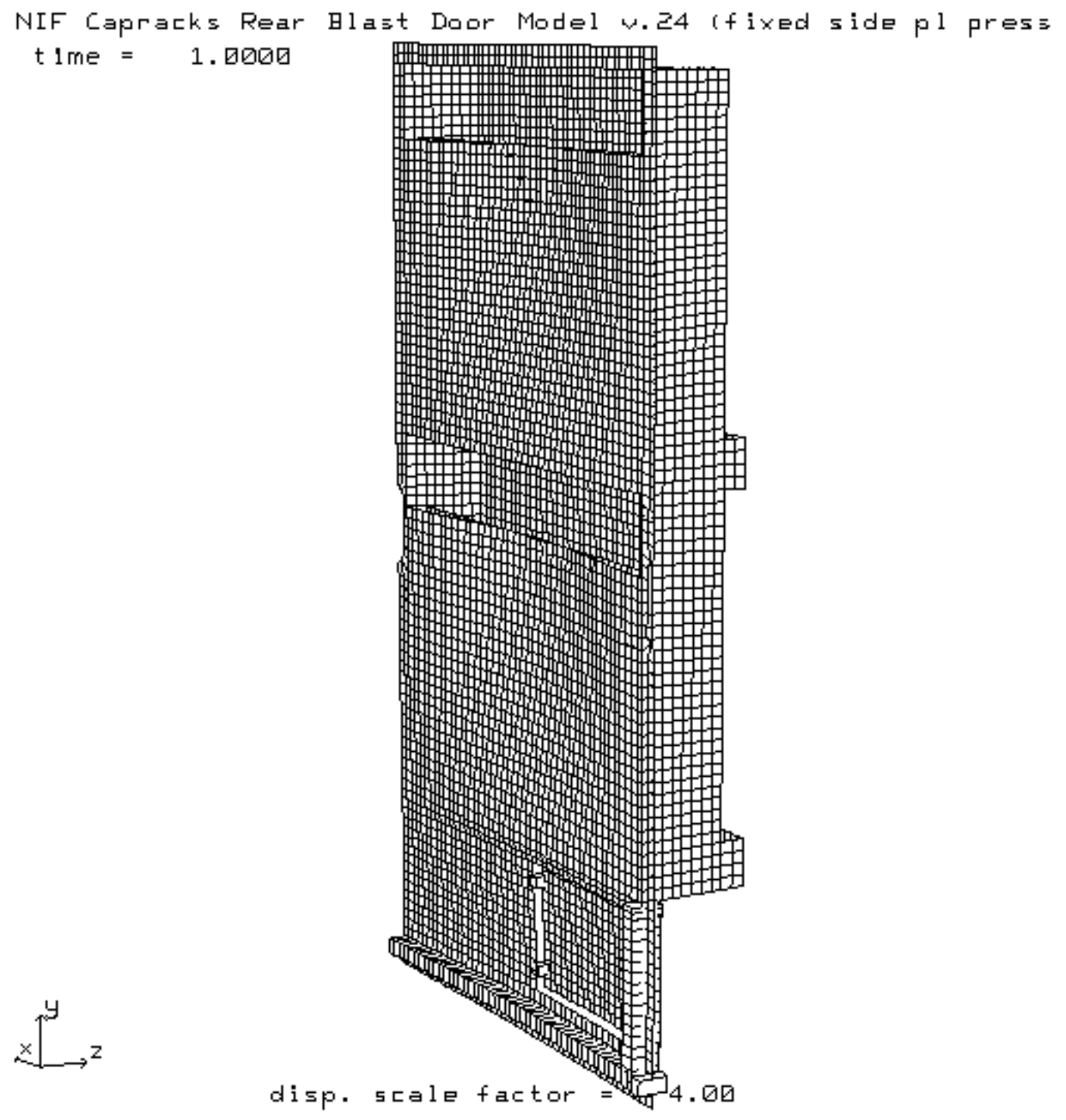

Figure E.2-5: Deformed shape of the back side of the rear door. 
NIF Capracks Frant Daor, reinforcements expladed wiew $\mathrm{t} 1 \mathrm{me}=1.000 \mathrm{\theta}$
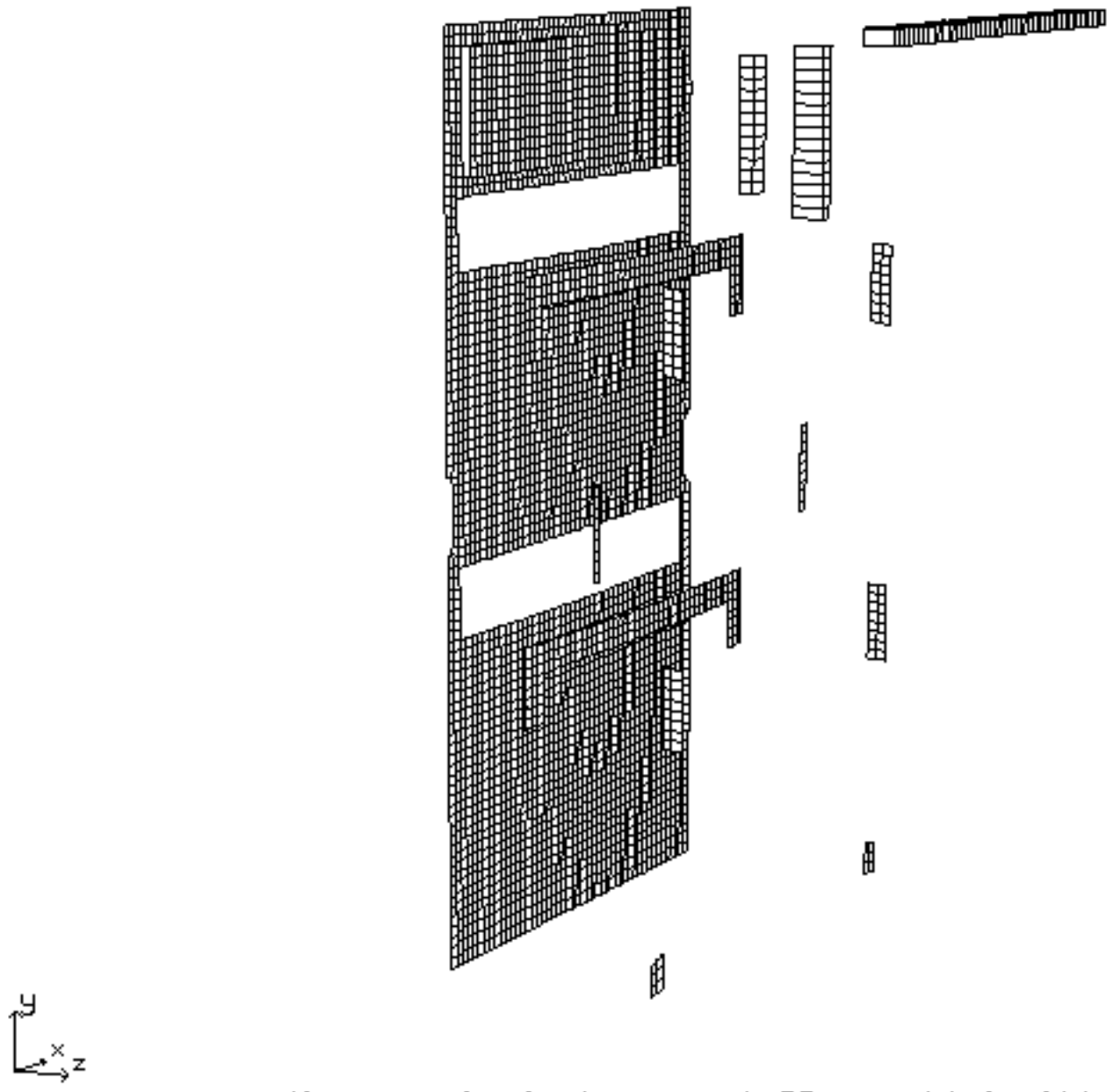

$$
\text { disp. 5calefactor }=1.00 \text { (default) }
$$

Figure E.2-6: Exploded View of reinforcements on the front door. 


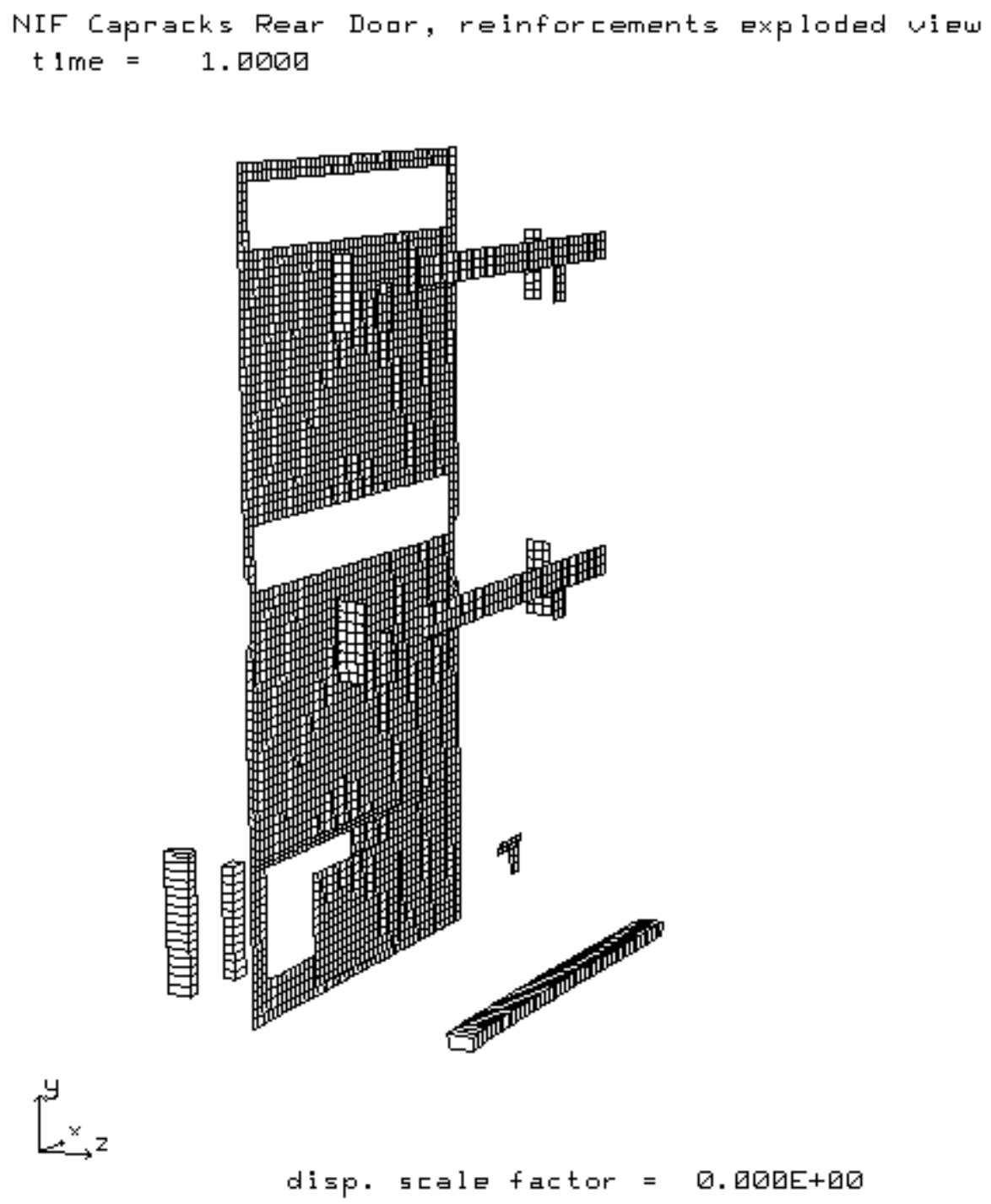

Figure E.2-7: Exploded View of reinforcements on the rear door. 
MESN99-066-OA

NIF-0063594

N.M. 6.4. NIF Capracks Frant Blast Door Madel u32 (40 frequencies \& mo
t $1 \mathrm{me}=46.112$

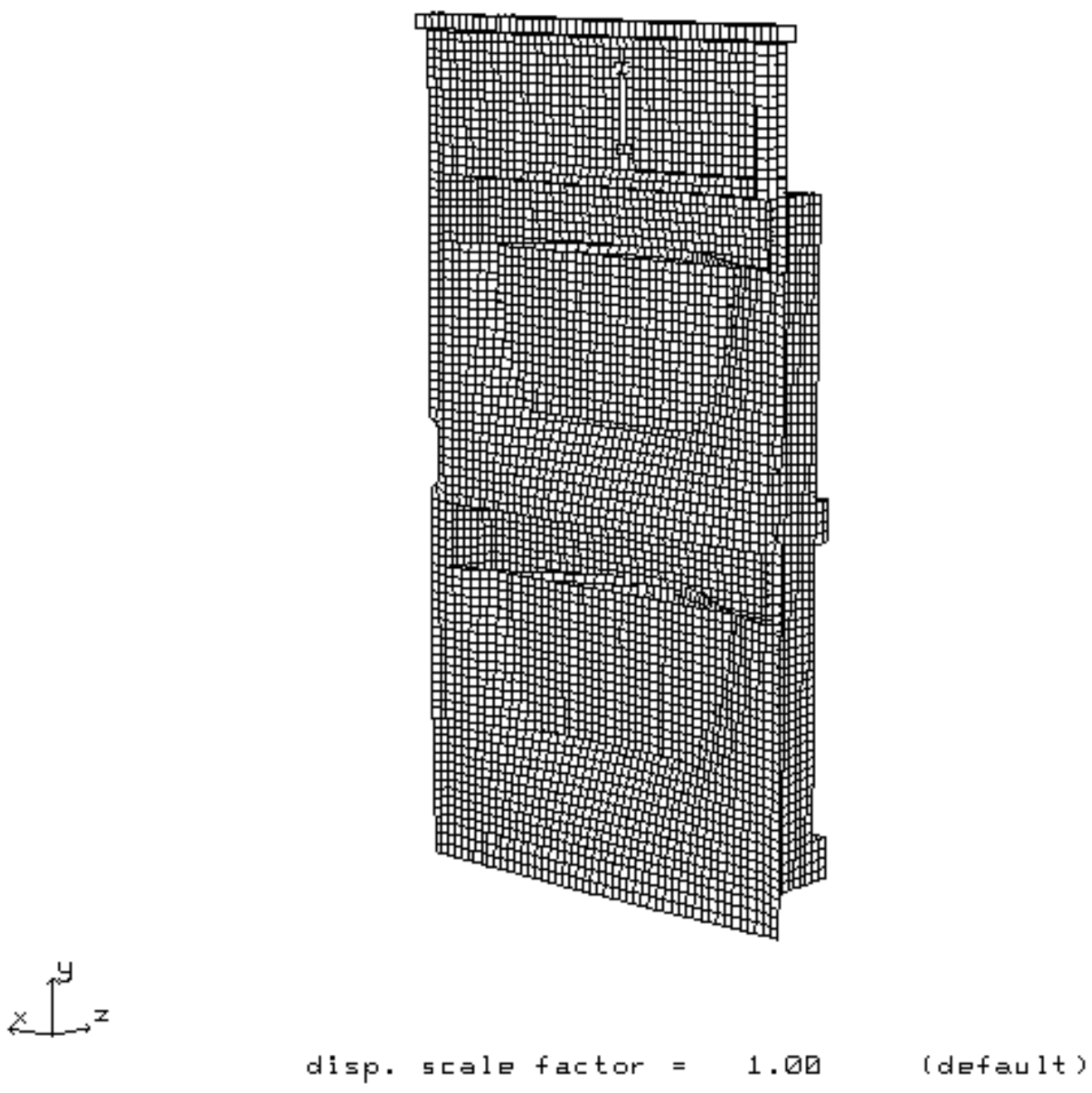

Figure E.2-8: Front Door Natural Mode \# 4. 
MESN99-066-OA

NIF-0063594

N.M. 6.4.

NIF Capracks Rear Blast Door Model weS (40 frequencies \& mad t $1 \mathrm{me}=45.952$
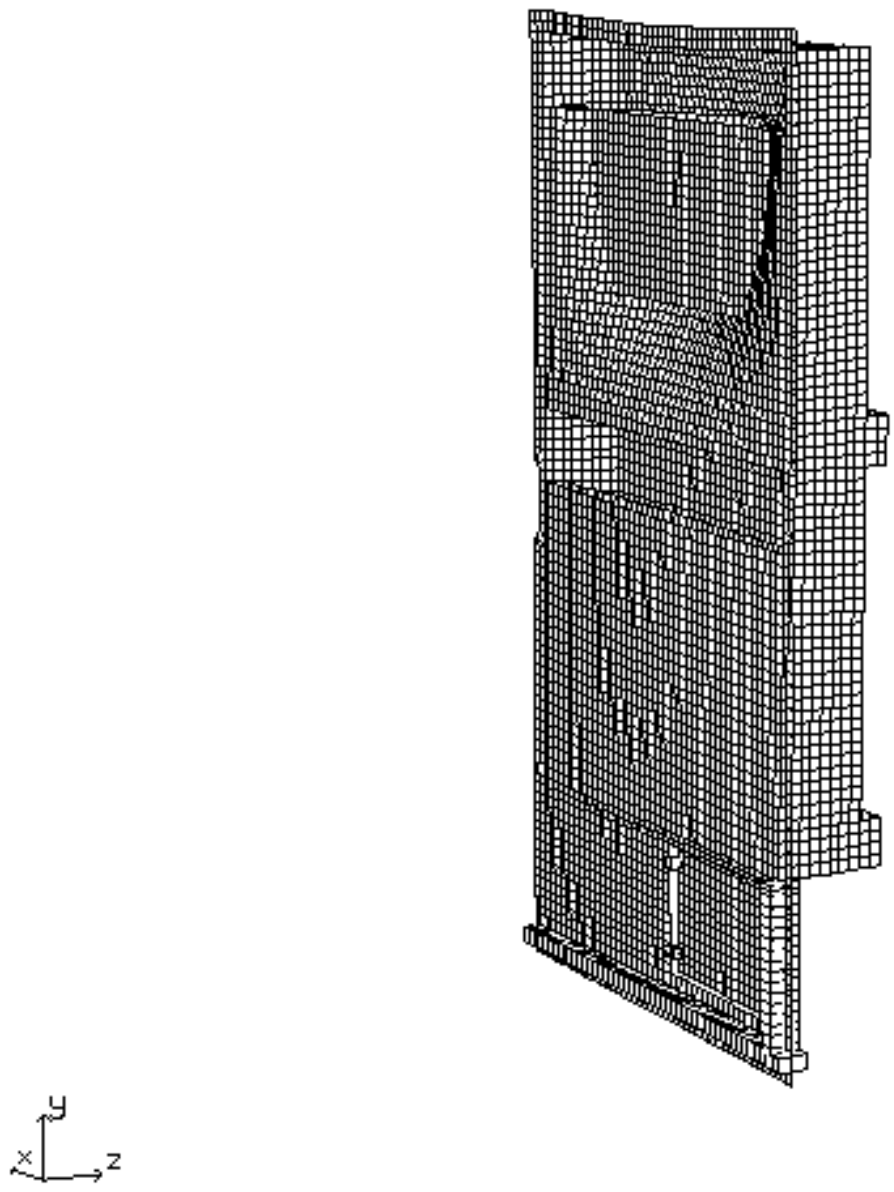

$$
\text { disp. scale factor }=1.00 \text { (default) }
$$

Figure E.2-9: Rear Door Natural Mode \# 3. 
MESN99-066-OA

NIF-0063594

N.M. 6.4.
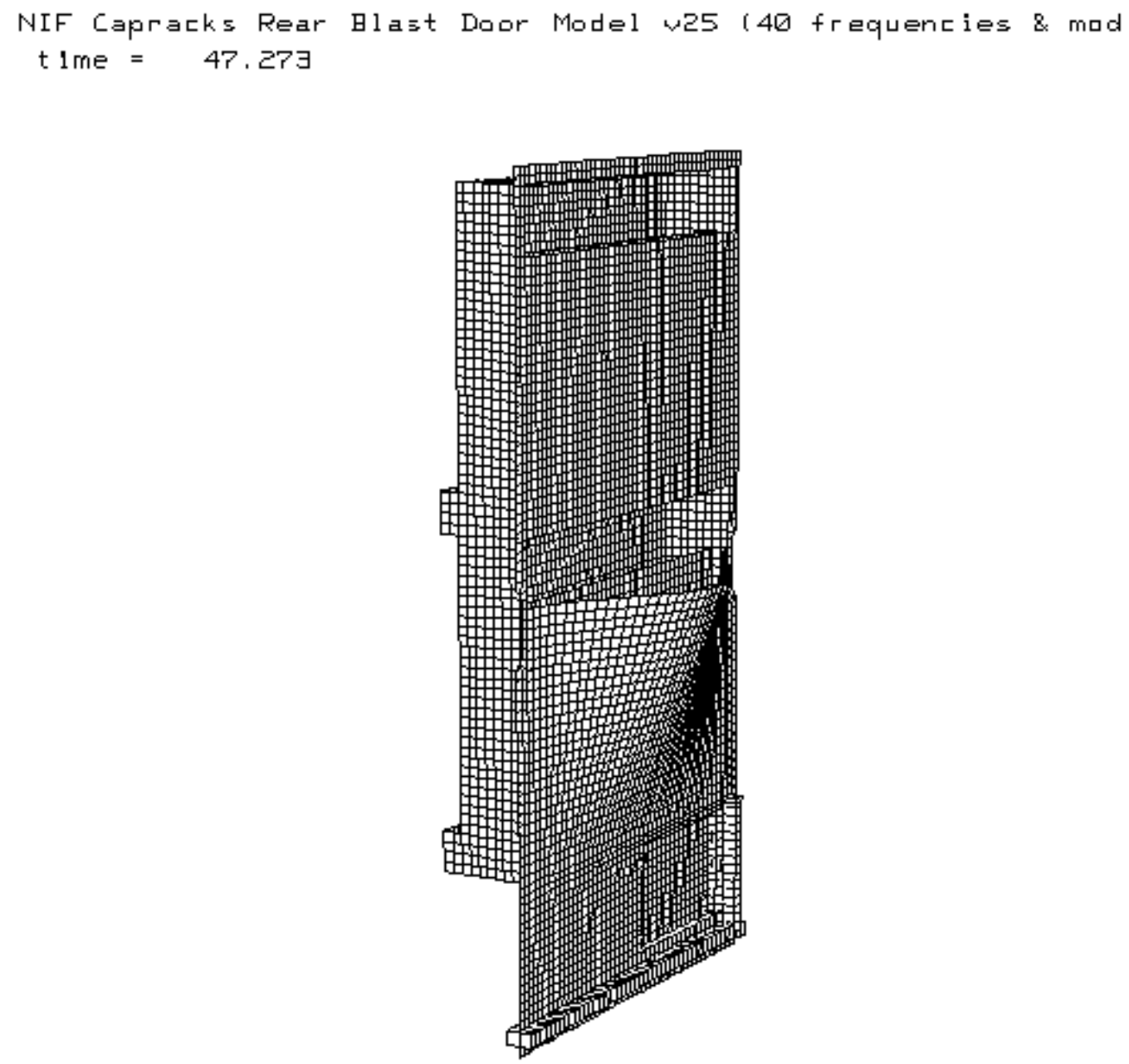

$$
\text { disp. scale factor }=1.00 \text { (default) }
$$

Figure E.2-10: Rear Door Natural Mode \# 5. 


\section{Appendix E.3}

\section{Sample Flat-Plate Hand Calculation for Module End Panel Stress}

NIF, Power Conditioning, Capacitor Racks Cabinets

Dec 19, 2000

3-Sided End-Plate Bending due to Internal Pressure.

file: end-pl31.cal

$\begin{array}{ll}\text { Plate height }= & 89 \text { inches } \\ \text { Plate width }= & 60 \text { inches, one side unsupported } \\ \text { Plate thickness }= & .375\end{array}$

Material $=\quad$ A36 stl yield stress $=\quad 36000 \mathrm{psi}$

(properties: AISC Handbook of Steel Design, Ninth

Edition, 1996, page 1-7, for plate under 8" thick.)

Concentrated load $\quad 0$ pounds on small spot

Uniform Load "q" = 4 pounds per square inch

(calculated reduced pressure, based on distance from door.)

Uniform load formula (Young, "Roark's Formulas...", 6 ed., page 468):

3-Sided Plate with clamped (welded) edges

stress $=$ beta $1{ }^{*} \mathrm{q} *(\mathrm{~b} / \mathrm{t})^{* * 2} \quad$ (at middle of edge opp. free side)

aspect ratio $=.6741573=$ width $/$ height.

beta1 at $.5=.081$

beta1 at $.75=.173$

beta1 $=.1450899$

$(b / t)=237.3333$

stress $=32689.98 \mathrm{psi} \quad$ (at middle of edge opp. free side)

stress $=$ beta $2 * q *(b / t) * * 2 \quad$ (at middle of free edge).

beta2 at $.5=.066$

beta2 at $.75=.148$

beta2 $=.1231236$

stress $=27740.79 \mathrm{psi} \quad($ at middle of free edge $)$.

stress $=$ beta $3 * q^{*}(b / t) * * 2 \quad$ (at ends of free edge).

beta3 at $.5=.126$

beta3 at $.75=.286$

beta3 $=.2374607$

stress $=53501.90 \mathrm{psi} \quad$ (at ends of free edge).

Since panel did not yield, actual max pressure was approx. ...

$$
4 * 36000 / 53501.90=
$$

2.691493 psi.

(assuming that actual panel yield was same as minimum yield). 